University of Rhode Island

DigitalCommons@URI

Open Access Dissertations

2014

\title{
BLACK CARBON CONCENTRATIONS, SOURCES, AND FLUXES IN THE TROPICAL ATLANTIC OCEAN
}

Kari Ann Pohl

University of Rhode Island, kpohl@gso.uri.edu

Follow this and additional works at: https://digitalcommons.uri.edu/oa_diss

\section{Recommended Citation}

Pohl, Kari Ann, "BLACK CARBON CONCENTRATIONS, SOURCES, AND FLUXES IN THE TROPICAL ATLANTIC OCEAN" (2014). Open Access Dissertations. Paper 278.

https://digitalcommons.uri.edu/oa_diss/278

This Dissertation is brought to you for free and open access by DigitalCommons@URI. It has been accepted for inclusion in Open Access Dissertations by an authorized administrator of DigitalCommons@URI. For more information, please contact digitalcommons-group@uri.edu. 


\section{BLACK CARBON CONCENTRATIONS, SOURCES, AND FLUXES IN THE TROPICAL ATLANTIC OCEAN}

BY

KARI ANN POHL

\section{A DISSERTATION SUBMITTED IN PARTIAL FULFILLMENT OF THE REQUIREMENTS FOR THE DEGREE OF \\ DOCTOR OF PHILOSOPHY}

IN

OCEANOGRAPHY

UNIVERSITY OF RHODE ISLAND 


\section{DOCTOR OF PHILOSOPHY DISSERTATION}

OF

KARI ANN POHL

\section{APPROVED:}

Dissertation Committee:

Major Professor $\quad$ Rainer Lohmann
S. Bradley Moran
Dawn Cardace
Nasser H. Zawia
DEAN OF THE GRADUATE SCHOOL

UNIVERSITY OF RHODE ISLAND

2014 


\begin{abstract}
Black carbon (BC) is the highly graphitized byproduct of incomplete combustion that could be a sink for fixed carbon. Little data is currently available for $\mathrm{BC}$ concentrations and fluxes to remote marine environments and there are often great discrepancies between model simulations and actual field measurements. This research analyzed $\mathrm{BC}$ concentrations in the mixed boundary layer, surface water, and deep pelagic sediments of the Tropical Atlantic Ocean in order to understand the fate and transport of $\mathrm{BC}$ to the marine environment. It also aimed to assess the importance of aeolian versus fluvial BC deposition. Black carbon concentrations were elevated in regions directly influenced by fluvial and atmospheric deposition in all environmental matrices compared to regions with minimal terrestrial inputs (such as the Sargasso Sea). Black carbon concentrations and fluxes to deep pelagic sediments were approximately 5 times greater in the Sierra Leone Rise (within an atmospheric emission plume) than the remote South Atlantic (minimal terrestrial inputs). Elevated $\mathrm{BC}$ fluxes at the Sierra Leone Rise were most likely due to biomass burning from the African continent, as evidence by biomarkers, enriched stable carbon isotopes, and a modern radiocarbon age. Atmospheric deposition composed 4-28\% of the soot-like $\mathrm{BC}$ and at least $43 \%$ of the total $\mathrm{BC}$ in the fluvial region of the Niger Delta, suggesting that atmospheric $\mathrm{BC}$ deposition to remote sediments can be significant in areas with elevated biomass burning. Atmospheric BC concentrations were also enhanced within the African biomass burning emission plume. Charcoal composed up to $66 \%$ of the $\mathrm{BC}$, suggesting that measurements which only quantify soot-like $\mathrm{BC}$ forms may be underestimating this carbonaceous fraction. Additionally, surface mixed layer BC was
\end{abstract}


found to compose an average of $17 \%$ of bulk total organic carbon. This implies that terrigenous organic carbon composes a larger fraction of the pelagic organic pool than previously estimated. Overall, BC was detected in all samples regardless of environmental matrix, demonstrating its stability and persistence in the marine environment. Fluvial deposition appeared to be the greatest transport mechanism of $\mathrm{BC}$ to the marine environment; however atmospheric transport is quantitatively important and should be included in mass balance estimates of both black carbon and terrigenous organic carbon, especially in areas with significant inputs of biomass burning. 


\section{ACKNOWLEDGMENTS}

Funding for this work came from a Nation Science Foundation grant (OCE0851044) to Rainer Lohmann. Additional funding for travel came from a Graduate School of Oceanography alumni scholarship. Support for elemental analysis came from a U.S. EPA student grantee contract with Mark Cantwell.

First and foremost, I would like to thank my husband Michael St.Laurent for the continued support and encouragement throughout this entire graduate school experience. Without your support, and additional support from my cat Sahara, finishing this project would have been almost impossible. I would also like to express my gratitude and appreciation for the support from my adviser Rainer Lohmann. Rainer has spent countless hours (probably closer to days) working out problems and editing earlier drafts of this work. Without the creative freedom but well-set deadlines Rainer provided, this research would not have become as inter-disciplinary or quantitative. I have truly appreciated the opportunity Rainer has given me, as well as the foundational knowledge to complete my academic and educational goals. I also appreciate the numerous diversions Rainer has allowed me to take, including the outreach opportunities within Rhode Island and the numerous conferences he has funded.

I would also like to thank my committee members, Mark Cantwell, S. Bradley Moran, Dawn Cardace, and Tom Boving, for all input, advise, constructive criticism, and flexibility with meeting. The combined knowledge of my committee has been inspirational and extremely helpful for my professional and academic growth. I also would like to acknowledge the captain and crew of the $R / V$ Endeavor for helping to 
keep me sane and fed during the summer of 2010. I also would like to profusely thank Ann McNichol and Mary Laudie (WHOI), Rick McKinney and Julia Sullivan (U.S. EPA), Bertrand Ligouis (University of Tübingen), A.D.A Hanson (Magee Scientific), Pierre Herckes (Arizona State University), Pat Kelley (GSO-URI), and Matthias Zabel (Bremen University). I also appreciate the help and support by my past and present lab mates, Carey Friedman, Pam Luey, Matt Lambert, Victoria Sacks, Lin Zhang, Shifra Yonis, Mohammed Khairy, Dave Adelman, Zoe Ruge, Carrie McDonough, Erin Markham, Caoxin Sun, Torey Hart, Hilary Hamer, and Bridget Murphy, for help with analyses, procedures, instrumentation, and listening to me practice for everything. Lastly, I would like to thank my friends, family, the Boston Bruins and Red Sox organizations, and everyone else who supported me along the way. 


\section{PREFACE}

This dissertation is written and organized in the manuscript format as described by the URI Graduate school guidelines for dissertation preparation. The body of the text is divdided into four sections which correspond to the format of journal articles. The first manuscript (Chapter 2) will be submitted to Global Biogeochemical Cycles with authors K. Pohl, M. Cantwell, M. Zabel, and R. Lohmann. The second manuscript (Chapter 3) is under review in Geophysical Research Letters with the authors K. Pohl and R. Lohmann. The third manuscript (Chapter 4) has been accepted for publication in the journal Atmospheric Chemsitry and Physics with the authors K. Pohl, M.

Cantwell, P. Herckes, and R. Lohmann. The fourth manuscript (Chapter 5) has been submitted to the journal Geochimica et Cosmochimica Acta with the authors K. Pohl, M. Cantwell, and R. Lohmann. 


\section{TABLE OF CONTENTS}

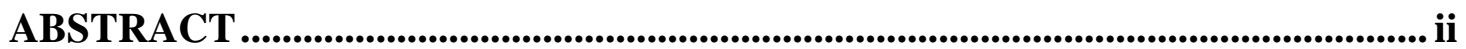

ACKNOWLEDGMENTS ..................................................................................................... iv

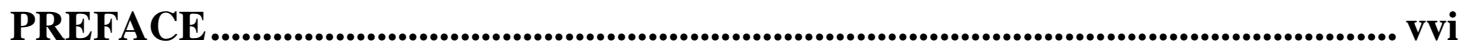

TABLE OF CONTENTS................................................................................................. vvii

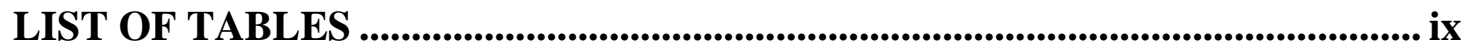

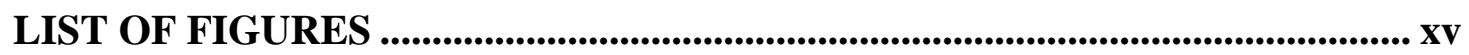

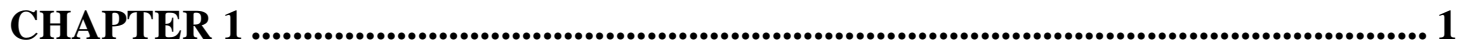

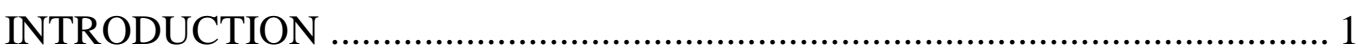

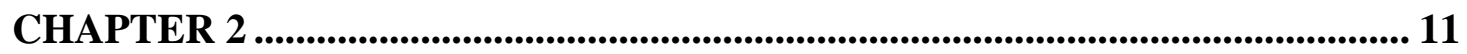

AN ASSESSMENT OF FLUVIAL VERSUS ATMOSPHERIC FLUXES OF BLACK CARBON TO SUBTROPICAL ATLANTIC SEDIMENTS ............... 11

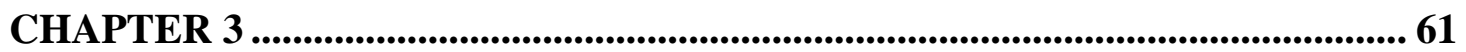

SIGNIFICANT CONCENTRATIONS OF TERRESTRIAL ORGANIC

CARBON IN TROPICAL ATLANTIC OCEAN SEDIMENTS ......................... 61

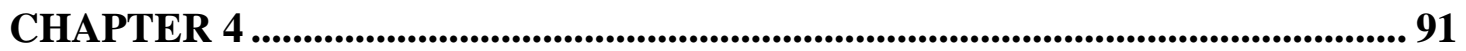

BLACK CARBON CONCENTRATIONS AND SOURCES IN THE MARINE

BOUNDARY LAYER OF THE TROPICAL ATLANTIC OCEAN USING

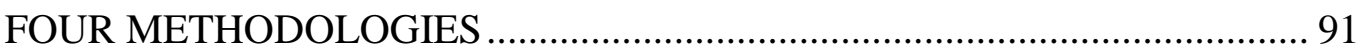

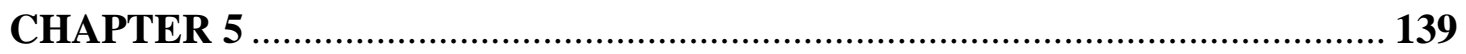

PARTICULATE BLACK CARBON CONCENTRATIONS IN THE SURFACE MIXED LAYER ACROSS THE SUBTROPICAL ATLANTIC OCEAN ..... 139

CHAPTER 6 ............................................................................................................................ 180 


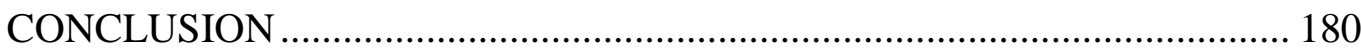




\section{LIST OF TABLES}

TABLE

PAGE

Ch. 2, Table 1. Global comparison of black carbon (BC) concentrations and fluxes to marine sediments from selected studies

Ch. 2, Table 2. Surface sediment concentrations of the total organic carbon (TOC) and black carbon (BC) as quantified using the chemothermal oxidation (CTO-375) and pyrene fluorescence loss (PFL) methods with the associated regional and sample replicate standard deviation. The black carbon concentration derived from the petrographic analysis was $0.8 \%$ for the Amazon Delta and $0.9 \%$ for the Sierra Leone

Rise 42

Ch. 2, Table 3. Regional average black carbon fluxes $\left(\mathrm{mgBC} \mathrm{cm}^{-2} \mathrm{ka}^{-1}\right)$ to marine sediments determined using three approaches: published sedimentation rates from nearby cores, using a radiocarbon analysis to estimate sedimentation rate, and using an empirical approach developed by Middelburg et al. (1997). ВC $_{\text {Сто }}$ used the chemothermal oxidation at $375^{\circ} \mathrm{C}, \mathrm{BC}_{\mathrm{PFL}}$ used the pyrene fluorescence loss method, and $\mathrm{BC}_{\text {petro }}$ used the visual petrographic analysis method including soot and charcoal particles. 43

Ch. 2, Table S1. Dates, coordinates, and water depth of sediment samples.

Ch. 2, Table S2. Surface sediment concentrations of black carbon (BC) as quantified using a chemothermal oxidation (CTO-375) and pyrene fluorescence loss (PFL).... 50

Ch. 2, Table S3. Array of n-alkane indices to apportion the source of the sediment organic carbon. The following n-alkanes ( $\Sigma$ n-alkanes $)$ were quantified: decane, 
undecane, dodecane, tridecane, tetradecane, pentadecane, heptadecane, octadecane, nonadecane, eiosane, heeicosane, decosane, tetracosane, pentacosane, hexacosane, heptacosane, octacosane, nonacosane, triacosane, hentriacontane, triacontane, dotricosane, tetratricosane, hexatriacontane, and tetracosane 51

Ch. 2, Table S4. The regional average stable carbon fraction $\left(\delta^{13} \mathrm{C}\right)$ of the total organic carbon (TOC) and black carbon (BC), and the carbonate concentration $\left(\mathrm{CO}_{3}{ }^{2-}\right)$....... 52 Ch. 2, Table S5. Summary chart of petrographic analysis for sediments from the (A) Amazon Delta and (B) Sierra Leone Rise (SLR). Note that concentrations are in \%volume. The $\mathrm{x}$ indicates that the Maceral group was present, but a volume concentration was not expressed due to scarcity.

Ch. 3, Table 1. Surface sediment regional averages of organic carbon concentrations $\left(\mathrm{g}_{\mathrm{BC}} \mathrm{kg}_{\text {sediment }}{ }^{-1}\right)$ and stable carbon isotope ratios $\left(\delta^{13} \mathrm{C}, \%\right)$ in tropical Atlantic sediments for the total organic carbon (TOC), black carbon (BC), and the thermally labile carbon (OC) fractions. The sediments used were $\leq 4 \mathrm{~cm}$ from the surface and presumed to be well mixed as indicated by the radiocarbon ages. 79

Ch. 3, Table S1. All data compiled for the Amazon Delta; core 1 was taken with a multi-core and grab-1 and grab-2 was taken with a Van Veen grab sampler during July 2010 on EN-480 84

Ch. 3, Table S2. All data compiled for the Niger Delta; GeoB cores were collected using a box .corer during February-March 1998 by the German Research Foundation. These sediments were provided by Dr. M. Zabel from Bremen University 85 Ch. 3, Table S3. All data compiled for the Senegal Delta; GeoB core 4901 was collected with a box corer during April-May 2003 by the German Research 
Foundation. These sediments were provided by Dr. M. Zabel from Bremen University 86

Ch. 3, Table S4. All data compiled for the Sierra Leone Rise; core 8 and core 9 were taken with a multi-core and grabs 5-7 were collected with a Van Veen grab sampler

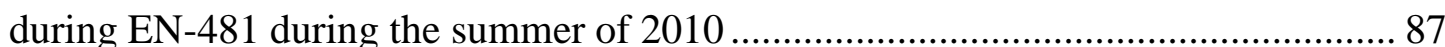

Ch. 3, Table S5. All data compiled for the Northwest (NW) Argentina basin; GeoB 2814 was collected with a box corer during July-August of 1994 by the German Research Foundation and were provided by Dr. M. Zabel from Bremen University. 88 Ch. 3, Table S6. Regional organic carbon contribution estimates to pelagic sediments. These estimates represent the lowest percentage of marine material required to achieve a mass balance of the labile organic carbon fraction 88

Ch. 3, Table S7. Auxiliary data including the collection date, sampling coordinates, location, and water depth of all sediments analyzed in this study

Ch. 4, Table 1. Sampling dates, volumes, coordinates, and total distance for each sample collected. Regional abbreviations are CS (Caribbean Sea), SA (South America), AP (Africane Plume), and SubAt (Subtropical Atlantic). 124

Ch. 4, Table 2. Average regional total organic carbon concentrations and ranges ( $\mu \mathrm{g}$ $\mathrm{m}^{-3}$ ) for the TOT methods (TOC ${ }^{\mathrm{a}}$ ) and CTO-375 (TOC ${ }^{\mathrm{b}}$ ) methods and the $\delta^{13} \mathrm{C}$ value (\%o) for the total organic carbon and black carbon determined by the CTO-375 method. 125

Ch. 4, Table 3. Average black carbon concentrations and range by region $\left(\mu \mathrm{g} \mathrm{m}^{-3}\right)$ using four different methods: the chemothermal oxidation at $375^{\circ} \mathrm{C}(\mathrm{CTO}-375)$, thermal optical transmittance (TOT), pyrene fluorescence loss (PFL), and optical 
attenuation (OT-21)

Ch. 4, Table S1. Black carbon concentration $\left(\mu \mathrm{g} \mathrm{m}^{-3}\right)$ per individual filter for each method. 133

Ch. 4, Table S2. Total organic carbon concentrations as measured by the CTO-375 $\left(\right.$ TOC $^{\mathrm{a}}$ ) and TOT $\left(\mathrm{TOC}^{\mathrm{b}}\right.$ ) methods and the $\delta^{13} \mathrm{C}$ values for the total organic carbon and black carbon determined for each filter by CTO-375 after blank correction 134

Ch. 4, Table S3. Regional average of soot-like black carbon (CTO-375) to the broader black carbon spectrum (PFL) ratio and the ratio of black carbon in the total organic carbon determined by the CTO-375 and TOT methods.

Ch. 4, Table S4. Measured elemental carbon (EC) values of lab and field blanks via the chemothermal oxidation (CTO-375) method $\left(\mu \mathrm{gEC} \mathrm{cm}^{-2}\right)$. An average laboratory glass fiber filter blank (GFF) is also included.

Ch. 5, Table 1. Concentrations of particulate black carbon (BC), bulk particulate organic carbon (POC), and the labile organic carbon (OC) fraction (POC-BC), along with the ratio of $\mathrm{BC}$ within the $\mathrm{POC}$, and the carbon to nitrogen ratio for each organic carbon pool. 172

Ch. 5, Table 2. Stable carbon $\left(\delta^{13} \mathrm{C}\right)$ and nitrogen $\left(\delta^{15} \mathrm{~N}\right)$ ratios for the particulate organic carbon (POC) and black carbon (BC) fractions, as well as particulate organic nitrogen $(\mathrm{PON})$ and black nitrogen $(\mathrm{BN})$ concentrations 173

Ch. 5, Table 3. Deduced black carbon (BC) export flux approximations using reported

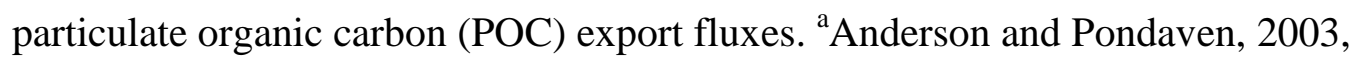
${ }^{\mathrm{b}}$ Buesseler, 1998, ${ }^{\mathrm{C}}$ Jahnke, 1996; ${ }^{\mathrm{d}}$ Thomalla et al., 2006; ${ }^{\mathrm{e}}$ Antia et al., 2001, ${ }^{\mathrm{f}}$ Charette and Moran, 1999, ${ }^{\mathrm{g}}$ Flores-Cervantes et al., 2009. 174 
Ch. 5, Table S1. Average black carbon (BC) concentration and number of samples (n) derived for each standard reference material (SRM) used in the analysis. The nd is a non-detect and represents carbon values below the instrumental detection limit. ... 178 Ch. 5, Table S2. The average blank carbon and nitrogen value for the total organic carbon (POC), total organic nitrogen (PON), black carbon (BC), and black nitrogen (BN) for this study. All sample concentrations were blank corrected by these averaged values. 178

Ch. 6, Table 1. Deduced black carbon export flux $\left(\mathrm{F}_{\mathrm{BC}}\right)$ from the surface mixed layer to the deep ocean. ${ }^{\text {a }}$ Flores-Cervantes et al., 2009. 190

Ch. 6, Table 2. A) Sediment black carbon fluxes $\left(\mathrm{F}_{\mathrm{BC}}\right)$ derived by the chemothermal oxidation method using B) sedimentation rates from previously reported values from www.pangaea.de (Literature), radiocarbon $\left(\Delta^{14} \mathrm{C}\right)$, or from a depth-based algorithm (Depth) using Middelburg et al., 1999.

Ch. 6, Table 3. Estimated atmospheric black carbon settling fluxes $\left(\mathrm{F}_{\mathrm{BC}}\right)$ to the Tropical Atlantic surface ocean using previously derived depositional velocities $\left(\mathrm{v}_{\mathrm{D}}\right)$ or dry deposition particle fluxes $\left(\mathrm{F}_{\mathrm{DD}}\right)$ for various particle diameters $\left(\mathrm{D}_{\mathrm{p}}\right)$. 192

Ch. 6, Table 4. Summary of black carbon fluxes $\left(\mu \mathrm{gBC} \mathrm{cm}^{-2} \mathrm{yr}\right)$ in all environmental matrices analyzed in this work. Black carbon fluxes in this table were derived using the chemothermal oxidation at $375^{\circ} \mathrm{C}$ method since this approach was used for all samples. Marine boundary layer predicts the terminal black carbon flux out of the atmosphere into the surface water using depositional velocities from Table 3 , the surface mixed layer flux is the black carbon export from the surface to deep ocean using the low-end export fluxes in Table 2, and pelagic sediment is the black carbon 
flux to the sediments using the sedimentation rates in Table 1. * Lohmann et al., 2009 **pre-industrial estimate derived by Coppola et al., $2014 * * *$ Suman et al., 1997... 193 


\section{LIST OF FIGURES}

FIGURE

PAGE

Ch. 2, Figure 1. Locations of the sediment collected for this study; light gray dots are cores taken during EN-480 to EN-481 and dark gray dots are cores analyzed from

Bremen University, Germany.

Ch. 2, Figure 2. The average surface sediment concentration of total organic carbon (TOC) for each region divided into the organic carbon (OC) and soot-like black carbon fraction as defined by the chemothermal oxidation (CTO-375) and pyrene fluorescence loss (PFL) methods.

Ch. 2, Figure 3. The black carbon concentration derived with the pyrene fluorescence loss (PFL) versus the chemothermal oxidation at $375^{\circ} \mathrm{C}(\mathrm{CTO}-375)$ methods according to region. The dashed line represents a 1:1 line, where samples plotted below this line are dominated by soot-like black carbon.

Ch 2, Figure S1. The total organic carbon (TOC) versus the soot-like black carbon (BC) fractions for all sediments from each region. The respective correlations $\left(\mathrm{R}^{2}\right)$ are as follows: Amazon Delta (0.11), Niger Delta (0.20), Senegal Delta (0.002), Sierra Leone Rise (0.003), and South Atlantic (0.02). 56

Ch 2, Figure S2. Source apportionment of all surface sediments using the ratio of indeno(1,2,3,c,d)pyrene (IP) and benzo(g,h,i)perylene (Bghi) versus fluoranthene (Fl) and pyrene (Py). The following PAHs were also quantified: naphthalene, 2-methyl naphthalene, acenapthalene, acenapthylene, biphenyl,1,5-dimethyl naphthalene, fluorine, 2,3,5-trimethyl naphthalene, phenanthrene, anthracene, 2-methyl fluorine, 
dibenzothiophene, 1-methyl phenanthrene, 9-methyl phenanthrene, 2-methyl dibenzothiophene, pyrene, fluoranthene, 4,5-dimethyl phenathrene, 3,6-dimethyl phenathrene, 1-methyl pyrene, retene, perylene, benzo(g,h,i)perylene, indeno(1,2,3c,d)pyrene, and dibenzo(a,h)anthracene. 57

Ch 2, Figure S3. Microscopic images of anthropogenic particles from the Amazon Delta (A, B) and Sierra Leone Rise (C, D). A) soot and char particle, B) high volatile bituminous coal, C) soot, and D) char. 58

Ch 2, Figure S4. Mass concentrations of black carbon versus sediment depth at the (A) Amazon Delta and (B) Sierra Leone Rise. Black carbon concentrations at these two sites were derived using three methods: pyrene fluorescence loss (PFL), chemothermal oxidation at $375^{\circ} \mathrm{C}(\mathrm{CTO})$, and by petrographic analysis (Petro). The bulk total organic carbon (\%TOC) is also included.

Ch 3, Figure 1. The fraction of black carbon (BC) and thermally labile organic carbon (OC) within the total organic carbon (TOC) in the tropical Atlantic Ocean. The dark gray shading is the soot-like BC fraction and the lighter gray shading is the labile OC fraction as determined by the chemothermal oxidation at $375^{\circ} \mathrm{C}$ method. The Amazon, Senegal, and Niger Deltas are fluvial-influenced sites while the Sierra Leone Rise and Northwest Argentina basin are presumed to have minimal freshwater inputs, thusly are dominated by atmospheric deposition. The Sierra Leone Rise is within the African dust plume which is associated with elevated aerosol deposition 80

Ch 3, Figure 2. Linear regression of the total organic carbon (TOC) versus the thermally labile organic carbon (OC) on the primary axis and soot-like black carbon (BC) and the secondary $\mathrm{x}$-axis. The TOC and labile OC fractions were significantly 
correlated $\left(\mathrm{R}^{2}=0.83, \mathrm{p}<0.5\right)$; no correlation was found for the TOC versus the BC fractions

Ch. 3, Figure 3. The maximum contribution of the marine material required to balance the $\delta^{13} \mathrm{C}$-OC as derived by a weighed mass balance between the $\delta^{13} \mathrm{C}$-TOC and $\delta^{13} \mathrm{C}$ BC. A three end-member model (Eq. 2) was used to estimate the maximum contribution of marine material required to balance the stable carbon isotope of the labile organic carbon fraction. Terrestrial is the sum of $\mathrm{C}_{4}$ and $\mathrm{C}_{3}$ carbon fixation pathways for terrestrial plants. The Niger Delta was removed since its average stable carbon isotope ratio is below that of $100 \% \mathrm{C}_{4}$ plant material, possible due to kerogen or petroleum inputs.

Ch 3, Figure S1. Scatter plot of all sediment carbon concentrations (\%) versus the stable carbon isotope ratio $\left(\delta^{13} \mathrm{C}\right)$ for the total organic carbon (TOC), black carbon (BC), and labile organic carbon (OC) fractions

Ch 4, Figure 1. HySplit estimates of a 10-day backward wind trajectory at the end of each filter sample at a height of 20 meters and the average regional fraction of black carbon within the total organic carbon (Mercator projection). Black carbon is further divided between the labile organic carbon, soot (CTO-375), and charcoal (pyrene fluorescence loss). The size of each pie chart is in accordance to regional average total organic carbon concentrations ranging from 0.2 to $1.8 \mu \mathrm{g} \mathrm{m}^{-3}$........ 127

Ch 4, Figure 2. Comparison of black carbon concentrations $\left(\mu \mathrm{g} \mathrm{m}^{-3}\right)$ from the four selected methods grouped by region with one standard deviation. Error associated with the OT-21 method was $\pm 0.1 \mu \mathrm{g} \mathrm{m}^{-3}$.

Ch 4, Figure S1. Global fire maps generated from the MODIS Terra and Aqua 
satellites for (a) June 30-July 9, 2010, (b) July 20-27, 2010, (c) July 30-August 8, 2010, and (d) August 18-28, 2010. Both (a) and (b) co-occurred during the Caribbean and South America regional sampling, (c) occurred during the African Plume regional sampling, and (d) for the subtropical Atlantic. The color indicates the number of detected wildfires from red (low) to yellow (high). Credits: Jacques Descloitres, Louis Giglio, and Reto Stokli. 136

Ch 4, Figure S2. HySPLIT estimates of a 10-day backward wind trajectory at the end of each filter sample at a height of 20 meters and the average regional fraction of black carbon within the total organic carbon (rectilinear projection). Black carbon is further divided between the labile organic carbon, soot (CTO-375), and charcoal (pyrene fluorescence loss). The size of each pie chart is in accordance to the regional average total organic carbon concentration ranging from 0.2 to $1.8 \mu \mathrm{g} \mathrm{m}^{-3}$. 137

Ch 5, Figure 1. Concentrations of A) particulate black carbon (BC) and B) particulate organic carbon (POC) for all samples within the study region. Concentrations are in $\mu \mathrm{g} \mathrm{L}^{-1}$ and gray dots represent the endpoint of water filtration. 175

Ch 5, Figure 2. Scatter plot of the particulate organic carbon (POC) versus the particulate organic nitrogen and black carbon (BC) versus black nitrogen 176 Ch 5, Figure S1. Surface water current direction and intensity for A) July 15, 2010 and B) April 15, 2013 predicted from the Ocean Surface Current Analysis-Real Time (OSCAR) model through NOAA. 


\section{CHAPTER 1}

\section{INTRODUCTION}

Black carbon (BC) is a ubiquitous byproduct of the incomplete combustion of fossil fuels and biomass burning, making it produced strictly in the terrestrial biosphere (Goldberg, 1985; Gustafsson et al.; 1997; Schmidt and Noack, 2000; Masiello, 2004). It is an environmentally stable structure composed of condensed sheets of polycyclic aromatic hydrocarbons (PAHs) and is depleted in nitrogen and oxygen relative to carbon (Elmquist et al., 2006; Keiluweit et al., 2010). Black carbon is presumed to have a low potential for degradation via microbial respiration; it is deemed at least semi-refractory carbon (Seiler and Crutzen, 1980). It is difficult to assess BC concentrations in different environmental matrices since BC is operationally defined by quantification method and there is no standard measurement protocols to date.

Black carbon is the broad term for a range of forms described by the $\mathrm{BC}$ combustion continuum (Masiello, 2004). These forms range from the solid residues produced by combustion called chars to the highly inert recondensed volatiles known as soot. Physical factors which determine the BC form generated depend largely on the formation temperature, concentration of oxygen, and density of organic matter during combustion (Elmquist et al., 2006; Keiluweit et al., 2010). The environmental stability and persistence of $\mathrm{BC}$ is largely dependent on its original formation process. In general, there is a greater potential for soot generation (more stable) during high 
temperature combustion with woody and dense fossil fuel materials since the lower oxygen to fuel ratio promotes inefficiencies in combustion (Schmidt and Noack, 2000). Alternatively, grasses $\left(\mathrm{C}_{4}\right.$ plants $)$ are more likely to produce char-like materials (less stable) due to the greater oxygen transfer efficiency and lower $\left(\leq 300^{\circ} \mathrm{C}\right)$ combustion temperature (Knicker, 2010). Char materials retain some of their original plant cellular material, including the macronutrient nitrogen, due to this lower formation temperature (Masiello, 2004; Knicker, 2010). The degree of BC graphitization will control its lability by determining the concentration of nutrients and plant remnants, in addition to its molecular stability.

It is important to understand the fate and transport of $\mathrm{BC}$ to resolve better human health and climatic processes. Firstly, BC aerosols are correlated with high concentrations of $\mathrm{PM}_{2.5}$ and carcinogenic PAHs, making them a hazardous pollutant when inhaled (Miguel et al., 1998). Alternatively, in environmental matrices such as soil and sediment, BC acts as a sink for persistent organic pollutants including polycyclic aromatic hydrocarbons (Gustafsson et al., 1997). Secondly, atmospheric $\mathrm{BC}$ alters local and regional climates by both reducing and increasing the albedo and acting as cloud condensation nuclei to redistribute moisture and latent heat (Menon et al., 2002). Thirdly, BC represents a fraction of the carbon cycle that is largely underexplored, especially in the marine environment. Black carbon deposited to the sediment has the potential to be a sink for fixed atmospheric carbon, effectively removing it from the active organic carbon pool for short to long geological timescales (Kuhlbusch and Crutzen, 1995; Lohmann et al., 2009). 
Many previous investigations have made the assumption that $\mathrm{BC}$ will favor coastal deposition and long-range $\mathrm{BC}$ transport to a pelagic system will be negligible (Suman et al., 1997; Mitra et al., 2002; Elmquist et al., 2006). These previous works have used the generalization that at least $90 \%$ of $\mathrm{BC}$ input to the ocean will deposit on the continental shelf (Suman et al., 1997). However, BC fluxes to the margin sediments in the Gulf of Maine were comparable to the regional production of $\mathrm{BC}$ via combustion emissions suggesting that non-coastal sediments have the potential be large organic carbon sinks (Gustafsson et al., 1998). Similarly, fluvial inputs are predicted to be the most significant transport mechanism of $\mathrm{BC}$ to the marine system and often ignore the atmospheric BC inputs (Masiello and Druffel, 1998; Mitra et al., 2002). However, atmospheric deposition could be important where fluvial inputs are minimal. The atmospheric residence time of $\mathrm{BC}$ averages between 5-7 days, but can be up to one month, allowing for long-range transport (Reddy and Boucher, 2007; Ramanathan and Carmichael, 2008). The long-range atmospheric transport of BC is clearly noticeable by the deposition of soot materials on Arctic ice. Ignoring this atmospheric fraction can grossly under-predict BC fluxes to the pelagic ocean.

The presence of $\mathrm{BC}$ in both coastal and pelagic sediments is ubiquitous. Black carbon concentrations in urban-influenced sediments have ranged from $<0.02 \%$ off the Washington, USA coast (Dickens et al., 2004) to $>0.3 \%$ on the Swedish continental shelf (Sanchez-Garcia et al., 2012) up to 0.8\% in the Mississippi River (Mitra et al., 2002). Concentrations of BC detected in deep sediments (>1200 m) from the remote 
Atlantic are approximately $0.1 \%$, however only few investigations have been made (Middelburg et al., 1999; Lohmann et al., 2009). Measured BC fluxes to coastal sediments around the globe (26-354 $\left.\mathrm{mgBC} \mathrm{cm}^{-2} \mathrm{ka}^{-1}\right)$ compared to the pelagic Pacific Ocean (0.002-3.6 mgBC cm $\left.\mathrm{ka}^{-1}\right)$ often differ by orders of magnitude (Suman et al., 1997). However, a more recent study had measured pelagic BC fluxes nearly double this estimate at $7.8 \mathrm{mgBC} \mathrm{cm}^{-2} \mathrm{ka}^{-1}$ (Lohmann et al., 2009). In order to resolve better the fate of $\mathrm{BC}$, its deposition and mass in poorly studied regions needs to be further explored.

The sources and inputs of $\mathrm{BC}$ to the marine environment are also poorly resolved. The assumption that fluvial inputs are significantly greater than aeolian deposition could under-estimate the export of terrestrial organic carbon to deep sediments. Previous work has measured fluvial total suspended solids to be up to $7.8 \mu \mathrm{g}_{\mathrm{BC}} \mathrm{mg}_{\text {sediment }}{ }^{-1}$ in the Mississippi and $1.6 \mu \mathrm{g}_{\mathrm{BC}} \mathrm{mg}_{\text {sediment }}{ }^{-1}$ in sediments within the Congo Delta (Mitra et al., 2002; Lohmann et al., 2009). However, aerosols in the marine boundary layer have detected high $\mathrm{BC}$ concentrations (compared to the convention of $40 \mathrm{ng} \mathrm{m}^{-3}$ for 'clean air') of $0.3 \mu \mathrm{g} \mathrm{m}^{-3}$ over the Indian Ocean to $0.6 \mu \mathrm{g} \mathrm{m}^{-3}$ over the Azores, suggesting that the atmospheric lifetime of $\mathrm{BC}$ allows for significant wind-driven transport to the remote ocean (Cavalli et al., 2004; Corrigan et al., 2008; Spracklen et al., 2008). Past investigations have estimated that as much as $40 \%$ of coastal sediments could be the result of atmospheric $\mathrm{BC}$ contributions and the positively buoyant fluvial plumes have the potential to horizontally transport particles hundreds of kilometers away from the river mouth (Masiello and Druffel, 1998; Geyer et al., 2004). Thus, an understanding 
of the transport of $\mathrm{BC}$ beyond a coastal environment is necessary to understand the terrestrial-marine boundary in the cycling of organic matter.

To understand fully that fate of $\mathrm{BC}$ in the marine environment, we must understand the presence of $\mathrm{BC}$ in all media. While $\mathrm{BC}$ concentrations in sediments and air have been investigated, very little work has been done to resolve the particulate surface water concentration. Black carbon must be vertically transported through the marine surface mixed layer before it reaches the sediments. To date, only one other study has measured aqueous particulate $\mathrm{BC}$ concentrations; this study detected a wide range of concentrations in the Gulf of Maine from $<0.1$ up to $16 \mu \mathrm{g} \mathrm{L}^{-1}$ and determined that $\mathrm{BC}$ composed up to $20 \%$ of the total organic carbon, which significantly alters the lability potential of organic carbon in this system (Flores-Cervantes et al., 2009). The fate of $\mathrm{BC}$ in the surface water is heavily debated and two hypotheses have come forth: 1) this aqueous $\mathrm{BC}$ pool could be an aged and refractory carbon sink that ultimately becomes part of the DOC pool (Jaffe et al., 2013; Masiello and Louchouarn, 2013) or 2) that aqueous $\mathrm{BC}$ is a source of terrestrial nutrients to an oligotrophic environment and will help stimulate minor productivity (Knicker, 2010).

The dissolved phase of black carbon, operationally defined as the black carbon which passes through a $1 \mu \mathrm{m}$ filter, could be an important mechanism for the mobilization of soil-bound black carbon to rivers and ultimately the marine environment (Dittmar, 2008; Jaffe et al., 2013; Masiello and Louchouarn, 2013). Recent studies have estimated that approximately $10 \%$ of the fluvial dissolved organic carbon is composed 
of combustion-derived materials (Jaffe et al., 2013; Masiello and Louchouarn, 2013). However, the pelagic dissolved organic carbon pool is composed of $0.9-2.6 \%$ dissolved black carbon (Dittmar, 2008). This mismatch implies that a loss of the dissolved black carbon must occur within rivers and at the fluvial-marine boundary.

Microbial decomposition of a labile black carbon pool within soil occurs on centennial timescales, suggesting that the biodegradation of this labile black carbon pool could allow for the mobilization of black carbon into the aqueous environment (Jaffe et al., 2013). Once in the marine environment, it is presently unclear if this dissolved black carbon pool undergoes further losses to bio- and photo-degradation or if it is adsorbed to particulate organic carbon (Masiello and Louchouarn, 2013; Coppola et al., 2014). Regardless, the estimated contribution of black carbon to the particulate organic carbon pool is presumably greater than that of the dissolved pool; additionally, previous studies have hypothesized that pelagic black carbon is recalcitrant since its labile fraction is degraded within soils and rivers (Mannino and Harvey, 2004; Masiello and Louchouarn, 2013). It is important to further evaluate the presence of particulate black carbon in pelagic surface water to better understand its mobility and recalcitrance in the marine system.

The fate of terrestrial organic matter in the marine environment is a mystery since the inputs are much greater than what is actually detected in the sediments (Hedges et al., 1997). This is a conundrum since terrestrial organic matter is considered to be more refractory than autochthonous marine production due to its high degree of aromaticity, 
high C/N ratio, and depleted radiocarbon age (Hopkinson et al., 1998; Kaushal and Binford, 1999; Raymond and Bauer, 2001). Ultimately, BC is a form of terrestrial organic matter that is mostly stable in marine sediments, but is often quantified as part of the total organic carbon. Previous works have found that coastal sediments generally contain $10 \% \mathrm{BC}$ compared to the total organic carbon and deep sediments off the SW Brazilian coast composed up to 34\% (Gustafsson et al., 1997; Lohmann et al., 2009). Quantifying the BC as a separate organic carbon fraction can help resolve the complex fate of terrestrial organic matter in the ocean.

The subtropical Atlantic Ocean is a dynamic study region since it contains many large fluvial systems, including the Amazon, Congo, Niger, and Paraná Rivers. Additionally, the African emission plume transports high concentrations of aerosol byproducts from grass and agricultural burnings, as well as fossil fuel combustion byproducts, across the equatorial Atlantic region (Ramanathan and Carmichael, 2008; Lohmann et al., 2009). Thus, the tropical Atlantic has the potential to be a "hotspot" for $\mathrm{BC}$ deposition. These atmospheric and fluvial BC inputs could make the tropical Atlantic comparable to a coastal system for terrestrial organic matter contributions. Ignoring the transport of $\mathrm{BC}$ in areas with emission plumes and major rivers systems could underestimate the mass balance of $\mathrm{BC}$.

Collectively, the purpose of this work was to quantify the concentrations, fluxes, and sources of BC in the marine boundary layer, surface mixed layer, and deep pelagic 
sediments in the tropical Atlantic Ocean. The ultimate goal of this work is to better understand the fate and transport of $\mathrm{BC}$ to a remote marine environment.

\section{Literature Cited in Introduction}

Cavalli, F., et al. (2004), Advances in characterization of size-resolved organic matter in marine aerosol over the North Atlantic, J Geophys Res-Atmos, 109(D24).

Coppola, A. Z., L.; Masiello, C.; Druffel, E. (2014), Aged black carbon in marine sediments and sinking particles, Geophysical Reserach Letters, 41(7), 2427-2433.

Corrigan, C. E., G. C. Roberts, M. V. Ramana, D. Kim, and V. Ramanathan (2008), Capturing vertical profiles of aerosols and black carbon over the Indian Ocean using autonomous unmanned aerial vehicles, Atmos Chem Phys, 8(3), 737-747.

Dickens, A. F., Y. Gelinas, C. A. Masiello, S. Wakeham, and J. I. Hedges (2004), Reburial of fossil organic carbon in marine sediments, Nature, 427(6972), 336-339.

Dittmar, T. (2008), The molecular level determination of black carbon in marine dissolved organic matter, Org Geochem, 39(4), 396-407.

Elmquist, M., G. Cornelissen, Z. Kukulska, and O. Gustafsson (2006), Distinct oxidative stabilities of char versus soot black carbon: Implications for quantification and environmental recalcitrance, Global Biogeochem Cy, 20(2).

Flores-Cervantes, D. X., D. L. Plata, J. K. MacFarlane, C. M. Reddy, and P. M. Gschwend (2009), Black carbon in marine particulate organic carbon: Inputs and cycling of highly recalcitrant organic carbon in the Gulf of Maine, Mar Chem, 113(34), 172-181.

Geyer, W. R., P. S. Hill, and G. C. Kineke (2004), The transport, transformation and dispersal of sediment by buoyant coastal flows, Cont Shelf Res, 24(7-8), 927-949.

Goldberg, E. D. (1985), Black Carbon in the Environment, Wiley, New York.

Gustafsson, O., and P. M. Gschwend (1998), The flux of black carbon to surface sediments on the New England continental shelf, Geochim Cosmochim Ac, 62(3), 465472.

Gustafsson, O., F. Haghseta, C. Chan, J. MacFarlane, and P. M. Gschwend (1997), Quantification of the dilute sedimentary soot phase: Implications for PAH speciation and bioavailability, Environ Sci Technol, 31(1), 203-209. 
Hedges, J. I., R. G. Keil, and R. Benner (1997), What happens to terrestrial organic matter in the ocean?, Org Geochem, 27(5-6), 195-212.

Hopkinson, C. S., et al. (1998), Terrestrial inputs of organic matter to coastal ecosystems: An intercomparison of chemical characteristics and bioavailability, Biogeochemistry, 43(3), 211-234.

Jaffe, R., Y. Ding, J. Niggemann, A. V. Vahatalo, A. Stubbins, R. G. M. Spencer, J. Campbell, and T. Dittmar (2013), Global Charcoal Mobilization from Soils via Dissolution and Riverine Transport to the Oceans, Science, 340(6130), 345-347.

Kaushal, S., and M. W. Binford (1999), Relationship between C : N ratios of lake sediments, organic matter sources, and historical deforestation in Lake Pleasant, Massachusetts, USA, J Paleolimnol, 22(4), 439-442.

Keiluweit, M., P. S. Nico, M. G. Johnson, and M. Kleber (2010), Dynamic Molecular Structure of Plant Biomass-Derived Black Carbon (Biochar), Environ Sci Technol, 44(4), 1247-1253.

Knicker, H. (2010), "Black nitrogen" - an important fraction in determining the recalcitrance of charcoal, Org Geochem, 41(9), 947-950.

Kuhlbusch, T. A. J., and P. J. Crutzen (1995), Toward a Global Estimate of Black Carbon in Residues of Vegetation Fires Representing a Sink of Atmospheric Co2 and a Source of O-2, Global Biogeochem Cy, 9(4), 491-501.

Lohmann, R., K. Bollinger, M. Cantwell, J. Feichter, I. Fischer-Bruns, and M. Zabel (2009), Fluxes of soot black carbon to South Atlantic sediments, Global Biogeochem Cy, 23.

Mannino, A., and H. R. Harvey (2004), Black carbon in estuarine and coastal ocean dissolved organic matter, Limnol Oceanogr, 49(3), 735-740.

Masiello, C. A. (2004), New directions in black carbon organic geochemistry, Mar Chem, 92(1-4), 201-213.

Masiello, C. A., and E. R. M. Druffel (1998), Black carbon in deep-sea sediments, Science, 280(5371), 1911-1913.

Masiello, C. A., and P. Louchouarn (2013), Fire in the Ocean, Science, 340(6130), 287-288.

Menon, S., J. Hansen, L. Nazarenko, and Y. F. Luo (2002), Climate effects of black carbon aerosols in China and India, Science, 297(5590), 2250-2253. 
Middelburg, J. J., J. Nieuwenhuize, and P. van Breugel (1999), Black carbon in marine sediments, Mar Chem, 65(3-4), 245-252.

Miguel, A. H., T. W. Kirchstetter, R. A. Harley, and S. V. Hering (1998), On-road emissions of particulate polycyclic aromatic hydrocarbons and black carbon from gasoline and diesel vehicles, Environ Sci Technol, 32(4), 450-455.

Mitra, S., T. S. Bianchi, B. A. McKee, and M. Sutula (2002), Black carbon from the Mississippi River: Quantities, sources, and potential implications for the global carbon cycle, Environ Sci Technol, 36(11), 2296-2302.

Ramanathan, V., and G. Carmichael (2008), Global and regional climate changes due to black carbon, Nat Geosci, 1(4), 221-227.

Raymond, P. A., and J. E. Bauer (2001), Riverine export of aged terrestrial organic matter to the North Atlantic Ocean, Nature, 409(6819), 497-500.

Reddy, M. S., and Boucher (2007), Climate impact of black carbon emitted from energy consumption in the world's regions, Geophys Res Lett, 34.

Sanchez-Garcia, L., I. Cato, and O. Gustafsson (2012), The sequestration sink of soot black carbon in the Northern European Shelf sediments, Global Biogeochem Cy, 26.

Schmidt, M. W. I., and A. G. Noack (2000), Black carbon in soils and sediments: Analysis, distribution, implications, and current challenges, Global Biogeochem Cy, 14(3), 777-793.

Seiler, W., and P. J. Crutzen (1980), Estimates of Gross and Net Fluxes of Carbon between the Biosphere and the Atmosphere from Biomass Burning, Climatic Change, 2(3), 207-247.

Spracklen, D. V., B. Bonn, and K. S. Carslaw (2008), Boreal forests, aerosols and the impacts on clouds and climate, Philos TR Soc A, 366(1885), 4613-4626.

Suman D. O., K. T. A. J., and Lim B. (1997), Marine sediments: A reservoir for black carbon and their use as spatial and temporal records of combustion., Sediment Records of Biomass Burning and Global Change ed. J. S. Clark et al.(MIT Press). 


\section{CHAPTER 2}

\section{An assessment of fluvial versus atmospheric fluxes of black carbon to subtropical Atlantic sediments}

This manuscript will be submitted and is formatted for the journal Global

Biogeochemical Cycles

Kari Pohl ${ }^{1}$, Mark Cantwell ${ }^{2}$, Matthias $Z_{\text {abel }}{ }^{3}$, Rainer Lohmann ${ }^{1 *}$

${ }^{1}$ Graduate School of Oceanography, University of Rhode Island, Narragansett, Rhode Island, U.S.A.

${ }^{2}$ U.S. Environmental Protection Agency, Atlantic Ecology Division, Narragansett, Rhode Island, U.S.A.

${ }^{3}$ Department of Marine Geology/Inorganic Geochemistry, Bremen University, Bremen, Germany

*Corresponding author: email: rlohmann@mail.uri.edu ; Tel: 401-874-6612; Fax: 401-874-6811 


\title{
Key Points
}

- Black carbon fluxes to pelagic sediments where elevated in the equatorial Atlantic Ocean

- Soot was the primary form of black carbon

- Atmospheric deposition of black carbon is significant in pelagic sediments

\begin{abstract}
Black carbon (BC) is the highly graphitized byproduct of incomplete combustion that could be a sink for fixed carbon. Little data are currently available for BC fluxes to remote marine sediment. Sediments from the Amazon, Niger, and Senegal Deltas, Sierra Leone Rise, and South Atlantic were analyzed for BC using two methods: a chemothermal oxidation $\left(\mathrm{BC}_{\mathrm{CTO}}\right)$ and pyrene fluorescence loss $\left(\mathrm{BC}_{\mathrm{PFL}}\right)$. The ratio of $\mathrm{BC}_{\mathrm{C} \text { то }}$ to sedimentary total organic carbon decreased from $55 \%$ at the Amazon Delta, $30 \%$ at the Sierra Leone Rise to $15 \%$ in the South Atlantic. The ratio of $\mathrm{BC}_{\mathrm{PFL}}$ to the sedimentary organic carbon mostly agreed with the $\mathrm{BC}_{\mathrm{C} \text { то }}$ fraction with the exception of the Niger Delta (19\%) and the South Atlantic (67\%). The $\mathrm{BC}_{\mathrm{C} \text { то sediment flux was }}$ greatest in the Niger Delta at $23 \mathrm{mg} \mathrm{cm}^{-2} \mathrm{kyr}^{-1}$, followed by the Sierra Leone Rise at an average of $6 \mathrm{mg} \mathrm{cm}^{-2} \mathrm{kyr}^{-1}$. The Sierra Leone Rise had a $\mathrm{BC}_{\mathrm{CTO}}$ flux six times greater than the remote South Atlantic, which had a flux of $0.9 \mathrm{mg} \mathrm{cm}^{-2} \mathrm{kyr}^{-1}$. Elevated BC fluxes at the Sierra Leone Rise were most likely due to biomass burning from the African continent, as evidenced by organic biomarkers and stable carbon isotopes. Atmospheric deposition composed $4-28 \%$ of the $\mathrm{BC}_{\mathrm{CTO}}$ and at least $43 \%$ of the $\mathrm{BC}_{\mathrm{PFL}}$ in the fluvial Niger Delta region, suggesting that $\mathrm{BC}$ atmospheric deposition to remote sediments can be significant in areas with elevated biomass burning.
\end{abstract}


Keywords: black carbon, soot, sediments, carbon sinks, subtropical Atlantic, atmospheric deposition, biomass burning

\subsection{Introduction}

Black carbon $(\mathrm{BC})$ is a ubiquitous and refractory portion of the total organic carbon (TOC) pool that is a byproduct of the incomplete combustion of fossil fuels and biomass burning (Seiler and Crutzen, 1980; Goldberg, 1985; Schmidt and Noack, 2000). Atmospheric BC could be the second greatest contributor to global warming (Bond and Sun, 2005) and its deposition onto ice may be altering the global albedo and expediting glacial melting (Flanner et al., 2007). Black carbon has the potential to be a long term sink for fixed atmospheric carbon when deposited to marine sediments (Kuhlbusch, 1998) because it is removed from the active carbon pool by being mostly biologically inert (Seiler and Crutzen, 1980). Thus, in order to understand better the role $\mathrm{BC}$ plays in the carbon cycle, we must understand better its transport and fate in the marine environment.

The stability of BC arises from its highly graphitized structure. The operational definition of $\mathrm{BC}$ varies by quantification method; it is hypothesized to be part of a continuum of incompletely combusted materials ranging from solid residues called chars to re-condensed volatiles termed soot (Schmidt and Noack, 2000; Masiello, 2004). Fluvial and atmospheric deposition are the two primary modes of transport to the environment. Black carbon has a short atmospheric residence time ranging from hours to 30 days, averaging one week (Masiello and Druffel, 1998; Ramanathan and 
Carmichael, 2008). Thus, atmospheric deposition is an important transport mechanism for $\mathrm{BC}$, especially to remote regions with little potential for $\mathrm{BC}$ genesis, such as the ocean. Fluvial deposition is generally assumed to be quantitatively the most important source of BC to marine sediments (Suman et al., 1997; Kuhlbusch, 1998; Masiello and Druffel, 2001; Mitra et al., 2002; Elmquist et al., 2006). A previous study determined that atmospherically deposited BC composed $\leq 40 \%$ of the TOC in coastal sediments (Masiello and Druffel, 1998).

The expense and difficulty of measuring BC in deep marine sediments has made knowledge of BC fluxes confined to few regions. Previous studies (Table 1) have focused primarily on BC fluxes in heavily urbanized areas and shallow sediments. In urban marine environments, TOC is expected to dilute the $\mathrm{BC}$ due to large algal biomass, usually making BC account for $<10 \%$ of the TOC (Ribeiro et al., 2008; Flores-Cervantes et al., 2009; Gonzalez-Vila et al., 2009). The local burning activity and prevailing wind direction will heavily influence the $\mathrm{BC}$ depositional fluxes to nearby sediments. Masiello and Druffel (1998) found that BC accounted for 12-31\% of the organic carbon from deep (>4000 m) marine sediments in the Pacific Abyssal plains, where little fluvial input is expected. Likewise, $\mathrm{BC}$ concentrations from the South American margin (depth 1228-4949 m) ranged between 8-34\% of the sedimentary total organic carbon, indicating that BC in deep sediments could account for a higher percentage of the TOC than urban environments, possibly due to the remineralization of labile organic carbon species within the water column and sediments (Lohmann et al., 2009). 
Black carbon fluxes to the marine environment depend largely on the magnitude of BC production and the distance from source regions (Suman et al., 1997). Coastal BC fluxes have been measured as high as 26-354 $\mathrm{mg} \mathrm{cm}^{-2} \mathrm{kyr}^{-1}$ and $86-1900 \mathrm{mg} \mathrm{cm}^{-2} \mathrm{kyr}^{-1}$ for the coastal Pacific and Gulf of Maine, USA (Suman et al., 1997; Gustafsson and Gschwend, 1998, Table 1) to as low as 1.2-3.1 $\mathrm{mg} \mathrm{cm}^{-2} \mathrm{kyr}^{-1}$ for the Washington Coast, USA (Dickens et al., 2004). Atlantic margin sediments, sediments >1000 m deep near a continental source, are mostly lower than coastal fluxes in both magnitude and range at $0.5-7.8 \mathrm{mg} \mathrm{cm}^{-2} \mathrm{kyr}^{-1}$ (Lohmann et al., 2009). In the remote Pacific Ocean, presumably removed from fluvial and atmospheric influence, BC fluxes are as low as $0.002-3.6 \mathrm{mg} \mathrm{cm}^{-2} \mathrm{kyr}^{-1}$ and contributed $\sim 15 \%$ to the sedimentary TOC pool (Suman et al., 1997; Masiello and Druffel, 1998). These measurements suggest that fluvial $\mathrm{BC}$ deposition is a much greater transport mechanism of $\mathrm{BC}$ to marine sediments in comparison to the atmospheric transport. However, regions with elevated seasonal biomass burning and wind direction towards the ocean, such as the Subtropical Atlantic, could have enhanced BC fluxes.

The Subtropical Atlantic has the potential to be a "hotspot" for atmospheric BC deposition. Intense Savanna grass burning events coupled with anthropogenic emissions give this region a high potential for $\mathrm{BC}$ emissions and transport off-shore (Cahoon et al., 1992; Andreae and Merlet, 2001). Savanna grass has aBC emission factor of $0.48 \pm 0.18 \mathrm{~g} \mathrm{~kg}^{-1}$ dry matter, which suggests that up to $24 \mathrm{Tg} \mathrm{yr}^{-1}$ of $\mathrm{BC}$ could be generated by Savanna grass burning events annually (Hao et al., 1990; 
Andreae and Merlet, 2001). Savanna grass burning could account for up to $60 \%$ of the global biomass burning. Global inventories of the $\mathrm{BC}$ formation predict that open biomass burning and fossil fuel combustion are roughly equivalent in magnitude (Hao et al., 1990; Andreae, 1991; Ramanathan and Carmichael, 2008). Thus, the pelagic Subtropical Atlantic could receive a significant input of BC, making the sediments a potential sink for fixed carbon.

In this study, sediments from the remote Sierra Leone Rise and South Atlantic, a coastal sample at the Senegal Delta, and the Amazon and Niger Deltas (Fig. 1) were collected and analyzed with the goals of: 1) determining the $\mathrm{BC}$ fluxes to pelagic Equatorial Atlantic sediments, 2) measuring the fractions of the various forms of $\mathrm{BC}$ (i.e. soot vs. charcoal), and 3) assessing the importance of atmospheric versus fluvial $\mathrm{BC}$ deposition in this region.

\section{Materials and Methods}

\subsection{Sediment sample collection}

Sediment samples were collected in the summer of 2010 aboard the $R / V$ Endeavor during legs EN-480 and EN-481 (Fig. 1). Surface sediments and shallow cores (1-12 $\mathrm{cm}$ ) were recovered at eight sites using a multicorer and Van Veen grab sampler. Multicorer samples were sliced into $1 \mathrm{~cm}$ sections immediately after recovery. All sediments were stored in pre-combusted $\left(450^{\circ} \mathrm{C}\right)$ amber glass jars in a $-10^{\circ} \mathrm{C}$ chest freezer until analysis. Additional sediments from the Department of Geosciences at Bremen University (GeoB cores 1701, 2814, 4901, 4903, 4904, 4907, 4908, and 9501) 
were also analyzed. These sediment samples had been taken by multicorer and box corer, sliced into $1-10 \mathrm{~cm}$ sections, freeze-dried and ground with a mortar and pestle (Wagner et al., 2003; Zabel et al., 2003).

Sediment cores were grouped into the following regions (with average water depth): Amazon Delta (3360 m), Niger Delta (2500 m), Senegal Delta (330 m), Sierra Leone Rise (3500 m), and South Atlantic (4950 m) (Fig. 1).

\subsection{Black carbon and total organic carbon analysis}

$\mathrm{BC}$ was chemically quantified using two separate, but complementary, techniques which measure overlapping portions of the proposed $\mathrm{BC}$ combustion continuum. The first method was a chemothermal oxidation at $375^{\circ} \mathrm{C}\left(\mathrm{BC}_{\mathrm{Cто}}\right)$, which utilizes the thermal stability of refractory soot-like BC but will oxide charcoal-like carbonwith the organic carbon (Gustafsson et al., 1997; Elmquist et al., 2004). Sediments were decalcified using $10 \%$ hydrochloric acid, dried slowly at $35^{\circ} \mathrm{C}$, and homogenized with a mortar and pestle. A portion of the decalcified sediment was reserved to measure the TOC. A thin layer of $\sim 5 \mathrm{mg}$ of sediment was combusted at $375^{\circ} \mathrm{C}$ with a steady stream of high purity compressed air for 24 hours to isolate the $\mathrm{BC}_{\mathrm{C} \text { то }}$. Sediment samples from the GeoB cores were quantified using an Elementar Vario MICRO cube elemental analyzer coupled to an Isoprime100 isotope ratio-mass spectrometer (IRMS); sediments collected on EN-480 and EN-481 were analyzed on a Carlo Erba elemental analyzer coupled to a GV Optima 588 system IR-MS. The detection limit of both instruments was $100 \mathrm{ng}$ of carbon. 
Sediments were also analyzed for $\mathrm{BC}$ using a pyrene fluorescence loss $\left(\mathrm{BC}_{\mathrm{PFL}}\right)$, a chemical technique which uses the adsorption of pyrene to BC (Accardi-Dey and Gschwend, 2002; Flores-Cervantes et al., 2009; Pohl et al., 2013). Approximately 20 $\mathrm{mg}$ of each sample was added to a $50 \mathrm{~mL}$ amber vial with a $1 \mu \mathrm{g} \mathrm{L}-1$ aqueous pyrene solution and $0.05 \mathrm{M}$ sodium azide to prevent microbial growth. Prior to adding the sediment sample, a Shimadzu RF-1501 spectrophotofluorometer was used to obtain the initial fluorescence (excitation at $275 \mathrm{~nm}$; emission spectra $250-450 \mathrm{~nm}$ ). Samples were placed on a shaker table for 30 days to reach equilibrium before the final fluorescence was measured. $\mathrm{BC}_{\mathrm{PFL}}$ was calculated using equations (1)-(3).

$$
f_{w}=\frac{C_{f}}{C_{i}}
$$

The fraction of dissolved pyrene after equilibrium was achieved $\left(f_{w}\right)$ was determined by the ratio of the final pyrene concentration $\left(\mathrm{C}_{\mathrm{f}} ; \mu \mathrm{g}_{\text {pyrene }} \mathrm{L}^{-1}\right)$ by the initial pyrene concentration $\left(\mathrm{C}_{\mathrm{i}} ; \mu \mathrm{g}_{\text {pyrene }} \mathrm{L}^{-1}\right)$.

$$
K_{d}=\frac{\left(1-f_{w}\right)}{f_{w} r_{s w}}
$$

The solid-water partitioning coefficient $\left(\mathrm{K}_{\mathrm{d}} ; \mathrm{L} \mathrm{kg}_{\text {sample }}{ }^{-1}\right)$ was then determined by using Eq. 2 where $\mathrm{r}_{\mathrm{sw}}$ is the ratio of the sample mass $(\mathrm{kg})$ added to the volume of water $(\mathrm{L})$. Finally the fraction of $\mathrm{BC}_{\mathrm{PFL}}$ present $\left(\mathrm{f}_{\mathrm{bc}}\right)$ was determined by equation 3. 


$$
f_{B C}=\frac{\left[K_{d}-f_{O C} K_{O C}\right]}{K_{B C} C_{w}^{n-1}}
$$

Here, $\mathrm{f}_{\mathrm{OC}}$ is the organic carbon fraction determined by IR-MS during the CTO-375 methodology, $\mathrm{K}_{\mathrm{OC}}$ and $\mathrm{K}_{\mathrm{BC}}$ are predetermined distribution coefficients of $10^{4.7}(\mathrm{~L}$ $\left.\mathrm{kg}_{\mathrm{OC}}{ }^{-1}\right)$ and $10^{6.25}\left(\left[\mu \mathrm{g}_{\text {pyrene }} \mathrm{kg}_{\mathrm{BC}}{ }^{-1}\right] /\left[\mu_{\text {pyrene }} \mathrm{L}^{-1}\right]\right)$ respectively, $\mathrm{C}_{\mathrm{w}}$ is the initial truly dissolved concentration of pyrene $\left(\mu \mathrm{g}_{\text {pyrene }} \mathrm{L}^{-1}\right)$, and $\mathrm{n}$ is the Freundlich constant of 0.62 (Accardi-Dey and Gschwend, 2002). The initial pyrene concentration of $1 \mu \mathrm{g}_{\text {pyrene }} \mathrm{L}^{-1}$ was selected to make $\mathrm{C}_{\mathrm{w}}$ approach 1, eliminating the uncertainty of the Freundlich exponent.

In addition to the chemical approach to quantify sedimentary BC, a visual-based petrographic analysis was applied for comparison $\left(\mathrm{BC}_{\text {petro }}\right)$. Approximately $50 \mathrm{~g}$ of sediment from the Amazon Delta (sediment depths 0-6, 5.5-9, and 8.5-12 cm) and Sierra Leone Rise $(0-4$ and 4-8 cm) where analyzed with a quantitative microscope analysis by Dr. Bertrand Ligouis at the Laboratories for Applied Organic Petrology at the University of Tübingen, Germany. Briefly, polished sediments were observed under a Leitz DMRX-MPVSP microscope photometer using a total magnification up to 500X with reflected white light, uv fluorescence, plane-polarized light, and crosspolarized light (Taylor et al., 1998; Crelling et al., 2006). Various anthropogenic and natural organic matter fragments were observed including char, soot, coal, plastic, pollen, and fungal spores (Supplementary Materials).

\subsection{Sedimentation Rates and BC Fluxes to sediments}


Sedimentation rates were obtained using three approaches: published data from nearby sites or existing data bases, radiocarbon dating, and with an empirical relationship using depth as the independent variable as outlined by Middelburg et al. (1997). These sedimentation rates were applied to calculate the $\mathrm{BC}_{\mathrm{CTO}}, \mathrm{BC}_{\mathrm{PFL}}$, and $\mathrm{BC}_{\text {petro }}$ sediment fluxes.

In the first approach, sedimentation rates for all regions were estimated using published data and through the global inventory www.pangaea.de. If there was no published data for a specific core, the averaged sedimentation rates of nearby sites were used as an approximation.

In the second approach, sediments from the Amazon Delta and Sierra Leone Rise regions were analyzed for radiocarbon $\left(\Delta{ }^{14} \mathrm{C}\right)$ using the reconnaissance method at the National Ocean Science-Accelerated Mass Spectrometry facility at Woods Hole Oceanographic Institute (Burke et al., 2010; Xu et al., 2007). $\Delta^{14} \mathrm{C}$ was determined in the top $6 \mathrm{~cm}$ as well as the bottom two (deepest) centimeters. The determined ages of the bottom sediment sections were applied to calculate the sedimentation rate and depositional flux of $\mathrm{BC}_{\mathrm{CTO}}, \mathrm{BC}_{\mathrm{PFL}}$, and $\mathrm{BC}_{\text {petro }}$ to these sediments.

The third approach to determine sedimentation rate was calculated using a depth-based algorithm (Middelburg et al. 1997). The sediment accumulation rate $(\omega)$ and BC flux $\left(F_{b}\right)$ was calculated using equations (4) and (5) with the sediment porosity $(\varnothing)$, the sediment dry bulk density $\left(\rho_{\mathrm{s}}\right)$, and the surface sediment concentration of $\mathrm{BC}\left(\mathrm{C}_{\mathrm{BC}}\right)$ as 
determined from the chemothermal oxidation, pyrene fluorescence loss, and petrographic analysis methods. The estimated $\omega$ was predicted using depth $(Z)$ as the independent variable along with the linear regression parameters of $a(-0.87478367)$ and $b(-0.00043512)$, and a correction factor (CF; 3.3).

$$
\begin{gathered}
\omega=10^{(a+b Z)} * C F \\
F_{b}=(1-\emptyset) \rho_{S} C_{B C} \omega
\end{gathered}
$$

For the $\mathrm{BC}_{\text {petro }}$ fluxes, soot values were converted from a volume concentration $\left(\mathrm{cm}_{\mathrm{BC}}{ }^{3}\right.$

$\mathrm{cm}_{\text {sediment }}{ }^{-3}$ ) to mass concentration $\left(\mathrm{mg}_{\mathrm{BC}} \mathrm{g}_{\text {sediment }}{ }^{-1}\right)$ using an approximated soot density of $1 \mathrm{~g} \mathrm{~cm}^{-3}$, charcoal density range of 0.24 to $0.48 \mathrm{~g} \mathrm{~cm}^{-3}$, and an average sediment density of $1.7 \mathrm{~g} \mathrm{~cm}^{-3}$ (Tenzer and Gladkikh, 2014).

\subsection{Hydrocarbon Analysis and Source Determination}

Black carbon sources were estimated using $\delta^{13} \mathrm{C}$, select polycyclic aromatic hydrocarbons (PAHs), and n-alkanes. $\delta^{13} \mathrm{C}$ values were determined with the chemothermal oxidation method on the IR-MS. For the PAH analysis, homogenized sediments were extracted with an accelerated solvent extractor (Dionex ASE 350) in 6 cycles at $150^{\circ} \mathrm{C}$ using a $50 / 50 \mathrm{mix}$ of hexane and acetone. Prior to extraction, $\mathrm{d}_{10^{-}}$ acenapthene, $d_{10}$-phenanthrene, $d_{12}$-chrysene, and $d_{12}$-perylene were added to each sample to assess recovery. Solvent extracts were evaporated to $1 \mathrm{~mL}$ using a rotary evaporator and purified through a column containing $2 \mathrm{mg}$ of activated silica with 45 
$\mathrm{mL}$ of a 30/70 solvent mixture of dichloromethane and hexane. Extracts were evaporated with $\mathrm{N}_{2}$ gas to $50 \mu \mathrm{L}$ and an injection surrogate of $\mathrm{p}$-terphenyl was added before analysis on an Agilent 6890 Series gas chromatograph coupled to a 5973 Network Mass Selection Detector (GC-MS). All samples were quantified using ChemStation software. Source apportionment was assessed on all surface sediments using the ratio of indeno(1,2,3,c,d)pyrene (IP) and benzo(g,h,i)perylene (Bghi) versus fluoranthene $(\mathrm{Fl})$ and pyrene $(\mathrm{Py})$. The same extract was also analyzed for the selected n-alkanes on all surface sediments $(0-2 \mathrm{~cm})$ using the GC-MS as outlined by Sachse et al. (2006). The n-alkanes not in the calibration curve were linearly extrapolated based on molecular weight.

\subsection{Quality Control and Quality Assurance}

The standard reference materials (SRM) 1941b (marine sediment), 1650 (diesel soot), 1649a (urban dust), mollisol (chernozem), risotto char, and sand as a methodological blank were quantified alongside $\mathrm{BC}$ as recommended by the $\mathrm{BC}$ ring trials (Hammes et al., 2007). Previous works have suggested that the CTO-375 method could char environmental matrix samples, such as sediment, by artificially creating soot-like BC during the chemothermal oxidation treatment (Gustafsson et al., 2001; Elmquist et al., 2004; Hammes et al., 2007; Flores-Cervantes et al., 2009). We used the interlaboratory investigation by Hammes et al. (2007) as a reference for these commonly applied SRMs. The investigation quantified the analytical average and range, respectively for theses SRMs using the CTO-375 method: $1941 \mathrm{~b}(0.51 \%$; 0.38- 
0.74\%), 1649a (1.49\%; 0.9-2.59\%), mollisol (0.11\%; 0-0.44\%), risotto char (0.9\%; 0$2.1 \%)$, and $1650(43.2 \% ; 32.5-44.0 \%)$.

The average $\mathrm{BC}$ concentration for $1941 \mathrm{~b}$ was $0.7 \%$ for the chemothermal oxidation $( \pm 0.04)$ and pyrene fluorescence loss method $( \pm 0.2)$ methods. Mollisol was $0.1 \%$ also for both methods. $\mathrm{BC}_{\mathrm{PFL}}$ was greater for $1649 \mathrm{a}(5.8 \%)$ than the chemothermal oxidation (2.4\%) method, which was expected according to Flores-Cervantes et al. (2009), suggesting a large fraction of charcoal. A greater $\mathrm{BC}_{\text {Сто }}$ concentration was measured for 1650 (48.0\%) than $\mathrm{BC}_{\mathrm{PFL}}(12.2 \%)$, which suggests that diesel particulate matter may contain a thermally stable form of carbon that was not detected using the pyrene fluorescence loss. No risotto char was recovered by $\mathrm{BC}_{\mathrm{CTO}}$, as expected, suggesting that little charring of organic carbon was occurring; risotto char was not measured via pyrene fluorescence loss method since it altered the color of the aqueous solution, obscuring the results. No BC was detected on the sand by either method.

\subsection{Results and Discussion}

\subsection{Black carbon concentrations}

$\mathrm{BC}_{\mathrm{CTO}}$ represents the most refractory and thermally stable forms of the $\mathrm{BC}$ combustion continuum (Masiello, 2004). Thus, $\mathrm{BC}_{\mathrm{CTO}}$ is optimized to quantify the soot-like fractions of BC and will oxidize charcoal. The pyrene fluorescence loss method is a chemical technique which does not have a thermal bias. It should be able to detect a broader range of $\mathrm{BC}$ forms (Flores-Cervantes et al., 2009). In this study, most sediments had a ratio of $\mathrm{BC}_{\mathrm{CTO}}$ to $\mathrm{BC}_{\mathrm{PFL}}($ soot $/$ soot + charcoal $) \geq 1$, indicating that 
soot dominated $\mathrm{BC}$ fraction in sediments (Table 2, Fig. 2, Fig. 3). $\mathrm{BC}_{\mathrm{CTO}} / \mathrm{BC}_{\mathrm{PFL}}$ ratios were $>1$ in the Niger and Sierra Leone Rise, suggesting that a thermally refractory, carbonaceous material, such as pollen, could be present in these deep water systems (Gustafsson et al., 1997). However, petrographic analysis demonstrated that only trace amounts of pollen and plant spores were present, thus their interference should be minimal. The chemothermal oxidation has been shown to char sediments rich in phytoplankton exudates by giving $\mathrm{BC}_{\mathrm{C} \text { то }}$ measurements up to $27 \%$ on $\mathrm{BC}$-free, but OC-rich, sediments (Gustafsson et al., 2002; Masiello, 2004). However, SRM analysis suggests that charring was minimal. Diesel soot-like BC (SRM 1650) gave similar results with $\mathrm{BC}_{\mathrm{CTO}} / \mathrm{BC}_{\mathrm{PFL}}$ being $>1$, so a similar material may have been present in the Niger Delta sediments.

$\mathrm{BC}_{\mathrm{CTO}}$ and $\mathrm{BC}_{\mathrm{PFL}}$ sediment concentrations were most comparable in the Amazon Delta (Fig. 2). $\mathrm{BC}_{\mathrm{PFL}}$ concentrations averaged $0.3 \pm 0.2 \%$ and composed $52 \pm 30 \%$ of the TOC while the $\mathrm{BC}_{\mathrm{CTO}}$ was $0.4 \pm 0.2 \%$ and composed an average of $55 \pm 30 \%$ of the TOC (Table 2). The $\mathrm{BC}_{\mathrm{CTO}} / \mathrm{BC}_{\mathrm{PFL}}$ ratio was 0.9 , implying that the Amazon Delta was comprised mostly of refractory soot. This finding agrees with the petrographic analysis in which only soot particles derived from traffic combustion were observed. The $\mathrm{BC}_{\text {Petro }}$ concentration for the surface Amazon Delta sediments $(0-6 \mathrm{~cm})$ was $0.8 \%$. Total organic carbon, $\mathrm{BC}_{\mathrm{PFL}}$, and $\mathrm{BC}_{\mathrm{CTO}}$ concentrations were lower than expected for this fluvial system (Table 1). This could be the result of the large distance from the source (200 km from river mouth) or due to enhanced remineralization of organic material in both the water column and sediments. The Amazon is known as the global 
incinerator, and these sites could have undergone enhanced biological respiration during and after deposition (Aller and Blair, 2006).

Both the Sierra Leone Rise and South Atlantic regions were expected to be dominated by atmospheric deposition and have minimal fluvial inputs. $\mathrm{BC}_{\text {Сто }}$ concentrations were elevated in the Sierra Leone Rise compared to the South Atlantic. $\mathrm{BC}_{\mathrm{PFL}}$ and $\mathrm{BC}_{\text {Сто }}$ in the Sierra Leone Rise composed an average of $28 \pm 20 \%$ and $30 \pm 10 \%$ of the TOC, respectively (Fig. 2). Soot dominated the BC in the sediment and TOC concentrations were $1.7 \pm 0.6 \%$, which were among the highest in this study region. Both the $\mathrm{BC}_{\mathrm{PFL}}$ and $\mathrm{BC}_{\mathrm{CTO}}$ concentrations were $0.5 \%$ ( \pm 0.4 and $0.2 \%$, respectively). Petrographic analysis observed both soot particles $(0.8 \%)$ and charcoal particles $(0.06$ to $0.11 \%$ ) derived from coal combustion, resulting in a $\mathrm{BC}_{\text {petro }}$ concentration of $0.9 \%$. In the remote South Atlantic, $\mathrm{BC}_{\mathrm{CTO}}$ concentrations were $0.1 \pm 0 \%$ and composed $15 \pm 0 \%$ of the TOC. This agreed with the findings by Masiello and Druffel for Pacific pelagic sediments (1998). $\mathrm{BC}_{\mathrm{PFL}}$ concentrations were $0.5 \pm 0 \%$ in the South Atlantic $\left(\mathrm{BC}_{\mathrm{CTO}} / \mathrm{BC}_{\mathrm{PFL}}\right.$ of 0.2$)$, suggesting an input of charcoal-like $\mathrm{BC}$ (Fig. 2, Fig. 3.).

$\mathrm{BC}_{\mathrm{CTO}} / \mathrm{BC}_{\mathrm{PFL}}$ concentration ratio at the Niger Delta sites were $>1$, suggesting that soot was dominant in this heavily urbanized fluvial system (Table 2, Fig. 2). The regional average $\mathrm{BC}$ concentration was $0.4 \pm 0.7 \%$ for $\mathrm{BC}_{\mathrm{PFL}}$ and $0.7 \pm 0.2 \%$ for $\mathrm{BC}_{\mathrm{CTO}}$, which were among the highest in the Subtropical Atlantic region. In oxygenated sediments, up to $64 \%$ of the BC (both charcoal and soot) can be degraded (Middelburg et al., 1999; Burdige, 2007). This proposes that the more labile charcoal is either 
respired in the water column and sediment and/or undergoes more oxidation in the sediments than soot.

The petrographic analysis supported the trends derived via CTO-375 and PFL, however, petrographic results were elevated in comparison to these analytical methods (Supplementary Materials). Anthropogenic particles were detected in all sediments analyzed in the Amazon Delta and Sierra Leone Rise regardless of sediment depth. Soot derived from traffic combustion (size fraction 3-60 and 3-100 $\mu \mathrm{m}$ for the top sediment of the Amazon Delta and Sierra Leone Rise, respectively) was the dominant form of anthropogenic material, followed by plastic, and char from coal combustion (Sierra Leone Rise only). Anthropogenic-derived carbonaceous materials were elevated in the Sierra Leone Rise compared to the Amazon Delta, suggesting that atmospheric deposition and vertical surface water advection deposited greater amounts of terrigenous material than the Amazon River. In general, natural and anthropogenic particles were smaller in the Amazon Delta than the Sierra Leone Rise, suggesting greater fragmentation and sorting during transport. Previous work had hypothesized that fluvial-deposited BC particles would be more degraded than atmosphericdeposited since they can age in soils before transport to the ocean (Jaffe et al., 2013; Masiello and Louchouarn, 2013). Alternatively, this could also suggest that the carbon remineralization is greater in the Amazon plume during deposition (Aller and Blair, 2006). 
The mass concentration of microscopic soot in the Amazon Delta decreased with sediment depth from $0.8 \%(0-4 \mathrm{~cm})$ to $0.6 \%(5.5-9 \mathrm{~cm})$ to $0.2 \%(8.5-12 \mathrm{~cm})$ compared to $\mathrm{BC}_{\mathrm{CTO}}$ surface sediment $(0-2 \mathrm{~cm})$ concentration of $0.4 \%$ and deep sediment concentration $(11-12 \mathrm{~cm})$ of $0.1 \% . \mathrm{BC}_{\mathrm{CTO}}$ and $\mathrm{BC}_{\mathrm{PFL}}$ also displayed the general trend of $\mathrm{BC}$ concentration decreasing with sediment depth; this trend was significant for the $\mathrm{BC}_{\mathrm{PFL}}\left(\mathrm{p}\right.$-value $\left.=0.04, \mathrm{R}^{2}=0.63\right)$, but not for the $\mathrm{BC}_{\mathrm{CTO}}\left(\mathrm{p}\right.$-value $\left.=0.06, \mathrm{R}^{2}=0.59\right)$. No char (natural or from coal combustion) was detected. This agreed with our quantitative analysis that soot was the dominant BC form in the Amazon sediments, as shown by the ratio of $\mathrm{BC}_{\mathrm{CTO}} / \mathrm{BC}_{\mathrm{PFL}} \sim 1$ (Table 2$)$.

Microscopic soot concentrations $(0.8 \%)$ were also elevated above the $\mathrm{BC}_{\mathrm{C} \text { то derived }}$ measurement $(0.5 \%)$ in the Sierra Leone Rise surface sediments. All black carbon analysis $\left(\mathrm{BC}_{\mathrm{CTO}}, \mathrm{BC}_{\mathrm{PFL}}\right.$, and $\left.\mathrm{BC}_{\text {petro }}\right)$ displayed no trend with sediment depth. Char produced from coal combustion was detected at this site with a mass concentration of $0.1 \%$, also agreeing that soot was the primary from of $\mathrm{BC}$, but that char-like material was present. The Sierra Leone Rise top sediments also had volume concentration $0.4 \%$ of fusinite, a rare char associated with wildfires, demonstrating that this region received fire-derived carbon inputs.

\subsection{Black carbon fluxes to deep marine sediments}

$\mathrm{BC}_{\mathrm{C} \text { то }}$ fluxes from previously published sedimentation rates ranged from $0.9 \mathrm{mg} \mathrm{cm}^{-2}$ $\mathrm{ky}^{-1}$ in the pelagic South Atlantic site to a regional average of $23 \mathrm{mg} \mathrm{cm}^{-2} \mathrm{ky}^{-1}$ in the Niger Delta (Table 3). The South Atlantic was expected to have the lowest $\mathrm{BC}_{\mathrm{CTO}}$ 
flux as there are no fluvial and little atmospheric soot inputs; this region was comparable to soot-like BC fluxes measured in open ocean and margin sediments (Table 1; Suman et al., 1997; Lohmann et al. 2009). Thus, the South Atlantic represents a background concentration of $\mathrm{BC}_{\mathrm{CTO}}$ fluxes to open ocean sediments. The Sierra Leone Rise region, which is also a pelagic site, had $\sim 7 \mathrm{X}$ the flux of the South Atlantic site, $6.3 \mathrm{mg} \mathrm{cm}^{-2} \mathrm{ky}^{-1}$, implying an enhanced input of soot-like BC, presumably by the intense African biomass burning events that occur annually during the dry season (Cahoon et al., 1992). This is further supported by the more enriched ${ }_{\mathrm{BC}} \mathrm{C}$ о $^{13} \mathrm{C}$ value of $-24 \pm 3 \%$, suggesting large inputs of $\mathrm{C}_{4}$ plant material, and the model simulations of elevated black and elemental carbon in this region (Schmidt and Noack, 2000; Lohmann et al., 2009). If we assume that the Sierra Leone Rise and South Atlantic regions receive no fluvial $\mathrm{BC}$ inputs, then atmospheric $\mathrm{BC}_{\mathrm{CTO}}$ deposition could account for $4-28 \%$ of the BC fluxes in the Niger Delta.

$\mathrm{BC}_{\mathrm{PFL}}$ fluxes were expected to quantify a broader portion of the $\mathrm{BC}$ combustion continuum (soot and charcoal). $\mathrm{BC}_{\mathrm{PFL}}$ fluxes were similar to the $\mathrm{BC}_{\mathrm{CTO}}$ fluxes in the Amazon Delta $\left(2.8 \mathrm{mg} \mathrm{cm}^{-2} \mathrm{ky}^{-1}\right)$ and Sierra Leone Rise $\left(6.1 \mathrm{mg} \mathrm{cm}^{-2} \mathrm{ky}^{-1}\right)$, and were greater than previously measured in pelagic Pacific sediments (Suman et al., 1997). The South Atlantic region was measured to have approximately $5 \mathrm{X}$ greater of a $\mathrm{BC}_{\mathrm{PFL}}$ flux than the $\mathrm{BC}_{\mathrm{C} \text { Tо }}$ flux $\left(5.9 \mathrm{mg} \mathrm{cm}^{-2} \mathrm{ky}^{-1}\right)$. The Niger Delta had a lower $\mathrm{BC}_{\mathrm{PFL}}$ flux of $14.3 \mathrm{mg} \mathrm{cm}^{-2} \mathrm{ky}^{-1}$. This flux calculation estimates that the atmospheric contribution of $\mathrm{BC}_{\mathrm{PFL}}$ to the Niger Delta is at least $43 \%$, which agrees with the estimates previously made by Masiello and Druffel (1998). 
Radiocarbon was measured on sediments from the Amazon Delta and Sierra Leone Rise. The radiocarbon derived $\mathrm{BC}_{\mathrm{CTO}}$ fluxes agreed with the fluxes derived from previously published sedimentation rates, with the exception of the equatorial sample in the Sierra Leone Rise region (Table 3). This could be a result of the high concentrations of carbonates in this region, which could have caused a greater sedimentation rate due to the faster sinking rates of the denser calcified plankton (Boeckel et al., 2006). The $\mathrm{BC}_{\mathrm{PFL}}$ radiocarbon fluxes were the same between the Amazon Delta and Sierra Leone Rise at $6 \mathrm{mg} \mathrm{cm}^{-2} \mathrm{ky}^{-1}$, which was lower than the Sierra Leone Rise and higher than the Amazon Delta compared to the $\mathrm{BC}_{\mathrm{C}}$ fluxes.

The third flux determination used an empirical relationship between carbon burial rate and sedimentation rate, where the sedimentation rate was determined empirically using water depth as an independent variable (Middelburg et al., 1997). With the exception of the remote South Atlantic, empirically derived $\mathrm{BC}_{\mathrm{PFL}}$ and $\mathrm{BC}_{\mathrm{CTO}}$ fluxes were an order of magnitude greater than both the radiocarbon and sedimentation rate derived fluxes (Eq. 4-5). The algorithm used to calculate this flux is based on a global average of carbon burial and sedimentation rates including remote, marginal, and coastal data. We hypothesize that this approach is a regional estimation that may not accurately depict sites heavily influenced by fluvial and atmospheric carbon inputs, such as the Subtropical Atlantic. The South Atlantic was the only site with comparable fluxes. The $\mathrm{BC}_{\text {Сто }}$ flux was $0.6 \mathrm{~m} \mathrm{~cm}^{-2} \mathrm{ky}^{-1}$ and the $\mathrm{BC}_{\mathrm{PFL}}$ flux was $3.6 \mathrm{~m} \mathrm{~cm}^{-2} \mathrm{ky}^{-1}$. This further supports that this relationship is optimized for sites that are primarily 
removed from fluvial and intense atmospheric deposition of organic material, and serves as a regional approximation of $\mathrm{BC}$ burial.

Soot fluxes derived from the petrographic analysis in the Amazon Delta and Sierra Leone Rise were elevated compared to the $\mathrm{BC}_{\mathrm{CTO}}$ and $\mathrm{BC}_{\mathrm{PFL}}$ quantification methods (Table 3). In the Amazon Delta, the $\mathrm{BC}_{\text {petro }}$ flux was approximate $2 \mathrm{X}$ greater for the published sedimentation rate approach $\left(5.7 \mathrm{mg} \mathrm{cm}^{-2} \mathrm{ky}^{-1}\right), 4 \mathrm{X}$ greater than the radiocarbon approach $\left(19.7 \mathrm{mg} \mathrm{cm}^{-2} \mathrm{ky}^{-1}\right)$, and $4 \mathrm{X}$ greater than the depth-derived approach $\left(83.6 \mathrm{mg} \mathrm{cm}^{-2} \mathrm{ky}^{-1}\right)$. Flux values were closer to the $\mathrm{BC}_{\mathrm{CTO}}$ and $\mathrm{BC}_{\mathrm{PFL}}$ values in the Sierra Leone Rise sediments, but still elevated at $\sim 2 \mathrm{X}$ greater for the published sedimentation rates $\left(12.0 \mathrm{mg} \mathrm{cm}^{-2} \mathrm{ky}^{-1}\right), 1.5 \mathrm{X}$ greater for the radiocarbon analysis

(15.4 $\mathrm{mg} \mathrm{cm}^{-2} \mathrm{ky}^{-1}$ ), and 3X greater for the Middelburg et al. (1999) approach (72 mg $\left.\mathrm{cm}^{-2} \mathrm{ky}^{-1}\right)$. The elevated $\mathrm{BC}_{\text {petro }}$ fluxes could be due to uncertainties in the soot and sediment densities used to convert from \%volume to \%mass or, alternatively, could suggest that the petrographic analysis was able to visually detect forms of soot-like particles that the CTO-375 and PFL methods could not.

\subsection{Source apportionment of $\mathrm{BC}$ in the tropical Atlantic sediments}

All Amazonian sediment cores had a $\delta^{13} \mathrm{C}-\mathrm{BC}$ signal indicative of $\mathrm{C}_{3}$ terrestrial biomass, averaging $-28 \pm 4 \%$ for the surface sediments (Holtvoeth et al., 2003; Farquhar et al., 1989; Lohmann et al., 2009). The Niger Delta and Senegal Delta both had a more enriched $\delta^{13} \mathrm{C}-\mathrm{BC}$ at $-23 \%$ ( \pm 4 and $0 \%$, respectively). The Niger Delta surface sediments are most likely influenced by both grassland burning and fossil fuel 
combustion byproducts since Africa consumes $477 \mathrm{Gg} \mathrm{yr}^{-1}$ of fossil and biofuels, with Nigeria (part of the Niger Delta's watershed) being one of the highest areas of emission (Bond et al., 2004). This carbon emission is comparable to Europe.

The Sierra Leone Rise region also had an enriched $\delta^{13} \mathrm{C}-\mathrm{BC}$ signal, averaging $24 \pm 3 \%$, likely resulting from a mix of $\mathrm{C}_{3}$ and $\mathrm{C}_{4}$ combusted biomass. Plants which use $\mathrm{C}_{4}$ carbon fixation comprises approximately $13 \%$ of the modern day plants and have a highly enriched signature between -10 to $-14 \%$ in comparison to $C_{3}$ carbon fixation (Cerling et al., 1993). $\mathrm{C}_{4}$ plants are most notably warm season grasses, such as the Savanna grassland biome in Central and Southern Africa; these enriched $\delta^{13} \mathrm{C}$ values heavily suggest significant BC inputs from grass combustion (Schwartz et al., 1986). The remote South Atlantic region had a $\delta^{13} \mathrm{C}-\mathrm{BC}$ of $-26 \pm 2 \%$ which we apportion as $\mathrm{C}_{3}$ biomass combustion.

The $\delta^{13} \mathrm{C}$-TOC for all sediments ranged narrowly between $-17 \pm 1 \%$ in the Sierra Leone Rise to $-23 \pm 1 \%$ in the South Atlantic which is indicative of marine phytoplankton. This agrees with previous $\delta^{13} \mathrm{C}$-TOC measurements of $-21.7 \%$ in the South Atlantic and -20.2 to $-20.8 \%$ for the northwest Atlantic (Emerson and Hedges, 1988; Lohmann et al, 2009).

Black carbon and PAHs are both combustion byproducts, and have been used to apportion combustion sources (Schmidt and Noack, 2000; Reddy et al., 2002). Select PAHs were quantified and used for source assessment as outline by Yunker et al. 
(2002). The ratio of fluoranthene / (fluoranthene + pyrene) can indicate a raw petroleum source $(<0.4)$, petroleum combustion $(0.4-0.5)$, or the combustion of grass, wood, and coal (>0.5). The ratio of indeno(1,2,3,c,d)pyrene / (indeno(1,2,3,c,d)pyrene + benzo(g,h,i)perylene) apportioned source of $<0.2$ is assigned as petroleum, $0.2-0.5$ is mixed sources and $>0.5$ is combustion. Analysis of these two ratios estimated that the maximum petroleum combustion contribution is approximately $10 \%$ for all surface samples and $80 \%$ of the surface sediments are possibly derived from grass, wood, or coal combustion. The Niger Delta had up to $67 \%$ of its surface sediments being denoted as petroleum-derived, which is expected since the Niger Delta is a known petroleum reserve (Olajire et al., 2005). The ratio of anthracene/anthracene+phenanthene and fluoranthene / (fluoranthene + pyrene) implies that up to $100 \%$ of the PAHs from these regions are derived from the combustion of grass, wood or coal.

Plant waxes, n-alkanes, are also useful biomarkers to assess organic carbon source. We calculated four commonly used indices to assess marine, terrestrial and oil sources (Table S3). A ratio of the low molecular weight ( $<20$ carbons) to the high molecular weight ( $\geq 20$ carbons) that is $\geq 1$ is indicative of marine algae, plankton, and/or petroleum while a ratio <1 suggests higher order plants (Gearing et al., 1976). The Amazon Delta (0.7) and Sierra Leone Rise (0.4) appear to be dominated by terrestrial material while the others could be inputs of marine biomass or petroleum. The carbon preference index (CPI) utilizes the sum of $\mathrm{C}_{27}$ and $\mathrm{C}_{29}$, which are often associated with vascular terrestrial plants, by $\mathrm{C}_{26}, \mathrm{C}_{28}$, and $\mathrm{C}_{30}$ (Colombo et al., 1989; Commendatore 
et al., 2000). A ratio $\sim 1$ is considered to be influenced by petroleum, microbes, or algae whereas a ratio near 3-6 is associated with vascular terrestrial plants. The Amazon and Niger Deltas were the only regions to have a CPI > 1 (2.3 and 2.4, respectively), suggesting an input of terrestrial organic matter. This is supported by the ratio of $\mathrm{C}_{27}$, a wax associated with woody plants, to $\mathrm{C}_{31}$, which is often associated with grasses (Cranwell, 1973; Maffei, 1996). This analysis suggests that woody material $\left(\mathrm{C}_{3}\right)$ is more present than grass material $\left(\mathrm{C}_{4}\right)$ in the Amazon and Niger Deltas, which is also observed in the $\delta^{13} \mathrm{C}$ data. The last assessment determined the overall contribution of terrestrial vascular plants using $\mathrm{C}_{27}, \mathrm{C}_{29}$, and $\mathrm{C}_{31}$ (Colombo et al., 1989; Table S3). The Amazon and Niger Deltas contained the overall highest fractions of these waxes (27 and 30\%), followed by the Sierra Leone Rise (10\%).

The petrographic analysis also supported that wildfire combustion was a likely a major source of charred particles to the Sierra Leone Rise region. In addition to the high concentration of fusinite, a natural wildfire char, above-trace concentrations of cutinite (leaf epidermis) and funginite (fungal remains including hyphae) were also observed.

\subsection{Conclusions}

Black carbon composed up to $96 \%$ of the total organic carbon, and had an overall average of $38 \pm 23 \%$ throughout the Equatorial Atlantic, suggesting that it is highly recalcitrant in pelagic marine sediments. Soot-like black carbon fluxes, as determined by the chemothermal oxidation method, were greatest in the Senegal and Niger Deltas at 38 and $23 \mathrm{mgC} \mathrm{cm}{ }^{-2} \mathrm{ka}^{-1}$, respectively. Soot-like black carbon fluxes in the remote 
Sierra Leone Rise $\left(6.3 \mathrm{mgC} \mathrm{cm}{ }^{-2} \mathrm{ka}^{-1}\right)$ were approximately seven times greater than the remote South Atlantic $\left(0.9 \mathrm{mgC} \mathrm{cm}^{-2} \mathrm{ka}^{-1}\right)$ suggesting that soot-like black carbon deposition is enhanced by the African aerosol and dust plume in the equatorial Atlantic. Black carbon fluxes, as determined by the pyrene fluorescence method, were similar to the soot-like black carbon fluxes. This proposes that soot-like carbon was the dominate form of black carbon in the deep sediments.

Sediments at the Sierra Leone Rise presumably only received atmospherically deposited black carbon. Thus, remote regions can have high black carbon concentrations due to elevated atmospheric deposition. The South Atlantic was another region with little fluvial deposition. Soot-like black carbon displayed low concentrations $(0.1 \%)$, reinforcing the importance of atmospheric deposition of black carbon in regions impacted by atmospheric emission plumes and seasonal burning events. Stable carbon ratios implied that the combustion of Savanna grasses from Southern Africa was an important source of the elevated black carbon concentrations and fluxes in the Sierra Leone Rise compared to the South Atlantic sites. This could imply that $4-43 \%$ of the black carbon in the Niger Delta fluvial sediments is from atmospheric deposition and that black carbon fluxes to remote marine sediments could be elevated compared to the global background in regions with intense biomass burning activities. 


\section{Acknowledgements}

We thank the National Science Foundation for support (OCE-0851044) and the crew and captain of the $\mathrm{R} / \mathrm{V}$ Endeavor for their help with collecting the samples. We also thank Ann McNichol and Mary Laudie from the NOS-AMS facility at WHOI for assistance with the radiocarbon measurements. We acknowledge the help Rick McKinney and Julia Sullivan (U.S. Environmental Protection Agency) for help with carbon analyses and Bertrand Ligouis for petrography analyses. Two undergraduate workers, Torey Hart (URI) and Hilary Hamer (RPI), are acknowledged for all their contributions in sample collection and analysis.

\section{References}

Accardi-Dey, A., and P. M. Gschwend (2002), Assessing the combined roles of natural organic matter and black carbon as sorbents in sediments, Environ Sci Technol, 36(1), 21-29.

Aller, R. C., and N. E. Blair (2006), Carbon remineralization in the Amazon-Guianas tropical mobile mudbelt: A sedimentary incinerator, Cont Shelf Res, 26(17-18), 22412259.

Andreae, M. O. (1991), Biomass burning: Its history, use, and distribution and its impact on environmental quality and global climate, BGlobal Biomass Burning, Atmospheric, climatic, and biospheric implications, J. S. Levine(MIT Press), 3-21.

Andreae, M. O., and P. Merlet (2001), Emission of trace gases and aerosols from biomass burning, Global Biogeochem Cy, 15(4), 955-966.

Biscaye, P. E., V. Kolla, and K. K. Turekian (1976), Distribution of CalciumCarbonate in Surface Sediments of Atlantic Ocean, J Geophys Res-Oc Atm, 81(15), 2595-2603.

Boeckel, B., K. H. Baumann, R. Henrich, and H. Kinkel (2006), Coccolith distribution patterns in South Atlantic and Southern Ocean surface sediments in relation to environmental gradients, Deep-Sea Res Pt I, 53(6), 1073-1099.

Bond, T. C., and H. L. Sun (2005), Can reducing black carbon emissions counteract global warming?, Environ Sci Technol, 39(16), 5921-5926. 
Bond, T. C., D. G. Streets, K. F. Yarber, S. M. Nelson, J. H. Woo, and Z. Klimont (2004), A technology-based global inventory of black and organic carbon emissions from combustion, J Geophys Res-Atmos, 109(D14).

Burdige, D. J. (2007), Preservation of organic matter in marine sediments: Controls, mechanisms, and an imbalance in sediment organic carbon budgets?, Chem Rev, 107(2), 467-485.

Burke, A., L. F. Robinson, A. P. McNichol, W. J. Jenkins, K. M. Scanlon, and D. S. Gerlach (2010), Reconnaissance dating A new radiocarbon method applied to assessing the temporal distribution of Southern Ocean deep-sea corals, Deep-Sea Res Pt I, 57(11), 1510-1520.

Cahoon, D. R., B. J. Stocks, J. S. Levine, W. R. Cofer, and K. P. Oneill (1992), Seasonal Distribution of African Savanna Fires, Nature, 359(6398), 812-815.

Cerling, T. E., Y. Wang, and J. Quade (1993), Expansion of C4 Ecosystems as an Indicator of Global Ecological Change in the Late Miocene, Nature, 361(6410), 344345 .

Colombo, J. C., E. Pelletier, C. Brochu, M. Khalil, and J. A. Catoggio (1989), Determination of Hydrocarbon Sources Using N-Alkane and Polyaromatic Hydrocarbon Distribution Indexes - Case-Study - Rio-De-La-Plata Estuary, Argentina, Environ Sci Technol, 23(7), 888-894.

Commendatore, M. G., J. L. Esteves, and J. C. Colombo (2000), Hydrocarbons in coastal sediments of Patagonia, Argentina: Levels and probable sources, Mar Pollut Bull, 40(11), 989-998.

Cranwell, P. A. (1973), Branched-Chain and Cyclopropanoid Acids in a Recent Sediment, Chem Geol, 11(4), 307-313.

Crelling J., G. M., Huggett W., Borrego A.G., Hower J., Ligouis B., Mastalerz M., Misz M., Suárez-Ruiz I., Valentim B. (2006), International Committee for Coal and Organic Petrology (ICCP), Atlas of anthropogenic particles: Indiana Geological Survey Open-File Study 06-01, CD-ROM,.

Dickens, A. F., Y. Gelinas, C. A. Masiello, S. Wakeham, and J. I. Hedges (2004), Reburial of fossil organic carbon in marine sediments, Nature, 427(6972), 336-339.

Elmquist, M., O. Gustafsson, and P. Andersson (2004), Quantification of sedimentary black carbon using the chemothermal oxidation method: an evaluation of ex situ pretreatments and standard additions approaches, Limnol Oceanogr-Meth, 2, 417-427. 
Elmquist, M., G. Cornelissen, Z. Kukulska, and O. Gustafsson (2006), Distinct oxidative stabilities of char versus soot black carbon: Implications for quantification and environmental recalcitrance, Global Biogeochem Cy, 20(2).

Emerson, S., and J. I. Hedges (1988), Processes Controlling the Organic Carbon Content of Open Ocean Sediments, Paleoceanography, 3(5), 621-634.

Farquhar, G. D., J. R. Ehleringer, and K. T. Hubick (1989), Carbon Isotope Discrimination and Photosynthesis, Annu Rev Plant Phys, 40, 503-537.

Flanner, M. G., C. S. Zender, J. T. Randerson, and P. J. Rasch (2007), Present-day climate forcing and response from black carbon in snow, J Geophys Res-Atmos, 112(D11).

Flores-Cervantes, D. X., C. M. Reddy, and P. M. Gschwend (2009), Inferring Black Carbon Concentrations in Particulate Organic Matter by Observing Pyrene Fluorescence Losses, Environ Sci Technol, 43(13), 4864-4870.

Gearing, P., J. N. Gearing, T. F. Lytle, and J. S. Lytle (1976), Hydrocarbons in 60 Northeast Gulf of Mexico Shelf Sediments - Preliminary Survey, Geochim Cosmochim Ac, 40(9), 1005-1017.

Goldberg, E. D. (1985), Black Carbon in the Environment, Wiley, New York.

Gonzalez-Vila, F. J., de la Rosa, J. M., Gonzalez-Perez (2009), Black Carbon and other refractory forms in recent sediments from the Gulf of Cadiz, Spain, IOP Conference Series: Earth and Environmental Science, 5(1).

Gustafsson, O., and P. M. Gschwend (1998), The flux of black carbon to surface sediments on the New England continental shelf, Geochim Cosmochim Ac, 62(3), 465472 .

Gustafsson, O., T. D. Bucheli, H. Barring, and J. Persson (2002), Evaluation of black carbon as a carrier of halogenated and aromatic contaminants in nature., Abstr Pap Am Chem S, 224, U522-U522.

Gustafsson, O., F. Haghseta, C. Chan, J. MacFarlane, and P. M. Gschwend (1997), Quantification of the dilute sedimentary soot phase: Implications for PAH speciation and bioavailability, Environ Sci Technol, 31(1), 203-209.

Hammes, K., et al. (2007), Comparison of quantification methods to measure firederived (black/elemental) carbon in soils and sediments using reference materials from soil, water, sediment and the atmosphere, Global Biogeochem Cy, 21(3).

Hao, W. M., Liu, M. H., crutzen, P. J. (1990), Estimates of annual and regional 
releases of $\mathrm{CO}_{2}$ and other trace gases to the atmosphere from fires in the tropics, based on the FAO statistics for period 1975-1980, Fire and Tropical Biota: Ecosystem Processes and Global Challenges, Ecological Studies 84(edited by J. G. Goldammer), 440-462.

Heiri, O., A. F. Lotter, and G. Lemcke (2001), Loss on ignition as a method for estimating organic and carbonate content in sediments: reproducibility and comparability of results, J Paleolimnol, 25(1), 101-110.

Holtvoeth, J., T. Wagner, and C. J. Schubert (2003), Organic matter in riverinfluenced continental margin sediments: The land-ocean and climate linkage at the Late Quaternary Congo fan (ODP Site 1075), Geochem Geophy Geosy, 4.

Jaffe, R., Y. Ding, J. Niggemann, A. V. Vahatalo, A. Stubbins, R. G. M. Spencer, J. Campbell, and T. Dittmar (2013), Global Charcoal Mobilization from Soils via Dissolution and Riverine Transport to the Oceans, Science, 340(6130), 345-347. Kuhlbusch, T. A. J. (1998), Black carbon and the carbon cycle, Science, 280(5371), 1903-1904.

Lohmann, R., K. Bollinger, M. Cantwell, J. Feichter, I. Fischer-Bruns, and M. Zabel (2009), Fluxes of soot black carbon to South Atlantic sediments, Global Biogeochem Cy, 23 .

Maffei, M. (1996), Chemotaxonomic significance of leaf wax n-Alkanes in the Umbelliferae, Cruciferae and Leguminosae (subf papilionoideae), Biochem Syst Ecol, 24(6), 531-545.

Masiello, C. A. (2004), New directions in black carbon organic geochemistry, Mar Chem, 92(1-4), 201-213.

Masiello, C. A., and E. R. M. Druffel (1998), Black carbon in deep-sea sediments, Science, 280(5371), 1911-1913.

Masiello, C. A., and E. R. M. Druffel (2001), Carbon isotope geochemistry of the Santa Clara River, Global Biogeochem Cy, 15(2), 407-416.

Masiello, C. A., and P. Louchouarn (2013), Fire in the Ocean, Science, 340(6130), 287-288.

Middelburg, J. J., K. Soetaert, and P. M. J. Herman (1997), Empirical relationships for use in global diagenetic models, Deep-Sea Res Pt I, 44(2), 327-344.

Middelburg, J. J., J. Nieuwenhuize, and P. van Breugel (1999), Black carbon in marine sediments, Mar Chem, 65(3-4), 245-252. 
Olajire, A. A., R. Altenburger, E. Kuster, and W. Brack (2005), Chemical and ecotoxicological assessment of polycyclic aromatic hydrocarbon-contaminated sediments of the Niger Delta, southern Nigeria, Sci Total Environ, 340(1-3), 123-136.

Ramanathan, V., and G. Carmichael (2008), Global and regional climate changes due to black carbon, Nat Geosci, 1(4), 221-227.

Reddy, C. M., A. Pearson, L. Xu, A. P. McNichol, B. A. Benner, S. A. Wise, G. A. Klouda, L. A. Currie, and T. I. Eglinton (2002), Radiocarbon as a tool to apportion the sources of polycyclic aromatic hydrocarbons and black carbon in environmental samples, Environ Sci Technol, 36(8), 1774-1782.

Ribeiro, L. G. L., R. S. Carreira, and A. L. R. Wagener (2008), Black carbon contents and distribution in sediments from the Southeastern Brazilian coast (Guanabara Bay), J Brazil Chem Soc, 19(7), 1277-1283.

Sachse, D., J. Radke, and G. Gleixner (2006), delta D values of individual n-alkanes from terrestrial plants along a climatic gradient - Implications for the sedimentary biomarker record, Org Geochem, 37(4), 469-483.

Schmidt, M. W. I., and A. G. Noack (2000), Black carbon in soils and sediments: Analysis, distribution, implications, and current challenges, Global Biogeochem Cy, 14(3), 777-793.

Schwartz, D., A. Mariotti, R. Lanfranchi, and B. Guillet (1986), C-13/C-12 Ratios of Soil Organic-Matter as Indicators of Vegetation Changes in the Congo, Geoderma, 39(2), 97-103.

Seiler, W., and P. J. Crutzen (1980), Estimates of Gross and Net Fluxes of Carbon between the Biosphere and the Atmosphere from Biomass Burning, Climatic Change, 2(3), 207-247.

Suman, D. O., Kuhlbusch, T. A. J., Lim, B. (1997), Marine Sediments: A reservoir for black carbon and their use as spatial and temporal records of combustion, Sediment Records of Biomass Burning and Global Change, edited by J. S. Clark, H. Cachier, J. G. Goldhammer, B. J. Stocks(Springer-Verlag).

Taylor, G. H., Teichmüller, M., A., D., Diessel, C.F.K., Littke, R., and Robert, P. (1998), Organic Petrology. Gebrüder Bornträger, Berlin-Stuttgart, 704p.

Tenzer, R., and V. Gladkikh (2014), Assessment of Density Variations of Marine Sediments with Ocean and Sediment Depths, Sci World J.

Wagner, T. Z., M.; Dupont, L.; Holtvoeth, J.; Schubert, C. J. (2003), Terrigenous signal in sediments of the low-latitude Atlantic-Implication for environmental variations during the later Quarternary, Part I: Organic carbon, The South Atlantic in 
the Late Quarternary: Reconstruction of Material Budgets and Current Systems(edited by G. Wefer, S. Mulitza, and V. Ratmeyer), 295-322.

Xu, S., A. Dougans, S. P. H. T. Freeman, C. Maden, and R. Loger (2007), A gas ion source for radiocarbon measurement at SUERC, Nucl Instrum Meth B, 259(1), 76-82.

Yunker, M. B., R. W. Macdonald, R. Vingarzan, R. H. Mitchell, D. Goyette, and S. Sylvestre (2002), PAHs in the Fraser River basin: a critical appraisal of PAH ratios as indicators of PAH source and composition, Org Geochem, 33(4), 489-515.

Zabel, M., Wagner, T., and deMenocal, P. (2003), Terrigenous signals in sediments of the low-latitude Atlantic- Indications to environmental variations during the Late Quarternary, part II: Lithogenic Matter The South Atlantic in the Late Quarternary: Reconstruction of the Material Budgets and Current Systems 323-345. 


\section{Tables}

\begin{tabular}{|c|c|c|c|c|}
\hline Region & $\% \mathrm{BC}$ & $\%$ ВC/TOC & $\begin{array}{c}\text { BC flux } \\
\left(\mathbf{m g ~ c m}^{-2} \mathbf{k a}^{-1}\right) \\
\end{array}$ & Reference \\
\hline Washington Coast, USA & $.014-.065$ & $1.01-5.6$ & $1.5-3.1$ & Dickens et al. 2004 \\
\hline Swedish continental shelf & $0.10-0.34$ & $2.3-6.6$ & $\mathrm{n} / \mathrm{a}$ & $\begin{array}{l}\text { Sanchez-Garcia et al. } \\
2012\end{array}$ \\
\hline South American Coast & $0.04-0.10$ & $8-34$ & $0.6-2.6$ & Lohmann et al. 2009 \\
\hline African Coast & $0.08-0.11$ & $3-12$ & $0.5-7.8$ & Lohmann et al. 2009 \\
\hline Iberian Margin (Atlantic) & $0.047-0.16$ & $16-29$ & $\mathrm{n} / \mathrm{a}$ & Middelburg et al. 1999 \\
\hline North Sea & $0.028-0.457$ & $16-61$ & $\mathrm{n} / \mathrm{a}$ & Middelburg et al. 1999 \\
\hline Gulf of Maine, USA & $0.011-0.173$ & $3.1-14.6$ & $86-190$ & $\begin{array}{c}\text { Gustafsson and Gschwend } \\
1998\end{array}$ \\
\hline Brazil (SE coast) & $0.03-0.31$ & $2.32-12.75$ & $\mathrm{n} / \mathrm{a}$ & Ribeiro et al. 2008 \\
\hline Pacific Abyssal Plain & $\mathrm{n} / \mathrm{a}$ & $15 \pm 2$ & $\mathrm{n} / \mathrm{a}$ & Masiello and Druffel 1998 \\
\hline Open Ocean Pacific & $\mathrm{n} / \mathrm{a}$ & $\mathrm{n} / \mathrm{a}$ & $0.002-3.6$ & Suman et al. 1997 \\
\hline Coastal & $\mathrm{n} / \mathrm{a}$ & $\mathrm{n} / \mathrm{a}$ & $26-354$ & Suman et al. 1997 \\
\hline
\end{tabular}

Table 1. Global comparison of black carbon (BC) concentrations and fluxes to marine sediments from selected studies. 


\begin{tabular}{c|c|c|c|c|c|c}
\multicolumn{2}{c|}{} & \multicolumn{2}{c|}{ CTO-375 } & \multicolumn{2}{c}{ PFL } & \\
\hline Region & \%OC & \%BC & BC/TOC & $\% B C$ & BC/TOC & BC $_{\text {CTO} / B C_{\text {PFL }}}$ \\
\hline Amazon Delta & $0.6 \pm 0.2$ & $0.4 \pm 0.2$ & $55 \pm 30 \%$ & $0.3 \pm 0.2$ & $52 \pm 30 \%$ & $0.9 \pm 0.3$ \\
Niger Delta & $1.7 \pm 0.9$ & $0.7 \pm 0.2$ & $51 \pm 30 \%$ & $0.4 \pm 0.7$ & $19 \pm 20 \%$ & $3.1 \pm 3.3$ \\
Senegal Delta & $3.2 \pm 0.02$ & $0.7 \pm 0.01$ & $23 \%$ & 0.0 & $5 \%$ & 1.0 \\
Sierra Leone Rise & $1.7 \pm 0.6$ & $0.5 \pm 0.2$ & $30 \pm 10 \%$ & $0.5 \pm 0.4$ & $28 \pm 20 \%$ & $1.5 \pm 1.3$ \\
South Atlantic & $0.8 \pm 0.01$ & $0.1 \pm 0.01$ & $15 \%$ & 0.5 & $67 \%$ & 0.2
\end{tabular}

Table 2. Surface sediment concentrations of the total organic carbon (TOC) and black carbon (BC) as quantified using the chemothermal oxidation (CTO-375) and pyrene fluorescence loss (PFL) methods with the associated regional and sample replicate standard deviation. The black carbon concentration derived from the petrographic analysis was $0.8 \%$ for the Amazon Delta and $0.9 \%$ for the Sierra Leone Rise. 


\begin{tabular}{c|ccc|ccc|ccc|} 
& \multicolumn{3}{|c|}{ Published Sed. Rates } & \multicolumn{3}{|c|}{ Radiocarbon } & \multicolumn{3}{c|}{ Middelburg et al. 1997 } \\
Region & $\mathrm{BC}_{\mathrm{CTO}}$ & $\mathrm{BC}_{\mathrm{PFL}}$ & $\mathrm{BC}_{\mathrm{Petro}}$ & $\mathrm{BC}_{\mathrm{CTO}}$ & $\mathrm{BC}_{\mathrm{PFL}}$ & $\mathrm{BC}_{\text {Petro }}$ & $\mathrm{BC}_{\mathrm{CTO}}$ & $\mathrm{BC}_{\mathrm{PFL}}$ & $\mathrm{BC}_{\text {Petro }}$ \\
\hline Amazon & 2.9 & 2.8 & 5.7 & 4.1 & 6.0 & 19.7 & 18.5 & 20.3 & 83.6 \\
Equator & 2.9 & 0 & $\mathrm{n} / \mathrm{a}$ & 0.6 & 0.0 & $\mathrm{n} / \mathrm{a}$ & 16.8 & 17.5 & $\mathrm{n} / \mathrm{a}$ \\
SLR & 6.3 & 6.1 & 12.0 & 10.0 & 6.2 & 15.4 & 23.6 & 23.6 & 72.0 \\
Niger & 22.5 & 14.3 & $\mathrm{n} / \mathrm{a}$ & $\mathrm{n} / \mathrm{a}$ & $\mathrm{n} / \mathrm{a}$ & $\mathrm{n} / \mathrm{a}$ & 47.0 & 30.0 & $\mathrm{n} / \mathrm{a}$ \\
Senegal & 38 & 5.4 & $\mathrm{n} / \mathrm{a}$ & $\mathrm{n} / \mathrm{a}$ & $\mathrm{n} / \mathrm{a}$ & $\mathrm{n} / \mathrm{a}$ & 870.4 & 124.3 & $\mathrm{n} / \mathrm{a}$ \\
S-Atlantic & 0.9 & 5.9 & $\mathrm{n} / \mathrm{a}$ & $\mathrm{n} / \mathrm{a}$ & $\mathrm{n} / \mathrm{a}$ & $\mathrm{n} / \mathrm{a}$ & 0.6 & 3.6 & $\mathrm{n} / \mathrm{a}$
\end{tabular}

Table 3. Regional average black carbon fluxes $\left(\mathrm{mgBC} \mathrm{cm}^{-2} \mathrm{ka}^{-1}\right)$ to marine sediments determined using three approaches: published sedimentation rates from nearby cores, using a radiocarbon analysis to estimate sedimentation rate, and using an empirical approach developed by Middelburg et al. (1997). ВC $_{\text {Сто }}$ used the chemothermal oxidation at $375^{\circ} \mathrm{C}, \mathrm{BC}_{\mathrm{PFL}}$ used the pyrene fluorescence loss method, and $\mathrm{BC}_{\text {petro }}$ used the visual petrographic analysis method including soot and charcoal particles. 


\section{Figures}

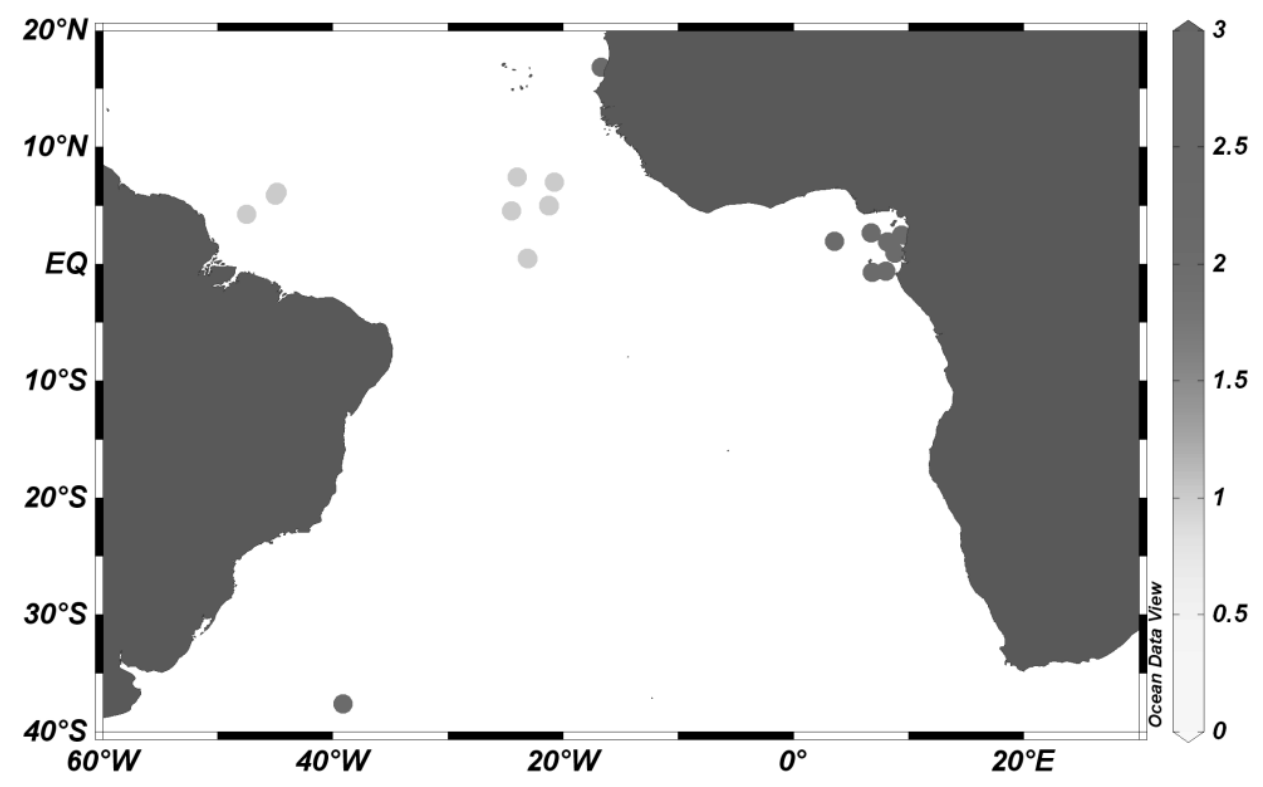

Figure 1. Locations of the sediment collected for this study; light gray dots are cores taken during EN-480 to EN-481 and dark gray dots are cores analyzed from the Bremen University, Germany. 


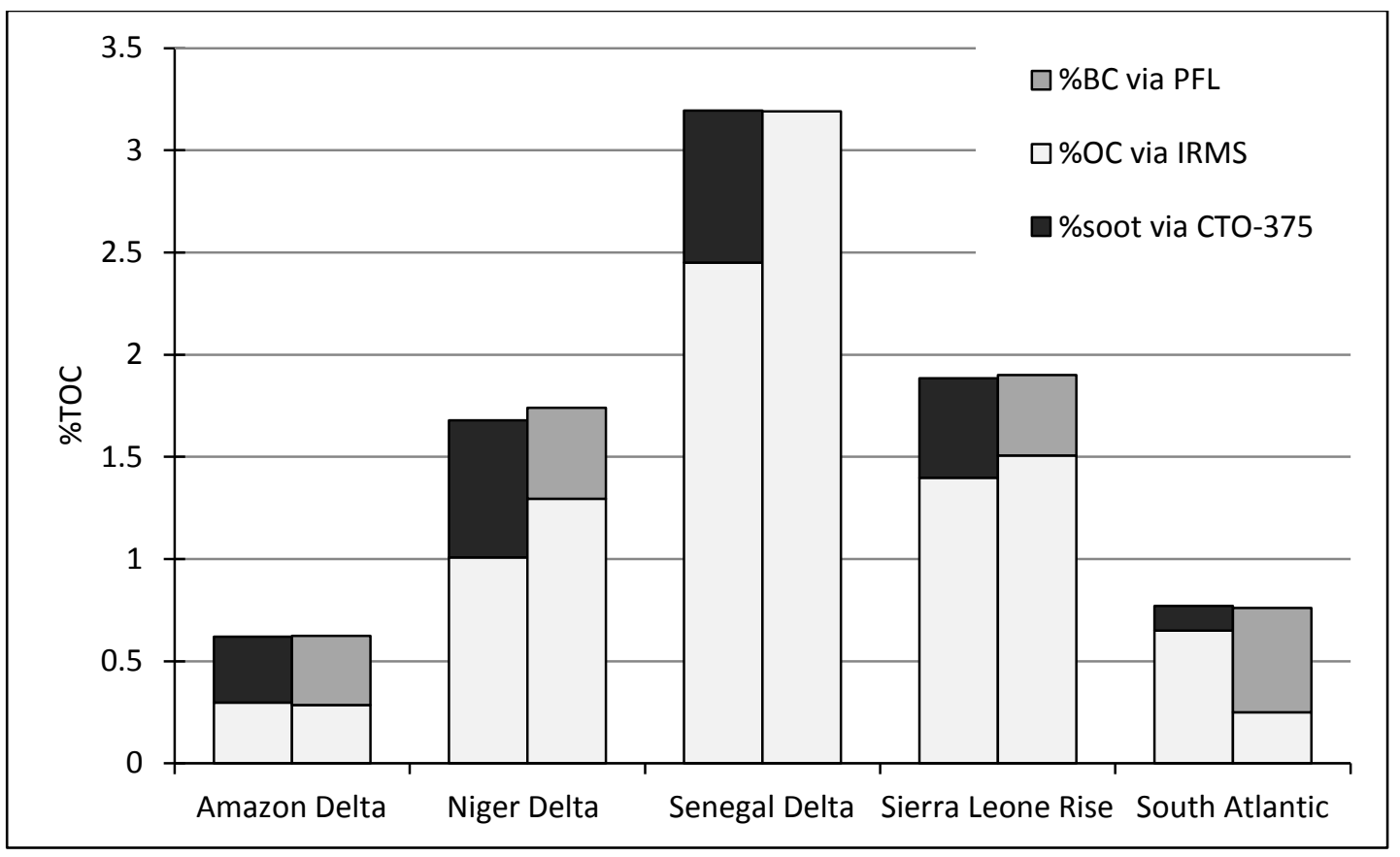

Figure 2. The average surface sediment concentration of total organic carbon for each region divided into the organic carbon and soot-like black carbon fraction as defined by the chemothermal oxidation (CTO-375) and pyrene fluorescence loss (PFL) methods. 


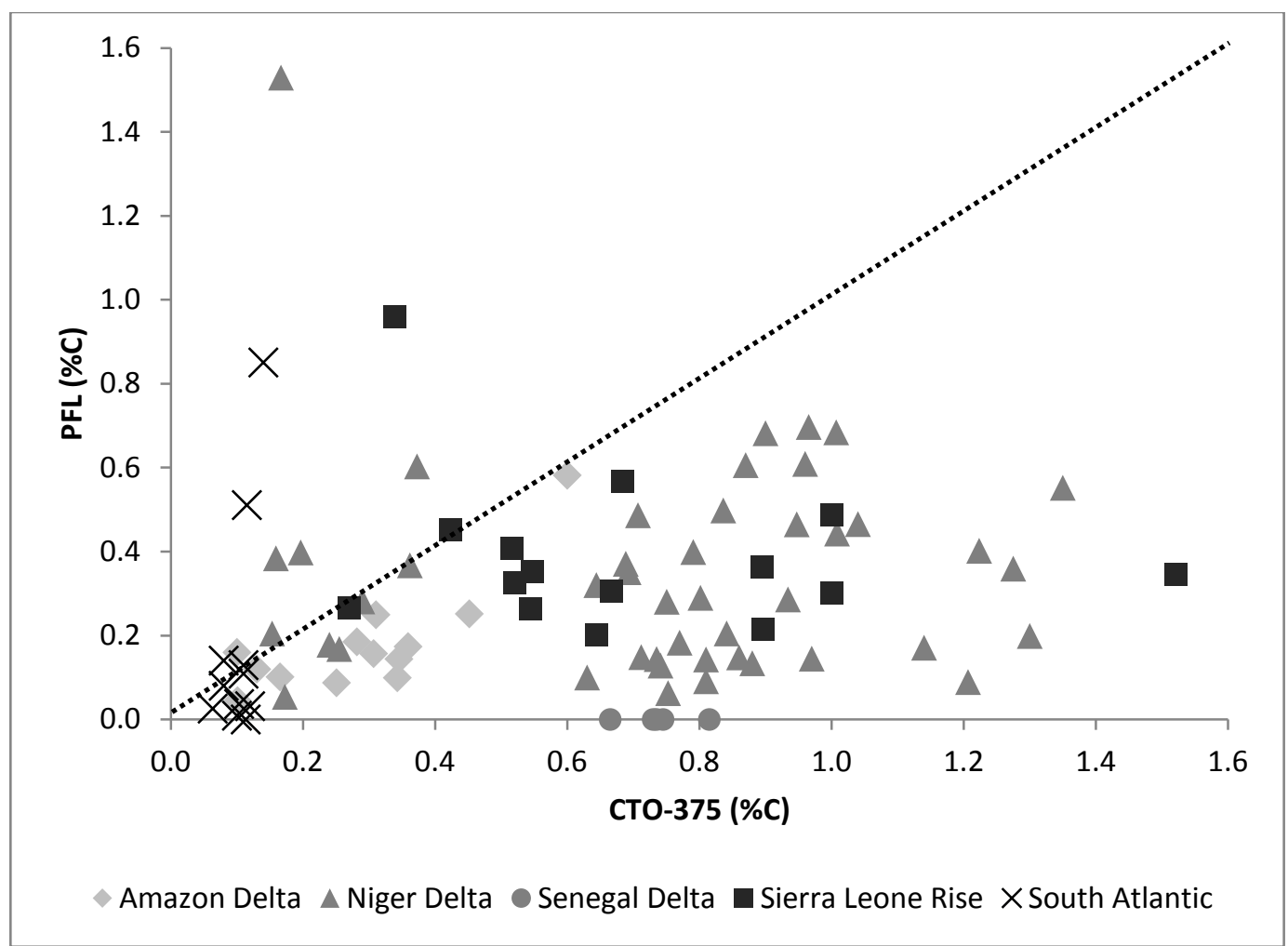

Figure 3. The black carbon concentration derived with the pyrene fluorescence loss (PFL) versus the chemothermal oxidation at $375^{\circ} \mathrm{C}(\mathrm{CTO}-375)$ methods according to region. The dashed line represents a 1:1 line, where samples plotted below this line are dominated by soot-like black carbon. 


\section{Supporting Information}

An assessment of fluvial versus atmospheric fluxes of black carbon to subtropical Atlantic sediments

Kari Pohl

Mark Cantwell

Matthias Zabel

Rainer Lohmann

Included in the supporting information are:

Table S1. Dates, coordinates, and water depth of sediment sampling.

Table S2. Surface sediment concentrations of black carbon (BC) as quantified using a chemothermal oxidation (CTO-375) and pyrene fluorescence loss (PFL) method.

Table S3. Array of n-alkane indices to apportion the source of the sediment organic carbon. The following n-alkanes ( $\Sigma$ n-alkanes) were quantified: decane, undecane, dodecane, tridecane, tetradecane, pentadecane, hexadecane, heptadecane, octadecane, nonadecane, eicosane, heeicosane, decosane, tetracosane, pentacosane, hexacosane, heptacosane, octacosane, nonacosane, triacosane, hentriacontane, triacontane, dotricosane, tetratricosane, hexatriacontane, and tetracosane

Table S4. The regional average stable carbon fraction $\left(\delta^{13} \mathrm{C}\right)$ of the total organic carbon (TOC) and black carbon (BC), and carbonate concentration $\left(\mathrm{CO}_{3}{ }^{2-}\right)$.

Table S5. Summary chart of petrographic analysis for sediments from the (A) Amazon Delta and (B) Sierra Leone Rise (SLR). Note that concentrations are in $\%$ volume. The $\mathrm{x}$ indicates that the Maceral group was present, but a volume concentration was not expressed due to scarcity.

Figure S1. The total organic carbon (TOC) versus the soot-like black carbon (BC) fractions for all sediments samples from each region. The respective correlations $\left(\mathrm{R}^{2}\right)$ are as follows: Amazon Delta (0.11), Niger Delta (0.20), Senegal Delta (0.002), Sierra Leone Rise (0.003), and South Atlantic (0.02). 
Figure S2. Figure 2: Source apportionment of all surface sediments using the ratio of indeno(1,2,3,c,d)pyrene (IP) and benzo(g,h,i)perylene (Bghi) versus fluoranthene (Fl) and pyrene (Py). The following PAHs were quantified:

Napthalene, 2-methyl naphthalene, acenapthylene, acenapthene, biphenyl, 1,5dimethyl naphthalene, flourene, 2,3,5-trimethyl naphthalene, phenanthrene, anthracene, 2-methyl flourene, dibenzothiophene, 1-methyl phenanthrene, 9methyl antracene, 2-methyl dibenzothiophene, pyrene, fluoranthene, 4,5-dimethyl phenanthrene, 3,6-dimethyl phenathrene, 1-methyl pyrene, retene, perylene, benzo(g,h,i)perylene, indeno(1,2,3-c,d)pyrene, and dibenze(a,h)anthracene.

Figure S3. Microscopic images of anthropogenic particles from the Amazon Delta (A,B) and Sierra Leone Rise (C,D). A) soot and char particle, B) high volatile bituminous coal, C) soot, and D) char.

Figure S4. Mass concentrations of black carbon versus sediment depth at the (A) Amazon Delta and (B) Sierra Leone Rise. Black carbon concentrations at these two sites were derived using three methods: pyrene fluorescence loss (PFL), chemothermal oxidation at $375^{\circ} \mathrm{C}$ (CTO), and by petrographic analysis (Petro). The bulk total organic carbon (\% TOC) is also included. 


\begin{tabular}{|c|c|c|c|c|c|}
\hline $\begin{array}{c}\text { Sediment } \\
\text { ID }\end{array}$ & $\begin{array}{c}\text { Sampling } \\
\text { Month/Year }\end{array}$ & Latitude & Longitude & Location & $\begin{array}{c}\text { Water } \\
\text { Depth (m) }\end{array}$ \\
\hline 1 & July 2010 & 4.282778 & -47.484444 & Amazon Delta & 2365 \\
\hline $2 \mathrm{a}$ & July 2010 & 5.915833 & -45.001111 & Amazon Delta & 3545 \\
\hline $2 \mathrm{~b}$ & July 2010 & 5.900833 & -45.002222 & Amazon Delta & 3520 \\
\hline 3 & July 2010 & 6.168333 & -44.8525 & Amazon Delta & 3999 \\
\hline $5 \mathrm{~d}$ & August 2010 & 0.485556 & -23.1225 & Equator & 3567 \\
\hline $5 \mathrm{e}$ & August 2010 & 0.47 & -23.068611 & Equator & 3690 \\
\hline 6 & August 2010 & 7.003889 & -20.795278 & Sierra Leone Rise & 3853 \\
\hline $7 \mathrm{e}$ & August 2010 & 5.018056 & -21.243611 & Sierra Leone Rise & 2811 \\
\hline $7 \mathrm{f}$ & August 2010 & 4.968889 & -21.201667 & Sierra Leone Rise & 2787 \\
\hline $7 \mathrm{~g}$ & August 2010 & 5.005833 & -21.250556 & Sierra Leone Rise & 2794 \\
\hline $8 \mathrm{c}$ & August 2010 & 4.560833 & -24.509167 & Sierra Leone Rise & 4030 \\
\hline $9 \mathrm{a}$ & August 2010 & 7.435278 & -24.010556 & Sierra Leone Rise & 4065 \\
\hline $9 \mathrm{~b}$ & August 2010 & 7.450278 & -24.010278 & Sierra Leone Rise & 4052 \\
\hline $\begin{array}{c}\text { GeoB } \\
4901\end{array}$ & $\begin{array}{c}\text { February/March } \\
1998\end{array}$ & 2.668889 & 6.717222 & Niger Delta & 2180 \\
\hline $\begin{array}{c}\text { GeoB } \\
4903\end{array}$ & $\begin{array}{c}\text { February/March } \\
1998\end{array}$ & 1.916667 & 8.166944 & Niger Delta & 2834 \\
\hline $\begin{array}{c}\text { GeoB } \\
4904\end{array}$ & $\begin{array}{c}\text { February/March } \\
1998\end{array}$ & 0.95 & 8.8 & Niger Delta & 1208 \\
\hline $\begin{array}{c}\text { GeoB } \\
4905\end{array}$ & $\begin{array}{c}\text { February/March } \\
1998\end{array}$ & 2.5 & 9.384444 & Niger Delta & 2184 \\
\hline $\begin{array}{c}\text { GeoB } \\
4907\end{array}$ & $\begin{array}{c}\text { February/March } \\
1998\end{array}$ & -0.584722 & 8.018333 & Niger Delta & 2060 \\
\hline $\begin{array}{c}\text { GeoB } \\
4908\end{array}$ & $\begin{array}{c}\text { February/March } \\
1998\end{array}$ & -0.701667 & 6.834167 & Niger Delta & 3028 \\
\hline $\begin{array}{c}\text { GeoB } \\
1701\end{array}$ & $\begin{array}{c}\text { Dec./March } \\
1991 / 92\end{array}$ & 1.95 & 3.55 & Niger Delta & 4162 \\
\hline $\begin{array}{c}\text { GeoB } \\
\text { GeoB }\end{array}$ & April/May 2003 & 16.834444 & -16.719167 & Senegal Delta & 330 \\
\hline July/August & -37.618056 & -39.116667 & South Atlantic & 4949 \\
\hline
\end{tabular}

Table S1. Dates, coordinates, and water depth of sediment sampling. 


\begin{tabular}{|c|c|c|c|c|c|c|c|}
\cline { 4 - 7 } \multicolumn{2}{c}{} & \multicolumn{2}{c|}{ CTO-375 } & \multicolumn{2}{c|}{ PFL } & \multicolumn{1}{c}{} \\
\hline $\begin{array}{c}\text { Sediment } \\
\text { Core }\end{array}$ & Position & \% TOC & \%BC & BC/TOC & \% BC & BC/TOC & CTO/PFL \\
\hline 1 & Amazon & 0.5 & 0.3 & $64 \%$ & 0.3 & $51 \%$ & 1.2 \\
\hline 2 & Amazon & 0.8 & 0.6 & $78 \%$ & 0.6 & $79 \%$ & 1.0 \\
\hline 3 & Amazon & 0.6 & 0.1 & $24 \%$ & 0.2 & $26 \%$ & 0.6 \\
\hline 5 & Equator & 2.7 & 0.5 & $16 \%$ & 0.0 & $0 \%$ & 0.0 \\
\hline 6 & SLR & 1.6 & 0.4 & $27 \%$ & 0.5 & $29 \%$ & 0.9 \\
\hline 7 & SLR & 2.0 & 0.5 & $28 \%$ & 0.4 & $19 \%$ & 1.6 \\
\hline 8 & SLR & 1.7 & 0.3 & $20 \%$ & 1.0 & $52 \%$ & 0.4 \\
\hline 9 & SLR & 1.5 & 0.6 & $43 \%$ & 0.2 & $13 \%$ & 3.2 \\
\hline $\begin{array}{c}\text { GeoB } \\
4901\end{array}$ & Niger Delta & 1.4 & 0.8 & $56 \%$ & 0.1 & $10 \%$ & 5.7 \\
\hline $\begin{array}{c}\text { GeoB } \\
4903\end{array}$ & Niger Delta & 1.4 & 0.8 & $59 \%$ & 0.1 & $7 \%$ & 8.9 \\
\hline $\begin{array}{c}\text { GeoB } \\
4904\end{array}$ & Niger Delta & 2.6 & 0.3 & $11 \%$ & 0.3 & $11 \%$ & 1.0 \\
\hline $\begin{array}{c}\text { GeoB } \\
4905\end{array}$ & Niger Delta & 3.2 & 0.5 & $15 \%$ & 1.9 & $59 \%$ & 0.2 \\
\hline $\begin{array}{c}\text { GeoB } \\
4907\end{array}$ & Niger Delta & 1.4 & 0.7 & $50 \%$ & 0.5 & $27 \%$ & 1.5 \\
\hline $\begin{array}{c}\text { GeoB } \\
4908\end{array}$ & Niger Delta & 1.2 & 0.8 & $73 \%$ & 0.2 & $18 \%$ & 4.1 \\
\hline $\begin{array}{c}\text { GeoB } \\
1701\end{array}$ & Niger Delta & 0.7 & 0.7 & $96 \%$ & 0.0 & $0 \%$ & 0.0 \\
\hline $\begin{array}{c}\text { GeoB } \\
9501\end{array}$ & Senegal & 3.2 & 0.7 & $23 \%$ & 0.0 & $5 \%$ & 0.1 \\
\hline $\begin{array}{c}\text { GeoB } \\
2814\end{array}$ & S-Atlantic & 0.8 & 0.1 & $15 \%$ & 0.5 & $67 \%$ & 0.2 \\
\hline
\end{tabular}

Table S2. Surface sediment concentrations of black carbon (BC) as quantified using a chemothermal oxidation (CTO-375) and pyrene fluorescence loss (PFL) method. 


\begin{tabular}{c|c|c|c|c} 
Region & $\mathbf{C}<\mathbf{2 0 / C}>\mathbf{2 0}$ & $\mathbf{2}\left(\mathbf{C}_{\mathbf{2 7}}+\mathbf{C}_{\mathbf{2 9}}\right) / \mathbf{C}_{\mathbf{2 6}}+\mathbf{2} \mathbf{C}_{\mathbf{2 8}}+\mathbf{C}_{\mathbf{3 0}}$ & $\mathbf{C}_{\mathbf{2 7}} / \mathbf{C}_{\mathbf{3 1}}$ & $\begin{array}{c}\left(\mathbf{C}_{\mathbf{2 7}}+\mathbf{C}_{\mathbf{2 9}}+\mathbf{C}_{\mathbf{3 1}}\right) / \\
\mathbf{\Sigma} \mathbf{n}-\mathbf{a l k a n e s}\end{array}$ \\
\hline Amazon Delta & 0.7 & 2.4 & 10.1 & $27 \%$ \\
Niger Delta & 1.2 & 2.3 & 19.1 & $30 \%$ \\
Senegal Delta & 6.0 & 0.0 & 0.0 & $7 \%$ \\
Sierra Leone Rise & 0.4 & 0.2 & 3.8 & $10 \%$ \\
South Atlantic & 28.8 & 0.0 & 0.0 & $1 \%$
\end{tabular}

Table S3. Array of n-alkane indices to apportion the source of the sediment organic carbon. The following n-alkanes ( $\Sigma$ n-alkanes) were quantified: decane, undecane , dodecane, tridecane, tetradecane, pentadecane, hexadecane, heptadecane, octadecane, nonadecane, eicosane, heeicosane, decosane, tetracosane, pentacosane, hexacosane, heptacosane, octacosane, nonacosane, triacosane, hentriacontane, triacontane, dotricosane, tetratricosane, hexatriacontane, and tetracosane. 


\begin{tabular}{c|ccc} 
Region & $\boldsymbol{\delta}^{\mathbf{1 3}} \mathbf{C}-\mathbf{T O C}(\mathbf{\% o})$ & $\boldsymbol{\delta}^{\mathbf{1 3}} \mathbf{C}-\mathbf{B C}(\mathbf{\% o})$ & $\mathbf{\% C O}_{\mathbf{3}}{ }^{\mathbf{2 -}}$ \\
\hline Amazon Delta & $-19 \pm 1.2$ & $-28 \pm 4.0$ & $21 \pm 6 \%$ \\
Niger Delta & $-19 \pm 1.1$ & $-23 \pm 3.8$ & $11 \pm 8 \%$ \\
Senegal Delta & $-20 \pm 0.02$ & $-23 \pm 0.01$ & $1 \%$ \\
Sierra Leone Rise & $-17 \pm 0.6$ & $-24 \pm 3.0$ & $29 \pm 6 \%$ \\
South Atlantic & $-23 \pm 0.35$ & $-26 \pm 1.74$ & $3 \%$
\end{tabular}

Table S4. The regional average stable carbon fraction $\left(\delta^{13} \mathrm{C}\right)$ of the total organic carbon (TOC) and black carbon (BC), and carbonate concentration $\left(\mathrm{CO}_{3}{ }^{2-}\right)$. 


\begin{tabular}{|c|c|c|c|c|}
\hline A. Amazon Delta & & $(0-6 \mathrm{~cm})$ & $(5.5-9 \mathrm{~cm})$ & $(8.5-9 \mathrm{~cm})$ \\
\hline Maceral Group & Maceral subgroup & (vol. \%) & $($ vol. \%) & (vol. \%) \\
\hline Huminite & $\begin{array}{l}\text { Telohuminite } \\
\text { Detrohuminite } \\
\text { Gelohuminite }\end{array}$ & & & \\
\hline Vitrinite & $\begin{array}{c}\text { Telovitrinite } \\
\text { Detrovitrinite } \\
\text { Gelovitrinite }\end{array}$ & $\begin{array}{l}0.6 \\
2.4\end{array}$ & $\begin{array}{l}x \\
3\end{array}$ & $\begin{array}{c}\mathrm{x} \\
2.2\end{array}$ \\
\hline Liptinite & $\begin{array}{c}\text { Sporinite } \\
\text { Cutinite } \\
\text { Fluorinite } \\
\text { Suberinite } \\
\text { Resinite } \\
\text { Chlorophyllinite } \\
\text { Telalginite } \\
\text { Lamalginite } \\
\text { Liptodetrinite } \\
\text { Bituminite (AOM) grey } \\
\text { Bituminite (AOM) gray-brown } \\
\text { Migrabitumen } \\
\text { Oil inclusions } \\
\text { Oil expulsions }\end{array}$ & $\begin{array}{c}1.4 \\
60.4 \\
30.9\end{array}$ & $\begin{array}{c}\mathrm{x} \\
0.8 \\
0.6 \\
26.6 \\
67.6\end{array}$ & $\begin{array}{c}\mathrm{x} \\
\\
\mathrm{x} \\
\\
1.8 \\
\mathrm{x} \\
40 \\
55.2\end{array}$ \\
\hline Inertinite & $\begin{array}{c}\text { Fusinite } \\
\text { Semifusinite } \\
\text { Secretinite } \\
\text { Macrinite } \\
\text { Micrinite } \\
\text { Inertodetrinite }\end{array}$ & $\begin{array}{c}\mathrm{x} \\
0.2 \\
0.4\end{array}$ & $\begin{array}{l}\mathrm{x} \\
\mathrm{x} \\
\mathrm{x}\end{array}$ & $\begin{array}{c}\mathrm{x} \\
0.2 \\
\\
0.2\end{array}$ \\
\hline $\begin{array}{l}\text { Natural Coke } \\
\text { Natural Char }\end{array}$ & & & & \\
\hline Hard Coal & $\begin{array}{c}\text { Sub-bituminous } \\
\text { High volitile bit. Coal } \\
\text { Medium-volitile bit. Coal } \\
\text { Low-volitile bit. Coal } \\
\text { Anthracite }\end{array}$ & $\begin{array}{l}x \\
x\end{array}$ & $\begin{array}{l}0.2 \\
0.2\end{array}$ & $\mathrm{x}$ \\
\hline Coke (coal carbonization) & & $\mathrm{x}$ & $\mathrm{x}$ & \\
\hline Char (coal combustion) & & $\mathrm{x}$ & $\mathrm{x}$ & $\mathrm{x}$ \\
\hline Soot (traffic combustion) & & 1.4 & 1 & 0.4 \\
\hline Coal/petroleum-derived & & $\mathrm{x}$ & $\mathrm{x}$ & $\mathrm{x}$ \\
\hline Plastic & & 0.2 & $\mathrm{x}$ & $\mathrm{x}$ \\
\hline
\end{tabular}




\begin{tabular}{|c|c|c|c|}
\hline B. SLR & & $(0-4 \mathrm{~cm})$ & $(4-9 \mathrm{~cm})$ \\
\hline Maceral Group & Maceral subgroup & (vol. \%) & (vol. \%) \\
\hline Huminite & $\begin{array}{c}\text { Telohuminite } \\
\text { Detrohuminite } \\
\text { Gelohuminite }\end{array}$ & & \\
\hline Vitrinite & $\begin{array}{l}\text { Telovitrinite } \\
\text { Detrovitrinite } \\
\text { Gelovitrinite }\end{array}$ & $\begin{array}{l}0.2 \\
7.4\end{array}$ & $\begin{array}{l}0.6 \\
8.4\end{array}$ \\
\hline Liptinite & $\begin{array}{c}\text { Sporinite } \\
\text { Cutinite } \\
\text { Fluorinite } \\
\text { Suberinite } \\
\text { Resinite } \\
\text { Chlorophyllinite } \\
\text { Telalginite } \\
\text { Lamalginite } \\
\text { Liptodetrinite } \\
\text { Bituminite (AOM) grey } \\
\text { Bituminite (AOM) gray-brown } \\
\text { Migrabitumen } \\
\text { Oil inclusions } \\
\text { Oil expulsions }\end{array}$ & $\begin{array}{c}x \\
\\
x \\
46.2 \\
41.2\end{array}$ & $\begin{array}{c}x \\
x \\
x \\
76 \\
10.6\end{array}$ \\
\hline Inertinite & $\begin{array}{c}\text { Fusinite } \\
\text { Semifusinite } \\
\text { Secretinite } \\
\text { Macrinite } \\
\text { Micrinite } \\
\text { Inertodetrinite }\end{array}$ & $\begin{array}{c}0.4 \\
0.2 \\
1\end{array}$ & $\begin{array}{l}0.2 \\
1.4 \\
0.2 \\
\\
\\
0.8 \\
\end{array}$ \\
\hline \multicolumn{4}{|l|}{ Natural Coke } \\
\hline \multicolumn{4}{|l|}{ Natural Char } \\
\hline Hard Coal & $\begin{array}{c}\text { Sub-bituminous } \\
\text { High volitile bit. Coal } \\
\text { Medium-volitile bit. Coal } \\
\text { Low-volitile bit. Coal } \\
\text { Anthracite }\end{array}$ & & $\mathrm{x}$ \\
\hline Coke (coal carbonization) & & $\mathrm{x}$ & $\mathrm{x}$ \\
\hline Char (coal combustion) & & 0.4 & $\mathrm{x}$ \\
\hline Soot (traffic combustion) & & 1.4 & $\mathrm{x}$ \\
\hline Coal/petroleum-derived & & $\mathrm{x}$ & $\mathrm{x}$ \\
\hline Plastic & & 0.4 & 0.2 \\
\hline
\end{tabular}


Table S5. Summary chart of petrographic analysis for sediments from the (A) Amazon Delta and (B) Sierra Leone Rise (SLR). Note that concentrations are in \%volume. The $\mathrm{x}$ indicates that the Maceral group was present, but a volume concentration was not expressed due to scarcity. 


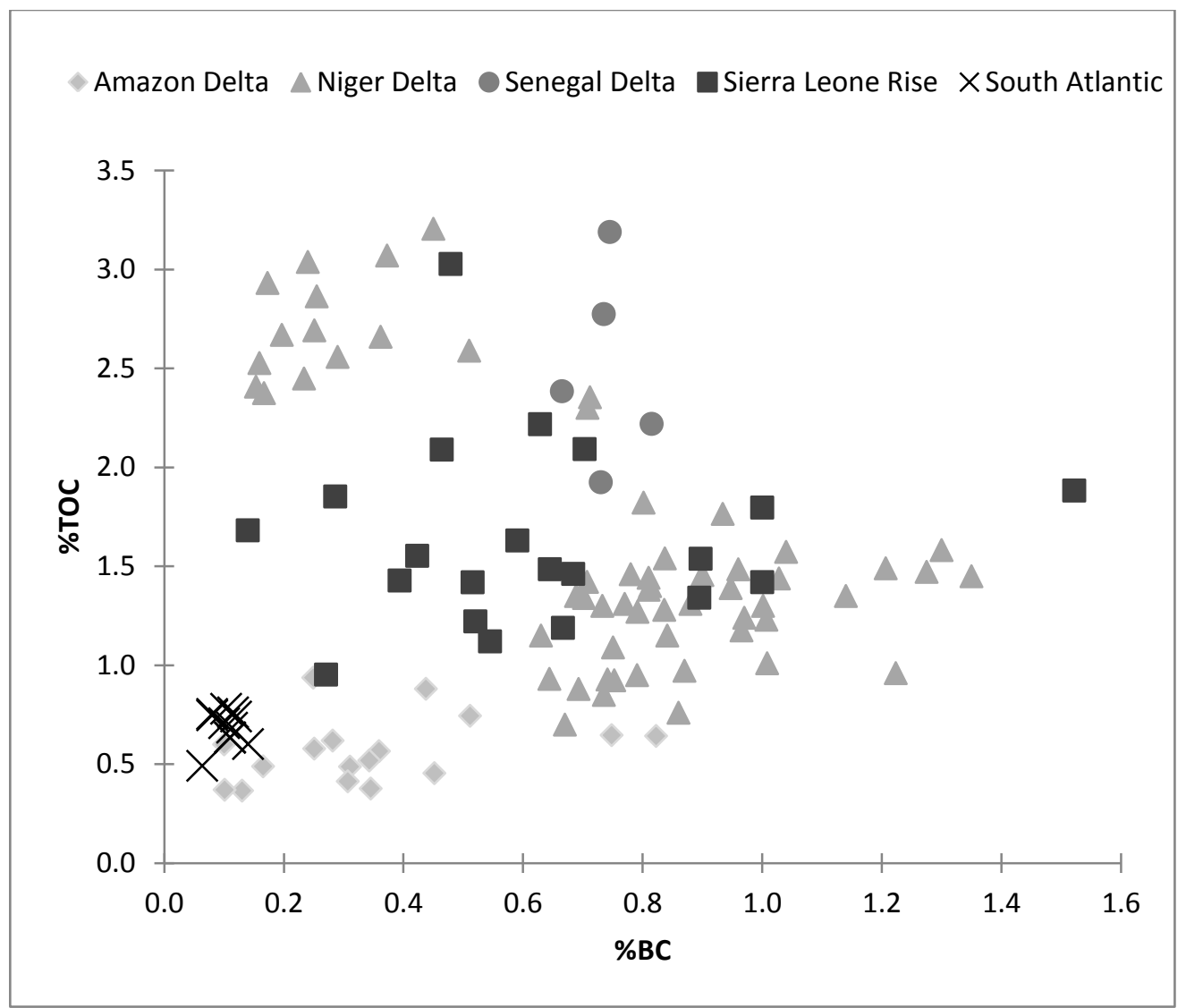

Figure S1. The total organic carbon (TOC) versus the soot-like black carbon (BC) fractions for all sediments samples from each region. The respective correlations $\left(\mathrm{R}^{2}\right)$ are as follows: Amazon Delta (0.11), Niger Delta (0.20), Senegal Delta (0.002), Sierra Leone Rise (0.003), and South Atlantic (0.02). 


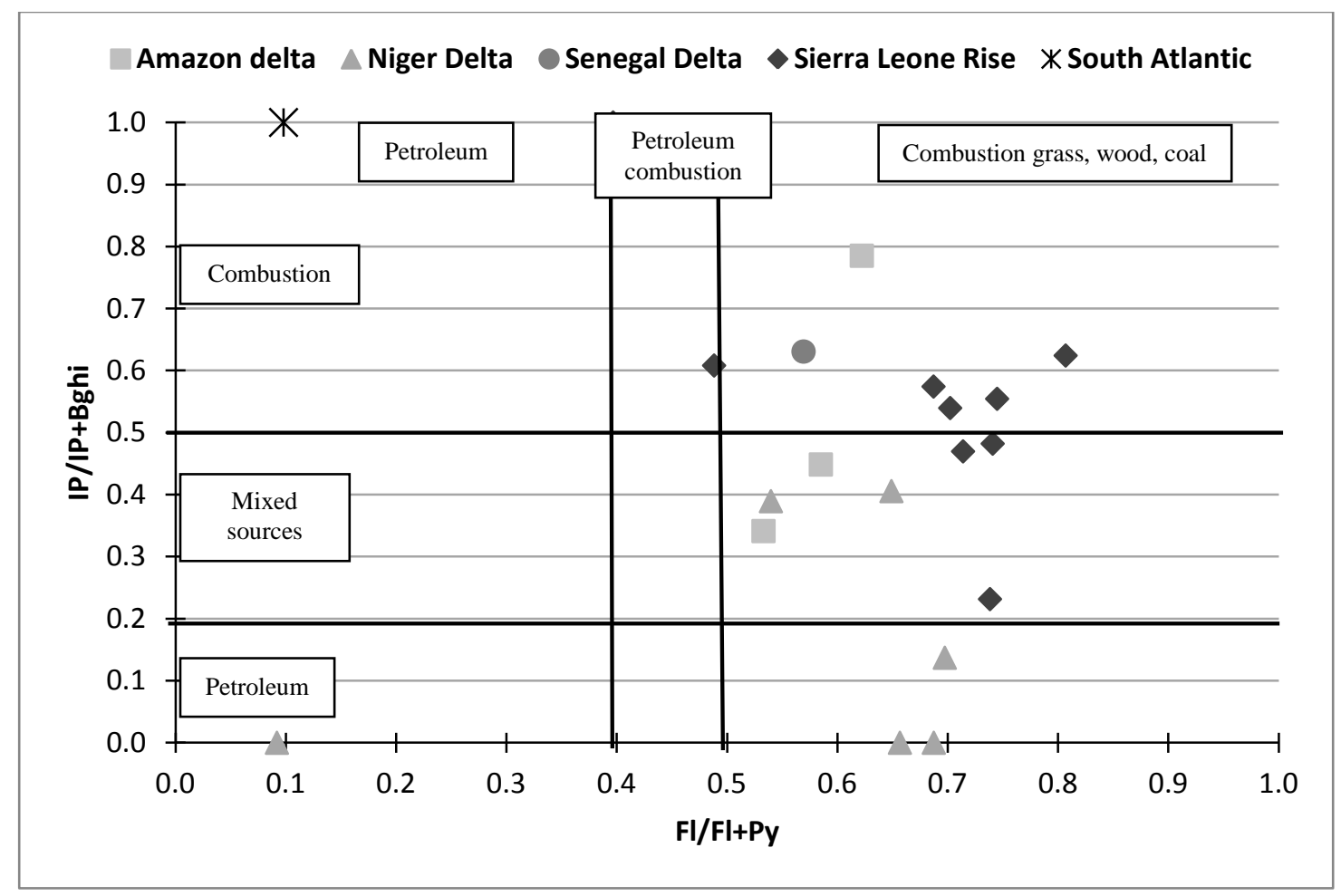

Figure S2. Source apportionment of all surface sediments using the ratio of indeno(1,2,3,c,d)pyrene (IP) and benzo(g,h,i)perylene (Bghi) versus fluoranthene (Fl) and pyrene (Py). The following PAHs were quantified: Napthalene, 2-methyl naphthalene, acenapthylene, acenapthene, biphenyl, 1,5-dimethyl naphthalene, flourene, 2,3,5-trimethyl naphthalene, phenanthrene, anthracene, 2-methyl flourene, dibenzothiophene, 1-methyl phenanthrene, 9-methyl antracene, 2-methyl dibenzothiophene, pyrene, fluoranthene, 4,5-dimethyl phenanthrene, 3,6-dimethyl phenathrene, 1-methyl pyrene, retene, perylene, benzo(g,h,i)perylene, indeno(1,2,3c,d)pyrene, and dibenze(a,h)anthracene. 


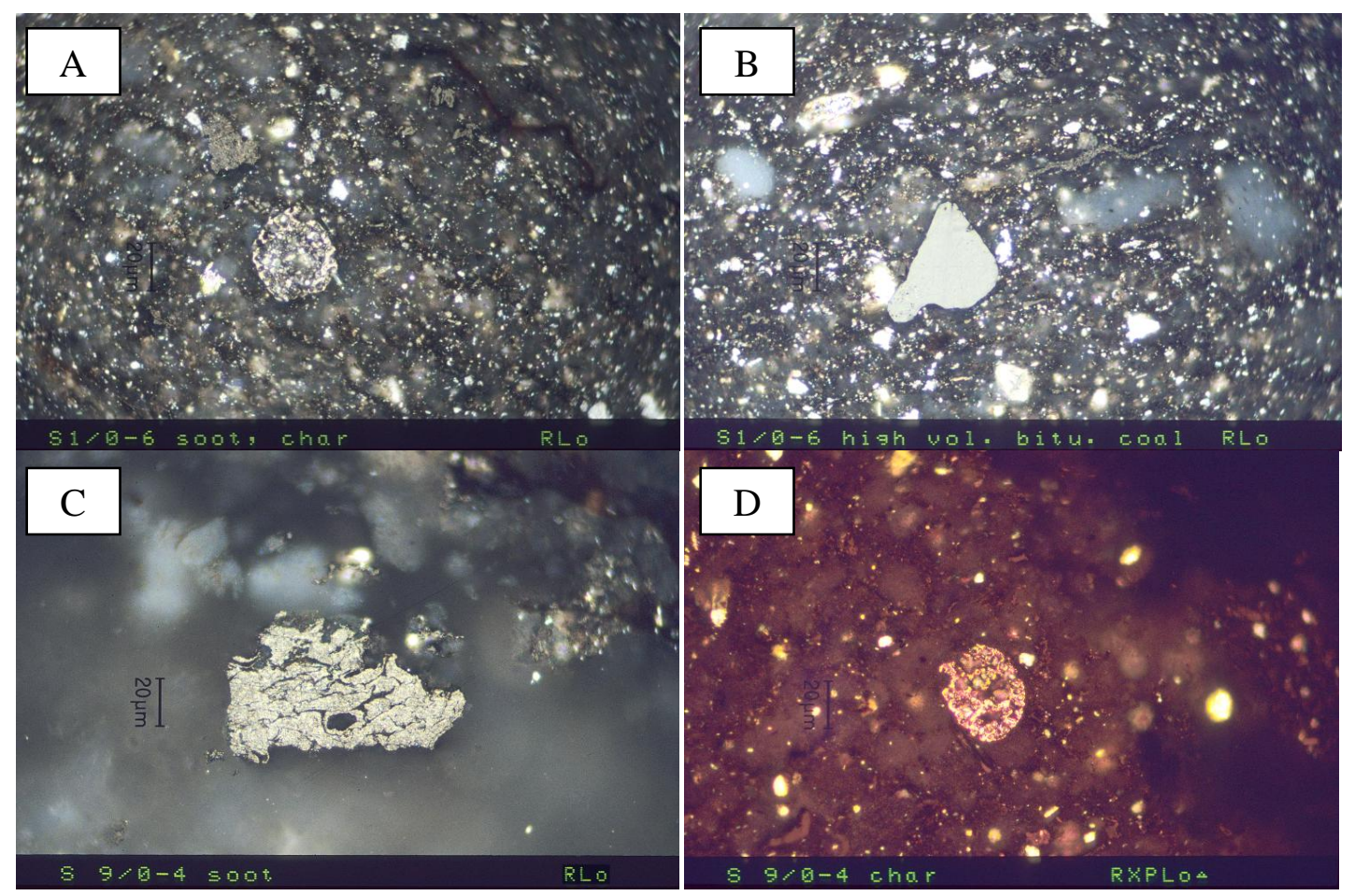

Figure S3. Microscopic images of anthropogenic particles from the Amazon Delta (A,B) and Sierra Leone Rise (C,D). A) soot and char particle, B) high volatile bituminous coal, C) soot, and D) char. 

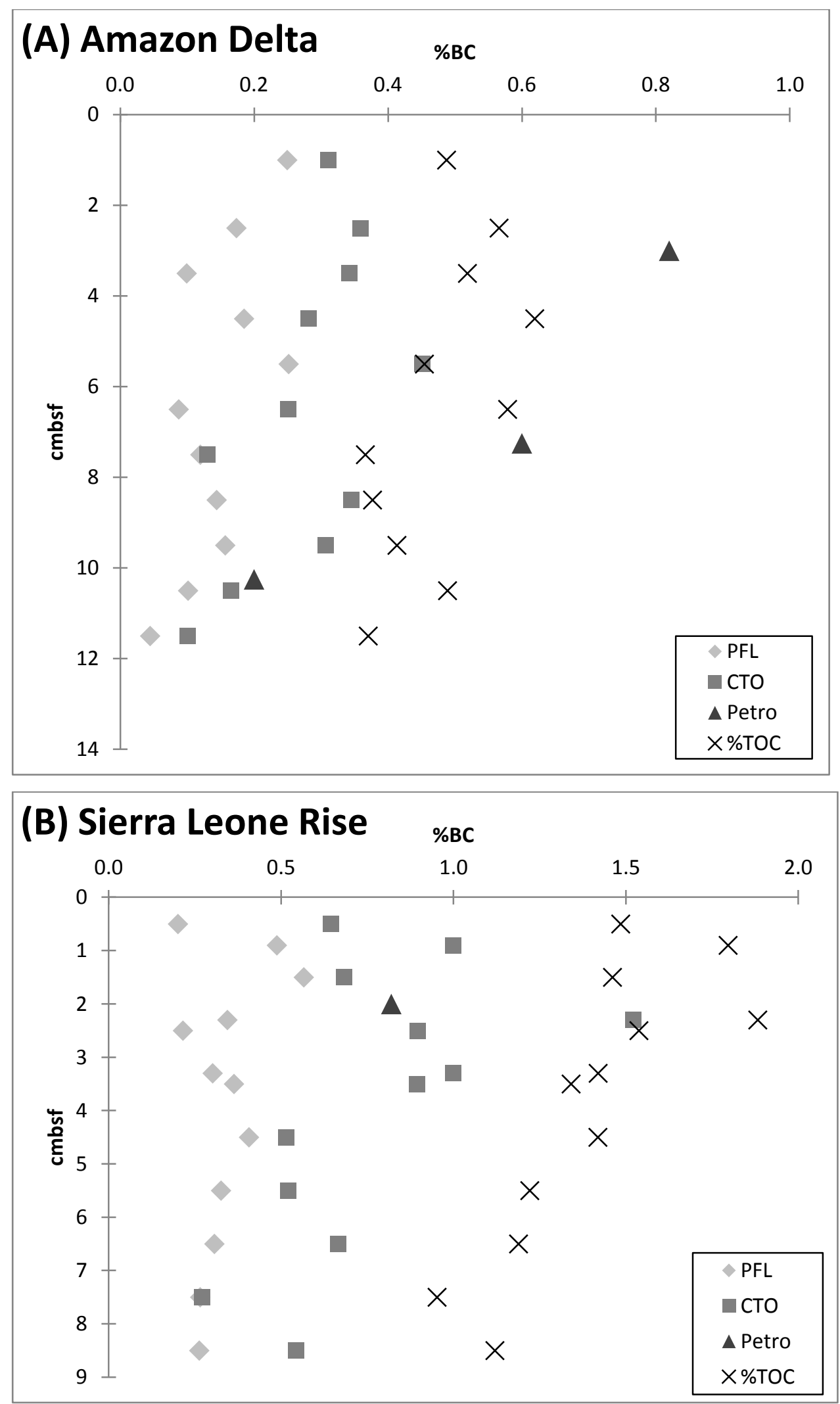
Figure S4. Mass concentrations of black carbon versus sediment depth at the (A) Amazon Delta and (B) Sierra Leone Rise. Black carbon concentrations at these two sites were derived using three methods: pyrene fluorescence loss (PFL), chemothermal oxidation at $375^{\circ} \mathrm{C}(\mathrm{CTO})$, and by petrographic analysis (Petro). The bulk total organic carbon (\% TOC) is also included. 


\section{CHAPTER 3}

\section{Significant concentrations of terrestrial organic carbon in tropical Atlantic Ocean sediments}

This manuscript has been submitted to and is formatted for the journal Geophysical

Research Letters

Kari Pohl ${ }^{1}$ and Rainer Lohmann ${ }^{1 *}$

${ }^{\mathbf{1}}$ Graduate School of Oceanography, University of Rhode Island, Narragansett, RI, 02882, USA

* Corresponding author: (email: rlohmann@mail.uri.edu ; Tel: 401-874-6612; Fax: 401-874-6811) 


\title{
Key Points:
}

1) Black carbon composed significant fractions of the sedimentary organic carbon

2) The labile organic carbon fraction has a $\delta^{13} \mathrm{C}$ suggestive of terrestrial inputs

3) Most carbon was terrestrial in origin across tropical Atlantic sediments

\begin{abstract}
Biomarker evidence predicts $<50 \%$ of input terrestrial organic matter is buried in sediments, despite this carbon form being recalcitrant. Terrestrial organic matter includes black carbon (BC), a refractory incomplete combustion byproduct which constitutes significant fractions of sedimentary organic carbon. We quantified two separate organic carbon fractions (BC and labile organic carbon) to assess terrigenous organic carbon concentrations in tropical Atlantic sediments. Black carbon composed $15-62 \%$ of the pelagic organic carbon. Bulk organic carbon had an average $\delta^{13} \mathrm{C}$ of $20 \pm 2 \%$, indicative of marine plankton. When this $\delta^{13} \mathrm{C}$ is adjusted for the BC inputs, the labile organic carbon is more enriched with an average of $-15 \pm 7 \%$, indicative of $\mathrm{C}_{4}$ plant inputs. This adjusted $\delta^{13} \mathrm{C}$ suggests $\mathrm{C}_{4}$ material is more resistant to degradation, possibly due to the heavier isotopic signature. Tropical Atlantic sediments contained as little as $12 \%$ marine materials, implying that terrestrial organic carbon composes a greater sedimentary fraction than previously measured.
\end{abstract}

\section{Introduction}

Terrestrial organic matter reaching the ocean is refractory due to its aromaticity, nitrogen depletion, and older age than marine fixed carbon (Hopkinson et al., 1998; 
Kaushal and Binford, 1999; Raymond and Bauer, 2001). Biomarker evidence, however, estimates that $<50 \%$ of input terrestrial material is buried in sediment (Hedges et al., 1997; Schlunz and Schneider, 2000; Schubert and Calvert, 2001). At least $0.5 \mathrm{Pg} \mathrm{yr}^{-1}$ of terrestrial organic carbon is deposited into the ocean by fluvial and atmospheric transport (Hedges et al., 1997; Schlunz and Schneider, 2000; Schlesinger and Melack, 1981). The atmospheric flux alone is roughly equivalent to the burial of marine phytoplankton in modern sediments (Berner, 1989; Hedges and Keil, 1995; Hedges et al., 1997). Despite this large input, deep pelagic sediments contain only 10$20 \%$ terrestrial organic material demonstrating an imbalance between the inputs and our understanding of the fate of terrigenous carbon in the ocean (Prahl et al., 1994; Schlunz and Schneider, 2000). The lack of evidence that terrestrial organic material is preserved in sediments could be due to our inability to trace the original structures once they enter the ocean and are subjected to photochemical and microbial degradation.

Total organic carbon (TOC) can be operationally divided into two fractions: the refractory black carbon (BC) and the thermally labile organic carbon (OC) fraction (Gustafsson et al., 1997). Black carbon is a highly graphitized form of terrestrial organic carbon created through incomplete combustion and is protected from degradation in soils but subjected to breakdown into smaller fragments upon entry into the ocean (Stubbins et al., 2012; Masiello and Louchouarn, 2013). There is on-going debate whether BC structures survive long enough in the ocean to compose significant fractions of the sediment, or whether they are partially oxidized and enter into the 
dissolved organic carbon pool (Middelburg et al., 1999; Burdige, 2005; Masiello and Louchouarn, 2013). While the BC fraction is terrestrially derived by definition, the labile OC fraction could be a mix of marine and terrestrial material and is presumed to be more labile and susceptible to degradation (Schmidt and Noack, 2000; Lohmann et al., 2009; Sanchez-Garcia et al., 2012).

Few studies have measured $\mathrm{BC}$ and other forms of terrestrial organic matter in pelagic sediments. It is assumed that rivers are the primary transport of terrestrial organic matter to the ocean thus the majority $(\geq 90 \%)$ of $\mathrm{BC}$ is deposited on the continental shelf (Suman et al., 1997; Mitra et al., 2002). However, the bulk TOC is rarely assessed as two separate fractions $(\mathrm{BC}+$ labile $\mathrm{OC})$, thus this terrigenous signal can be diluted when it is not isolated from the sedimentary TOC pool. Sedimentary BC was found to compose $15 \%$ of the TOC from the equatorial Pacific (depth $>4000 \mathrm{~m}$ ) and up to $34 \%$ in the Equatorial Atlantic $(>1200 \mathrm{~m})$. Not including BC as a separate fraction can substantially under-estimate terrigenous inputs to the sediment (Masiello and Druffel, 1998; Lohmann et al., 2009).

Pelagic sediments in the tropical Atlantic have the potential to receive elevated inputs of terrigenous materials due to a combination of fluvial and atmospheric inputs. The Amazon, Congo, and Niger Rivers all flow into the equatorial Atlantic region in addition to the intense grassland burnings delivered by the African emission plume (Cahoon et al., 1992). Atmospheric deposition of terrestrial organic matter, such as BC, could contribute high inputs to the tropical Atlantic sediments. A previous study 
determined that up to $40 \%$ of $\mathrm{BC}$ deposited in coastal sediments originates from atmospheric deposition, thus the atmospheric input into pelagic sediments could be equally significant (Masiello and Druffel, 1998).

The aims of this work were to 1) assess the contribution BC makes to the sedimentary TOC in the tropical Atlantic, 2) to apply stable carbon isotope ratios to determine the source of the labile organic carbon (TOC-BC) fraction, and 3) to estimate the maximum contribution that terrigenous organic carbon could contribute to the sediments analyzed in this study.

\section{Methodology}

Sediments from the Amazon Delta (4.282778, -47.484444) and Sierra Leone Rise (7.435278, -24.010556) were collected in the summer of 2010 on the R/V Endeavor (EN-480 to EN-481) using a multicorer (Fig. 1). Additional sediments from the Niger and Senegal Deltas and NW Argentina basin were received from the University of Bremen as previously collected and stored by the German Research Foundation (Lohmann et al., 2009). A total of 17 sediments cores were used throughout the tropical Atlantic basin ranging from surface sediments $(0-4 \mathrm{~cm})$ up to 33 centimeters below the sea floor.

All sediments were acidified with $10 \%$ hydrochloric acid, dried at ambient temperature, and homogenized with mortar and pestle before analysis. A portion of the decalcified sediment was analyzed for bulk total organic carbon (TOC) by an 
Elementar Vario MICRO cube elemental analyzer coupled to an Isoprime100 isotope ratio-mass spectrometer (IR-MS). Soot-like black carbon (BC) was quantified using a chemothermal oxidation at $375^{\circ} \mathrm{C}(\mathrm{CTO}-375)$ in which a thin layer of sediment is heated at $375^{\circ} \mathrm{C}$ with an inflow of excess oxygen for 24 hours (Gustafsson et al., 1997; Elmquist et al., 2004). This process oxidizes the thermally labile organic carbon (OC) fraction and the remaining carbon measured via IR-MS is defined as soot-like BC. The labile OC fraction was defined as the difference between the BC and TOC fractions. The IR-MS instrumentation also determined the stable carbon isotope ratios $\left(\delta^{13} \mathrm{C}\right)$ of the TOC and BC portions.

A series of standard reference materials (SRM), including 1941b (marine sediment), 1649a (urban dust), grass char, and sand (as a methodological blank) were quantified via CTO-375 with the sediment samples as a measure of quality control. All SRMs produced soot-like BC concentrations as expected at $0.7 \%$ for $1941 \mathrm{~b}$ and $2.4 \%$ for 1649a (Hammes et al., 2007; Lohmann et al., 2009). No grass char mass was recovered after the CTO-375 process, which was expected since the chemothermal oxidation is optimized to quantify the soot-like BC fraction and will oxidize the more labile char-like fractions. This result suggests that minimal organic matter charring occurred during our quantification. No carbon was detected on the sand.

Radiocarbon $\left(\Delta^{14} \mathrm{C}\right)$ values for sediments from the Amazon Delta and Sierra Leone Rise were analyzed at the National Ocean Science-Accelerated Mass Spectrometry 
facility at Woods Hole Oceanographic Institute using the reconnaissance method (Burke et al., 2010; Xu et al., 2007).

\subsection{Soot-like black carbon and labile organic carbon concentrations}

In this study, we analyzed sediments from four remote and one coastal region throughout the tropical Atlantic basin (Fig. 1). Fluvial-influenced sites included the Amazon, Niger, and Senegal Deltas. In contrast, sediments from the remote Sierra Leone Rise and NW Argentina Basin were also analyzed; these pelagic sites were assumed to receive minimal fluvial inputs. The Sierra Leone Rise is located in the African emission plume where enhanced atmospheric deposition of grassland and agricultural burnings can be expected while the NW Argentina basin has neither significant fluvial nor atmospheric inputs (Cahoon et al., 1992).

The surface sediment soot-like BC concentrations were greatest in the fluvialinfluenced regions (Table 1). Soot-like $\mathrm{BC}$ concentrations ranged from $3 \pm 2 \mathrm{~g}_{\mathrm{BC}}$

$\mathrm{kg}_{\text {sediment }}{ }^{-1}$ in the Amazon Delta to $7 \pm 1 \mathrm{~g}_{\mathrm{BC}} \mathrm{kg}_{\text {sediment }}{ }^{-1}$ in the Senegal Delta up to $8 \pm 4$ $\mathrm{g}_{\mathrm{BC}} \mathrm{kg}_{\text {sediment }}{ }^{-1}$ in the Niger Delta. The Amazon Deltaic sediments were the furthest from the river mouth compared to the Senegal and Niger sites. These lower soot-like $\mathrm{BC}$ concentrations could be due to preferential deposition near the coast or enhanced remineralization in the water column. Amazon plume water is known as a microbial hotspot, thus the potential for biological and photogenic degradation could be elevated in this region (Aller and Blair, 2006). 
The labile OC fraction (TOC-BC) at these fluvial sites ranged widely between $2 \pm 2 \mathrm{~g}_{\mathrm{OC}}$ $\mathrm{kg}_{\text {sediment }}{ }^{-1}$ in the Amazon Delta to $18 \pm 5 \mathrm{~g}_{\mathrm{OCC}} \mathrm{kg}_{\text {sediment }}{ }^{-1}$ in the coastal Senegal Delta, with the Niger Delta at a median value of $9 \pm 10 \mathrm{gOC}_{\mathrm{Og}} \mathrm{sediment}^{-1}$. The sedimentary total organic carbon concentration in the Amazon Delta was the lowest measured in the entire study $\left(6 \pm 2 \mathrm{~g}_{\text {TOC }} \mathrm{kg}_{\text {sediment }}{ }^{-1}\right)$, which further supports that either enhanced degradation was occurring or there was a reduced deposition of organic matter. The Senegal Delta had the overall greatest TOC concentration within the region at $25 \pm 5$ $\mathrm{g}_{\text {TOC }} \mathrm{kg}_{\text {sediment }}{ }^{-1}$.

For both the Sierra Leone Rise and NW Argentina basin, atmospheric deposition is presumed to be the main $\mathrm{BC}$ transport mechanism to these sediments, as they are removed from major fluvial inputs. The Sierra Leone Rise had elevated BC concentrations of $5 \pm 2 \mathrm{~g}_{\mathrm{BC}} \mathrm{kg}_{\text {sediment }}{ }^{-1}$ compared to the NW Argentina basin with a concentration of $1 \pm 0 \mathrm{~g}_{\mathrm{BC}} \mathrm{kg}_{\text {sediment }}{ }^{-1}$ (Table 1). This five times greater BC concentration at the Sierra Leone Rise is presumably due to the high aeolian inputs from the African grasslands (Cahoon et al., 1992; Lohmann et al., 2009). The NW Argentina basin site is located approximately $2600 \mathrm{~km}$ off the coast of Argentina and, as expected, had the lowest BC concentrations measured in this study. Labile OC concentrations were also elevated in the Sierra Leone Rise compared to the NW Argentina basin at $14 \pm 5$ and $6 \pm 1 \mathrm{gOC}_{\mathrm{OC}} \mathrm{kg}_{\text {sediment }}{ }^{-1}$, respectively. In addition to the atmospheric emission plume, the Sierra Leone Rise is also located in a region of equatorial upwelling, which could promote additional productivity (Weingartner and Weisberg, 1990). 
The TOC concentrations of all measured sediments were plotted against the soot-like $\mathrm{BC}$ and thermally labile $\mathrm{OC}$ concentrations in order to assess linearity as a quality control measure (Fig. 2). We found that the thermally labile OC fraction was significantly correlated to the TOC $(\mathrm{R} 2=0.83$; $\mathrm{p}$-value $<0.01)$, however there was no correlation to the $\mathrm{BC}$ fraction. This gives evidence that two separate carbon pools were isolated and that soot-like BC concentrations were independent of the organic matter input. This allows us to conclude that the charring of organic carbon during the CTO-375 method was minimal.

\section{4) Soot contribution to the total organic carbon pool}

Black carbon is by definition a form of terrigenous organic matter since it is a byproduct of incomplete combustion (Schmidt and Noack, 2000). We assessed the fraction of soot-like $\mathrm{BC}$ to TOC to establish the minimum amount of terrigenous organic material detected in these Tropical Atlantic sediments. Soot-like BC composed $15-62 \%$ of the TOC with the trend of being highest in the fluvial regions (Fig. 1). Black carbon composed $62 \pm 36,57 \pm 33$, and $30 \pm 6 \%$ of the TOC for the Amazon, Niger, and Senegal Deltas, respectively. This elevated fraction of BC in fluvial sediments displays the environmental stability and refractory nature of this carbon form (Seiler and Crutzen, 1980; Kuhlbusch, 1998; Masiello, 2004).

The ratio of soot-like BC to the TOC (BC/TOC) in the Sierra Leone Rise was nearly double that found in the NW Argentina Basin (Fig. 1). The regional average 
percentage of BC/TOC in the Sierra Leone Rise was $28 \pm 14 \%$, despite minimal fluvial contribution. Soot-like BC composed $15 \pm 4 \%$ of the TOC in the NW Argentina basin, as similarly found in the equatorial Pacific and Mississippi River (Masiello and Druffel, 1998; Mitra et al., 2002). The basin-wide average fraction of BC/TOC in the tropical Atlantic was $38 \pm 20 \%$ demonstrating that terrestrial inputs of $\mathrm{BC}$ were elevated compared to other regions. The fraction of soot-like $\mathrm{BC} / \mathrm{TOC}$ has been measured up to 6\% off the Washington, USA coast (Dickens et al., 2004), 7\% off the Swedish continental shelf (Sanchez-Garcia et al., 2012), and 29\% in the Iberian Margin within the Atlantic Ocean (Middelburg et al., 1999). We hypothesize that the African emission plume and the numerous large river-systems contributed elevated $\mathrm{BC}$ inputs to the tropical Atlantic region.

\section{5) Radiocarbon age and assessment}

The stable carbon ratio $\left(\delta^{13} \mathrm{C}\right)$ is often measured to assess the sources of sedimentary carbon. The bulk TOC- $\delta^{13} \mathrm{C}$ in marine surface sediments is typically in the range for marine phytoplankton between -19 and $-22 \%$ (Holtvoeth et al., 2003). Generally, the TOC in pelagic marine sediments is driven by phytoplankton deposition and burial coupled with poor terrestrial organic carbon preservation (Hedges et al., 1997;

Westerhausen et al., 1993). Conversely, a mixing between the two dominant terrestrial carbon fixation pathways, the Calvin-Benson cycle $\left(\mathrm{C}_{3}\right)$ and the Hatch-Slack cycle $\left(\mathrm{C}_{4}\right)$, could produce an artificial marine signal. The typical $\delta^{13} \mathrm{C}$ range of $\mathrm{C}_{3}$ carbon fixation is -25 to $-28 \%$ while the $\mathrm{C}_{4}$ fractionation is more enriched between -10 to 14\%o (Farquhar et al., 1989). Despite $\mathrm{C}_{4}$ biomass only composing $~ 13 \%$ of modern 
day plant metabolism, the Subtropical Atlantic receives significant $\mathrm{C}_{4}$ inputs from Savanna grasses from Africa delivered by the easterly winds (Cahoon et al., 1992; Cerling et al., 1993). Thus, a mix of $C_{3}$ and $C_{4}$ plant material, in addition to marine plankton, could lead to an artificial marine signature in the tropical Atlantic Ocean due to the African emission plume.

\section{5) Stable carbon mass balance}

The stable carbon ratio $\left(\delta^{13} \mathrm{C}\right)$ is often measured to assess the sources of sedimentary carbon. The bulk TOC- $-{ }^{13} \mathrm{C}$ in marine surface sediments is typically in the range for marine phytoplankton between -19 and $-22 \%$ (Holtvoeth et al., 2003). Generally, the TOC in pelagic marine sediments is driven by phytoplankton deposition and burial coupled with poor terrestrial organic carbon preservation (Hedges et al., 1997;

Westerhausen et al., 1993). Conversely, a mixing between the two dominant terrestrial carbon fixation pathways, the Calvin-Benson cycle $\left(\mathrm{C}_{3}\right)$ and the Hatch-Slack cycle $\left(\mathrm{C}_{4}\right)$, could produce an artificial marine signal. The typical $\delta^{13} \mathrm{C}$ range of $\mathrm{C}_{3}$ carbon fixation is -25 to $-28 \%$ while the $\mathrm{C}_{4}$ fractionation is more enriched between -10 to 14\%o (Farquhar et al., 1989). Despite $\mathrm{C}_{4}$ biomass only composing $~ 13 \%$ of modern day plant metabolism, the Subtropical Atlantic receives significant $\mathrm{C}_{4}$ inputs from Savanna grasses from Africa delivered by the easterly winds (Cahoon et al., 1992; Cerling et al., 1993). Thus, a mix of $C_{3}$ and $C_{4}$ plant material, in addition to marine plankton, could lead to an artificial marine signature in the tropical Atlantic Ocean due to the African emission plume. 
We assessed the $\delta^{13} \mathrm{C}$ of the TOC, BC, and adjusted labile OC fractions separately. The $\delta^{13} \mathrm{C}$-TOC had a regional average of $-20 \pm 2 \%$ ( $(-17 \pm 2$ to $-23 \pm 1 \%$ ) which is typically interpreted as in situ marine productivity. The $\delta^{13} \mathrm{C}-\mathrm{BC}$ showed a wide range of values from $-30 \pm 5$ (Amazon Delta) to $-21 \pm 4 \%$ (Senegal Delta and Sierra Leone Rise) where the more depleted ratios were found in the western basin and enriched $\delta^{13} \mathrm{C}$ values were closer to the African continent. This enrichment in the Niger Delta ($24 \pm 6 \%$ ) and Sierra Leone Rise is interpreted as $\mathrm{C}_{4}$ grass inputs from the southern African Savanna and South American Pampas and Chaco grasslands (Table 1).

A weighed mass balance was applied to determine the $\delta^{13} \mathrm{C}$ of the labile OC since BC composed a considerable fraction (15-62\%) of the TOC (Eq. 1; Fig. 3). These high fractions of soot-like BC to the TOC have the potential to dilute the labile OC $\delta^{13} \mathrm{C}$ signal within the bulk TOC.

$$
\delta^{13} \mathrm{OC}=\frac{\left\{\left([\mathrm{TOC}] * \delta^{13} \mathrm{TOC}\right)-\left([\mathrm{BC}] * \delta^{13} \mathrm{BC}\right)\right\}}{[\mathrm{OC}]}
$$

Most regions in the tropical Atlantic had a labile $\mathrm{OC}-\delta^{13} \mathrm{C}$ fraction that was more enriched compared to the TOC- $\delta^{13} \mathrm{C}$, suggesting an input from a non-marine organic carbon source (Table 1). Stable carbon isotope ratios at the Senegal Delta $(-19 \pm 2 \%$ ) and NW Argentina basin $(-22 \pm 1 \%)$ sites still suggested a predominantly marine origin of the labile OC pool. We propose that this was the result of the elevated sedimentary TOC concentration, indicative of a highly productive region, and shallow water depth in the Senegal Delta and the small BC fraction in the NW Argentina basin site. 
In contrast, both the Amazon Delta and Sierra Leone Rise had a labile OC- $\delta^{13} \mathrm{C}$ of 14\%, which we apportioned as terrestrial $\mathrm{C}_{4}$ material. The $\mathrm{BC}$ in the Amazon Delta $\mathrm{BC}$ was presumably from a $\mathrm{C}_{3}$ plant source $(-30 \pm 5 \%$ ), but the labile OC appears to be dominated by large inputs of $\mathrm{C}_{4}$-like materials. $\mathrm{BC}$ has a higher mass yield in woody $\left(\mathrm{C}_{3}\right)$ plants since the oxygen to fuel ratio is smaller than in grassy or shrub $\left(\mathrm{C}_{4}\right)$ plants (Schmidt and Noack, 2000).

$$
\delta^{13} \mathrm{C}_{\mathrm{OC}}=\mathrm{f}_{\mathrm{C}_{4}} \delta^{13} \mathrm{C}_{\mathrm{C}_{4}}+\mathrm{f}_{\mathrm{C}_{3}} \delta^{13} \mathrm{C}_{\mathrm{C}_{3}}+\mathrm{f}_{\text {marine }} \delta^{13} \mathrm{C}_{\text {marine }}
$$

We implemented a 3-endmember model to estimate the potential contributions of marine and terrestrial organic carbon to the labile OC fraction (Eq. 2). We used the median values of $-12,-26$, and $-20 \%$ for the $\mathrm{C}_{4}, \mathrm{C}_{3}$, and marine components, respectively. Both the Amazon Delta and Sierra Leone Rise require an input of at least $69 \% \mathrm{C}_{4}$ biomass to achieve the enriched labile $\delta^{13} \mathrm{C}$-OC of $-14 \%$ (Fig. 3). This suggests that only $31 \%$ of the labile OC fraction was actually marine in origin. Overall, the estimated contribution of marine plankton was $12 \%$ for the Amazon Delta and $22 \%$ for the Sierra Leone Rise, which implies that terrestrial material dominated the TOC despite the bulk $\delta^{13} \mathrm{C}$-TOC displaying a marine signature.

We propose that $\mathrm{C}_{4}$-derived labile $\mathrm{OC}$ either is more refractory than $\mathrm{C}_{3}$ biomass or is preferentially transported to deep sediments. Tropical grasses have a lower digestion rate than temperate species and mesophyll, a component of lignin, has been shown to 
degrade slower in $\mathrm{C}_{4}$ plants than $\mathrm{C}_{3}$ (Akin et al., 1983). Additionally, $\mathrm{C}_{3}$ derived material is lost quicker in coastal ecosystems than $\mathrm{C}_{4}$ since it is isotopically lighter (Mayer et al., 2007). Marine materials composed at least $70 \%$ and $60 \%$ of the labile OC for the Senegal Delta and NW Argentina basin, respectively, with variable inputs of $\mathrm{C}_{3}$ and $\mathrm{C}_{4}$ biomass. Our results emphasize the importance of assessing the $\mathrm{BC}$ and labile OC as separate fractions in areas with significant atmospheric or fluvial contributions.

\section{Conclusion}

The tropical Atlantic receives high inputs of atmospheric deposition from elevated regional biomass burning attributed to the Savanna grasslands. The weighted $\delta^{13} \mathrm{C}-\mathrm{OC}$ calculation implies that the thermally labile organic carbon fraction is partially of terrestrial origin, especially in the Amazon Delta and Sierra Leone Rise. Thus, more terrestrial organic matter is preserved in deep marine sediments than indicated by biomarkers (Prahl et al., 1994; Schlunz and Schneider, 2000). Future work needs to evaluate the total organic carbon as two separate carbon pools and work towards structurally identifying that thermally labile organic carbon. Our results imply that terrestrial organic matter composes a larger fraction of marine sediments than previously estimated. These elevated terrestrial organic carbon concentrations should similarly be found in other regions with high biomass burning depositional plumes.

\section{Acknowledgements}


All data supporting this information are available as Supplementary Materials in Tables S1-S7. We acknowledge support by the National Science Foundation (OCE0851044). We thank the crew and captain of the R/V Endeavor for their help with collecting the samples and Matthias Zabel (University of Bremen) for supplying the additional sediments; and Ann McNichol and Mary Laudie (NOS-AMS facility at WHOI) for assistance with the radiocarbon measurements. We acknowledge the help Mark Cantwell, Rick McKinney, and Julia Sullivan (U.S. Environmental Protection Agency) for help with carbon analyses.

\section{References}

Akin, D. E., J. R. Wilson, and W. R. Windham (1983), Site and Rate of Tissue Digestion in Leaves of C-3, C-4, and C3/C4 Intermediate Panicum Species, Crop Sci, 23(1), 147-155.

Aller, R. C., and N. E. Blair (2006), Carbon remineralization in the Amazon-Guianas tropical mobile mudbelt: A sedimentary incinerator, Cont Shelf Res, 26(17-18), 22412259.

Berner, R. A. (1989), Biogeochemical Cycles of Carbon and Sulfur and Their Effect on Atmospheric Oxygen over Phanerozoic Time, Global Planet Change, 75(1-2), 97122.

Burdige, D. J. (2005), Burial of terrestrial organic matter in marine sediments: A reassessment, Global Biogeochem Cy, 19(4).

Burke, A., L. F. Robinson, A. P. McNichol, W. J. Jenkins, K. M. Scanlon, and D. S. Gerlach (2010), Reconnaissance dating A new radiocarbon method applied to assessing the temporal distribution of Southern Ocean deep-sea corals, Deep-Sea Res Pt I, 57(11), 1510-1520.

Cahoon, D. R., B. J. Stocks, J. S. Levine, W. R. Cofer, and K. P. Oneill (1992), Seasonal Distribution of African Savanna Fires, Nature, 359(6398), 812-815.

Cerling, T. E., Y. Wang, and J. Quade (1993), Expansion of C4 Ecosystems as an Indicator of Global Ecological Change in the Late Miocene, Nature, 361(6410), 344345 . 
Dickens, A. F., Y. Gelinas, C. A. Masiello, S. Wakeham, and J. I. Hedges (2004), Reburial of fossil organic carbon in marine sediments, Nature, 427(6972), 336-339.

Elmquist, M., O. Gustafsson, and P. Andersson (2004), Quantification of sedimentary black carbon using the chemothermal oxidation method: an evaluation of ex situ pretreatments and standard additions approaches, Limnol Oceanogr-Meth, 2, 417-427.

Farquhar, G. D., J. R. Ehleringer, and K. T. Hubick (1989), Carbon Isotope Discrimination and Photosynthesis, Annu Rev Plant Phys, 40, 503-537.

Fry, B., and E. B. Sherr (1984), Delta-C-13 Measurements as Indicators of Carbon Flow in Marine and Fresh-Water Ecosystems, Contrib Mar Sci, 27(Sep), 13-47.

Goldberg, E. D. (1985), Black Carbon in the Environment, Wiley(New York, New York, USA, ).

Gustafsson, O., F. Haghseta, C. Chan, J. MacFarlane, and P. M. Gschwend (1997), Quantification of the dilute sedimentary soot phase: Implications for PAH speciation and bioavailability, Environ Sci Technol, 31(1), 203-209.

Hammes, K., et al. (2007), Comparison of quantification methods to measure firederived (black/elemental) carbon in soils and sediments using reference materials from soil, water, sediment and the atmosphere, Global Biogeochem Cy, 21(3).

Hedges, J. I., and R. G. Keil (1995), Sedimentary Organic-Matter Preservation - an Assessment and Speculative Synthesis, Mar Chem, 49(2-3), 81-115.

Hedges, J. I., R. G. Keil, and R. Benner (1997), What happens to terrestrial organic matter in the ocean?, Org Geochem, 27(5-6), 195-212.

Holtvoeth, J., T. Wagner, and C. J. Schubert (2003), Organic matter in riverinfluenced continental margin sediments: The land-ocean and climate linkage at the Late Quaternary Congo fan (ODP Site 1075), Geochem Geophy Geosy, 4.

Hopkinson, C. S., et al. (1998), Terrestrial inputs of organic matter to coastal ecosystems: An intercomparison of chemical characteristics and bioavailability, Biogeochemistry, 43(3), 211-234.

Jaffe, R., Y. Ding, J. Niggemann, A. V. Vahatalo, A. Stubbins, R. G. M. Spencer, J. Campbell, and T. Dittmar (2013), Global Charcoal Mobilization from Soils via Dissolution and Riverine Transport to the Oceans, Science, 340(6130), 345-347.

Kaushal, S., and M. W. Binford (1999), Relationship between C : N ratios of lake sediments, organic matter sources, and historical deforestation in Lake Pleasant, Massachusetts, USA, J Paleolimnol, 22(4), 439-442. 
Kuhlbusch, T. A. J. (1998), Black carbon and the carbon cycle, Science, 280(5371), 1903-1904.

Lohmann, R., K. Bollinger, M. Cantwell, J. Feichter, I. Fischer-Bruns, and M. Zabel (2009), Fluxes of soot black carbon to South Atlantic sediments, Global Biogeochem Cy, 23 .

Masiello, C. A. (2004), New directions in black carbon organic geochemistry, Mar Chem, 92(1-4), 201-213.

Masiello, C. A., and E. R. M. Druffel (1998), Black carbon in deep-sea sediments, Science, 280(5371), 1911-1913.

Masiello, C. A., and P. Louchouarn (2013), Fire in the Ocean, Science, 340(6130), 287-288.

Mayer, L. M., L. L. Schick, M. A. Allison, K. C. Ruttenberg, and S. J. Bentley (2007), Marine vs. terrigenous organic matter in Louisiana coastal sediments: The uses of bromine : organic carbon ratios, Mar Chem, 107(2), 244-254.

Middelburg, J. J., J. Nieuwenhuize, and P. van Breugel (1999), Black carbon in marine sediments, Mar Chem, 65(3-4), 245-252.

Mitra, S., T. S. Bianchi, B. A. McKee, and M. Sutula (2002), Black carbon from the Mississippi River: Quantities, sources, and potential implications for the global carbon cycle, Environ Sci Technol, 36(11), 2296-2302.

Olajire, A. A., R. Altenburger, E. Kuster, and W. Brack (2005), Chemical and ecotoxicological assessment of polycyclic aromatic hydrocarbon-contaminated sediments of the Niger Delta, southern Nigeria, Sci Total Environ, 340(1-3), 123-136.

Prahl, F. G., J. R. Ertel, M. A. Goni, M. A. Sparrow, and B. Eversmeyer (1994), Terrestrial Organic-Carbon Contributions to Sediments on the Washington Margin, Geochim Cosmochim Ac, 58(14), 3035-3048.

Raymond, P. A., and J. E. Bauer (2001), Riverine export of aged terrestrial organic matter to the North Atlantic Ocean, Nature, 409(6819), 497-500.

Sanchez-Garcia, L., I. Cato, and O. Gustafsson (2012), The sequestration sink of soot black carbon in the Northern European Shelf sediments, Global Biogeochem Cy, 26.

Schlesinger, W. H., and J. M. Melack (1981), Transport of Organic-Carbon in the Worlds Rivers, Tellus, 33(2), 172-187.

Schlunz, B., and R. R. Schneider (2000), Transport of terrestrial organic carbon to the oceans by rivers: re-estimating flux- and burial rates, Int J Earth Sci, 88(4), 599-606. 
Schmidt, M. W. I., and A. G. Noack (2000), Black carbon in soils and sediments: Analysis, distribution, implications, and current challenges, Global Biogeochem Cy, 14(3), 777-793.

Schubert, C. J., and S. E. Calvert (2001), Nitrogen and carbon isotopic composition of marine and terrestrial organic matter in Arctic Ocean sediments: implications for nutrient utilization and organic matter composition, Deep-Sea Res Pt I, 48(3), 789810.

Seiler, W., and P. J. Crutzen (1980), Estimates of Gross and Net Fluxes of Carbon between the Biosphere and the Atmosphere from Biomass Burning, Climatic Change, 2(3), 207-247.

Stubbins, A., J. Niggemann, and T. Dittmar (2012), Photo-lability of deep ocean dissolved black carbon, Biogeosciences, 9(5), 1661-1670.

Suman, D. O., Kuhlbusch, T. A. J., Lim, B. (1997), Marine Sediments: A reservoir for black carbon and their use as spatial and temporal records of combustion, Sediment Records of Biomass Burning and Global Change, edited by J. S. Clark, H. Cachier, J. G. Goldhammer, B. J. Stocks(Springer-Verlag).

Weingartner, T. J., and R. H. Weisberg (1991), On the Annual Cycle of Equatorial Upwelling in the Central Atlantic-Ocean, J Phys Oceanogr, 21(1), 68-82.

Westerhausen, L., J. Poynter, G. Eglinton, H. Erlenkeuser, and M. Sarnthein (1993), Marine and Terrigenous Origin of Organic-Matter in Modern Sediments of the Equatorial East Atlantic - the Delta-C-13 and Molecular Record, Deep-Sea Res Pt I, 40(5), 1087-1121.

Xu, S., A. Dougans, S. P. H. T. Freeman, C. Maden, and R. Loger (2007), A gas ion source for radiocarbon measurement at SUERC, Nucl Instrum Meth B, 259(1), 76-82. 


\section{Tables}

\begin{tabular}{c|c|ccc|ccc}
$\begin{array}{c}\text { Regional } \\
\text { Average }\end{array}$ & $\begin{array}{c}\text { Water } \\
\text { Depth }(\mathbf{m})\end{array}$ & $\boldsymbol{\delta}^{\mathbf{1 3}} \mathbf{C}-\mathbf{T O C}$ & $\boldsymbol{\delta}^{\mathbf{1 3}} \mathbf{C}-\mathbf{B C}$ & $\boldsymbol{\delta}^{\mathbf{1 3}} \mathbf{C}-\mathbf{O C}$ & TOC & BC & OC \\
\hline Amazon Delta & 3360 & $-20 \pm 2$ & $-30 \pm 5$ & $-14 \pm 13$ & $6 \pm 2$ & $3 \pm 2$ & $2 \pm 2$ \\
Niger Delta & 2500 & $-18 \pm 4$ & $-24 \pm 6$ & $-5 \pm 17$ & $17 \pm 8$ & $8 \pm 4$ & $9 \pm 10$ \\
Senegal Delta & 330 & $-20 \pm 1$ & $-21 \pm 4$ & $-19 \pm 2$ & $25 \pm 5$ & $7 \pm 1$ & $18 \pm 5$ \\
Sierra Leone Rise & 3500 & $-17 \pm 2$ & $-21 \pm 5$ & $-14 \pm 6$ & $18 \pm 5$ & $5 \pm 2$ & $14 \pm 5$ \\
NW Argentina & 4949 & $-23 \pm 1$ & $-26 \pm 2$ & $-22 \pm 1$ & $7 \pm 1$ & $1 \pm 0$ & $6 \pm 1$
\end{tabular}

Table 1. Surface sediment regional averages of organic carbon concentrations $\left(\mathrm{g}_{\mathrm{BC}}\right.$

$\left.\mathrm{kg}_{\text {sediment }}{ }^{-1}\right)$ and stable carbon isotope ratios $\left(\delta^{13} \mathrm{C}, \% \mathrm{o}\right)$ in tropical Atlantic sediments for the total organic carbon (TOC), black carbon (BC), and the thermally labile organic carbon $(\mathrm{OC})$ fractions. The sediments used were $\leq 4 \mathrm{~cm}$ from the surface and presumed to be well mixed as indicated by the radiocarbon ages. 


\section{Figures}

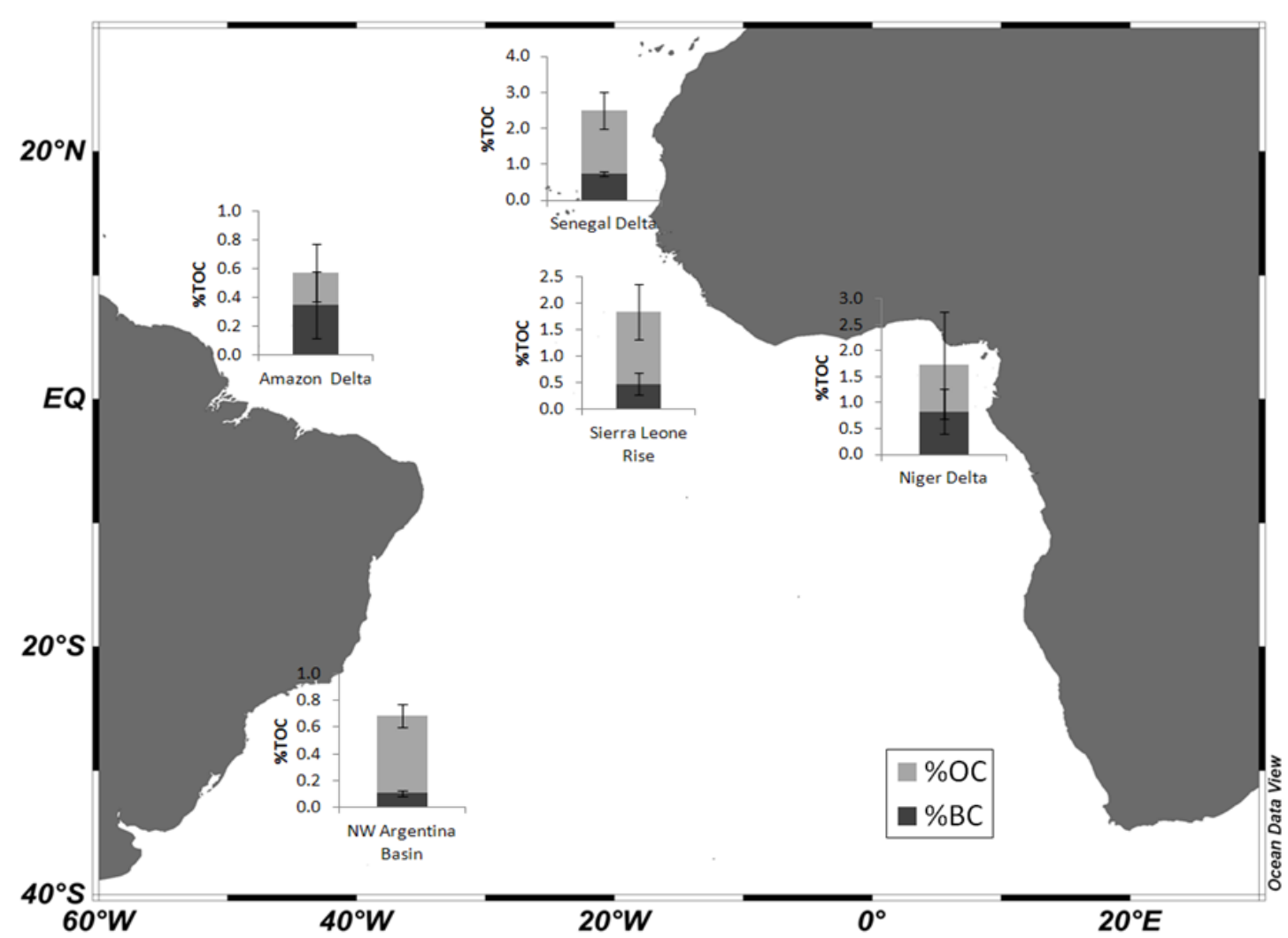

Figure 1. The fraction of black carbon (BC) and thermally labile organic carbon (OC) within the total sedimentary organic carbon (TOC) in the tropical Atlantic Ocean. The dark gray shading is the soot-like BC fraction and the lighter gray shading is the labile OC fraction as determined by the chemothermal oxidation at $375^{\circ} \mathrm{C}$ method. The Amazon, Senegal, and Niger Deltas are fluvial-influenced sites while the Sierra Leone Rise and NW Argentina basin are presumed to have minimal freshwater inputs, thusly are dominated by atmospheric deposition. The Sierra Leone Rise is within the African dust plume which is associated with elevated aerosol deposition. 


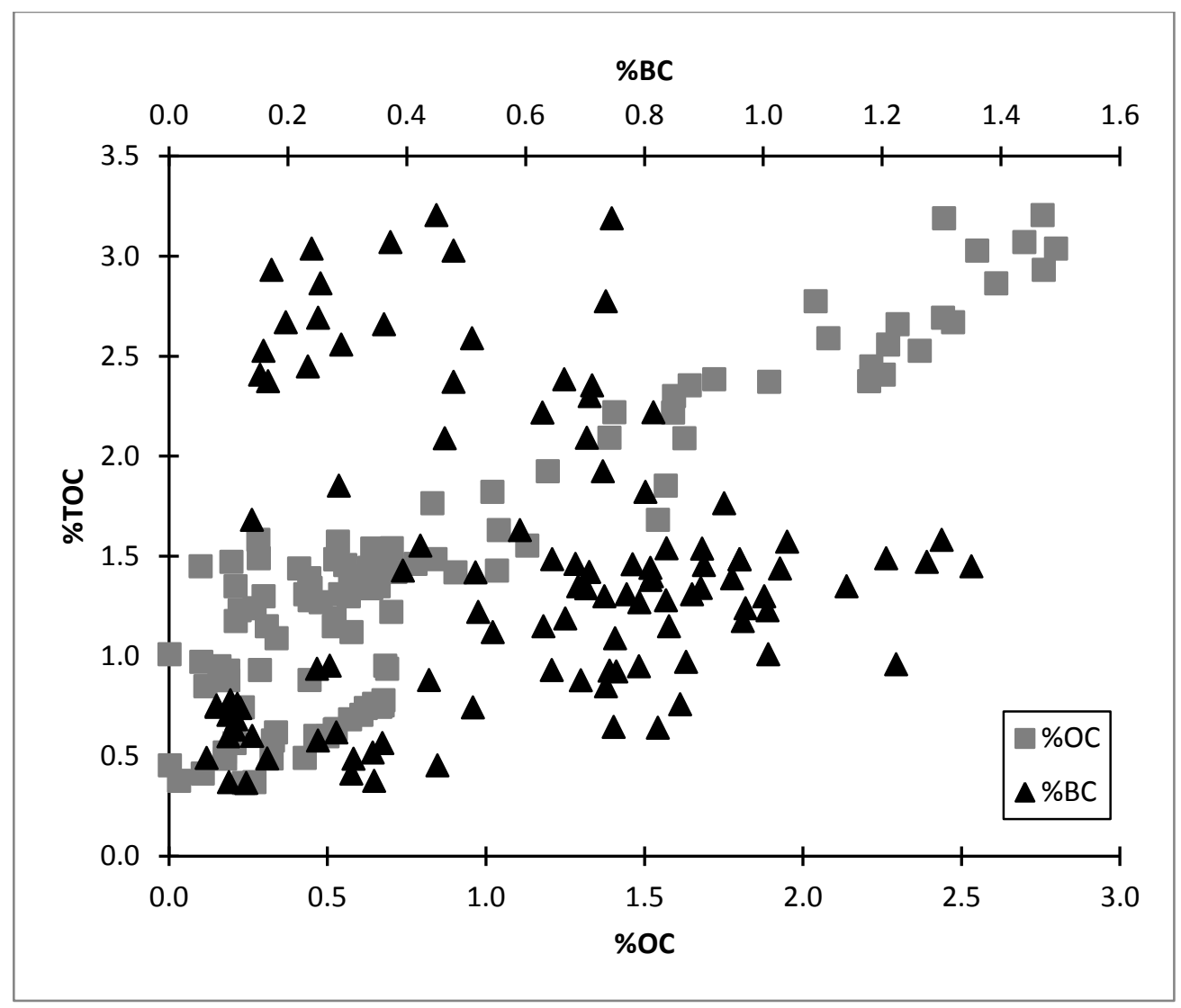

Figure 2. Linear regression of the total organic carbon (TOC) versus the thermally labile organic carbon (OC) on the primary axis and soot-like black carbon $(\mathrm{BC})$ on the secondary axis. The TOC and labile OC fractions were significantly correlated $\left(\mathrm{R}^{2}=0.83, \mathrm{p}<0.5\right)$; no correlation was found for the TOC versus the $\mathrm{BC}$ fractions. 


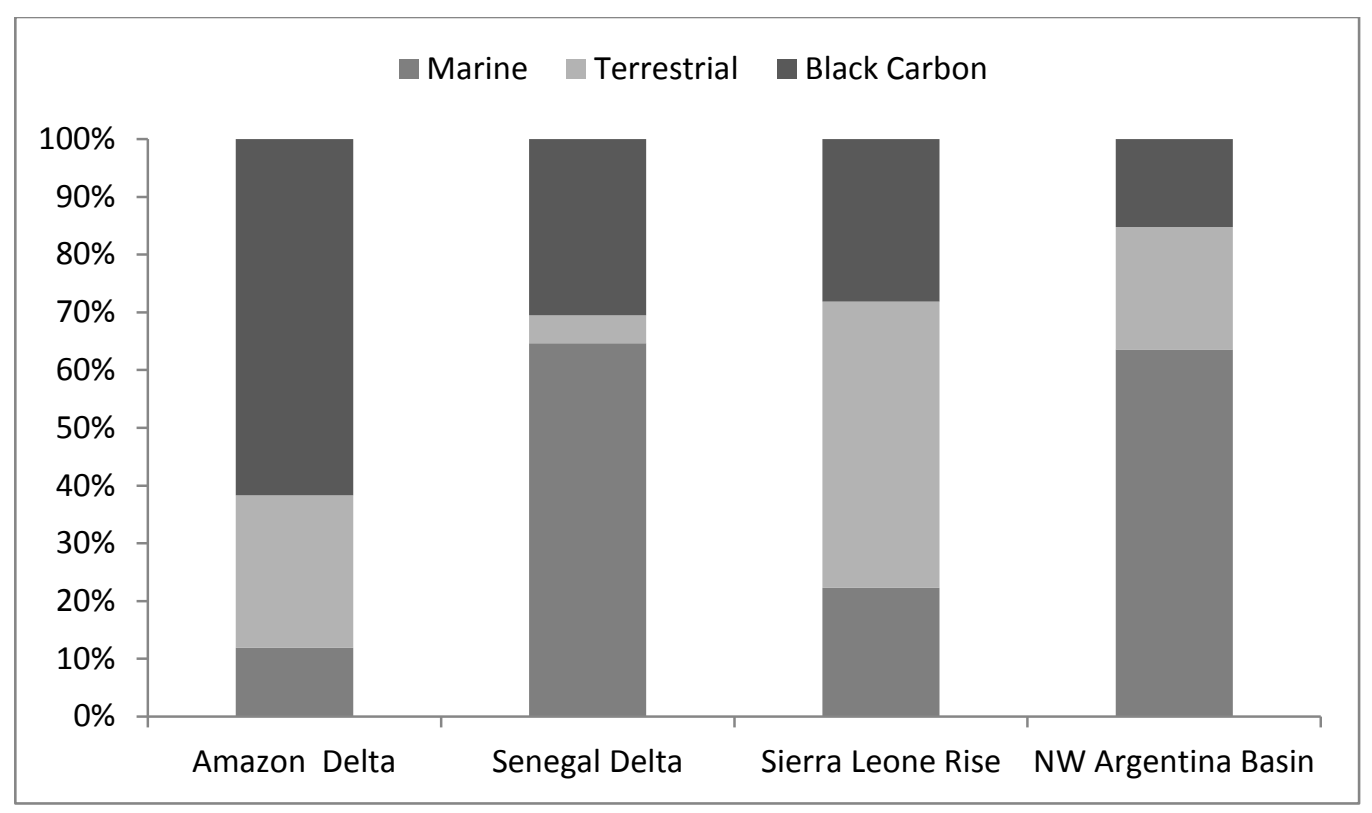

Figure 3. The maximum contribution of marine material required to balance the $\delta^{13} \mathrm{C}$-OC as derived by a weighed mass balance between the $\delta^{13} \mathrm{C}$-TOC and $\delta^{13} \mathrm{C}$ BC. A three end-member model (Eq. 2) was used to estimate the maximum contribution of marine material required to balance the stable carbon isotope of the labile organic carbon fraction. Terrestrial is the sum of $\mathrm{C}_{4}$ and $\mathrm{C}_{3}$ carbon fixation pathways for terrestrial plants. The Niger Delta was removed since its average stable carbon is below that of $100 \% \mathrm{C}_{4}$ plant material, possibly due to kerogen or petroleum inputs. 


\section{Supporting Information}

Significant concentrations of terrestrial organic carbon in tropical Atlantic Ocean sediments

Kari Pohl

Rainer Lohmann

Included in the supporting information are:

Introduction to content of the Supporting Information.

Table S1. All data compiled for the Amazon Delta; core 1 was taken with a multi-core and grab-1 and grab-2 was taken with a Van Veen grab sampler during July 2010 on EN-480.

Table S2. All data compiled for the Niger Delta; GeoB cores were collected using a box corer during February-March 1998 by the German Research Foundation. These sediments were provided by Dr. M. Zabel from Bremen University.

Table S3. All data compiled for the Senegal Delta; GeoB core 4901 was collected using a box corer during April-May 2003 by the German Research Foundation. These sediments were provided by Dr. M. Zabel from Bremen University.

Table S4. Table 4: All data compiled for the Sierra Leone Rise; core 8 and core 9 were taken with a multi-core and grabs 5-7 were collected with a Van Veen grab sampler during EN-481 during the summer of 2010.

Table S5. All data compiled for the Northwest (NW) Argentina basin; GeoB 2814 was collected with a box corer during July-August of 1994 by the German Research Foundation and were provided by Dr. M. Zabel from Bremen University.

Table S6. Regional organic carbon contribution estimates to pelagic sediments. These estimates represent the lowest percentage of marine material required to achieve a mass balance of the labile organic carbon fraction.

Table S7. Auxiliary data including the collection date, sampling coordinates, location, and water depth of all sediments analyzed in this study.

Figure S1. Scatter plot of all sediment carbon concentrations (\%) versus the stable carbon isotope ratio $\left(\delta^{13} \mathrm{C}\right)$ for the total organic carbon (TOC), black carbon (BC), and labile organic carbon (OC) fractions. 


\section{Introduction}

This supporting information provides all data used to derive the regionally averaged sedimentary concentrations of black carbon (BC), total organic carbon (TOC), and thermally labile organic carbon (OC) as defined as the difference between the TOC and $\mathrm{BC}$ fractions. It also includes the stable carbon isotope $\left(\delta^{13} \mathrm{C}\right)$ for the $\mathrm{BC}, \mathrm{TOC}$, and weighed mass balance derived OC. Additional information on the collection and storage of the GeoB sediment cores can be found at the global inventory

www.pangaea.de.

\begin{tabular}{|c|c|c|c|c|c|c|c|c|}
\hline $\begin{array}{c}\text { Amazon } \\
\text { Delta }\end{array}$ & $\begin{array}{c}\text { Depth } \\
\text { (cmbsf) }\end{array}$ & $\begin{array}{c}\delta^{13} \mathrm{C}- \\
\text { TOC (\%) }\end{array}$ & $\begin{array}{c}\delta^{13} \mathrm{C}-\mathrm{BC} \\
(\%)\end{array}$ & $\begin{array}{c}\% \\
\text { TOC }\end{array}$ & $\begin{array}{c}\% \\
\text { BC }\end{array}$ & $\begin{array}{c}\% \\
\text { OC }\end{array}$ & $\begin{array}{c}\delta^{13} \mathrm{C}-\mathrm{OC} \\
(\%)\end{array}$ & BC/TOC \\
\hline \multirow[t]{10}{*}{ Core 1} & 1 & -20 & -32 & 0.49 & 0.31 & 0.18 & 1.37 & 0.64 \\
\hline & 2.5 & -20 & -32 & 0.57 & 0.36 & 0.21 & -0.73 & 0.63 \\
\hline & 3.5 & -21 & -30 & 0.52 & 0.34 & 0.18 & -4.51 & 0.66 \\
\hline & 4.5 & -24 & -30 & 0.62 & 0.28 & 0.34 & -18.63 & 0.45 \\
\hline & 6.5 & -21 & -30 & 0.58 & 0.25 & 0.33 & -14.03 & 0.43 \\
\hline & 7.5 & -23 & -33 & 0.37 & 0.13 & 0.24 & -16.98 & 0.35 \\
\hline & 8.5 & -22 & -33 & 0.38 & 0.35 & 0.03 & 101.00 & 0.92 \\
\hline & 9.5 & -22 & -35 & 0.41 & 0.31 & 0.11 & 15.29 & 0.74 \\
\hline & 10.5 & -21 & -28 & 0.49 & 0.17 & 0.32 & -16.96 & 0.34 \\
\hline & 11.5 & -21 & -28 & 0.37 & 0.10 & 0.27 & -18.24 & 0.27 \\
\hline \multirow[t]{5}{*}{ Grab 1} & 1 & -18 & -33 & 0.64 & 0.82 & $\begin{array}{c}- \\
0.18\end{array}$ & -84.95 & 1.28 \\
\hline & 1 & -14 & -30 & 0.74 & 0.51 & 0.23 & 19.51 & 0.69 \\
\hline & 1 & -18 & -36 & 0.65 & 0.75 & $\begin{array}{c}- \\
0.10\end{array}$ & -149.52 & 1.16 \\
\hline & 1 & -19 & -28 & 0.88 & 0.44 & 0.44 & -9.84 & 0.50 \\
\hline & 1 & -19 & -22 & 0.94 & 0.25 & 0.69 & -17.46 & 0.27 \\
\hline Grab 2 & 1 & -18 & -23 & 0.60 & 0.10 & 0.50 & -16.84 & 0.17 \\
\hline
\end{tabular}

Table S1: All data compiled for the Amazon Delta; core 1 was taken with a multi-core and grab-1 and grab-2 was taken with a Van Veen grab sampler during July 2010 on EN-480. 


\begin{tabular}{|c|c|c|c|c|c|c|c|c|}
\hline $\begin{array}{l}\text { Niger } \\
\text { Delta }\end{array}$ & $\begin{array}{c}\text { Depth } \\
\text { (cmbsf) }\end{array}$ & $\begin{array}{c}\delta^{13} \mathrm{C}-\mathrm{TOC} \\
(\% \mathrm{o})\end{array}$ & $\begin{array}{c}\delta^{13} \mathrm{C}-\mathrm{BC} \\
(\%)\end{array}$ & $\%$ TOC & $\% \mathrm{BC}$ & $\% \mathrm{OC}$ & $\begin{array}{c}\delta^{13} \mathrm{C}-\mathrm{OC} \\
(\%)\end{array}$ & BC/TOC \\
\hline \multirow[t]{11}{*}{$\begin{array}{c}\text { GeoB } \\
4901\end{array}$} & 4.5 & -2 & -6 & 1.49 & 0.96 & 0.53 & 3.21 & 0.65 \\
\hline & 8.5 & -20 & -37 & 1.39 & 0.95 & 0.44 & 16.63 & 0.68 \\
\hline & 13.5 & -20 & -34 & 1.23 & 1.01 & 0.22 & 43.74 & 0.82 \\
\hline & 20.5 & -20 & -33 & 1.30 & 1.00 & 0.30 & 24.78 & 0.77 \\
\hline & 26.5 & -20 & -35 & 1.40 & 0.81 & 0.59 & 0.68 & 0.58 \\
\hline & 32.5 & -21 & -31 & 1.34 & 0.70 & 0.64 & -9.55 & 0.52 \\
\hline & 69.5 & -20 & -33 & 1.30 & 0.73 & 0.57 & -2.95 & 0.56 \\
\hline & 100.5 & -19 & -35 & 1.27 & 0.79 & 0.48 & 7.04 & 0.62 \\
\hline & 109.5 & -19 & -35 & 1.28 & 0.84 & 0.44 & 11.27 & 0.65 \\
\hline & 128.5 & -19 & -33 & 1.49 & 1.21 & 0.28 & 41.08 & 0.81 \\
\hline & 147.5 & -18 & -35 & 1.54 & 0.84 & 0.70 & 1.46 & 0.54 \\
\hline \multirow[t]{11}{*}{$\begin{array}{l}\text { GeoB } \\
4905\end{array}$} & 0.75 & -20 & -23 & 3.21 & 0.45 & 2.76 & -19.94 & 0.14 \\
\hline & 1.25 & -21 & -22 & 3.07 & 0.37 & 2.70 & -21.03 & 0.12 \\
\hline & 1.75 & -21 & -18 & 3.04 & 0.24 & 2.80 & -21.13 & 0.08 \\
\hline & 2.25 & -20 & -30 & 2.67 & 0.20 & 2.47 & -19.71 & 0.07 \\
\hline & 2.75 & -20 & -30 & 2.93 & 0.17 & 2.76 & -19.88 & 0.06 \\
\hline & 3.5 & -20 & -30 & 2.86 & 0.25 & 2.61 & -19.15 & 0.09 \\
\hline & 4.5 & -20 & -18 & 2.69 & 0.25 & 2.44 & -20.06 & 0.09 \\
\hline & 6.25 & -20 & -15 & 2.53 & 0.16 & 2.37 & -19.87 & 0.06 \\
\hline & 8.75 & -20 & -13 & 2.38 & 0.17 & 2.21 & -19.98 & 0.07 \\
\hline & 12.5 & -20 & -14 & 2.41 & 0.15 & 2.25 & -20.35 & 0.06 \\
\hline & 17.5 & -20 & -16 & 2.45 & 0.23 & 2.22 & -20.02 & 0.10 \\
\hline \multirow[t]{9}{*}{$\begin{array}{r}\text { GeoB } \\
4903\end{array}$} & 0.75 & -19 & -24 & 1.38 & 0.81 & 0.57 & -13.49 & 0.59 \\
\hline & 1.25 & -16 & -26 & 1.44 & 1.03 & 0.41 & 7.85 & 0.71 \\
\hline & 1.75 & -19 & -18 & 1.35 & 1.14 & 0.21 & -22.08 & 0.84 \\
\hline & 2.25 & -19 & -22 & 1.35 & 0.69 & 0.66 & -16.58 & 0.51 \\
\hline & 2.75 & -19 & -30 & 1.24 & 0.97 & 0.27 & 19.68 & 0.78 \\
\hline & 3.5 & -19 & -20 & 1.46 & 0.78 & 0.68 & -18.31 & 0.53 \\
\hline & 4.5 & -19 & -22 & 1.31 & 0.77 & 0.54 & -14.93 & 0.59 \\
\hline & 8.75 & -22 & -26 & 1.31 & 0.88 & 0.43 & -13.92 & 0.67 \\
\hline & 12.5 & -16 & -25 & 1.47 & 1.28 & 0.20 & 35.96 & 0.87 \\
\hline \multirow[t]{6}{*}{$\begin{array}{l}\text { GeoB } \\
4901\end{array}$} & 0.75 & -19 & -26 & 1.44 & 0.81 & 0.63 & -9.99 & 0.56 \\
\hline & 1.75 & -19 & -19 & 1.57 & 1.04 & 0.53 & -18.67 & 0.66 \\
\hline & 2.25 & -19 & -23 & 1.77 & 0.93 & 0.83 & -14.01 & 0.53 \\
\hline & 2.75 & -19 & -21 & 1.46 & 0.90 & 0.56 & -15.63 & 0.62 \\
\hline & 3.5 & -19 & -20 & 1.18 & 0.97 & 0.21 & -14.45 & 0.82 \\
\hline & 4.5 & -19 & -19 & 1.49 & 0.96 & 0.53 & -18.07 & 0.65 \\
\hline
\end{tabular}




\begin{tabular}{ccccccccc} 
& 6.25 & -19 & -18 & 1.15 & 0.63 & 0.52 & -19.82 & 0.55 \\
& 8.75 & -19 & -19 & 0.97 & 0.87 & 0.10 & -21.39 & 0.90 \\
\hline GeoB & 12.5 & -19 & -33 & 1.45 & 1.35 & 0.10 & 161.72 & 0.93 \\
& 17.5 & -19 & -32 & 1.58 & 1.30 & 0.28 & 41.19 & 0.82 \\
\hline G904 & 3.5 & -17 & -16 & 2.56 & 0.29 & 2.27 & -17.71 & 0.11 \\
& 4.5 & -18 & -17 & 2.66 & 0.36 & 2.30 & -17.68 & 0.14 \\
& 8.75 & -18 & -28 & 2.30 & 0.71 & 1.59 & -13.17 & 0.31 \\
& 12.5 & -18 & -27 & 2.35 & 0.71 & 1.64 & -13.58 & 0.30 \\
& 17.5 & -18 & -22 & 2.59 & 0.51 & 2.08 & -16.51 & 0.20 \\
\hline 4908 & 0.75 & -19 & -26 & 1.15 & 0.84 & 0.31 & -0.69 & 0.73 \\
& 1.75 & -19 & -31 & 0.95 & 0.79 & 0.16 & 39.34 & 0.83 \\
& 2.25 & -19 & -29 & 0.88 & 0.69 & 0.19 & 15.97 & 0.79 \\
& 2.75 & -19 & -19 & 0.96 & 1.22 & -0.26 & -20.66 & 1.27 \\
& 3.5 & -19 & -29 & 0.85 & 0.74 & 0.11 & 43.97 & 0.86 \\
& 6.25 & -19 & -29 & 0.93 & 0.64 & 0.29 & 2.35 & 0.69 \\
& 8.75 & -19 & -24 & 0.93 & 0.74 & 0.19 & -1.53 & 0.80 \\
& 11.25 & -19 & -28 & 0.92 & 0.75 & 0.17 & 17.67 & 0.81 \\
& 13.75 & -20 & -24 & 1.09 & 0.75 & 0.34 & -9.31 & 0.69 \\
\hline GeoB & 0.75 & -21 & -25 & 1.42 & 0.71 & 0.71 & -16.64 & 0.50 \\
& 1.25 & -20 & -26 & 1.82 & 0.80 & 1.02 & -16.27 & 0.44
\end{tabular}

Table S2: All data compiled for the Niger Delta; GeoB cores were collected using a box corer during February-March 1998 by the German Research Foundation. These sediments were provided by Dr. M. Zabel from Bremen University.

\begin{tabular}{|c|c|c|c|c|c|c|c|c|}
\hline $\begin{array}{c}\text { Senegal } \\
\text { Delta }\end{array}$ & $\begin{array}{c}\text { Depth } \\
\text { (cmbsf) }\end{array}$ & $\begin{array}{c}\delta^{13} \mathrm{C}-\mathrm{TOC} \\
(\%)\end{array}$ & $\begin{array}{c}\delta^{13} \mathrm{C}-\mathrm{BC} \\
(\%)\end{array}$ & \% TOC & $\%$ ВC & $\% \mathrm{OC}$ & $\begin{array}{c}\delta^{13} \mathrm{C}-\mathrm{OC} \\
(\%) \\
\end{array}$ & BC/TOC \\
\hline \multicolumn{9}{|l|}{ GeoB } \\
\hline \multirow[t]{5}{*}{4901} & 1.5 & -20 & -23 & 3.19 & 0.75 & 2.45 & -19.09 & 0.23 \\
\hline & 4.5 & -20 & -17 & 2.22 & 0.82 & 1.41 & -21.74 & 0.37 \\
\hline & 9.5 & -20 & -23 & 2.78 & 0.74 & 2.04 & -18.92 & 0.26 \\
\hline & 14.5 & -19 & -17 & 2.39 & 0.67 & 1.72 & -19.77 & 0.28 \\
\hline & 19.5 & -20 & -26 & 1.93 & 0.73 & 1.20 & -16.33 & 0.38 \\
\hline
\end{tabular}

Table S3: All data compiled for the Senegal Delta; GeoB core 4901 was collected using a box corer during April-May 2003 by the German Research Foundation. These sediments were provided by Dr. M. Zabel from Bremen University. 


\begin{tabular}{ccccccccc}
$\begin{array}{c}\text { Sierra } \\
\text { Leone Rise }\end{array}$ & $\begin{array}{c}\text { Depth } \\
(\mathbf{c m b s f})\end{array}$ & $\begin{array}{c}\boldsymbol{\delta}^{\mathbf{1 3}} \mathbf{C}- \\
\mathbf{T O C}(\mathbf{\%})\end{array}$ & $\begin{array}{c}\boldsymbol{\delta}^{\mathbf{1 3}} \mathbf{C - B C} \\
\mathbf{( \% )}\end{array}$ & $\boldsymbol{\%} \mathbf{T O C}$ & $\boldsymbol{\%} \mathbf{B C}$ & $\boldsymbol{\%} \mathbf{O C}$ & $\begin{array}{c}\boldsymbol{\delta}^{\mathbf{1 3}} \mathbf{C}-\mathbf{O C} \\
\mathbf{( \% )}\end{array}$ & BC/TOC \\
\hline Grab 5a & 0.5 & -17 & -16 & 3.03 & 0.48 & 2.55 & -16.92 & 0.16 \\
\hline Grab 6a & 0.5 & -18 & -21 & 1.55 & 0.42 & 1.13 & -16.08 & 0.27 \\
\hline Grab 7a & 0.5 & -14 & -17 & 1.43 & 0.39 & 1.03 & -13.21 & 0.28 \\
Grab 7b & 0.5 & -14 & -17 & 2.22 & 0.63 & 1.59 & -12.48 & 0.28 \\
Grab 7c & 0.5 & -16 & -19 & 2.09 & 0.46 & 1.63 & -15.39 & 0.22 \\
Grab 7d & 0.5 & -17 & -27 & 2.09 & 0.70 & 1.39 & -12.52 & 0.34 \\
\hline Core 8 & 0.5 & -17 & -20 & 1.68 & 0.14 & 1.54 & -16.31 & 0.08 \\
& 0.5 & -18 & -22 & 1.85 & 0.29 & 1.57 & -17.76 & 0.15 \\
& 0.75 & -17 & -25 & 1.63 & 0.59 & 1.04 & -13.29 & 0.36 \\
\hline Core 9 & 0.5 & -18 & -28 & 1.49 & 0.64 & 0.84 & -9.58 & 0.43 \\
& 1.5 & -17 & -26 & 1.46 & 0.68 & 0.78 & -9.14 & 0.47 \\
& 2.5 & -17 & -30 & 1.54 & 0.90 & 0.64 & 0.59 & 0.58 \\
& 3.5 & -16 & -28 & 1.34 & 0.89 & 0.45 & 6.86 & 0.67 \\
& 4.5 & -17 & -25 & 1.42 & 0.52 & 0.90 & -13.11 & 0.36 \\
& 5.5 & -17 & -22 & 1.22 & 0.52 & 0.70 & -13.31 & 0.43 \\
& 6.5 & -17 & -23 & 1.19 & 0.67 & 0.52 & -9.98 & 0.56 \\
& 8.5 & -16 & -31 & 1.12 & 0.54 & 0.58 & -2.04 & 0.49
\end{tabular}

Table S4: All data compiled for the Sierra Leone Rise; core 8 and core 9 were taken with a multi-core and grabs 5-7 were collected with a Van Veen grab sampler during EN-481 during the summer of 2010. 


\begin{tabular}{ccccccccc}
$\begin{array}{c}\text { NW } \\
\text { Argentina }\end{array}$ & $\begin{array}{c}\text { Depth } \\
(\mathbf{c m b s f})\end{array}$ & $\begin{array}{c}\boldsymbol{\delta}^{\mathbf{1 3}} \mathbf{C}- \\
\mathbf{T O C}(\mathbf{\%})\end{array}$ & $\begin{array}{c}\boldsymbol{\delta}^{\mathbf{1 3}} \mathbf{C - B C} \\
\mathbf{( \% )}\end{array}$ & $\boldsymbol{\%} \mathbf{T O C}$ & $\boldsymbol{\%} \mathbf{B C}$ & $\boldsymbol{\%} \mathbf{O C}$ & $\begin{array}{c}\boldsymbol{\delta}^{\mathbf{1 3}} \mathbf{C}-\mathbf{O C} \\
\mathbf{( \% )}\end{array}$ & BC/TOC \\
\hline $\mathbf{G e o B}$ & 0.75 & -23 & -26 & 0.76 & 0.12 & 0.65 & -22.13 & 0.15 \\
$\mathbf{2 8 1 4}$ & 1.25 & -23 & -25 & 0.75 & 0.08 & 0.67 & -22.19 & 0.11 \\
& 1.75 & -21 & -24 & 0.60 & 0.14 & 0.46 & -20.71 & 0.23 \\
& 3 & -22 & -24 & 0.75 & 0.08 & 0.67 & -21.46 & 0.11 \\
& 6 & -23 & -26 & 0.68 & 0.11 & 0.57 & -22.85 & 0.17 \\
& 10 & -23 & -24 & 0.49 & 0.06 & 0.43 & -22.67 & 0.13 \\
& 14 & -24 & -26 & 0.64 & 0.11 & 0.53 & -23.94 & 0.17 \\
& 18.5 & -24 & -32 & 0.74 & 0.12 & 0.62 & -22.09 & 0.16 \\
& 23 & -23 & -26 & 0.63 & 0.11 & 0.52 & -22.66 & 0.17 \\
& 27 & -23 & -27 & 0.78 & 0.10 & 0.68 & -22.40 & 0.13 \\
& 31 & -23 & -23 & 0.71 & 0.10 & 0.61 & -22.81 & 0.14
\end{tabular}

Table S5: All data compiled for the Northwest (NW) Argentina basin; GeoB 2814 was collected with a box corer during July-August of 1994 by the German Research Foundation and were provided by Dr. M. Zabel from Bremen University.

\begin{tabular}{c|ccc} 
Region & Marine & Terrestrial & Black Carbon \\
\hline Amazon Delta & $12 \%$ & $26 \%$ & $62 \%$ \\
Senegal Delta & $65 \%$ & $5 \%$ & $31 \%$ \\
Sierra Leone Rise & $22 \%$ & $50 \%$ & $28 \%$ \\
NW Argentina Basin & $64 \%$ & $21 \%$ & $15 \%$
\end{tabular}

Table S6: Regional organic carbon contribution estimates to pelagic sediments. These estimates represent the lowest percentage of marine material required to achieve a mass balance of the labile organic carbon fraction. 


\begin{tabular}{|c|c|c|c|c|c|}
\hline $\begin{array}{l}\text { Sediment } \\
\text { ID }\end{array}$ & $\begin{array}{c}\text { Sampling } \\
\text { Month/Year }\end{array}$ & Latitude & Longitude & Location & $\begin{array}{c}\text { Water Depth } \\
(\mathbf{m})\end{array}$ \\
\hline Core 1 & July 2010 & 4.282778 & -47.484444 & Amazon Delta & 2365 \\
\hline Grab 1 & July 2010 & 5.915833 & -45.001111 & Amazon Delta & 3545 \\
\hline Grab 2 & July 2010 & 6.168333 & -44.8525 & Amazon Delta & 3999 \\
\hline Grab 5a & August 2010 & 0.485556 & -23.1225 & $\begin{array}{l}\text { Sierra Leone } \\
\quad \text { Rise }\end{array}$ & 3567 \\
\hline Grab 6a & August 2010 & 7.003889 & -20.795278 & $\begin{array}{l}\text { Sierra Leone } \\
\quad \text { Rise }\end{array}$ & 3853 \\
\hline Grab 7a & August 2010 & 5.018056 & -21.243611 & $\begin{array}{l}\text { Sierra Leone } \\
\quad \text { Rise }\end{array}$ & 2811 \\
\hline Grab 7b & August 2010 & 4.968889 & -21.201667 & $\begin{array}{l}\text { Sierra Leone } \\
\text { Rise }\end{array}$ & 2787 \\
\hline Grab 7c & August 2010 & 5.005833 & -21.250556 & $\begin{array}{l}\text { Sierra Leone } \\
\text { Rise }\end{array}$ & 2794 \\
\hline Core 8 & August 2010 & 4.560833 & -24.509167 & $\begin{array}{l}\text { Sierra Leone } \\
\text { Rise }\end{array}$ & 4030 \\
\hline Core 9 & August 2010 & 7.435278 & -24.010556 & $\begin{array}{l}\text { Sierra Leone } \\
\text { Rise }\end{array}$ & 4065 \\
\hline GeoB 4901 & February/March 1998 & 2.668889 & 6.717222 & Niger Delta & 2180 \\
\hline GeoB 4903 & February/March 1998 & 1.916667 & 8.166944 & Niger Delta & 2834 \\
\hline GeoB 4904 & February/March 1998 & 0.95 & 8.8 & Niger Delta & 1208 \\
\hline GeoB 4905 & February/March 1998 & 2.5 & 9.384444 & Niger Delta & 2184 \\
\hline GeoB 4907 & February/March 1998 & -0.584722 & 8.018333 & Niger Delta & 2060 \\
\hline GeoB 4908 & February/March 1998 & -0.701667 & 6.834167 & Niger Delta & 3028 \\
\hline GeoB 9501 & April/May 2003 & 16.834444 & -16.719167 & Senegal Delta & 330 \\
\hline GeoB 2814 & July/August 1994 & $\begin{array}{c}- \\
37.618056\end{array}$ & -39.116667 & NW Argentina & 4949 \\
\hline
\end{tabular}

Table S7: Auxiliary data including the collection date, sampling coordinates, location, and water depth of all sediments analyzed in this study. 


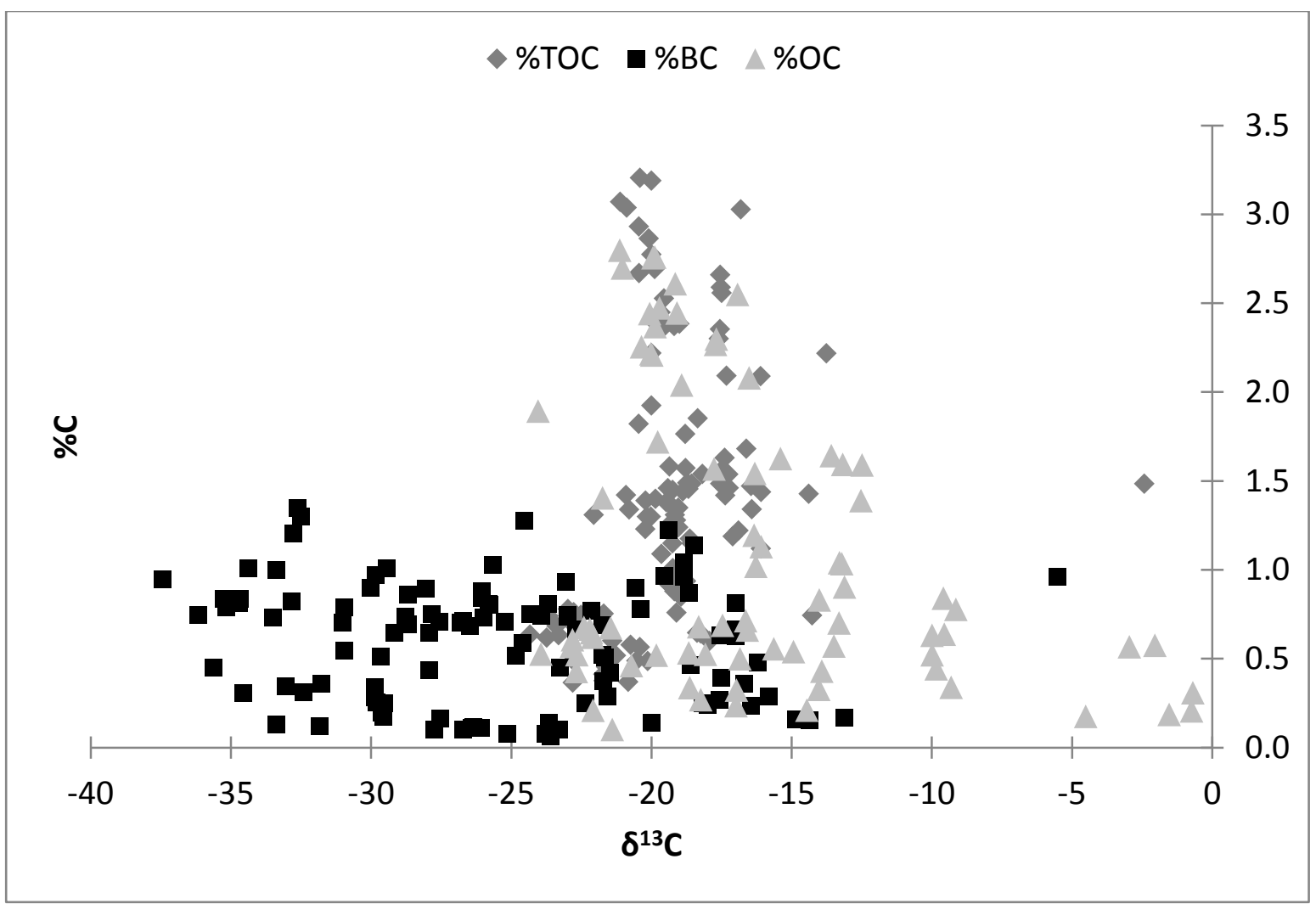

Figure S1: Scatter plot of all sediment carbon concentrations (\%) versus the stable carbon isotope ratio $\left(\delta^{13} \mathrm{C}\right)$ for the total organic carbon (TOC), black carbon (BC), and labile organic carbon (OC) fractions. 


\section{CHAPTER 4}

\section{Black carbon concentrations and sources in the marine boundary layer of the tropical Atlantic Ocean using four methodologies}

This manuscript has been accepted for publication and is formatted for the journal Atmospheric Chemistry and Physics

K. Pohl ${ }^{1}$, M. Cantwell ${ }^{2}$, P. Herckes ${ }^{3}$, R. Lohmann ${ }^{1} *$

${ }^{1}$ Graduate School of Oceanography-University of Rhode Island, Narragansett, RI, USA

${ }^{2}$ U.S. Environmental Protection Agency-Atlantic Ecology Division, Narragansett, RI, USA

${ }^{3}$ Department of Chemistry and Biochemistry, Arizona State University, Tempe, AZ, USA

* Corresponding author: (email: rlohmann@mail.uri.edu ; Tel: 401-874-6612; Fax: 401-874-6811) 


\begin{abstract}
Combustion-derived aerosols in the marine boundary layer have been poorly studied, especially in remote environments such as the open Atlantic Ocean. The tropical Atlantic has the potential to contain a high concentration of aerosols, such as black carbon, due to the African emission plume of biomass and agricultural burning products. Atmospheric particulate matter samples across the tropical Atlantic boundary layer were collected in the summer of 2010 during the Southern Hemispheric dry season when open fire events were frequent in Africa and South America. The highest black carbon concentrations were detected in the Caribbean Sea and within the African plume, with a regional average of $0.6 \mu \mathrm{g} \mathrm{m}{ }^{-3}$ for both. The lowest average concentrations were measured off the coast of South America at 0.2 to $0.3 \mu \mathrm{g} \mathrm{m}{ }^{-3}$. Samples were quantified for black carbon using multiple methods to provide insights into the form and stability of the carbonaceous aerosols (i.e. thermally unstable organic carbon, soot-like, and charcoal-like). Soot-like aerosols composed up to $45 \%$ of the carbonaceous aerosols in the Caribbean Sea to as little as $4 \%$ within the African Plume. Charcoal-like aerosols composed up to $29 \%$ of the carbonaceous aerosols over the oligotrophic Sargasso Sea, suggesting that non-soot-like particles could be present in significant concentrations in remote environments. To better apportion concentrations and forms of black carbon, multiple detection methods should be used, particularly in regions impacted by biomass burning emissions.
\end{abstract}




\section{Introduction}

Black carbon (BC) is the byproduct of the incomplete combustion of biomass and fossil fuels that is composed of highly condensed matrices of aromatic sheets (Goldberg, 1985). It has the potential for long range atmospheric transport which makes it ubiquitous in the environment (Ogren and Charlson, 1983; Chuang et al., 2002; Masiello, 2004). Atmospheric BC is an important forcing factor with respect to climate change, second only to carbon dioxide (Husain et al., 2007; Bond et al., 2013; Novakov and Rosen, 2013). Its optical properties make it a strong absorber of incident sunlight and its deposition to the ocean is a potential long-term sink for fixed carbon and organic pollutants (Schmidt and Noack, 2000; Forbes et al., 2006). Black carbon is rarely measured in remote environments causing aerosol models such as MOGUNTIA, NCAR GM3, GISS ModelE, and ECHAM5-HAM-OM1 to deal with significant uncertainty in ground-truthing their predictions (Lohmann et al., 2009). Instead, results are often extrapolated to estimate $\mathrm{BC}$ concentrations in these remote regions. This uncertainty is further exacerbated by the fact that $\mathrm{BC}$ results are operationally defined by the selected analytical method (Schmidt et al., 2001; Andreae and Gelencser, 2006).

Combustion-derived aerosols in the marine boundary layer have been poorly investigated. Field investigations in the North Atlantic have determined that a 'clean air' background concentration of black carbon ranges from 20-40 $\mathrm{ng} \mathrm{m}^{-3}$, demonstrating that black carbon is ubiquitous even in remote marine systems (Cavalli et al., 2004; O'Dowd et al., 2004). Peak concentrations of black carbon in the remote marine boundary layer have been reported up to $600 \mathrm{ng} \mathrm{m}^{-3}$ in the Azores 
(summertime) and $300 \mathrm{ng} \mathrm{m}^{-3}$ in the Indian Ocean (Corrigan et al., 2008; Spracklen et al., 2008). The tropical Atlantic Ocean has the potential to contain even greater BC concentrations due to the intense emission plume originating from equatorial Africa. Simulations from the NCAR GM3 model coupled to IMPACT have projected that one of the strongest anthropogenic surface $\mathrm{BC}$ signals is confined in-between $0-40^{\circ} \mathrm{N}$ as a result of African biomass and fossil fuel emissions (Liu et al., 2009).

The subtropical Atlantic Ocean is expected to have elevated BC concentrations due to this African emission plume, which is a combination of intense grassland and agricultural burning transported off-shore by easterly winds (Chester et al., 1979; Perry et al., 1997; Bond et al., 2004; Ramanathan and Carmichael, 2008; Koch et al., 2009; Lohmann et al., 2009). High concentrations of water soluble biomass burning products created by this intercontinental plume, which can be seen in satellite images, are horizontally ejected into the planetary boundary layer below $6 \mathrm{~km}$ (Talbot et al., 1986). Model simulations by the LMD GCM model have predicted that the residence time of $\mathrm{BC}$ aerosols generated from Africa is approximately 7 days compared to 5 days from South America, representing $10 \%$ and $6 \%$ of the global mean BC emissions, respectively (Reddy and Boucher, 2007). This emission plume has the potential to contain high concentrations of fire-derived aerosols with atmospheric residence times sufficient for significant remote marine boundary layer concentrations.

Analytical methods to measure BC are classified into numerous different approaches: light absorption, thermal radiation, thermal carbon evolution, Raman Spectroscopy, 
and mircoscopy, with some hybridization of these approaches (Schmidt and Noack, 2000; Currie et al., 2002; Petzold et al., 2013). Black carbon is composed of various forms classified by its thermal recalcitrance, ranging from less stable charcoal to the highly refractory soot (Masiello, 2004; Elmquist et al., 2006). Charcoal is the solid combustion residue that retains some cellular characteristics of its parent material (Schmidt and Noack, 2000). It will be oxidized when exposed to a significant combination of heat and oxygen, thus methods that utilize high temperature combustion to isolate BC will result in a loss of charcoal (Forbes et al., 2006). Soot particles are formed by the re-condensation of volatiles during combustion. Generally, soot is smaller than charcoal (typically $<1 \mu \mathrm{m}$ ), thus is expected to be a dominant fraction in remote environments due to enhanced export (Andreae et al., 1983; Masiello, 2004; Lohmann et al., 2009). However, micro-charcoal has been found and well studied in deep sediment cores. It is often used as a paleo-fire proxy for ecosystem reconstructions (Verardo and Ruddiman, 1996; Hoetzel et al., 2013).

The application of multiple BC analytical methods, such as chemothermal oxidation, thermal optical transmittance, pyrene fluorescence loss, and optical transmission attenuation, offers unique insights into the form and spatial trend of the various components of the BC combustion continuum (Masiello, 2004). The BC combustion continuum implies that $\mathrm{BC}$ is an operational definition of various forms of carbonaceous combustion byproducts which are classified by formation temperature, size, reactivity, and remnants of original organic material. It ranges from the solid residues of combustion termed charcoal to the re-condensed volatile aromatic 
structures termed soot. A multi-analytical approach is optimal in determining the fraction of soot-like and charcoal-like combustion-derived aerosols in poorly studied regions, such as the tropical Atlantic. Both the chemothermal oxidation and thermal optical transmittance methods evolve the less refractory carbon constituents; the remaining carbon quantified is termed elemental carbon (Zencak et al., 2007; Gustafsson et al., 2009). Elemental carbon consists of highly reduced, graphitic-like, combustion-derived aerosols that is methodologically defined as a structure that will be oxidized at temperatures upward to $\sim 800^{\circ} \mathrm{C}$ (Birch and Cary, 1996; Lavanchy et al., 1999; Sharma et al., 2004; Park et al., 2006; Chow et al., 2009; Dutkiewicz et al., 2009). The pyrene fluorescence loss and optical transmission attenuation methods do not use gas evolution to isolate the refractory combustion-derived aerosols, thus have the potential to measure less stable combustion-derived aerosols, such as charcoal and macromolecular organics (Flores-Cervantes et al., 2009).

We hypothesize that (1) black carbon would be elevated in the tropical Atlantic boundary layer compared to other remote environments due to the African emission plume, (2) soot would be the dominant fraction of black carbon, and (3) the use of multiple methods would enable us to assess the relative proportions of the combustion-derived aerosols present i.e. charcoal-like versus soot-like aerosols.

\section{Materials and Methods}

\subsection{Sample Collection}


A high volume air sampler (Tisch Environmental Model TE-PNY1123) was used to collect total suspended particulate samples on QM-A quartz fiber filters (QFF) on the $R / V$ Endeavor cruises EN-479 to EN-482 during the summer (July-August) of 2010 (Table 1). Filters were precombusted $\left(450^{\circ} \mathrm{C}\right)$ before use and stored in precombusted aluminum foil in a freezer at $-10^{\circ} \mathrm{C}$. An average of $500 \mathrm{~m}^{3}$ of air was filtered per QFF at a flow rate of $0.42 \mathrm{~m}^{3} \mathrm{~min}^{-1}$ for QFF 1-12 and thereafter an average air volume of $3860 \mathrm{~m}^{3}$ at a flow rate of $1.35 \mathrm{~m}^{3} \mathrm{~min}^{-1}$ was filtered when we adjusted the flow to increase the sample size. Each filter sampled for approximately 20 hours (QFFs 1-12) and 48 hours (QFFs 13-24) and had an exposed area of $414 \mathrm{~cm}^{2}$. Sampling was conducted when underway and was stopped when wind direction blew exhaust towards our sampler and during stationary periods. After a sample was collected, filters were returned to the foil and freezer until analysis. Four laboratory blanks and two field blanks, of which $1 \mathrm{~m}^{3}$ of air was sampled, were also collected. All blanks were treated identically to sample QFFs.

Atmospheric BC samples were collected from four regions: The Caribbean Sea (QFF 1-9; QFF 11-13), South America (QFF 9-10; QFF 14), the African Plume (QFF 1519), and the subtropical Atlantic (QFF 20-24). We note that QFF-9 was placed in both the Caribbean and South America since we had crossed the inter-tropical convergence zone during sampling (Table 1). The NOAA HYSPLIT (HYbrid Single-Particle Lagrangian Integrated Trajectory) model was used to estimate the wind backward trajectory $(20 \mathrm{~m})$ at the end time of each sample extending for ten days (Draxler and 
Rolph, 2013; Rolph, 2013; Figure 1). Based on back trajectories, the inter-tropical convergence zone was around $10^{\circ} \mathrm{N}$.

\subsection{Chemothermal oxidation at $375^{\circ} \mathrm{C}(\mathrm{CTO}-375)$}

Duplicates of a $2.4 \mathrm{~cm}^{2}$ punch from each filter sample were acidified for 24 hours with hydrochloric acid vapors to remove carbonate carbon. Filters were then oxidized in a Barnstead Thermolyne muffle oven at $375^{\circ} \mathrm{C}$ with a steady flow of high purity air following the procedure by Gustafsson et al. (1997) and Gelinas et al. (2001). Samples were pelletized in $30 \mathrm{~mm}$ diameter tin discs then analyzed on a Carlo Erba elemental analyzer coupled to a GV Optima 588 system isotope ratio mass spectrometer (IRMS) to determine carbon concentration and $\delta^{13} \mathrm{C}$ value. Total organic carbon (nonoxidized but acidified $2.4 \mathrm{~cm}^{2}$ filter punches) was also quantified. The detection limit for the instrument was $0.1 \mu \mathrm{g}$ of carbon. Carbon values quantified with the CTO-375 method will be denoted as $\mathrm{EC}_{\text {Сто }}$.

\subsection{Thermal Optical Transmittance}

Samples were measured by the thermal optical transmittance (TOT) method for EC $\left(\mathrm{EC}_{\mathrm{TOT}}\right)$ at Arizona State University. A thermal-optical instrument (Sunset laboratory TOT analyzer, NIOSH protocol) detects both the organic carbon and $\mathrm{EC}_{\mathrm{TOT}}$ concentrations using one filter (adapted from Birch and Cary, 1996) and has a detection limit of $0.1 \mu \mathrm{g} \mathrm{cm}^{-2}$. Organic carbon was analyzed with varying time steps between $60 \mathrm{~s}$ and $200 \mathrm{~s}$ during the organic carbon evolution at 310,475, 615, and $870^{\circ} \mathrm{C}$ in an inert atmosphere. This was followed by the $\mathrm{EC}_{\mathrm{TOT}}$ analysis with 
temperature profiles of $550,625,700,775$, and $850^{\circ} \mathrm{C}$ with hold time of $45 \mathrm{~s}$ and a final hold at $870^{\circ} \mathrm{C}$ for $120 \mathrm{~s}$ in an oxidizing environment (Adapted from Birch and Carey, 1996). In the TOT method, any pyrolytic carbon formation is corrected by optical transmission measurements, however, in the present study, no pyrolytic carbon formation was observed. Samples 1 and 22-24 were not quantified via TOT since filters shrank during analysis, suggesting they were glass filters. We will still refer to these samples as QFFs in text.

\subsection{Pyrene Fluorescence Loss}

The initial fluorescence of a $1 \mu \mathrm{g} \mathrm{L}^{-1}$ aqueous pyrene solution with $0.05 \mathrm{M}$ sodium azide was measured using an RF-1501 Shimadzu fluorometer in the emission range of 300 to $450 \mathrm{~nm}$ with excitation at $275 \mathrm{~nm}$. Five aqueous pyrene standards with concentrations ranging from 0.5 to $2.0 \mu \mathrm{g} \mathrm{L} \mathrm{L}^{-1}$ were used to produce a calibration curve $\left(\mathrm{R}^{2}=0.99\right)$. Duplicates of a $1.5 \mathrm{~cm}$ diameter punch were added to the pyrene spiked MilliQ water and placed on a shaker table in a closed $50 \mathrm{~mL}$ amber vial to equilibrate for 30 days at ambient conditions (Flores-Cervantes et al., 2009). The final fluorescence was measured and used to calculate the $\mathrm{BC}$ concentration $\left(\mathrm{BC}_{\mathrm{PFL}}\right)$ as outlined by Flores-Cervantes et al. (2009). The methodological detection limit was 0.1 $\mu \mathrm{g} \mathrm{cm}^{-2}$ of $\mathrm{BC}_{\mathrm{PFL}}$ (methodological information in Supplementary Materials).

\subsection{Optical transmission attenuation (OT-21)}

Filter samples were analyzed for $\mathrm{BC}\left(\mathrm{BC}_{\mathrm{OT} 21}\right)$ at Magee Scientific in Berkeley, California using the optical Transmissometer Model OT21. This instrument measured 
the light attenuation through a $25 \mathrm{~mm}$ diameter punch of each QFF at the a wavelength of $880 \mathrm{~nm}$, and compared it to that of a blank filter using an absorption coefficient of $16.6 \mathrm{~m}^{2} \mathrm{~g}^{-1}$ to convert the absorbance to a $\mathrm{BC}_{\mathrm{OT} 21}$ concentration. (Husain et al., 2007; Ahmed et al., 2009; Dutkiewicz et al., 2009). and an The detection limit was $0.06 \mu \mathrm{g}$ $\mathrm{cm}^{-2}$

\subsection{Methodological Comparisons}

We applied multiple methods to quantify $\mathrm{EC}$ and $\mathrm{BC}$ concentrations to gain insights into the forms (charcoal, soot), long range transport capability, and recalcitrance of combustion-derived aerosols in a remote environment. The CTO-375 method has been shown to detect only the most reduced and condensed EC forms since the thermal oxidization process will volatilize the less thermally stable forms of $\mathrm{BC}$, such as charcoal (Flore-Cervantes et al., 2009). Thus, the measured $\mathrm{EC}_{\mathrm{CTO}}$ has been termed in the literature soot-like carbon since it detects only the most refractory and structurally ordered portion of the BC combustion continuum (Gustafsson et al., 1997; Masiello 2004; Lohmann et al., 2009; Han et al., 2013).

Similarly, the TOT method also uses high temperature treatments to quantify the fraction of EC present in aerosols. The TOT method was originally developed, in part, to detect diesel exhaust particles, which are generally more graphitized than biomass burning carbonaceous byproducts due to the lower oxygen to fuel ratio (Birch and Cary, 1996; Schmidt and Noack, 2000; Elmquist et al., 2006; Keiluweit et al., 2010). It is projected that the CTO-375 and TOT methods will give insight into the more 
reduced, thermally stable, and environmentally persistent forms of soot-like EC produced by the condensation of volatiles during combustion (Hammes et al., 2007). Typically, the CTO-375 quantifies a lower EC concentration compared to the TOT method on the same sample since it represents only the soot fraction of EC (Han et al., 2013).

The CTO-375 and TOT methods, in addition to quantifying the more thermally stable and lower volatile EC fraction of the combustion continuum, also measure the concentration of organic carbon. Thus, implementing these two thermally-based detection methods allows for an additional inter-method comparison of the presence of the thermally unstable primary and secondary organic aerosols. Additionally, the CTO-375 method allows for the measurement of the stable carbon isotope ratio, allowing for source apportionment between the organic carbon and EC fractions.

The novel pyrene fluorescence loss technique does not have a thermal bias and is suggested to detect a broader portion of the $\mathrm{BC}$ combustion continuum, including charcoal-like fractions. This pyrene fluorescence loss method has been shown to report black carbon in grass and wood chars while the CTO-375 method routinely oxidizes the entire sample (Flores-Cervantes et al., 2009). The PFL method utilizes the chemical adsorption of pyrene to black carbon particles and has been demonstrated to quantify the solid residue combustions byproducts, i.e. charcoal, in addition to condensed volatiles, i.e. soot. Likewise, the OT-21 method uses an optical approach 
and the wavelength of $880 \mathrm{~nm}$ has been show to quantify larger fractions of forest fireproduced aerosols in comparison to the TOT method (Jeong et al., 2004).

We propose that the PFL and OT-21 methods will detect a broader spectrum of combustion-derived byproducts whereas the CTO-375 and TOT methods are optimized to quantify only the soot and non-volatile fractions. Differences between quantified EC (CTO-375 and TOT) and BC (PFL and OT-21) values for the same sample would suggest the presence of non-soot-like carbon. Alternatively, similar values between these four methods would suggest that soot-like carbon dominated in the samples.

\subsection{Quality Control and Quality Assurance}

Quality control and assurance was assessed on all QFF samples using a combination of blanks and standard reference materials. Field and laboratory blank QFFs were treated and handled identically to all samples. No carbon was detected on blank QFFs for the pyrene fluorescence loss method. We note that optical transmission attenuation corrects for the blank as part of the protocol. Carbon was detected on blank filters for the CTO-375 and TOT techniques. There was no difference found between the field and laboratory blanks. We subtracted the average blank BC concentration of $1.7 \pm 0.5$ $\mu \mathrm{g} \mathrm{cm}^{-2}$ for the CTO-375 method and $0.04 \pm 0.1 \mu \mathrm{g} \mathrm{cm}^{-2}$ for the TOT method from each sample. We hypothesized that this inherent carbon was entrained inside of the filters, and was liberated during the high temperate oxidation step. We confirmed in follow-up experiments that the blank associated carbon remained constant regardless 
of the air volume filtered. A laboratory GFF blank was also quantified via pyrene fluorescence loss and CTO-375. No $\mathrm{BC}_{\mathrm{PFL}}$ was detected and an $\mathrm{EC}_{\mathrm{CTO}}$ value of $2.6 \pm$ $0.4 \mu \mathrm{g} \mathrm{cm}^{-2}$ was produced. We note that samples 1 and $22-24$ could have had a higher associated blank carbon value if they were GFF instead of QFF filters.

Methodological quality control was assessed using the NIST standard reference material NIST 1649a (urban dust). The international standard grass char was also used for the CTO-375 method only as suggested by the BC ring trial (Hammes et al., 2007). Elemental carbon mass fractions for the CTO-375 method were within the expected range for NIST $1649 \mathrm{a}$ at $2.7 \pm 0.1 \%$. An insufficient mass of the grass char was recovered, as expected, since the CTO-375 is optimized to measure the soot-like fraction and chars are oxidized (Gustafsson et al., 1997; Flores-Cervantes et al., 2009). The absence of grass char recovery suggests that methodological charring did not occur. Higher $\mathrm{BC}_{\mathrm{PFL}}$ concentrations were detected with NIST 1649a (7.9\%) using the pyrene fluorescence loss method, which was expected (Flores-Cervantes et al., 2009). The TOT method produced an expected median value of $4.2 \pm 0.4 \%$ (Currie et al., 2002). Precombusted sand blanks were also used for the CTO-375 and pyrene fluorescence loss methods with no carbon detected. Statistical analyses were conducted using the data analysis tool in Microsoft EXCEL.

\section{Results and Discussion}

\subsection{Regional trends for black carbon with respect to the total organic carbon}

\subsubsection{General black carbon concentrations and trends}


The highest $\mathrm{BC}$ concentrations were found in the Caribbean Sea and the African Plume (Table 3; Figure 1). Concentrations of BC for the Caribbean Sea ranged from below instrumental detection limit (of all quantification methods) to $3.4 \mu \mathrm{g} \mathrm{m}^{-3}$ and had an average regional concentration of $0.6 \pm 0.4 \mu \mathrm{g} \mathrm{m}^{-3}$. Black carbon concentrations for the African Plume, located in the remote equatorial Atlantic, had an equivalent average concentration of $0.6 \pm 0.4 \mu \mathrm{g} \mathrm{m} \mathrm{m}^{-3}$ with concentrations ranging from below detection limit to $1.4 \mu \mathrm{g} \mathrm{m}^{-3}$. We had anticipated the greatest concentrations in the region to be impacted by the African Plume; however, we had not expected the Caribbean Sea to have the overall highest measured BC concentrations. Samples collected from the Caribbean Sea were closest to land, suggesting that local urban burning could have dominated the regional tropical marine boundary layer (Duncan et al., 2003). The samples collected in the African Plume were between 815-1700 km directly removed from land, and at least $4300 \mathrm{~km}$ away from the projected source region of the African Savanna according to the backward wind trajectories.

Black carbon concentrations were lowest in the Subtropical Atlantic (above the oligotrophic Sargasso Sea) and South America (>2km removed from land in the tropical Western Atlantic). Both regions had an average BC concentration of $0.2 \mu \mathrm{g} \mathrm{m}$ 3. Black carbon concentrations from the Subtropical Atlantic and South American ranged from below detection limit to $0.6 \mu \mathrm{g} \mathrm{m}^{-3}$ and from 0.1 to $0.5 \mu \mathrm{g} \mathrm{m} \mathrm{m}^{-3}$, respectively. Backward wind trajectories suggest that the regional Subtropical Atlantic air could have been diluted by clean arctic air inputs, supporting the low BC concentrations we detected (Koch and Hansen, 2005; Wang et al., 2013; Fig. 1). The 
greatest measured $\mathrm{BC}$ concentration between these two regions was detected on the last sample, which was influenced by outflow from the North American airshed.

\subsubsection{Total organic carbon concentrations and trends}

Total organic carbon (TOC) concentrations varied considerably and followed a similar regional pattern as the $\mathrm{BC}$ (Table 2; Figure 1). Total organic carbon concentrations were measured using two different instruments, an isotope ratio mass spectrometer and a Sunset TOT analyzer. Total organic carbon concentrations between the two methods were significantly correlated in the African Plume and Caribbean Sea regions $\left(p\right.$-value $=0.002 ; R^{2}=0.98 ; p$-value $=3 E^{-5} ; R^{2}=0.84$, respectively $)$. Greatest TOC concentrations, for both methods, were measured in the Caribbean Sea with a range from 0.3 to $6.1 \mu \mathrm{g} \mathrm{m}^{-3}$ and a regional average of $1.9 \pm 1.8 \mu \mathrm{g} \mathrm{m}^{-3}$. Our TOC concentrations exceeded the GISS ModelE simulations of $\leq 5.0 \mu \mathrm{g} \mathrm{m}^{-3}$, possibly due to a wildfire event which caused temporary elevated $\mathrm{BC}$ concentrations, and may not be representative of a seasonal summer TOC mean (Koch et al., 2007). The elevated TOC concentrations from the Caribbean Sea also could have included biomass generated molecules such as a macromolecular humic acids and polycyclic aromatic hydrocarbons.

Total organic carbon concentrations in the African plume also had a similar pattern to the $\mathrm{BC}$ and contained the second highest TOC concentration range of 0.1 to $1.9 \mu \mathrm{g} \mathrm{m}$

${ }^{3}$, with a regional average of $1.0 \pm 0.6 \mu \mathrm{g} \mathrm{m}^{-3}$. This agreed with the modeled organic carbon concentrations of 0.5 to $5.0 \mu \mathrm{g} \mathrm{m}^{-3}$ (Liousse et al., 1996; Koch et al. 2007). 
Likewise, previous field measurements across the Atlantic Ocean in the July-August of 2002 and 2004 measured an average TOC aerosol concentration of $4.5 \pm 1.6 \mu \mathrm{m} \mathrm{m}^{-3}$ and $1.4 \pm 0.7 \mu \mathrm{m} \mathrm{m}^{-3}$, respectively (Bates et al., 2006). The TOC concentrations were greatest closer the grassland burning source region. We propose that TOC concentrations in the marine boundary layer were a mix between degraded secondary organic aerosols from marine precursor volatile organic carbons, and primary organic aerosols ejected from sea spray (Keene et al., 2007; O’Dowd and Leeuw, 2007; Hodzic et al., 2010).

The lowest TOC concentrations, similar to the regional BC patterns, occurred in the South Atlantic (0.2 to 0.9 with a mean of $\left.0.4 \pm 0.2 \mu \mathrm{g} \mathrm{m}^{-3}\right)$ and the Subtropical Atlantic ( 0.1 to 0.4 with a mean of $0.3 \pm 0.1 \mu \mathrm{g} \mathrm{m}^{-3}$ ) regions for both methods. The main form of TOC in these remote environments were likely marine secondary organic aerosols, thus may represent a background level of TOC for the remote marine boundary layer with minimal urban influence (O'Dowd and Leeuw, 2007). Model simulations in South America have estimated a wide range in organic matter concentrations from 0.1$1.0 \mu \mathrm{g} \mathrm{m}^{-3}$ (Koch et al., 2007). The same study had predicted low anthropogenic sulfate $(<100 \mathrm{pptv})$ which indicates that biomass burning rather than fossil fuel combustion is the primary mechanism for combustion-derived aerosols in this region.

\subsubsection{BC/TOC regional patterns}

The Caribbean Sea and South Atlantic both had the largest ratio of $\mathrm{EC}_{\mathrm{CTO}} / \mathrm{TOC}_{\mathrm{CTO}}$ (0.45). This ratio measured the fraction of soot-like $\mathrm{EC}\left(\mathrm{EC}_{\mathrm{CTO}}\right)$ that composed the 
organic aerosols (primary and secondary), thus implied that nearly $50 \%$ of the carbonaceous aerosols were soot-like. The Subtropical Atlantic region had an $\mathrm{EC}_{\mathrm{CTO}} / \mathrm{TOC}_{\mathrm{CTO}}$ of 0.36 , which also suggests that $\mathrm{EC}_{\mathrm{CTO}}$ composed large fractions of remote aerosols despite being removed from point sources of biomass burning and fossil fuel combustion. The African Plume has the lowest regional $\mathrm{EC}_{\mathrm{CTO}} / \mathrm{TOC}_{\mathrm{CTO}}$ of 0.16, which indicated that the organic aerosols within this plume dominate over the $\mathrm{EC}_{\mathrm{CTO}}$ transport.

The ratio of $\mathrm{EC}_{\mathrm{TOT}} / \mathrm{TOC}_{\mathrm{TOT}}$ was not significantly correlated to the $\mathrm{EC}_{\mathrm{CTO}} / \mathrm{TOC}_{\mathrm{CTO}}$ in any of the regions investigated during this study, but were opposite in trends. The highest $\mathrm{EC}_{\mathrm{TOT}} / \mathrm{TOC}_{\mathrm{TO}}$ occurred in the African Plume and the Subtropical Atlantic at 0.73 and 0.67 , respectively (Table 2). The lowest $\mathrm{EC}_{\mathrm{TOT}} / \mathrm{TOC}_{\mathrm{TOT}}$ was 0.40 for South America and 0.16 for the Caribbean Sea. The elevated BC concentrations in the Caribbean Sea, and to a lesser extent South America, suggest local burning activities had significant inputs of carbonaceous aerosols and were favored over long-range transport. Methodological comparisons of $\mathrm{EC}_{\mathrm{TOT}}$ and $\mathrm{EC}_{\mathrm{CTO}}$ concentrations commonly differ by a factor of 2 on the same sample, implying different aerosol properties (Watson et al., 2005).

The difference in EC/TOC ratios between the two methods (CTO-375 and TOT) reflects on black carbon properties and local vs. distant sources. We detected a fraction of EC by the TOT method which was oxidized as thermally unstable organic carbon in the CTO-375 method (Fig. 1). Thus, the tropical Atlantic atmosphere contained EC- 
like aerosols other than the extremely inert graphitic-like carbon which could contain valuable nutrients like nitrate and phosphate for the oligotrophic Atlantic (Talbot et al., 1986).

We used the $\mathrm{EC}_{\mathrm{CTO}}$ value, and its associated $\mathrm{TOC}_{\mathrm{CTO}}$ value, with the $\mathrm{BC}_{\mathrm{PFL}}$ concentration to assess the fraction of soot and charcoal-like aerosols in the study area, where $\mathrm{EC}_{\mathrm{CTO}}$ represents only soot-like carbon, $\mathrm{BC}_{\mathrm{PFL}}$ measures all portions of the $\mathrm{BC}$ combustion continuum, and $\mathrm{TOC}_{\text {Сто measures the thermally unstable (non-black }}$ carbon) organic carbon (Fig. 1). We assumed that $\mathrm{BC}_{\mathrm{PFL}}$ would measure soot-like combustion byproducts in addition to the more thermally unstable fraction, such as charcoal. Thus, we determined the fraction of $\mathrm{EC}_{\mathrm{CTO}}$, or soot-like carbon that composes the $\mathrm{BC}_{\mathrm{PFL}}$ in order to access soot-like vs. charcoal like aerosols in this study region.

The average ratio of soot-like $\mathrm{EC}_{\mathrm{CTO}} / \mathrm{BC}_{\mathrm{PFL}}$ was $<1$ for all regions except for the Caribbean Sea (Fig. 1). The ratio of $\mathrm{EC}_{\mathrm{CTO}} / \mathrm{BC}_{\mathrm{PFL}}$ for the NIST standard reference material 1650 (diesel particulate matter) is 3.1, which indicates that our samples, with the possible exception to the Caribbean, were not dominated by fossil fuel-generated $\mathrm{BC}$ but by biomass-produced $\mathrm{BC}$ components, in agreement previous studies (Andreae 1983; Swap et al. 1996). We suggest that the Caribbean Sea region was dominated by soot-like EC. The Caribbean Sea had a ratio of $\mathrm{EC}_{\mathrm{CTO}} / \mathrm{BC}_{\mathrm{PFL}}$ of 1.2 , implying that $100 \%$ of the combustion-derived aerosols were soot-like and that minimal charcoallike particulates were present. 
The South American region contained the second highest ratio of $\mathrm{EC}_{\mathrm{CTO}} / \mathrm{BC}_{\mathrm{PFL}}$ at 0.6

(Fig. 1). The marine boundary layer of South America could be composed of $27 \%$ soot-like and $18 \%$ charcoal-like materials compared to the $\mathrm{TOC}_{\mathrm{CTO}}$. The African Plume and Subtropical Atlantic were dominated by the thermally unstable organic carbon that is a combination of secondary and primary organic aerosols. The African Plume was calculated to be $87 \%$ thermally unstable organic carbon, $4 \%$ soot-like, and 9\% charcoal-like carbon. The African Plume, although $>815 \mathrm{~km}$ from land, contained more charcoal-like particulates than soot-like. Similarly, the remote and oligotrophic Subtropical Atlantic region was estimated to be $64 \%$ thermally unstable organic carbon, 7\% soot-like, and 29\% charcoal-like. Both the African Plume and Subtropical Atlantic results reject our hypothesis that soot-like EC would be the dominant form of combustion-derived aerosols (Masiello 2004; Lohmann et al. 2009). This implies that charcoal-like (and other combustion derived macromolecules) could be present in significant concentrations in remote marine locations.

\subsection{Stable carbon isotope analysis for source apportionment}

Stable carbon isotopes $\left(\delta^{13} \mathrm{C}\right)$ can be utilized to assess the source of both the $\mathrm{TOC}_{\mathrm{CTO}}$

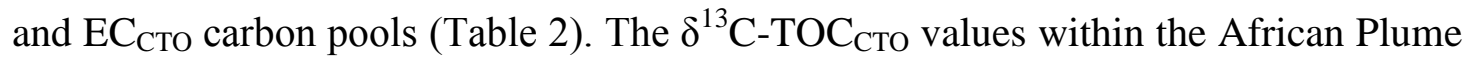
(-21\%o), Caribbean Sea (-22\%o), and Subtropical Atlantic (-23\%) were indicative of a marine plankton signature. This marine plankton signature is likely as mix of degraded secondary organic aerosols and primary organic particulates from sea spray (Keene et al. 2007; O'Dowd and Leeuw 2007; Hodzic et al. 2010). A previous study found that 
primary submicron organic carbon aerosols can be present in significant concentrations in the mixed boundary layer, even in an oligotrophic environment (Keene et al. 2007). We cannot ignore that the $\delta^{13}$ C-TOC ${ }_{\text {Сто }}$ range of -23 to $-21 \%$ o could also be a mixing of $\mathrm{C}_{4}$ and $\mathrm{C}_{3}$ carbon fixation constituents. However, previous studies have shown that the mixed boundary layer aerosols are dominated by marine organic carbon, thus marine plankton is the most probable source of TOC in these regions (Putaud et al., 2000; O’Dowd et al., 2004).

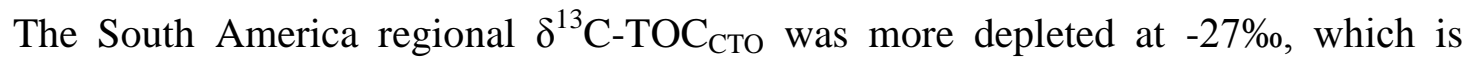
indicative of $\mathrm{C}_{3}$ plant material and is too depleted to be solely marine plankton or $\mathrm{C}_{4}$ grass material (Table 2). The backward wind trajectories showed that the air originated from a distal source in southern Africa, but local burning activities of $\mathrm{C}_{3}$ plants and crops in the Amazon rainforest was likely a significant source of the organic material.

Both the African Plume and Subtropical Atlantic regions had $\delta^{13} \mathrm{C}-\mathrm{EC}_{\mathrm{CTO}}$ values more

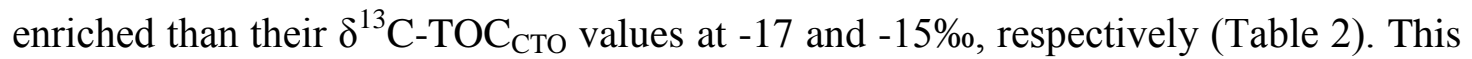
enrichment strongly indicates that the $\mathrm{EC}_{\mathrm{CTO}}$ was a byproduct of grass combustion, presumably from the African Savanna based on backward wind trajectories (Fig. 1; Farquhar et al., 1989; Lohmann et al., 2009). Underlying sediments in the African Plume region, such as from the Niger Delta, have been measured to be similarly enriched at $-17 \%$, which agrees with our data (Holtvoeth et al., 2005). 
The average $\delta^{13} \mathrm{C}-\mathrm{EC}_{\mathrm{CTO}}$ values of the Caribbean Sea (-34\%) and South America ($28 \%$ ) were strongly depleted, which is indicative of $\mathrm{C}_{3}$ carbon fixation carbon. We retrieved the intensity of open forest fires during the sampling time from the global fire emissions data base (Giglio et al., 2003; Davies et al., 2004). Elevated concentrations of $\mathrm{EC}_{\text {Сто }}$ could be partly due to forest fires, specifically in Cuba and central South America. We hypothesized that $\mathrm{C}_{4}$ grass combustion was not an important source of $\mathrm{EC}_{\mathrm{CTO}}$ to the Caribbean Sea and South America regions, thus more local burning events were a likely source of the combustion-derived aerosols.

\subsection{Carbonaceous combustion aerosol analysis by sub-region}

\subsubsection{African Plume}

A primary objective of this study was to sample the African emission plume to determine if the remote tropical Atlantic could be receiving significant inputs of combustion-derived aerosols. The GISS ModelE aerosol simulation estimated that up to $60 \%$, and an average of $18 \%$, of the global $\mathrm{BC}$ from biomass emissions originates from Africa, most of which are transported to the Atlantic Ocean (Koch et al. 2007). We sampled this plume during the Southern Hemispheric dry season when large scale South African Savanna fires were frequent (Cahoon et al., 1992). Approximately 13\% of the air parcels originated from the African continent according to the mean backward wind trajectory predictions (Fig. 1).

African Plume $\mathrm{EC}_{\text {Сто concentrations resulted in distinctly different concentrations }}$

compared to the other three methods. The $\mathrm{EC}_{\text {Сто }}\left(0.1 \mu \mathrm{g} \mathrm{m}^{-3}\right)$ detected the lowest 
concentrations and $\mathrm{EC}_{\mathrm{TOT}}$ and $\mathrm{BC}_{\mathrm{OT} 21}$ detected the greatest concentrations, both with regional averages of $0.8 \mu \mathrm{g} \mathrm{m}^{-3}$ (Table 3). Models simulations from the GISS ModelE estimated that $\mathrm{BC}$ concentrations in this region could range from 0.5 to $1.0 \mu \mathrm{g} \mathrm{m}^{-3}$, with $\mathrm{BC}$ concentrations decreasing with increasing distance from Africa (Koch et al. 2007; Allen et al., 2012). Our data found a similar trend of decreasing BC concentrations with distance from the African Savanna, however, many of our concentrations exceeded this model simulation. Aerosols from Africa during the Austral winter could compose a higher contribution to the global BC emissions than previously believed, which could cause changes in moisture transport and climate forcing, as well as the deposition of aerosols into the ocean.

The highest $\mathrm{EC}_{\mathrm{TO}}$ concentration in the African plume region was $1.4 \mu \mathrm{g} \mathrm{m}^{-3}$, which was close in magnitude to the highest $\mathrm{BC}_{\mathrm{OT} 21}$ concentration $\left(1.3 \mu \mathrm{g} \mathrm{m}{ }^{-3}\right)$ and $\mathrm{BC}_{\mathrm{PFL}}$ concentration $\left(0.9 \mu \mathrm{g} \mathrm{m}^{-3}\right)$. Both $\mathrm{BC}_{\mathrm{PFL}}$ and $\mathrm{BC}_{\mathrm{OT} 21}$ were found to be significantly correlated to each other $\left(\mathrm{p}\right.$-value $\left.=0.01 ; \mathrm{R}^{2}=0.90\right)$. Additionally, the $\mathrm{EC}_{\mathrm{TOT}}$ and EC $_{\text {CTO }}$ were also significantly correlated $\left(p\right.$-value $\left.=0.006 ; \mathrm{R}^{2}=0.94\right)$. The nonthermal methods, yielded $\mathrm{BC}_{\mathrm{PFL}}$ and $\mathrm{BC}_{\mathrm{OT} 21}$ concentrations similar to model simulations and were elevated compared the convention of $40 \mathrm{ng} \mathrm{m}^{-3}$ used to defined 'clean' area in over North America (Cavalli et al., 2004; O’Dowd et al., 2004). These concentrations are also elevated compared to the mixed boundary layer current over the oligotrophic southeast Pacific of which $2 \mathrm{ng} \mathrm{m}^{-3}$ was detected with single particle soot photometer instrumentation (Shank et al., 2012). 


\subsubsection{Caribbean Sea}

The greatest concentrations of combustion-derived aerosols measured in this study occurred in the Caribbean Sea region, particularly between the highly developed and populated islands of the Dominican Republic and Puerto Rico (Table 3; Fig. 3). The greatest measured $\mathrm{BC}$ concentration $\left(\mathrm{BC}_{\mathrm{PFL}}\right)$ had a regional average of $1.1 \mu \mathrm{g} \mathrm{m}^{-3}$ with four of the samples exceeding $1 \mu \mathrm{g} \mathrm{m} \mathrm{m}^{-3}$. Similarly, $\mathrm{EC}_{\mathrm{CTO}}$ had a maximum concentration of $3.2 \mu \mathrm{g} \mathrm{m}^{-3}$ and a regional average of $0.8 \mu \mathrm{g} \mathrm{m}^{-3}$. The $\mathrm{BC}_{\mathrm{PFL}}$ and $\mathrm{BC}_{\mathrm{OT21}}$ were found to be significantly correlated ( $\mathrm{p}$-value $=0.048 ; \mathrm{R}^{2}=0.37$ ) as was the $\mathrm{BC}_{\mathrm{OT} 21}$ and $\mathrm{EC}_{\text {TOT }}$ method (p-value $=0.007 ; \mathrm{R}^{2}=0.62$ ).

Few BC concentrations have been reported for the Caribbean Sea, leading to poor resolution in model predictions in the marine boundary layer. Mean summertime $\mathrm{BC}$ observation and model predictions in this region range from 0.01-0.1 $\mu \mathrm{g} \mathrm{m}^{-3}$ (Hansen et al., 1990; Koch et al. 2007; Wang et al. 2013). All measurements of EC and BC in this study exceed the previous model simulations and field investigations. We caution that model estimates are generally integrated over larger vertical and horizontal scales than the direct measurements from this study; hence model estimates may be diluted in comparison to our measurements. Our data cannot differentiate if these elevated BC and EC concentrations are typical for the summer, or a time specific anomaly, such as the occurrence of nearby wildfires.

\subsubsection{South America}


The South America region was represented by three samples collected $>200 \mathrm{~km}$ off the Brazilian Coast. Black and elemental carbon concentrations were lower in the South American region than the Caribbean Sea (Table 3). These samples represented Southern Hemispheric air (austral winter), as indicated by the backward wind trajectories (Fig. 1). The wind directionality was unfavorable for large organic aerosol deposition. Samples were taken in close proximity to the Amazon River mouth.

The highest regionally averaged concentration was $0.3 \mu \mathrm{g} \mathrm{m}{ }^{-3}$ for both $\mathrm{BC}_{\mathrm{PFL}}$ and $\mathrm{BC}_{\text {OT21. }}$. Elemental carbon $\left(\mathrm{EC}_{\mathrm{CTO}}\right.$ and $\left.\mathrm{EC}_{\mathrm{TOT}}\right)$ had an average concentration of $0.2 \mu \mathrm{g}$ $\mathrm{m}^{-3}$. Black carbon concentrations are generally higher in the winter months due to increased biomass burning and dryness, which reduces wet deposition (Wolff and Cachier, 1998; Sharma et al., 2004; Novakov and Rosen, 2013). The atmospheric residence time for soot-like BC in the Southern Hemisphere is longer, averaging $\sim 8$ days (Chuang et al., 2002; Reddy and Boucher 2007), suggesting that we sampled local aerosols from Brazil as well as long range transport aerosols from Southern Africa.

Very few BC and EC measurements have been made in the remote South American region, especially in the marine boundary layer. The South America region had been estimated to range in $\mathrm{BC}$ aerosols from $0.02-0.5 \mu \mathrm{g} \mathrm{m}^{-3}$ with concentrations highest closest to the Amazon River mouth and diminishing with distance offshore (Koch et al. 2005; Koch et al. 2007). Our measurements of 0.2 to $0.3 \mu \mathrm{g} \mathrm{m}^{-3}$ fall within this expected range and agree with the Fire Emission Data Base that we sampled above 
regional BC averages, but not at peak concentrations (Cooke and Wilson, 1996; Koch and Hansen, 2005). The measured concentrations reported here suggest that atmospheric deposition is an important transport mechanism of $\mathrm{BC}$ to the tropical Atlantic Ocean, in addition to fluvial deposition from the Amazon River.

\subsubsection{Subtropical Atlantic}

Northern Hemisphere air originating from the open ocean and the Arctic was sampled in the subtropical Atlantic region which crossed the Sargasso Sea (Fig. 1). Concentrations of $\mathrm{BC}$ and $\mathrm{EC}$ were low in the subtropical Atlantic, as expected, but increased upon approaching the United States coast. Previous studies have suggested that the clean Arctic air inputs would result in lowered BC concentrations, as compared to urban regions, with concentrations $\geq 0.05 \mu \mathrm{g} \mathrm{m}{ }^{-3}$ (Koch and Hansen, 2005). Similarly, the GISS ModelE simulates than BC inputs would be diluted by the organic matter aerosols in this region, which is supported by our data (Koch et al. 2007).

Samples from the Subtropical Atlantic displayed greatest BC concentrations near the African and United States coast and smallest across the subtropical gyre. Regional BC averages for this region were among the lowest measured in this study. Both $\mathrm{BC}_{\mathrm{PFL}}$ and $\mathrm{BC}_{\text {От21 }}$ measured their overall lowest mean concentrations in this region at $0.4 \mu \mathrm{g}$ $\mathrm{m}^{-3}$ and $0.2 \mu \mathrm{g} \mathrm{m}^{-3}$ respectively. The $\mathrm{EC}_{\mathrm{CTO}}$ concentration was an average of $0.1 \mu \mathrm{g} \mathrm{m}$

${ }^{3}$ for the Subtropical Atlantic, which was comparable to the method's lowest regional average, measured in the African Plume $\left(0.1 \mu \mathrm{g} \mathrm{m}^{-3}\right)$. 


\section{Conclusions}

Black carbon particulates were collected in four sub-regions within the tropical Atlantic Ocean to determine the concentrations and distributions of combustionderived aerosols in a remote and poorly sampled region. As expected, black carbon concentrations from $\mathrm{C}_{4}$ grass combustion were elevated in the African emission plume at 0.1 to $0.8 \mu \mathrm{g} \mathrm{m}^{-3}$. However, the greatest overall black carbon concentrations were measured in the Caribbean Sea at concentrations up to $1.1 \mu \mathrm{g} \mathrm{m}^{-3}$. Black carbon concentrations were still elevated above 'clean air' concentrations of $40 \mathrm{ng} \mathrm{m}^{-3}$ in all sub-regions. Soot-like carbon was expected to be the dominant type of combustionderived aerosols according to the black carbon combustion continuum. Multiple analytical methods were implemented to assess the contributions of thermally unstable organic carbon, soot-like, and charcoal-like carbon in the tropical marine boundary layer. We determined that up to $29 \%$ of the Subtropical Atlantic (over the oligotrophic Sargasso Sea), $19 \%$ of the Western Atlantic (South America), and 9\% of the African emission plume could be composed of charcoal-like aerosols. Future work should aim to both measure the entire black carbon combustion continuum and to apportion charcoal-like versus soot-like particulates when evaluating carbonaceous aerosols.

\section{Acknowledgements}

We thank the National Science Foundation for support (OCE-0851044) and the crew and captain of the $\mathrm{R} / \mathrm{V}$ Endeavor for their help with collecting the samples. We acknowledge the help of Dr. A.D.A. Hansen (Magee Scientific), Denise Napolitano 
and Youliang Wang (Arizona State University), Rick McKinney and Julia Sullivan (U.S. Environmental Protection Agency), Torey Hart (URI) and Hilary Hamer (RPI).

\section{References}

Ahmed, T., V. A. Dutkiewicz, A. Shareef, G. Tuncel, S. Tuncel, and L. Husain (2009), Measurement of black carbon (BC) by an optical method and a thermal-optical method: Intercomparison for four sites, Atmos Environ, 43(40), 6305-6311.

Allen, R. J., S. C. Sherwood, J. R. Norris, and C. S. Zender (2012), Recent Northern Hemisphere tropical expansion primarily driven by black carbon and tropospheric ozone, Nature, 485(7398), 350-U393.

Andreae, M. O. (1983), Soot Carbon and Excess Fine Potassium - Long-Range Transport of Combustion-Derived Aerosols, Science, 220(4602), 1148-1151.

Andreae, M. O., and A. Gelencser (2006), Black carbon or brown carbon? The nature of light-absorbing carbonaceous aerosols, Atmos Chem Phys, 6, 3131-3148.

Bates, T. S., et al. (2006), Aerosol direct radiative effects over the northwest Atlantic, northwest Pacific, and North Indian Oceans: estimates based on in-situ chemical and optical measurements and chemical transport modeling, Atmos Chem Phys, 6, 16571732.

Birch, M. E., and R. A. Cary (1996), Elemental carbon-based method for monitoring occupational exposures to particulate diesel exhaust, Aerosol Sci Tech, 25(3), 221-241.

Bond, T. C., D. G. Streets, K. F. Yarber, S. M. Nelson, J. H. Woo, and Z. Klimont (2004), A technology-based global inventory of black and organic carbon emissions from combustion, J Geophys Res-Atmos, 109(D14).

Bond, T. C., et al. (2013), Bounding the role of black carbon in the climate system: A scientific assessment, J Geophys Res-Atmos, 118(11), 5380-5552.

Cahoon, D. R., B. J. Stocks, J. S. Levine, W. R. Cofer, and K. P. Oneill (1992), Seasonal Distribution of African Savanna Fires, Nature, 359(6398), 812-815.

Cavalli, F., et al. (2004), Advances in characterization of size-resolved organic matter in marine aerosol over the North Atlantic, J Geophys Res-Atmos, 109(D24).

Chester, R., A. G. Griffiths, and J. M. Hirst (1979), Influence of Soil-Sized Atmospheric Particulates on the Elemental L Chemistry of the Deep-Sea Sediments of the Northeastern Atlantic, Mar Geol, 32(1-2), 141-154. 
Chow, J. C., J. G. Watson, P. Doraiswamy, L. W. A. Chen, D. A. Sodeman, D. H. Lowenthal, K. Park, W. P. Arnott, and N. Motallebi (2009), Aerosol light absorption, black carbon, and elemental carbon at the Fresno Supersite, California, Atmos Res, 93(4), 874-887.

Chuang, C. C., J. E. Penner, J. M. Prospero, K. E. Grant, G. H. Rau, and K. Kawamoto (2002), Cloud susceptibility and the first aerosol indirect forcing: Sensitivity to black carbon and aerosol concentrations, J Geophys Res-Atmos, 107(D21).

Cooke, W. F., and J. J. N. Wilson (1996), A global black carbon aerosol model, J Geophys Res-Atmos, 101(D14), 19395-19409.

Corrigan, C. E., G. C. Roberts, M. V. Ramana, D. Kim, and V. Ramanathan (2008), Capturing vertical profiles of aerosols and black carbon over the Indian Ocean using autonomous unmanned aerial vehicles, Atmos Chem Phys, 8(3), 737-747.

Currie, L. A., et al. (2002), A critical evaluation of interlaboratory data on total, elemental, and isotopic carbon in the carbonaceous particle reference material, NIST SRM 1649a, J Res Natl Inst Stan, 107(3), 279-298.

Davies, D., Kumar, S.; Descloitres, J. (2004), Global fire monitoring using MODIS near-real-time satelitte data, GIM International, 18(4), 41-43.

Draxler, R. R. a. R., G. D. (2013), HYSPLIT (HYbrid Single-Particle Lagrangian Integrated Trajectory) Model access via NOAA ARL READY Website (http://www.arl.noaa.gov/HYSPLIT.php). , NOAA Air Resources Laboratory, College Park, MD.

Duncan, B. N., R. V. Martin, A. C. Staudt, R. Yevich, and J. A. Logan (2003), Interannual and seasonal variability of biomass burning emissions constrained by satellite observations, J Geophys Res-Atmos, 108(D2).

Dutkiewicz, V. A., S. Alvi, B. M. Ghauri, M. I. Choudhary, and L. Husain (2009), Black carbon aerosols in urban air in South Asia, Atmos Environ, 43(10), 1737-1744.

Elmquist, M., G. Cornelissen, Z. Kukulska, and O. Gustafsson (2006), Distinct oxidative stabilities of char versus soot black carbon: Implications for quantification and environmental recalcitrance, Global Biogeochem Cy, 20(2).

Farquhar, G. D., J. R. Ehleringer, and K. T. Hubick (1989), Carbon Isotope Discrimination and Photosynthesis, Annu Rev Plant Phys, 40, 503-537.

Flores-Cervantes, D. X., C. M. Reddy, and P. M. Gschwend (2009), Inferring Black Carbon Concentrations in Particulate Organic Matter by Observing Pyrene Fluorescence Losses, Environ Sci Technol, 43(13), 4864-4870. 
Forbes, M. S., R. J. Raison, and J. O. Skjemstad (2006), Formation, transformation and transport of black carbon (charcoal) in terrestrial and aquatic ecosystems, Sci Total Environ, 370(1), 190-206.

Gelinas, Y., K. M. Prentice, J. A. Baldock, and J. I. Hedges (2001), An improved thermal oxidation method for the quantification of soot/graphitic black carbon in sediments and soils, Environ Sci Technol, 35(17), 3519-3525.

Giglio, L. D., J., Justice, C.O., Kaufman, Y.J. (2003), An enhanced cotextual fire detection algorithm for MODIS, Remote Sens Environ, 87, 273-282.

Goldberg, E. D. (1985), Black carbon in the environment.

Gustafsson, O., F. Haghseta, C. Chan, J. MacFarlane, and P. M. Gschwend (1997), Quantification of the dilute sedimentary soot phase: Implications for PAH speciation and bioavailability, Environ Sci Technol, 31(1), 203-209.

Gustafsson, O., M. Krusa, Z. Zencak, R. J. Sheesley, L. Granat, E. Engstrom, P. S. Praveen, P. S. P. Rao, C. Leck, and H. Rodhe (2009), Brown Clouds over South Asia: Biomass or Fossil Fuel Combustion?, Science, 323(5913), 495-498.

Hammes, K., et al. (2007), Comparison of quantification methods to measure firederived (black/elemental) carbon in soils and sediments using reference materials from soil, water, sediment and the atmosphere, Global Biogeochem Cy, 21(3).

Han, Y. M., A. Chen, J. J. Cao, K. Fung, F. Ho, B. Z. Yan, C. L. L. Zhan, S. X. Liu, C. Wei, and Z. S. An (2013), Thermal/Optical Methods for Elemental Carbon Quantification in Soils and Urban Dusts: Equivalence of Different Analysis Protocols, Plos One, 8(12).

Hansen, A. D. A., Artz, R. S., Pszenny, A. A. P., Larson, R. E. (1990), Aerosol black carbon and radon as tracers for air mass origin over the North Atlantic Ocean, Global Biogeochem Cy, 4(2), 189-199.

Hodzic, A., J. L. Jimenez, S. Madronich, M. R. Canagaratna, P. F. DeCarlo, L. Kleinman, and J. Fast (2010), Modeling organic aerosols in a megacity: potential contribution of semi-volatile and intermediate volatility primary organic compounds to secondary organic aerosol formation, Atmos Chem Phys, 10(12), 5491-5514.

Hoetzel, S., L. Dupont, E. Schefuss, F. Rommerskirchen, and G. Wefer (2013), The role of fire in Miocene to Pliocene C-4 grassland and ecosystem evolution, Nat Geosci, 6(12), 1027-1030. 
Holtvoeth, J., S. Kolonic, and T. Wagner (2005), Soil organic matter as an important contributor to late Quaternary sediments of the tropical West African continental margin, Geochim Cosmochim Ac, 69(8), 2031-2041.

Husain, L., V. A. Dutkiewicz, A. Khan, and B. M. Ghauri (2007), Characterization of carbonaceous aerosols in urban air, Atmos Environ, 41(32), 6872-6883.

Jeong, C. H., P. K. Hopke, E. Kim, and D. W. Lee (2004), The comparison between thermal-optical transmittance elemental carbon and Aethalometer black carbon measured at multiple monitoring sites, Atmos Environ, 38(31), 5193-5204.

Keene, W. C., et al. (2007), Chemical and physical characteristics of nascent aerosols produced by bursting bubbles at a model air-sea interface, J Geophys Res-Atmos, 112(D21).

Keiluweit, M., P. S. Nico, M. G. Johnson, and M. Kleber (2010), Complexity of aromatic carbon in biomass-derived black carbon (biochar): Implications for molecular structure and sorptive interactions, Abstr Pap Am Chem S, 240.

Koch, D., and J. Hansen (2005), Distant origins of Arctic black carbon: A Goddard Institute for Space Studies ModelE experiment, J Geophys Res-Atmos, 110(D4).

Koch, D., T. C. Bond, D. Streets, N. Unger, and G. R. van der Werf (2007), Global impacts of aerosols from particular source regions and sectors, J Geophys Res-Atmos, 112(D2).

Koch, D., et al. (2009), Evaluation of black carbon estimations in global aerosol models, Atmos Chem Phys, 9(22), 9001-9026.

Lavanchy, V. M. H., H. W. Gaggeler, S. Nyeki, and U. Baltensperger (1999), Elemental carbon (EC) and black carbon (BC) measurements with a thermal method and an aethalometer at the high-alpine research station Jungfraujoch, Atmos Environ, 33(17), 2759-2769.

Liousse, C., J. E. Penner, C. Chuang, J. J. Walton, H. Eddleman, and H. Cachier (1996), A global three-dimensional model study of carbonaceous aerosols, J Geophys Res-Atmos, 101(D14), 19411-19432.

Liu, X. H., J. E. Penner, and M. H. Wang (2009), Influence of anthropogenic sulfate and black carbon on upper tropospheric clouds in the NCAR CAM3 model coupled to the IMPACT global aerosol model, J Geophys Res-Atmos, 114.

Lohmann, R., K. Bollinger, M. Cantwell, J. Feichter, I. Fischer-Bruns, and M. Zabel (2009), Fluxes of soot black carbon to South Atlantic sediments, Global Biogeochem Cy, 23. 
Masiello, C. A. (2004), New directions in black carbon organic geochemistry, Mar Chem, 92(1-4), 201-213.

Novakov, T., and H. Rosen (2013), The Black Carbon Story: Early History and New Perspectives, Ambio.

O'Dowd, C. D., and G. De Leeuw (2007), Marine aerosol production: a review of the current knowledge, Philos T R Soc A, 365(1856), 1753-1774.

O'Dowd, C. D., M. C. Facchini, F. Cavalli, D. Ceburnis, M. Mircea, S. Decesari, S. Fuzzi, Y. J. Yoon, and J. P. Putaud (2004), Biogenically driven organic contribution to marine aerosol, Nature, 431(7009), 676-680.

Ogren, J. A., and R. J. Charlson (1983), Elemental Carbon in the Atmosphere - Cycle and Lifetime, Tellus B, 35(4), 241-254.

Park, K., et al. (2006), Comparison of continuous and filter-based carbon measurements at the Fresno Supersite, J Air Waste Manage, 56(4), 474-491.

Perry, K. D., T. A. Cahill, R. A. Eldred, D. D. Dutcher, and T. E. Gill (1997), Longrange transport of North African dust to the eastern United States, J Geophys ResAtmos, 102(D10), 11225-11238.

Petzold, A., et al. (2013), Recommendations for reporting "black carbon" measurements, Atmos Chem Phys, 13(16), 8365-8379.

Putaud, J. P., et al. (2000), Chemical mass closure and assessment of the origin of the submicron aerosol in the marine boundary layer and the free troposphere at Tenerife during ACE-2, Tellus B, 52(2), 141-168.

Ramanathan, V., and G. Carmichael (2008), Global and regional climate changes due to black carbon, Nat Geosci, 1(4), 221-227.

Reddy, M. S., and O. Boucher (2007), Climate impact of black carbon emitted from energy consumption in the world's regions, Geophys Res Lett, 34(11).

Rolph, G. D. (2013), Real-time Environmental Applications and Display sYstem (READY) Website (http://www.ready.noaa.gov). , NOAA Air Resources Laboratory, College Park, MD.

Schmidt, M. W. I., and A. G. Noack (2000), Black carbon in soils and sediments: Analysis, distribution, implications, and current challenges, Global Biogeochem Cy, 14(3), 777-793. 
Schmidt, M. W. I., J. O. Skjemstad, C. I. Czimczik, B. Glaser, K. M. Prentice, Y. Gelinas, and T. A. J. Kuhlbusch (2001), Comparative analysis of black carbon in soils, Global Biogeochem Cy, 15(1), 163-167.

Shank, L. M., S. Howell, A. D. Clarke, S. Freitag, V. Brekhovskikh, V. Kapustin, C. McNaughton, T. Campos, and R. Wood (2012), Organic matter and non-refractory aerosol over the remote Southeast Pacific: oceanic and combustion sources, Atmos Chem Phys, 12(1), 557-576.

Sharma, S., D. Lavoue, H. Cachier, L. A. Barrie, and S. L. Gong (2004), Long-term trends of the black carbon concentrations in the Canadian Arctic, J Geophys ResAtmos, 109(D15).

Spracklen, D. V., S. R. Arnold, J. Sciare, K. S. Carslaw, and C. Pio (2008), Globally significant oceanic source of organic carbon aerosol, Geophys Res Lett, 35(12).

Swap, R., M. Garstang, S. A. Macko, P. D. Tyson, W. Maenhaut, P. Artaxo, P. Kallberg, and R. Talbot (1996), The long-range transport of southern African aerosols the tropical South Atlantic, J Geophys Res-Atmos, 101(D19), 23777-23791.

Talbot, R. W., R. C. Harriss, E. V. Browell, G. L. Gregory, D. I. Sebacher, and S. M. Beck (1986), Distribution and Geochemistry of Aerosols in the Tropical NorthAtlantic Troposphere - Relationship to Saharan Dust, J Geophys Res-Atmos, 91(D4), 5173-5182.

Verardo, D. J., and W. F. Ruddiman (1996), Late pleistocene charcoal in tropical Atlantic deep-sea sediments: Climatic and geochemical significance, Geology, 24(9), 855-857.

Wang, R., Tao, S., Balkanski, Y., Ciais, P., Boucher, O., Lie, J., Piao, S., Shen, H., Vuolo, M. R., Valari, M., Chen, H., Chen, Y., Cozic, A., Huang, Y., Li, B., Li, W., Shen, G., Wang, B., Zhang, Y. (2013), Exposure to ambient black carbon derived from a unique inventory and high resolution model:, PNAS, 111(7), 2459-2463.

Watson, J. G., Chow, J. C., \& Chen, L., W. A. (2005), Summary of organic andelemental carbon/black carbon analysis methods and intercomparisons., Aerosol Air Qual. Res, 5(1), 65102.

Wolff, E. W., and H. Cachier (1998), Concentrations and seasonal cycle of black carbon in aerosol at a coastal Antarctic station, J Geophys Res-Atmos, 103(D9), 11033-11041. 
Zencak, Z., M. Elmquist, and O. Gustafsson (2007), Quantification and radiocarbon source apportionment of black carbon in atmospheric aerosols using the CTO-375 method, Atmos Environ, 41(36), 7895-7906. 
Tables

\begin{tabular}{ccccc|cccc|c} 
& & & & & \multicolumn{2}{|c}{ Start } & & End & $(\mathrm{km})$ \\
Sample & Region & $\begin{array}{c}\text { (2010) } \\
\text { Start }\end{array}$ & $\begin{array}{c}\text { Collect } \\
\text { Sample } \\
\text { Time }\end{array}$ & $\begin{array}{c}\text { Volume } \\
\left(\mathrm{m}^{3}\right)\end{array}$ & Lat. & Long. & Lat. & Long. & Distance \\
\hline 1 & CS & 6-Jul & 721 & 408 & 22.136 & -77.483 & 20.983 & -74.988 & 288 \\
2 & CS & 7-Jul & 725 & 308 & 20.983 & -74.988 & 20.021 & -70.654 & 464 \\
3 & CS & 7-Jul & 684 & 97 & 20.021 & -70.654 & 19.285 & -68.575 & 233 \\
4 & CS & 8-Jul & 737 & 104 & 19.285 & -68.575 & 17.615 & -67.033 & 246 \\
5 & CS & 8-Jul & 707 & 100 & 17.615 & -67.033 & 16.550 & -65.483 & 203 \\
6 & CS & 9-Jul & 741 & 315 & 16.550 & -65.483 & 15.416 & -63.783 & 221 \\
7 & CS & 9-Jul & 708 & 301 & 15.416 & -63.783 & 14.338 & -62.223 & 206 \\
8 & CS & 10-Jul & 691 & 294 & 14.338 & -62.223 & 13.453 & -60.817 & 181 \\
9 & CS/SA & 14-Jul & 2823 & 1199 & 13.453 & -60.817 & 7.079 & -49.156 & 1458 \\
10 & SA & 16-Jul & 2455 & 1043 & 7.079 & -49.156 & 5.906 & -45.011 & 476 \\
11 & CS & 20-Jul & 2884 & 1225 & 5.906 & -45.011 & 11.179 & -55.835 & 1326 \\
12 & CS & 22-Jul & 1420 & 603 & 11.179 & -55.835 & 13.100 & -59.650 & 466 \\
13 & CS & 23-Jul & 2794 & 3758 & 13.100 & -59.650 & 9.483 & -51.266 & 989 \\
14 & SA & 27-Jul & 3287 & 4421 & 9.483 & -51.266 & 4.600 & -46.200 & 778 \\
15 & AP & 30-Jul & 3983 & 5358 & 4.600 & -46.200 & 1.580 & -28.767 & 1966 \\
16 & AP & 3-Aug & 3353 & 4510 & 1.580 & -28.767 & 3.961 & -21.667 & 832 \\
17 & AP & 6-Aug & 4532 & 6096 & 3.961 & -21.667 & 4.977 & -21.215 & 123 \\
18 & AP & 10-Aug & 2235 & 3006 & 4.977 & -21.215 & 4.554 & -24.496 & 367 \\
19 & AP & 15-Aug & 2209 & 2971 & 4.554 & -24.496 & 12.813 & -20.066 & 1035 \\
20 & SubAt & 21-Aug & 2682 & 3608 & 12.813 & -20.066 & 20.521 & -25.118 & 1009 \\
21 & SubAt & 23-Aug & 2718 & 3656 & 20.521 & -25.118 & 25.717 & -32.768 & 918 \\
22 & SubAt & 25-Aug & 2863 & 3851 & 25.717 & -32.768 & 30.167 & -41.027 & 950 \\
23 & SubAt & 27-Aug & 2846 & 3828 & 30.167 & -41.027 & 31.871 & -50.100 & 886 \\
24 & SubAt & 29-Aug & 943 & 1269 & 31.871 & -50.100 & 32.516 & -53.764 & 353 \\
\hline
\end{tabular}

Table 1. Sampling dates, volumes, coordinates, and total distance for each sample collected. Regional abbreviations are CS (Caribbean Sea), SA (South America), AP (African Plume, and SubAt (Subtropical Atlantic). 


\begin{tabular}{c|cc|c|c}
\hline $\begin{array}{c}\text { Regional Average } \\
\text { (Range) }\end{array}$ & TOC $^{\mathbf{a}}$ & TOC $^{\mathbf{b}}$ & $\boldsymbol{\delta}^{\mathbf{1 3}} \mathbf{C}-\mathbf{T O C}$ & $\boldsymbol{\delta}^{\mathbf{1 3}} \mathbf{C}-\mathbf{B C}$ \\
\hline African Plume & $1.1 \pm 0.4$ & $0.9 \pm 0.5$ & $-21 \pm 4$ & $-17 \pm 5$ \\
& $(0.2-1.9)$ & $(0.1-1.5)$ & $(-19$ to -26$)$ & $(-2$ to -26$)$ \\
\hline Caribbean Sea & $1.9 \pm 0.3$ & $1.8 \pm 1.7$ & $-22 \pm 8$ & $-34 \pm 18$ \\
& $(0.4-6.1)$ & $(0.4-5.8)$ & $(-9$ to -34$)$ & $(-22$ to -42$)$ \\
\hline South America & $0.5 \pm 0.1$ & $0.4 \pm 0.1$ & $-27 \pm 2$ & $-28 \pm 14$ \\
& $(0.2-0.9)$ & $(0.2-0.5)$ & $(-24$ to -32$)$ & $(-16$ to -35$)$ \\
\hline Subtropical & $0.3 \pm 0.1$ & $0.2 \pm 0.0$ & $-23 \pm 5$ & $-15 \pm 12$ \\
Atlantic & $(0.1-0.4)$ & $(0.2-0.3)$ & $(-17$ to -25$)$ & $(3$ to -27$)$
\end{tabular}

Table 2. Average regional total organic carbon concentrations and ranges $\left(\mu \mathrm{g} \mathrm{m}^{-3}\right)$ for the TOT methods (TOC ${ }^{\mathrm{a}}$ ) and CTO-375 (TOC ${ }^{\mathrm{b}}$ ) methods and the $\delta^{13} \mathrm{C}$ value (\%o) for the total organic carbon and black carbon determined by the CTO-375 method. 


\begin{tabular}{c|c|c|c|c}
\hline $\begin{array}{c}\text { Regional Average } \\
\text { (Range) }\end{array}$ & CTO-375 & TOT & PFL & OT-21 \\
\hline \multirow{2}{*}{ African Plume } & $0.1 \pm 0.1$ & $0.8 \pm 0.4$ & $0.5 \pm 0.3$ & $0.8 \pm 0.4$ \\
& $(0-0.2)$ & $(0.2-1.4)$ & $(0.3-0.9)$ & $(0.2-1.3)$ \\
\hline \multirow{2}{*}{ Caribbean } & $0.8 \pm 0.9$ & $0.3 \pm 0.2$ & $1.1 \pm 1.2$ & $0.2 \pm 0.2$ \\
& $(0-3.2)$ & $(0-0.6)$ & $(0-3.4)$ & $(0-0.7)$ \\
\hline \multirow{2}{*}{ South America } & $0.2 \pm 0.1$ & $0.2 \pm 0.1$ & $0.3 \pm 0.1$ & $0.3 \pm 0.2$ \\
& $(0.1-0.3)$ & $(0.1-0.2)$ & $(0.2-0.3)$ & $(0.1-0.5)$ \\
\hline \multirow{2}{*}{ Subtropical Atlantic } & $0.1 \pm 0.1$ & $0.2 \pm 0.0$ & $0.4 \pm 0.2$ & $0.2 \pm 0.1$ \\
& $(0-0.2)$ & $(0.2)$ & $(0.1-0.6)$ & $(0-0.3)$
\end{tabular}

Table 3. Average black carbon concentrations and range by region $\left(\mu \mathrm{g} \mathrm{m}^{-3}\right)$ using four different methods: the chemothermal oxidation at $375^{\circ} \mathrm{C}$ (CTO-375), thermal optical transmittance (TOT), pyrene fluorescence loss (PFL), and optical attenuation (OT-21). 


\section{Figures}

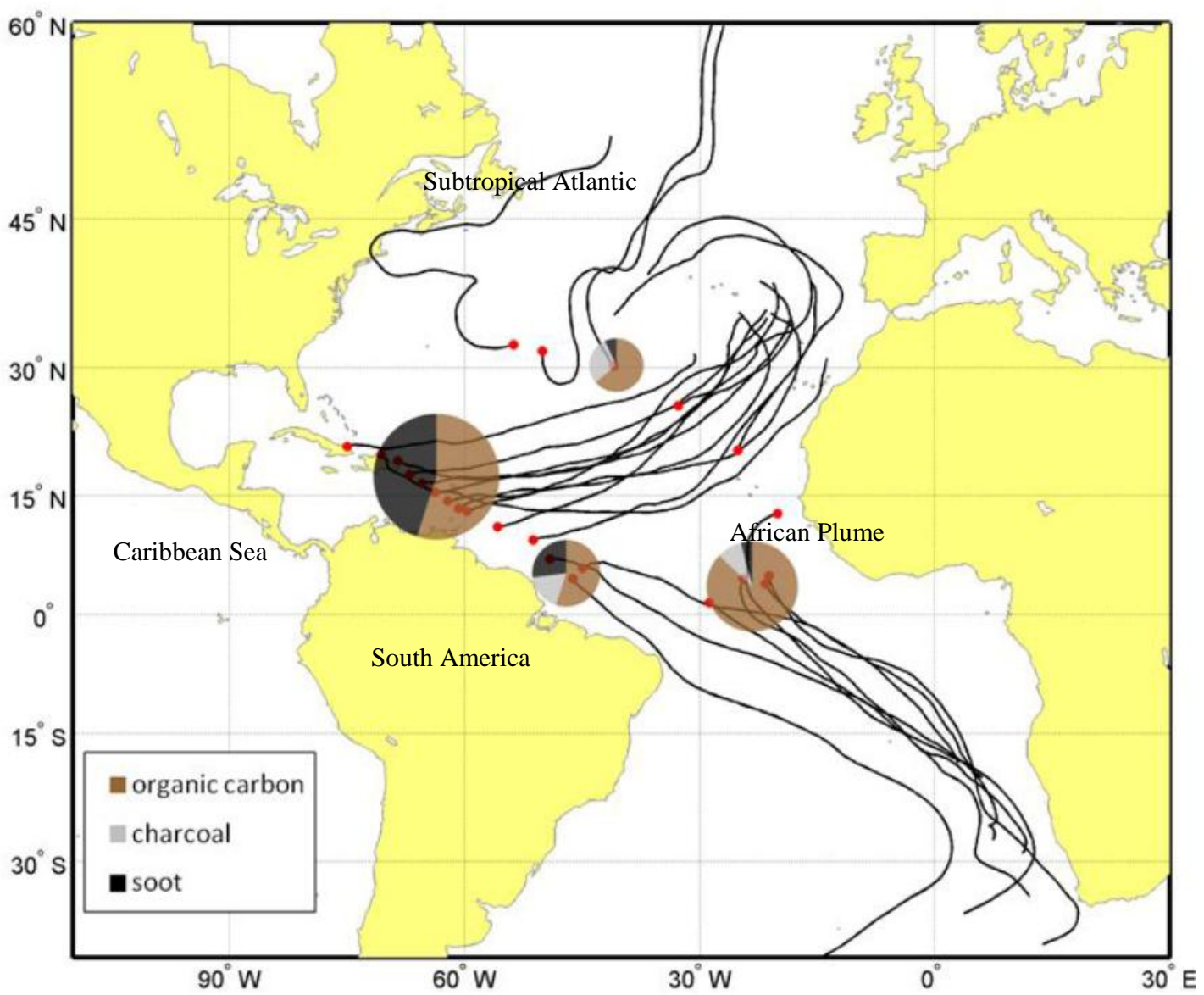

Figure 1. HySPLIT estimates of a 10-day backward wind trajectory at the end of each filter sample at a height of 20 meters and the average regional fraction of black carbon within the total organic carbon (Mercator projection). Black carbon is further divided between labile organic carbon, soot (CTO-375), and charcoal (pyrene fluorescence loss). The size of each pie chart is in accordance to regional average total organic carbon concentration ranging from 0.2 to 1.8 $\mu \mathrm{g} \mathrm{m} \mathrm{m}^{-3}$ 


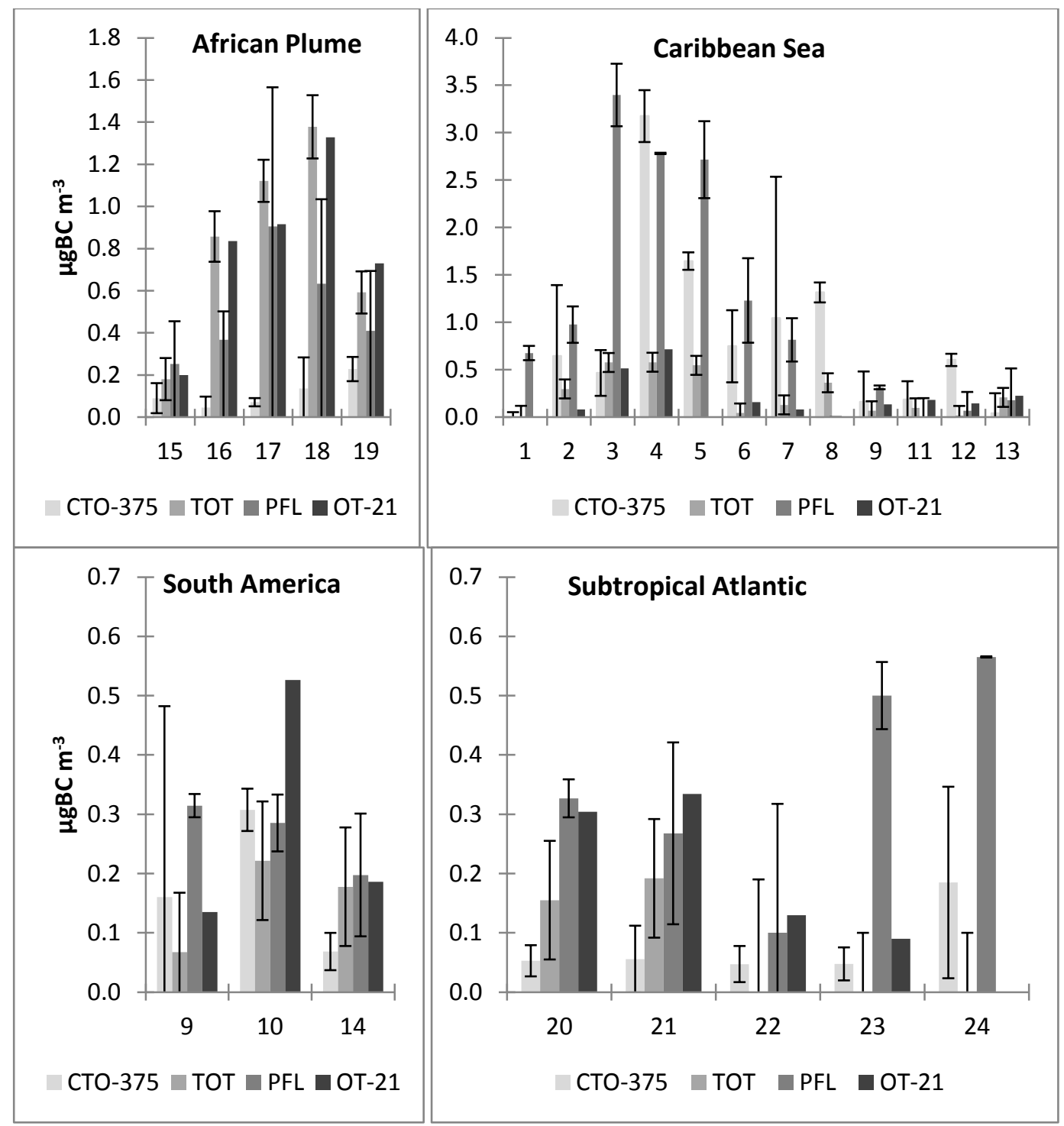

Figure 2. Comparison of black carbon concentrations $\left(\mu \mathrm{g} \mathrm{m}^{-3}\right)$ from the four selected methods grouped by region with one standard deviation. Error associated with the OT21 method was $\pm 0.1 \mu \mathrm{g} \mathrm{m}^{-3}$. 


\section{Supporting Information}

Black carbon concentrations and sources in the marine boundary layer of the tropical Atlantic Ocean using four methodologies

Kari Pohl

Mark Cantwell

Pierre Herckes

Rainer Lohmann

Included in the supporting information are:

Materials and Methods

Table S1. Black carbon concentration $\left(\mu \mathrm{g} \mathrm{m}^{-3}\right)$ per individual filter for each method.

Table S2. Total organic carbon concentrations as measured by the CTO-375 (TOC ${ }^{\mathrm{a}}$ ) and TOT $\left(\mathrm{TOC}^{\mathrm{b}}\right.$ ) methods and the $\delta^{13} \mathrm{C}$ values for the total organic carbon and black carbon determined for each filter by CTO-375 after blank correction.

Table S3. Regional average of soot-like black carbon (CTO-375) to the broader black carbon spectrum (PFL) ratio and the ratio of black carbon in the total organic carbon determined by the CTO-375 and TOT methods.

Table S4. Measured elemental carbon (EC) values of lab blanks and field blanks via the chemothermal oxidation (CTO-375) method $\left(\mu \mathrm{gEC} \mathrm{cm}^{-2}\right)$. An average laboratory glass fiber filter blank (GFF) is also included.

Figure S1. Global fire maps generated from the MODIS Terra and Aqua satellites for (a) June 30-July 9, 2010, (b) July 20-27, 2010, (c) July 30-August 8, 2010, and (d) August 18-28, 2010. Both (a) and (b) co-occurred during the Caribbean and South America regional sampling, (c) occurred during the African Plume regional sampling, and (d) for the subtropical Atlantic. The color indicates the number of detected wildfires from red (low) to yellow (high). Credits: Jacques Descloitres, Louis Giglio, and Reto Stokli.

Figure S2. HySPLIT estimates of a 10-day backward wind trajectory at the end of each filter sample at a height of 20 meters and the average regional fraction of black carbon within the total organic carbon (rectilinear projection). Black carbon is further divided between labile organic carbon, soot (CTO-375), and charcoal (pyrene fluorescence loss). The size of each pie chart is in accordance to regional average total organic carbon concentration ranging from 0.2 to $1.8 \mu \mathrm{g} \mathrm{m}^{-3}$.

References 
Materials and Methods: The pyrene fluorescence loss method is a novel approach to quantify a broader portion of the BC combustion continuum (Flores-Cervantes et al., 2009). BC concentrations were calculated from the loss of dissolved pyrene based on eq. $1-3$.

$$
f_{w}=\frac{C_{f}}{C_{i}}
$$

Where $f_{w}$ is the fraction of pyrene lost from solution due to adsorption to the $B C$, i.e. ratio of the final $\left(\mathrm{C}_{\mathrm{f}}\right)$ to the initial pyrene concentration $\left(\mathrm{C}_{\mathrm{i}}\right)$.

$$
K_{d}=\frac{\left(1-f_{w}\right)}{f_{w} r_{s w}}
$$

The solid-water partitioning coefficient $\left(\mathrm{K}_{\mathrm{d}}\right)$ for pyrene was determined using equation (2), where $\mathrm{r}_{\mathrm{sw}}$ is the solid-water ratio $\left(\mathrm{kg} \mathrm{L}^{-1}\right)$.

$$
f_{B C}=\frac{\left[K_{d}-f_{O C} K_{O C}\right]}{K_{B C} C_{w}^{n-1}}
$$

The calculated $\mathrm{K}_{\mathrm{d}}$ was used to determine the fraction of $\mathrm{BC}\left(\mathrm{f}_{\mathrm{BC}}\right)$ according to equation (3). The $\mathrm{K}_{\mathrm{OC}}$ and $\mathrm{K}_{\mathrm{BC}}$ are the previously determined pyrene partitioning coefficients of $10^{4.7}\left(\mathrm{~L} \mathrm{kgOC}^{-1}\right)$ for organic carbon (OC) and $10^{6.25}\left(\mathrm{~L} \mathrm{kgBC}^{-1}\right)$ for BC (BC), respectively (Accardi-Dey and Gschwend, 2002). The $\mathrm{C}_{\mathrm{w}}{ }^{\mathrm{n}-1}$ is the initial truly dissolved pyrene concentration, where $\mathrm{n}$ is the Freundlich exponent of 0.62. An initial 
concentration of $1 \mu \mathrm{g} \mathrm{L} \mathrm{L}^{-1}$ pyrene was purposely selected to allow the $\mathrm{C}_{\mathrm{w}}$ term to approach 1 since the Freundlich exponent is the component with the highest degree of uncertainty. Finally, the $f_{O C}$ is the fraction of the total organic carbon determined by the IRMS during the CTO-375 analysis. We assumed that $\mathrm{BC}$ would be a minor constituent so that the total organic carbon would be equivalent to the organic carbon concentration, as was done in Flores-Cervantes (2009).

Additionally, the salinity of five pyrene solutions with double the filter mass and half the volume were measured with a refractometer in order to assess if salinity could have affected pyrene's solubility in solution. A measurement of 0 ppt was received in triplicate for all five samples, concluding that the salting out effect of pyrene would be minimal in our set-up.

A series of blank filters were placed on a high volume air sampler at the Graduate School of Oceanography, Narragansett, Rhode Island at a rate of $1.35 \mathrm{~m}^{3} \mathrm{~min}^{-1}(47.5$ CFM) for $10,20,30,60$, and 120 minutes to test if the carbon blank would decrease inversely as air volume filtered increased. The associated carbon blank was constant for all air volumes, suggesting that the carbon detected by the thermal methods was not due to contamination but rather the filter matrix.

In separate work, corn pollen was analyzed by both CTO-375 and the pyrene fluorescence loss technique to assess its possible interference on the $\mathrm{BC}$ measurements. No BC was detected on the pollen using the pyrene fluorescence loss 
method; however approximately $66 \%$ of the pollen remained after the CTO-375 treatment.

Methodological quality control for the CTO-375 and pyrene fluorescence loss method was also assessed and compared using the NIST standard reference materials 1941b (marine sediment). $\mathrm{BC}$ mass fractions for were within the expected range of $0.7 \pm$ $0.1 \%$ for the CTO-375 method and 1.6\% for the pyrene fluorescence loss (Hammes et al., 2007; Flores-Cervantes et al., 2009). 


\begin{tabular}{|c|c|c|c|c|c|}
\hline QFF & CTO-375 & PFL & TOT & OT-21 & Region \\
\hline 1 & 0.00 & 0.62 & 0.32 & 0.00 & Caribbean \\
\hline 2 & 1.17 & 1.12 & 0.00 & 0.08 & Caribbean \\
\hline 3 & 0.64 & 3.56 & 0.00 & 0.52 & Caribbean \\
\hline 4 & 3.37 & 2.86 & 0.00 & 0.72 & Caribbean \\
\hline 5 & 1.71 & 2.98 & 0.00 & 0.00 & Caribbean \\
\hline 6 & 1.02 & 0.95 & 0.00 & 0.16 & Caribbean \\
\hline 7 & 0.00 & 0.99 & 0.00 & 0.08 & Caribbean \\
\hline 8 & 1.39 & 0.00 & 0.00 & 0.00 & Caribbean \\
\hline 9 & 0.02 & 0.19 & 0.00 & 0.14 & Caribbean/South America \\
\hline 10 & 0.35 & 0.42 & 0.00 & 0.53 & South America \\
\hline 11 & 0.04 & 0.06 & 0.00 & 0.18 & Caribbean \\
\hline 12 & 0.83 & 0.53 & 0.00 & 0.14 & Caribbean \\
\hline 13 & 0.02 & 0.25 & 0.00 & 0.23 & Caribbean \\
\hline 14 & 0.09 & 0.33 & 0.06 & 0.19 & South America \\
\hline 15 & 0.04 & 0.33 & 0.00 & 0.20 & African Plume \\
\hline 16 & 0.01 & 0.47 & 0.03 & 0.83 & African Plume \\
\hline 17 & 0.08 & 0.21 & 0.03 & 0.92 & African Plume \\
\hline 18 & 0.03 & 0.91 & 0.03 & 1.33 & African Plume \\
\hline 19 & 0.19 & 0.74 & 0.01 & 0.73 & African Plume \\
\hline 20 & 0.03 & 0.36 & 0.00 & 0.30 & Subtropical Atlantic \\
\hline 21 & 0.02 & 0.40 & 0.00 & 0.33 & Subtropical Atlantic \\
\hline 22 & 0.03 & 0.00 & 0.18 & 0.09 & Subtropical Atlantic \\
\hline 23 & 0.03 & 0.09 & 0.00 & 0.13 & Subtropical Atlantic \\
\hline 24 & 0.30 & 0.56 & 0.14 & 0.00 & Subtropical Atlantic \\
\hline
\end{tabular}

Table S1. Black carbon concentration $\left(\mu \mathrm{g} \mathrm{m}^{-3}\right)$ per individual filter for each method. 


\begin{tabular}{c|c|c|c|c}
\hline Sample & TOC $^{\mathbf{a}} \mathbf{u g ~ m}^{-\mathbf{3}}$ & TOC $^{\mathbf{b}} \mathbf{u g ~ \mathbf { ~ m } ^ { \mathbf { 3 } }}$ & $\boldsymbol{\delta}^{\mathbf{1 3}} \mathbf{C}-\mathbf{T O C}$ & $\boldsymbol{\delta}^{\mathbf{1 3}} \mathbf{C}-\mathbf{B C}$ \\
\hline 1 & 0.4 & 0.9 & -22 & 2 \\
2 & 2.1 & 2.3 & -32 & -91 \\
3 & 3.1 & 3.9 & -27 & -64 \\
4 & 3.8 & 6.1 & -27 & -39 \\
5 & 5.8 & 5.2 & -34 & -41 \\
6 & 1.1 & 0.4 & -33 & -42 \\
7 & 1.2 & 0.8 & -9 & -17 \\
8 & 1.9 & 1.6 & -26 & -36 \\
9 & 0.4 & 0.4 & -24 & -16 \\
10 & 0.5 & 0.9 & -26 & -35 \\
11 & 1.0 & 0.4 & 22 & -23 \\
12 & 0.8 & 0.7 & -28 & -40 \\
13 & 0.3 & 0.4 & -27 & -6 \\
14 & 0.2 & 0.2 & -32 & -34 \\
15 & 0.1 & 0.2 & -26 & -18 \\
16 & 0.7 & 1.1 & -19 & -26 \\
17 & 1.3 & 1.6 & -19 & -16 \\
18 & 1.5 & 1.9 & -20 & -2 \\
19 & 0.7 & 0.9 & -22 & -24 \\
20 & 0.2 & 0.4 & -23 & -13 \\
21 & 0.3 & 0.4 & -24 & 3 \\
22 & 0.2 & 0.1 & -27 \\
23 & 0.2 & 0.2 & -17 \\
24 & 0.2 & 0.4 & -21 \\
\end{tabular}

Table S2. Total organic carbon concentrations as measured by the CTO-375 (TOC ${ }^{\mathrm{a}}$ ) and TOT $\left(\mathrm{TOC}^{\mathrm{b}}\right.$ ) methods and the $\delta^{13} \mathrm{C}$ values for the total organic carbon and black carbon determined for each filter by CTO-375 after blank correction. 


\begin{tabular}{c|c|c|c}
\hline Regional Average & CTO/PFL & BC/TOC-IRMS & BC/TOC-TOT \\
\hline Caribbean & 1.2 & 0.45 & 0.16 \\
South America & 0.6 & 0.45 & 0.40 \\
African Plume & 0.3 & 0.13 & 0.73 \\
Subtropical Atlantic & 0.2 & 0.36 & 0.67 \\
\hline 1650 diesel particulate matter & 3.1 & 0.62 & \\
\hline
\end{tabular}

Table S3. Regional average of soot-like black carbon (CTO-375) to the broader black carbon spectrum (PFL) ratio and the ratio of black carbon in the total organic carbon determined by the CTO-375 and TOT methods.

\begin{tabular}{cc} 
Blank & CTO-375 $\left(\boldsymbol{\mu g E C ~} \mathbf{~ m}^{-\mathbf{2}}\right)$ \\
\hline lab-1 & 1.7 \\
lab-2 & 1.7 \\
lab -3 & 2.7 \\
lab-4 & 1.3 \\
field-1 & 1.7 \\
field-1 & 1.4 \\
\hline Average & $\mathbf{1 . 7} \pm \mathbf{0 . 5}$ \\
\hline GFF & $2.6 \pm 0.4$
\end{tabular}

Table S4. Measured elemental carbon (EC) values of lab blanks and field blanks via the chemothermal oxidation (CTO-375) method $\left(\mu \mathrm{gEC} \mathrm{cm}^{-2}\right)$. An average laboratory glass fiber filter blank (GFF) is also included. 


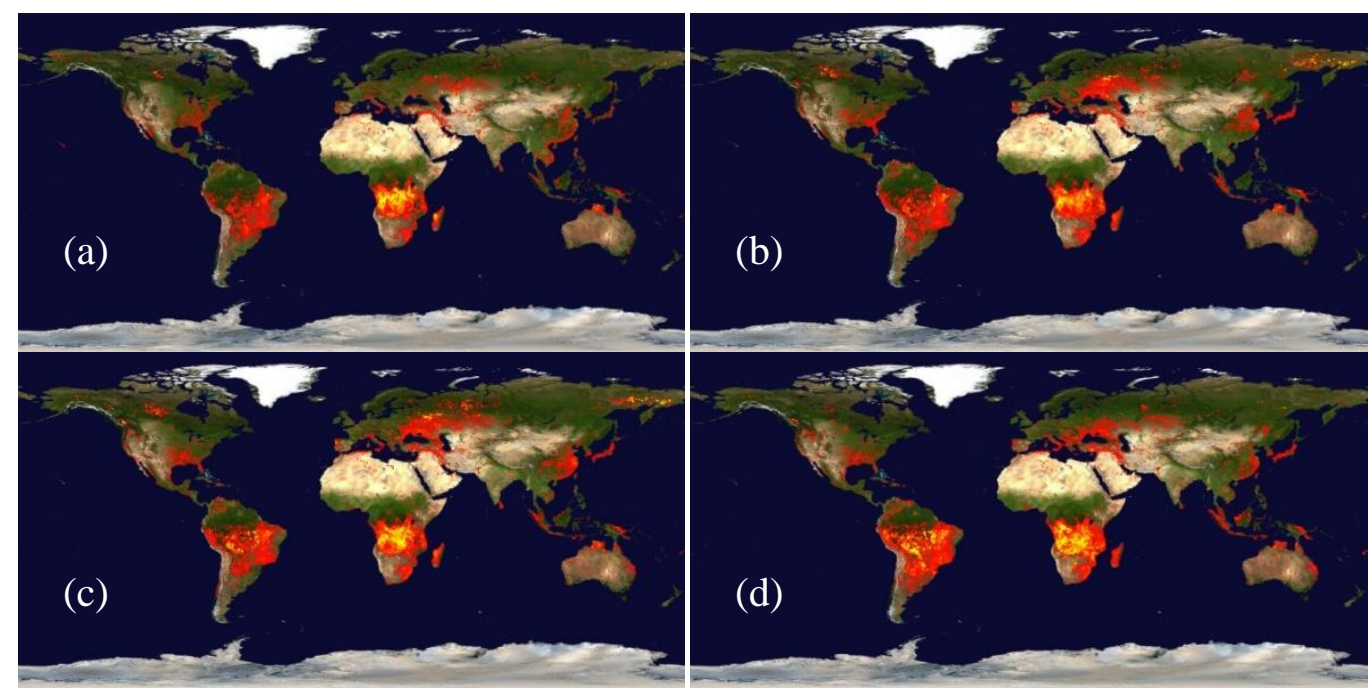

Figure S1. Global fire maps generated from the MODIS Terra and Aqua satellites for (a) June 30-July 9, 2010, (b) July 20-27, 2010, (c) July 30-August 8, 2010, and (d) August 18-28, 2010. Both (a) and (b) co-occurred during the Caribbean and South America regional sampling, (c) occurred during the African Plume regional sampling, and (d) for the subtropical Atlantic. The color indicates the number of detected wildfires from red (low) to yellow (high). Credits: Jacques Descloitres, Louis Giglio, and Reto Stokli. 


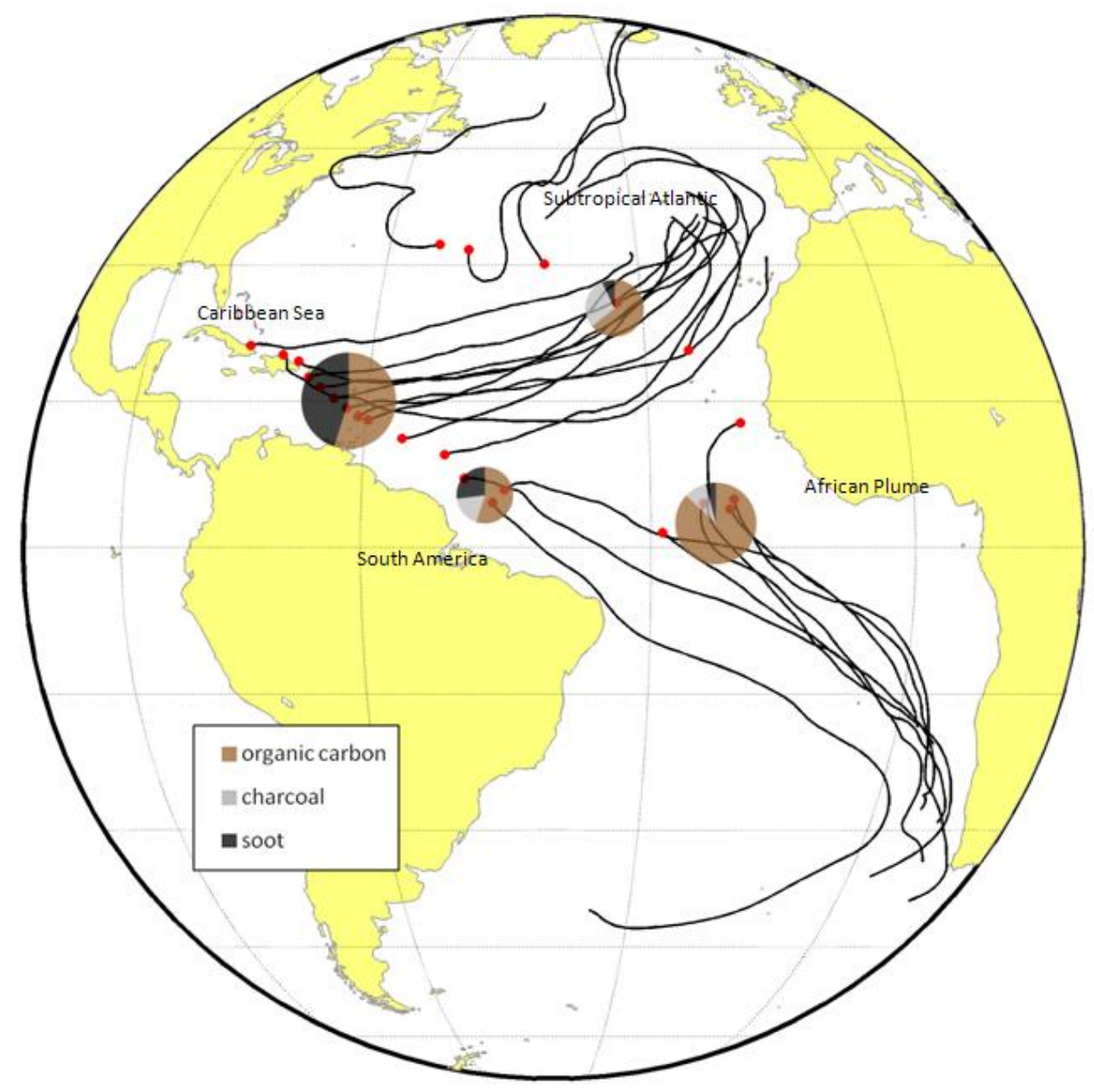

Figure S2. HySPLIT estimates of a 10-day backward wind trajectory at the end of each filter sample at a height of 20 meters and the average regional fraction of black carbon within the total organic carbon (rectilinear projection). Black carbon is further divided between labile organic carbon, soot (CTO-375), and charcoal (pyrene fluorescence loss). The size of each pie chart is in accordance to regional average total organic carbon concentration ranging from 0.2 to $1.8 \mu \mathrm{g} \mathrm{m}^{-3}$. 


\section{References}

Accardi-Dey, A., and Gschwend, P. M.: Assessing the combined roles of natural organic matter and black carbon as sorbents in sediments, Environ Sci Technol, 36, 21-29, Doi 10.1021/Es010953c, 2002.

Flores-Cervantes, D. X., Reddy, C. M., and Gschwend, P. M.: Inferring Black Carbon Concentrations in Particulate Organic Matter by Observing Pyrene Fluorescence Losses, Environ Sci Technol, 43, 4864-4870, Doi 10.1021/Es900043c, 2009.

Hammes, K., Schmidt, M. W. I., Smernik, R. J., Currie, L. A., Ball, W. P., Nguyen, T. H., Louchouarn, P., Houel, S., Gustafsson, O., Elmquist, M., Cornelissen, G., Skjemstad, J. O., Masiello, C. A., Song, J., Peng, P., Mitra, S., Dunn, J. C., Hatcher, P. G., Hockaday, W. C., Smith, D. M., Hartkopf-Froeder, C., Boehmer, A., Luer, B., Huebert, B. J., Amelung, W., Brodowski, S., Huang, L., Zhang, W., Gschwend, P. M., Flores-Cervantes, D. X., Largeau, C., Rouzaud, J. N., Rumpel, C., Guggenberger, G., Kaiser, K., Rodionov, A., Gonzalez-Vila, F. J., Gonzalez-Perez, J. A., de la Rosa, J. M., Manning, D. A. C., Lopez-Capel, E., and Ding, L.: Comparison of quantification methods to measure fire-derived (black/elemental) carbon in soils and sediments using reference materials from soil, water, sediment and the atmosphere, Global Biogeochem Cy, 21, Artn Gb3016 Doi 10.1029/2006gb002914, 2007. 


\section{CHAPTER 5}

\section{Particulate black carbon concentrations in the surface mixed layer across the Subtropical Atlantic Ocean}

This manuscript has been submitted and has been formatted for the journal Geochimica et Cosmochimica Acta

Kari Pohl ${ }^{1}$, Mark Cantwell ${ }^{2}$, Rainer Lohmann ${ }^{1 *}$

${ }^{1}$ Graduate School of Oceanography-University of Rhode Island, Narragansett, RI, USA

${ }^{2}$ U.S. Environmental Protection Agency, Atlantic Ecology Division, Narragansett, Rhode Island, U.S.A.

* Corresponding author: (email: rlohmann@mail.uri.edu ; Tel: 401-874-6612; Fax: 401-874-6811) 


\section{Abstract}

Black carbon (BC) particles are the highly condensed, carbonaceous, and aromatic structures produced by the incomplete combustion of fossil fuels and biomass burning. The transport and fate of particulate BC through the marine environment is largely unknown, but critical in understanding the role of $\mathrm{BC}$ as a terrestrial nutrient source and sink for fixed carbon. We collected surface water particles across the Subtropical Atlantic during two cruises in the summer of 2010 and the spring of 2013 to measure the $\mathrm{BC}$ concentrations in the surface mixed layer. Black carbon was detected on all samples with regionally-averaged concentrations ranging from $0.9 \pm 0.4 \mu \mathrm{g} \mathrm{L}^{-1}$ in the oligotrophic Sargasso Sea to $3.0 \pm 3.0 \mu \mathrm{g} \mathrm{L}^{-1}$ in the southwestern Atlantic along the eastern coast of South America. The overall basin-wide average BC concentration in the spring/summer of the Subtropical Atlantic was $1.9 \pm 1.8 \mu \mathrm{g} \mathrm{L}^{-1}$. Black carbon composed between $2-61 \%$ (average $17 \pm 6 \%$ ) of the particulate organic carbon. Black nitrogen was detected on $40 \%$ of the samples and represented up to $18 \%$ of the particulate nitrogen. This suggests that $\mathrm{BC}$ is present in substantial concentrations in the surface mixed layer and may be a potential nutrient source to oligotrophic environments. Surface water BC concentrations are greater than previously measured deep sediment concentrations, indicating that either significant degradation must occur to the $\mathrm{BC}$ or that the deep ocean could be a larger BC sink than previously understood. 


\section{Highlights:}

-Particulate black carbon detected in all surface water samples

-Black carbon composed an average of $17 \%$ of the particulate organic carbon -Black nitrogen was detected on $40 \%$ of the samples and composed up to $18 \%$ of the bulk nitrogen

Keywords: black carbon, particulate organic carbon, black nitrogen, stable carbon isotopes, terrigenous organic matter, Redfield ratio

\section{Introduction}

Black carbon (BC) is the thermally refractory form of terrestrial organic carbon that is composed of a complex matrix of condensed aromatic sheets (Gustafsson et al., 1997; Schmidt and Noack, 2000; Dickens et al., 2004; Elmquist et al., 2008; Lohmann et al., 2009). It is a byproduct of the incomplete combustion of fossil fuels and both natural and anthropogenic biomass burning. Black carbon is operationally defined as the spectrum of carbonaceous particles ranging from the re-condensed volatiles called soot to the solid combustion residues called chars (Masiello, 2004). The generated BC species is largely dependent on temperature and the amount of oxygen relative to fuel

during combustion (Schmidt and Noack, 2000; Keiluweit et al., 2010). In general, high temperature combustion increases the degree of $\mathrm{BC}$ aromaticity, making it more environmentally stable (Elmquist et al., 2006; Keiluweit et al., 2010). Additionally, dense biomass materials and fossil fuels are more likely to produce soot-like BC since 
they have a lower oxygen transfer efficiency (Schmidt and Noack, 2000; Schmidt et al., 2001; Elmquist et al., 2006). The degree of BC graphitization will control the lability of $\mathrm{BC}$ by determining the concentration of nutrients and plant remnants, in addition to its molecular stability.

Black carbon deposition to marine sediments removes organic carbon from the active carbon cycle, making it a sink for fixed atmospheric $\mathrm{CO}_{2}$ (Gustafsson and Gschwend, 1998; Dickens et al., 2004). However, the transport and fate of BC as it moves through the environment before sediment deposition is poorly understood. Field measurements of particulate $\mathrm{BC}$ are biased to coastal sediments since estimates have predicted that up to $90 \%$ of the BC input to the ocean deposits on the continental shelf (Gustafsson et al., 1998).The main BC input pathways into the marine environment is through fluvial and aeolian deposition (Masiello and Druffel, 1998; Mitra et al., 2002). Fluvial BC concentrations composed up to $0.78 \%$ of the total suspended solids in the Mississippi River and aerosols over London and the tropical Atlantic marine boundary layer were up to $3.0 \%$ and $0.72 \%$ BC by mass, respectively (Mitra et al., 2002; McMeeking et al., 2010; Pohl et al., 2013). Black carbon deposited via fluvial transport has the potential to be more refractory than atmospherically-deposited $\mathrm{BC}$ since the labile fraction can undergo alterations through microbial degradation in the soil before it enters the ocean, presumably allowing for a more refractory form to enter the marine environment (Jaffe et al., 2013; Masiello and Louchouarn, 2013). 
Sediment BC concentrations are mostly lower than the aerosol and fluvial input concentrations. Black carbon has been detected in sediments at concentrations of $0.3 \%$ off the Swedish continental shelf and coastal Brazil to $0.1 \%$ in deep (>3500 m) abyssal sediments (Ribeiro et al., 2004; Sanchez-Garcia et al., 2012, Lohmann et al., 2009). This imbalance between the inputs and presumed sediment sink indicates that surface water and the deep ocean must be a significant loss or storage reservoir for particulate BC. It is possible that photochemical and microbial interactions within the water column could dictate the degree of recalcitrance of the $\mathrm{BC}$ exported to pelagic sediments. However, there is little known about the concentration of this refractory black carbon pool in the surface ocean. One pivotal study detected BC water column concentrations in the Gulf of Maine ranging from $<0.1$ to $16 \mu \mathrm{g} \mathrm{L}{ }^{-1}$ (Flores-Cervantes et al., 2009). In this coastal region, particulate BC composed between 1-20\% of the particulate organic carbon, implying that it is a significant intermediate pool of organic carbon prior to deposition to the sediments.

The transport and fate of $\mathrm{BC}$ before it is deposited must be understood in order to assess the role that marine sediments play as a sink for organic carbon. It will also help to assess the role that $\mathrm{BC}$, a form of terrestrial organic matter, could play in transporting terrestrial nutrients to the marine system. The predicted BC production does not equate to the concentrations of $\mathrm{BC}$ found in soils and sediments, thus a portion of the BC must be lost or stored before deposition (Jaffe et al., 2013). Thus, the surface mixed layer has the potential to contain high $\mathrm{BC}$ concentrations. It is 
unclear if $\mathrm{BC}$ undergoes substantial degradation in the surface water or if aqueous $\mathrm{BC}$ could be an additional longer-term carbon storage reservoir.

The subtropical Atlantic Ocean has the potential to be a large reservoir for $\mathrm{BC}$ (Lohmann et al., 2009). Numerous major rivers, including the Amazon, Congo, Paraná, and Niger have far reaching plumes into the mid-Atlantic basin. Likewise, the African atmospheric emission plume, which contains high concentrations of grass and agricultural byproducts, deposits into the equatorial Atlantic region (Cahoon et al., 1992; Ramanathan and Carmichael, 2008).

Particles from the surface mixed layer of the subtropical Atlantic were collected from two separate cruises during the summer of 2010 and the spring of 2013 to quantify the concentration of particulate $\mathrm{BC}$ in the surface ocean. This study had three main hypotheses: 1) Black carbon composes a large percentage of the particulate organic carbon (POC) in the surface ocean, 2) biomass burning is a significance source of particulate black carbon due to the African emission plume, and 3) $\mathrm{BC}$ is an important source of terrestrially-derived nitrogen to the oligotrophic Atlantic.

\section{Materials and Methods}

\subsection{Study Area}

Filtered surface water samples were collected during two cruises within the subtropical Atlantic (Fig 1). A total of 70 glass fiber filter (GFF) samples were collected during EN-479 to EN-482 on the $R / V$ Endeavor during the summer of 2010 
(July 4-September 1) with an average water volume of $800 \mathrm{~L}$ filtered per sample. An additional 28 GFFs were collected during KN210-04 on the $R / V$ Knorr during the spring of 2013 (March 25-May 9) with an average of 740 L filtered per sample. We used the Ocean Surface Current Analysis- Real Time (OSCAR) model by NOAA to estimate the surface current velocity and directionality (Fig. S1).

Samples were grouped into 6 sub-regions based on geographical location to assess the major trends of surface water BC concentrations in the subtropical Atlantic: Caribbean Sea (EN-GFF 1-10, n=9), Amazon (EN-GFF 11-35, KN-GFF 19-28, n=32), Equator (EN-GFF 36-44, KN-GFF 16-18, n=12), Sargasso Sea (EN-GFF 59-70, n=12), Southwest Atlantic (KN-GFF 1-15, $\mathrm{n}=15)$, and East Atlantic (EN-GFF 45-58, $\mathrm{n}=13$ ). The East Atlantic region is within the African emission plume and the Southwest Atlantic is along the eastern coast of South America (Fig. 1).

\subsection{Sample Collection}

Surface mixed layer particles were collected during transit using Whatman binder-free glass microfiber filters with minimum particle retention of $1 \mu \mathrm{m}$ from an inflow pump positioned approximately $5 \mathrm{~m}$ under the vessel. The exposed filter area was $133 \mathrm{~cm}^{2}$. Glass fiber filters were pre-combusted at $450^{\circ} \mathrm{C}$ before sample collection; after collection, GFFs were stored loosely in pre-combusted aluminum foil and kept frozen at $-10^{\circ} \mathrm{C}$ until analysis. Water was filtered for 24 hours or was stopped when the flow rate decreased below $1 \mathrm{~L} \mathrm{~min}^{-1}$. We note that GFF samples from KN210-04 were 
additive for the 24 hour period whereas GFFs samples from EN-479 to EN-482 were treated as an individual samples even if sampled for $<24$ hours.

\subsection{Elemental Analysis}

Both POC and BC were measured using an Elementar Vario MICRO cube elemental analyzer (EA) coupled to an Isoprime100 isotope ratio-mass spectrometer (IR-MS). The instrumental limit of detection was $100 \mathrm{ng}$ of carbon. Black carbon was isolated using a chemothermal oxidation at $375^{\circ} \mathrm{C}(\mathrm{CTO}-375)$ as outlined by Gustafsson et al. (1997) and Elmquist et al. (2004). Briefly, filters were combusted at $375^{\circ} \mathrm{C}$ for 24 hours with excess oxygen present. This process oxidizes the labile organic (OC) carbon fraction while the thermally refractory soot-like BC remains. Subsamples of $2.4 \mathrm{~cm}^{2}$ were first acidified in a desiccator with concentrated hydrochloric acid vapors for 24 hours with a water vapor trap in order to remove carbonate carbon. Half of the acidified filters were analyzed for POC and the remaining filters were processed for BC using the CTO-375 method. Approximately $75 \%$ of the filters were analyzed for POC and BC in duplicate using IR-MS with $<15 \%$ difference from the mean. Elemental analysis detected both the carbon and nitrogen concentration.

We determined the fraction of labile $\mathrm{OC}$ by subtracting the $\mathrm{BC}$ concentration as follows: $[\mathrm{OC}]=[\mathrm{POC}]-[\mathrm{BC}]$.

Laboratory and field blanks were also analyzed. All blanks were handled and stored identically to sample filters; field blanks had approximately $1 \mathrm{~L}$ of water filtered 
through. A total of 6 blanks were collected from the R/V Endeavor cruises and 5 for the R/V Knorr cruise. There was no significant difference between field and laboratory blanks. We blank-corrected our data with the following values for each data set $(\mathrm{R} / \mathrm{V}$ Endeavor and $R / V$ Knorr, respectively): 0.9 and $1.3 \%$ for POC, 1.1 and $1.3 \%$ for BC, 0.2 and $0.3 \%$ for total nitrogen, and 0.2 and $0.3 \%$ for black nitrogen. In additional experiments, the blank-associated carbon and nitrogen remained constant despite a varying volume of filtered water. We assumed that this carbon and nitrogen was an inherent blank from retained carbon and nitrogen within the filters and remained constant during sampling.

\subsection{Isotopic analysis}

Stable carbon $\left(\delta^{13} \mathrm{C}\right)$ and nitrogen $\left(\delta^{15} \mathrm{~N}\right)$ isotopes for the POC and BC fractions were assessed using the IR-MS alongside the elemental analysis. We used acetanilide as the standard reference material along with a laboratory blue mussel tissue (BLUM) standard (Smyntek et al., 2007).

We derived the thermally labile $\delta^{13} \mathrm{OC}$ values using a weighed mass balance (eq. 1).

$$
\delta^{13} \mathrm{OC}=\frac{\left\{\left([\mathrm{POC}] * \delta^{13} \mathrm{POC}\right)-\left([\mathrm{BC}] * \delta^{13} \mathrm{BC}\right)\right\}}{[\mathrm{OC}]}
$$

\subsection{Quality Control and Quality Assurance}

Black carbon is operationally defined by method and there are numerous approaches established for quantification. We selected the CTO-375 method, which is optimized to detect the soot-like $\mathrm{BC}$ portion from the $\mathrm{BC}$ combustion continuum (Masiello, 
2004). The CTO-375 method has brought forth a concern that charring during the thermal oxidation process could artificially elevate the BC concentrations (Gelinas et al., 2001). To demonstrate the validity of our data, we employed numerous standard reference materials (SRM) as recommended by the $\mathrm{BC}$ ring trials (Hammes et al., 2007). We used the SRMs NIST 1941b (marine sediment), NIST 1649a (urban dust), mollisol, grass char, melanoidin, and sand; at least one SRM was analyzed per 9 samples.

All SRM analyses produced CTO-375 derived BC values similar to previous studies (Currie et al., 2002; Hammes et al., 2007; Flores-Cervantes et al., 2009; Lohmann et al., 2009). Standard reference materials NIST 1941b, NIST 1649a, and mollisol had average values of $0.8 \pm 0.1 \%(n=17), 3.0 \pm 0.2 \%(n=4)$, and $0.2 \pm 0.0 \%(n=3)$, respectively. Melanoidin $(n=2)$ and sand $(n=8)$, both of which are non-BC materials, were below the detection limit of the analysis. Likewise, no grass char mass was recovered after chemothermal oxidation, which was expected since the CTO-375 method is optimized to quantify soot-like carbon and routinely oxidized char-like substances (Flores-Cervantes et al., 2009). The lack of carbon recovered on the grass char and non-BC polymer melanoidin supports that limited methodological charring occurred during analysis.

Previous studies have brought forth the concern that charring potential could increase at higher levels of organic carbon. Gelinas et al. showed that produced BC values appeared to increase linearly with organic carbon values (2001). We applied a 
regression analysis to determine if the labile OC fraction was statistically correlated to the $\mathrm{BC}$ values produced for our samples for each sub-region. We repeated this test with the $\delta^{13} \mathrm{C}-\mathrm{OC}$ and $\delta^{13} \mathrm{C}-\mathrm{BC}$.

We found that $\mathrm{BC}$ was not significantly correlated to the labile $\mathrm{OC}$ fraction in four of the six sub-regions: the Caribbean Sea, Sargasso Sea, Southwest Atlantic, and East Atlantic regions were all found to have p-values $>0.05$, indicating that the $\mathrm{BC}$ concentrations did not display a significant correlation with the organic carbon fraction. This further suggests that $\mathrm{BC}$ was not a charring artifact of the organic matter present of the filters. The Amazon and Equator, although found to be correlated, both had the lowest ratio of $\mathrm{BC} / \mathrm{POC}$ at $10 \%$ in the study region. Likewise, we found that the $\delta^{13} \mathrm{C}-\mathrm{OC}$ and $\delta^{13} \mathrm{C}-\mathrm{BC}$ data were significantly different from each other in all regions with the exception of the Sargasso Sea. This further verifies that we sampled two separate carbon pools. Another indicator of quality control is the $\mathrm{C} / \mathrm{N}$ ratio of the labile OC and the BC pools on the samples of which nitrogen was detected. All subregions had $\mathrm{C}_{\mathrm{OC}} / \mathrm{N}_{\mathrm{OC}}$ statistically different than the $\mathrm{C}_{\mathrm{BC}} / \mathrm{N}_{\mathrm{BC}}$.

Lastly, our data (see next section) shows that elevated BC fractions do not co-vary with the regions with elevated POC concentrations. Additionally, there was no linear trend in the concentration of $\mathrm{BC}$ and POC with water volume filtered (Fig. S2). The lack of a positive y-intercept indicates that there was minimal dissolved organic carbon adsorption to the GFFs during sampling (Moran et al., 1999). Finally, we suggest that minimal ship contamination occurred since two research vessels were 
used for surface water collection and displayed similar patterns for the lowconcentration black carbon regions, such as the Amazon.

\section{Results and Discussion}

\subsection{Particulate black carbon concentrations}

Particulate black carbon concentrations were detected in every sample and were greatest when surface waters were directly influenced by a terrestrial source (Figure 1; Table 1). Both the black carbon (BC) and bulk particulate organic carbon (POC) were not significantly different between the two cruises, thus were treated as one data set. The sub-regions with the greatest $\mathrm{BC}$ concentrations each received fluvial inputs from a major river. These regions, with average concentration, were the Southwest Atlantic (3.0 $\left.\pm 3.0 \mu \mathrm{g} \mathrm{L}^{-1}\right)$, Amazon $\left(2.1 \pm 1.4 \mu \mathrm{g} \mathrm{L}^{-1}\right)$, and Caribbean Sea $\left(2.0 \pm 1 . \mu \mathrm{g} \mathrm{L}^{-1}\right)$, and received input from the Paraná, Amazon, and Orinoco Rivers, respectively. The Equator and East Atlantic sub-regions both received elevated atmospheric deposition due to the African emission plume and had average concentrations of $1.5 \pm 1.6 \mu \mathrm{g} \mathrm{L}^{-1}$ and 1.3 $\pm 1.9 \mu \mathrm{g} \mathrm{L}^{-1}$, respectively. The lowest sub-regional average $\mathrm{BC}$ concentrations occurred in the oligotrophic Sargasso Sea within the North Atlantic gyre at $0.9 \pm 0.4 \mu \mathrm{g}$ $\mathrm{L}^{-1}$. The mean $\mathrm{BC}$ concentration for the entire subtropical Atlantic basin was 1.9 \pm 1.8 $\mu g \mathrm{~L}^{-1}$.

Previous studies have hypothesized that fluvial runoff, and to a lesser degree aeolian transport, would favor coastal and near shore deposition of $\mathrm{BC}$ particles due to their density (Mitra et al., 2002; Duncan et al., 2003; Koch et al., 2007). Fluvial plumes can 
extend hundreds of kilometers away from the fresh water-marine boundary, however most particles deposit 30-50 m from the river mouth (Wright and Nittrouer, 1995; Geyer et al., 2004). The input of fresh water into the marine environment creates a positively buoyant plume that can range in thickness from $10 \mathrm{~cm}$ to $10 \mathrm{~m}$, which acts to trap and transport sediments horizontally. In general, organic matter concentrations are positively correlated to river discharge (Paolini, 1990; Moreira-Turcq et al., 2003). The western boundary of the Atlantic Ocean (Southwest Atlantic region), along the South American coast, had BC concentrations up to $10.5 \mu \mathrm{g} \mathrm{L}^{-1}$ and had the significantly greatest regional concentration $\left(3.0 \pm 3.0 \mu \mathrm{g} \mathrm{L}^{-1}\right)$. This region was closest to the terrestrial biosphere, including the Paraná and Saõ Francisco River plumes and urban inputs from Bueno Aires, Río de Janero, and Saõ Paulo. The Paraná River is the second largest river in South America and the Chaco and Pampas grasslands fall within its watershed, thus have a potential to transport high concentrations of firederived organic matter, including BC-like materials (Depertris and Lenardon, 1982; Moreira-Turcq et al., 2003).

Elevated BC concentrations were expected in the Eastern Atlantic and Equatorial regions of the subtropical Atlantic due to the intense African grassland and agricultural burning activities which are transported to this region by the easterly trade winds (Perry et al., 1997; Lohmann et al., 2009). Surface water within the East Atlantic region, within this atmospheric emission plume, was observed to have one of the highest $\mathrm{BC}$ concentrations detected at $7.6 \mu \mathrm{g} \mathrm{L}^{-1}$ (Figure 1). The atmospheric deposition of $\mathrm{BC}$ has the potential to be younger (less degraded) than fluvial- 
discharged organic matter; black carbon will age in soil but little aging is expected between the creation of $\mathrm{BC}$ and atmospheric deposition into the ocean (Raymond and Bauer, 2001; Masiello and Louchouarn, 2013).

Black carbon concentrations across the oligotrophic Sargasso Sea were significantly lower than the basin-wide mean concentration $\left(1.9 \pm 1.8 \mu \mathrm{g} \mathrm{L}^{-1}\right)$ at $0.9 \pm 0.4 \mu \mathrm{g} \mathrm{L}^{-1}$. This region has minimal fluvial and atmospheric deposition potentials, thus the presence of BC above detection limit on every sample in the Sargasso Sea demonstrates the ubiquity of $\mathrm{BC}$ particles and their persistence (Figure 1, Table 1). The Sargasso Sea region also contains a high density of marine traffic, thus these low $\mathrm{BC}$ concentrations further suggests that ship-produced soot was minimally sampled (Fig. S3).

There was no statistical difference between the BC concentrations from the summer 2010 (EN-479 to EN-482) and spring 2013 (Kn-210-04) cruises. The first cruise occurred during a strengthened South Equatorial Current, thus elevated equatorial BC concentrations during the sampling period were strongly influenced by water advected from Central Africa (Figure S1). Likewise, the Amazon River plume and Equatorial Counter Current also had an elevated eastward velocity, thus particles collected above $5^{\circ} \mathrm{N}$ likely contained Amazonian plume water. Current velocities during the spring 2013 cruise were weaker and trended more southward, presumably due to the position of the Intertropical Convergence Zone. The Brazilian Current had weaker velocities 
and likely had a minimal influence on transporting BC from the Southern Atlantic Ocean.

The average dry weight $\mathrm{BC}$ concentration in the subtropical Atlantic waters was $1.8 \pm 0.8 \%$ (BC/POC average of $17 \pm 6 \%$ ) with a sub-regional average of $1.3 \%$ in the Amazon region up to $2.2 \%$ in the Southwest Atlantic region. These surface water concentrations are an order of magnitude higher than the previously measured BC concentrations in the underlying sediments (Lohmann et al., 2009). However, the ratio of $\mathrm{BC} / \mathrm{POC}$ is fairly constant, possibly due to different inorganic mineral contributions. Sediment BC concentrations in the Amazonian fan ranged from 0.11 to $0.12 \%$ (BC/POC between $13-33 \%)$ and were $\leq 0.11 \%$ (BC/POC between $3-12 \%)$ off the west African coast of Cameroon and Angola (Lohmann et al., 2009). These surface water concentrations were also greater than urban-influenced coastal sediments from the Gulf of Maine $(\leq 0.173 \%$ with a BC/POC between 3-15\%) and from total suspended solids from the Mississippi River plume in the Gulf of Mexico, which had BC concentrations up to $0.78 \%$ with a BC/POC between 1-20\% (Gustafsson and Gschwend, 1998; Mitra et al., 2002).

This indicates that proportional degradation must occur to the surface water BC particles, in addition to the POC, before they are deposited to the sediment (Table 1). Black carbon concentrations from the marine boundary layer from the same cruise 2010 (EN-479 to EN-482) had concentrations ranging from 0.4 to $0.7 \%$ (regional 
average of $0.5 \pm 0.1 \%$ ), suggesting that atmospheric deposition alone cannot account for the measured surface water BC concentrations (Pohl et al., 2013).

\subsection{Bulk particulate organic carbon concentrations}

Particulate organic carbon concentrations were significantly greater in the Amazon plume (compared to the basin-wide mean of $15.2 \pm 12.6 \mu \mathrm{g} \mathrm{L}^{-1}$ ) with an average concentration of $21.3 \pm 11.2 \mu \mathrm{g} \mathrm{L}^{-1}$ (Table 1). This agrees with previous literature that the Amazon-Atlantic interface is highly productive up to hundreds of kilometers from the river mouth (Muller-Karger et al. 1995; Subramaniam et al. 2008). Particulate organic carbon concentrations in the regions influenced by the African emission plume (East Atlantic and Equator) were also elevated at $15.6 \pm 16.9 \mu \mathrm{g} \mathrm{L}^{-1}$ and $12.3 \pm 20.2$ $\mu \mathrm{g} \mathrm{L}{ }^{-1}$, respectively. These two regions had the potential for nutrient inputs, thus enhanced productivity, due to equatorial upwelling and atmospheric deposition from the emission plume (Wefer and Fischer, 1993). Bulk POC concentrations in the Caribbean Sea had a regional average of $13.9 \pm 11.5 \mu \mathrm{g} \mathrm{L}^{-1}$, presumably due to a combined input of the Orinoco River and local activities of the Caribbean Islands. The Caribbean Sea and Orinoco watershed is well documented to have temporal wildfire events highly coupled to climatic events resulting from agricultural practices (Armenteras-Pascual et al., 2011)

As expected, the lowest POC concentrations were found within the oligotrophic Sargasso Sea region. Average POC concentrations for this region were $4.4 \pm 2.2 \mu \mathrm{g} \mathrm{L}$

${ }^{1}$, which were significantly lower compared the overall mean POC concentrations 
detected in this study $\left(15.2 \pm 12.6 \mu \mathrm{g} \mathrm{L}^{-1}\right)$. These concentrations agree with previously measured particulate organic carbon concentrations in this region from 0.48 to $13.3 \mu \mathrm{g}$ $\mathrm{L}^{-1}$ (Schulz-Bull et al., 1998). Since the measurements of POC include black carbon, it is necessary to assess the thermally labile organic carbon (OC) fraction which is the difference between the POC and $\mathrm{BC}$ as determined by the chemothermal oxidation (Table 1). All concentrations of non-BC organic matter were reduced by a basin average of $14 \pm 5 \%$. This indicates that an average of $14 \%$ of the bulk POC pool (i.e., the BC) is at least semi-labile or recalcitrant.

The general pattern of bulk POC concentrations in the subtropical Atlantic surface waters were similar to the $\mathrm{BC}$ concentrations (Table 1). This could indicate that particulate BC inputs may be attributed to nutrient deposition that promotes productivity. Previous works have shown that the wet deposition of black carbon and $\mathrm{NO}_{\mathrm{y}}$ are positively correlated from boreal fire events and vehicular combustion-derive materials (Martin et al., 2006; Vanderstraeten et al., 2011). This supports our hypothesis that the $\mathrm{BC}$ atmospheric deposition is associated with the marine limiting nutrient nitrogen, and may be a source of nutrients, via fluvial and atmospheric transport, to oligotrophic regions (Talbot et al., 1986).

Satellite observations using the SeaWIFS model have projected concentrations of POC in the subtropical Atlantic ocean to range from 11.8 to $61.3 \mu \mathrm{g} \mathrm{L}{ }^{-1}$ with the lower concentrations occurring within the North and South Atlantic gyres and the higher concentrations occurring within the fluvial plumes attributed to the Congo, Niger, and 
Amazon rivers (Gardener et al., 2006; Thomalla et al., 2006). The POC concentrations measured in this study agreed with the lower end of these satellite estimates.

\section{3: Stable carbon and nitrogen isotope analysis for source assessment}

The stable carbon isotope ratio $\left(\delta^{13} \mathrm{C}\right)$ for the POC, with the exception of the Southwest Atlantic region, narrowly ranged from -19.5 to $-21.8 \%$ and is apportioned as marine plankton (Table 2; Holtvoeth et al., 2003). We applied a weighted mass balance to remove the $\delta^{13} \mathrm{C}-\mathrm{BC}$ signature to assess the labile $\mathrm{OC}$ fraction. The labile $\delta^{13} \mathrm{C}-\mathrm{OC}$ fraction remained in the marine plankton range from -18.8 to $-22.7 \%$, including the Southwest Atlantic region. While the marine signature of the POC in this region could result from the mixing of terrestrial $\mathrm{C}_{3}$ and $\mathrm{C}_{4}$ carbon fixation, previous studies have shown that equatorial Atlantic organic carbon is mostly marine-derived through chl-a analysis and plankton identification (Fischer, 1991; Agusti and Duarte, 1999; Putuad et al., 2000; O’Dowd et al. 2004).

By definition, BC can only be derived from the terrestrial biosphere (Schmidt and Noack, 2000; Mitra et al. 2002; Dickens et al., 2004). All regions had an enriched $\delta^{13} \mathrm{C}-\mathrm{BC}$ than the $\delta{ }^{13} \mathrm{C}$-POC (Table 2). The $\delta^{13} \mathrm{C}-\mathrm{BC}$ had a regional range from -17.5 to $-22.2 \%$. This enrichment could be the result of significant $\mathrm{C}_{4}$ inputs from the African and South American savanna biomes (Cahoon et al., 1992; Wagner and Dupont, 1999; Lohmann et al., 2009). The subtropical Atlantic receives elevated inputs of grass-carbon from the African and South American grasslands although $\mathrm{C}_{4}$ carbon fixation composes < 15\% of modern day vegetation (Schwartz et al., 1986; 
Cerling et al., 1993). Additionally, this $\delta^{13} \mathrm{C}-\mathrm{BC}$ enrichment could be the result of the preferential degradation of the ${ }^{12} \mathrm{C}$ isotope via photolysis and respiration or a greater

residence time for ${ }^{13} \mathrm{C}$-enriched materials. Previous laboratory works have shown that $\mathrm{C}_{4}$ materials degrade slower than $\mathrm{C}_{3}$ materials under the same environmental conditions; likewise, the lighter $\mathrm{C}_{3}$ materials have a greater advection potential, thus $\mathrm{C}_{4}$ organic matter could have a longer residence time in the surface waters (Akin et al., 1983; Mayer et al., 2007).

There was little variation in the stable nitrogen isotope ratio $\left(\delta^{15} \mathrm{~N}\right)$ between the POC and $\mathrm{BC}$ pools (Table 2). The $\delta^{15} \mathrm{~N}-\mathrm{POC}$ and $\delta^{15} \mathrm{~N}-\mathrm{BC}$ ranged from 3.4 to $-0.6 \%$ and 3.7 to $-0.4 \%$, respectively. These low $\delta^{15} \mathrm{~N}$ values could be attributed to significant inputs of degraded terrestrial soil organic matter, such as leaf and root litter, which span the range of $\delta^{15} \mathrm{~N}$ from -3.8 to $-1.6 \%$ (Nadelhoffer and Fry, 1988). Additionally, low $\delta^{15} \mathrm{~N}$ values have been previously quantified in the oligotrophic northern Subtropical Atlantic as a function of newly fixed nitrogen inputs by diazotrophs such as Trichodesmium (Benner et al., 1997; Montoya et al., 2002).

\section{4. $\mathrm{BC} / \mathrm{POC}$ ratio: Redefining lability of $\mathrm{POC}$ in the Atlantic}

We determined that $17 \pm 6 \%$ of the bulk POC in the subtropical Atlantic was composed of soot-like BC. Thus, not only was particulate BC found on every sample in this region, it also composed a significant fraction of the perceived bio-available organic carbon. These concentrations help bridge the knowledge gap of the BC cycle; specifically that it is found in particulate form in remote marine surface waters and 
could be a sink for fixed atmospheric carbon and persistent organic pollutants as these particles are transported to the deep ocean and sediment (Schmidt and Noack, 2000; Lohmann et al., 2009).

The structure of $\mathrm{BC}$, compared to the labile OC fraction, is more condensed and organized, and thus presumed to be more refractory to biological respiration (Schmidt and Noack, 2000; Lohmann et al. 2009). The ratio of BC/POC is an estimate of the minimum fraction of terrestrial carbon within the bulk total organic matter. The highest ratios of $\mathrm{BC} / \mathrm{POC}$ were found in the Caribbean Sea $(0.23 \pm 0.29)$ and Southwest Atlantic $(0.25 \pm 0.27)$ regions (Table 1$)$. Approximately a quarter of the bulk POC in these regions was terrestrial in origin and is potentially semi-labile. The BC/POC fraction for both regions is largely controlled by lowered POC concentrations (Table 1). Both regions have fluvial inputs and bordered land susceptible to wildfire events (Koch et al., 2007; Ramanthan and Carmichael, 2008; Armenteras-Pascual et al., 2011). In general, the ratio of BC/POC tended to decrease with increasing distance from a BC source region (Wagner and Dupont, 1999).

We suggest that atmospheric deposition provided a large fraction of the overall $\mathrm{BC}$ concentration to the surface water. The BC/POC ratio for the oligotrophic Sargasso Sea $(0.16 \pm 0.11)$ was comparable to the East Atlantic region $(0.15 \pm 0.12)$ which was influenced by the African emission plume (Table 1). Both of these regions are remote (non-coastal and not within a fluvial plume or major current), thus atmospheric deposition is presumably the primary BC input (Gustafsson et al. 1997; Gustafsson 
and Gschwend, 1998). The Amazon and Equator regions had the lowest regional average $\mathrm{BC} / \mathrm{POC}$ ratio in the subtropical Atlantic at $0.10 \pm 0.05$ and $0.10 \pm 0.13$, respectively. For the Amazon region, the POC was significantly elevated and diluted the $\mathrm{BC}$. It is possible that the extremely productive Amazon plume could have enhanced microbial respiration to degrade the particulate BC pool (Aller and Blair, 2006). Additionally, both the Amazon and Equator regions have the potential for BC to undergo enhanced photolysis due to the buoyancy of the Amazon plume and the vertical upwelling of water near the equator (Atkinson et al., 2002; Geyer et al., 2004).

\section{5: $\mathrm{C} / \mathrm{N}$ ratios: The presence of black nitrogen}

Black nitrogen is defined here as the nitrogen which remained after the chemothermal oxidation and was detected on $40 \%$ of the samples. Black carbon is part of a combustion continuum in which lower formation temperatures, often called chars in the literature, can retain nitrogen (Masiello, 2004). Nitrogen retention from combustion is particularly true for grass chars since its cellulose is stable and will not fully oxidize at a lower combustion temperature, typically $<300^{\circ} \mathrm{C}$ (Knicker, 2010). This terrestrial nitrogen could be a nutrient source to the subtropical Atlantic. Upwards to $18 \%$ of the particulate organic nitrogen was deemed as black nitrogen (Table 2).

The bulk POC carbon was significantly correlated to the total organic nitrogen (TON) and the regional average $C / N$ ratio was $7.7 \pm 2.7\left(R^{2}=0.89, p=0.005\right.$; Figure 4$)$. The labile OC to labile $\mathrm{N}$ ratio was $7.0 \pm 2.7$, which is classically apportioned as marine as

predicted by the Redfield ratio (Redfield, 1958). The ratio of BC to black nitrogen was 
also significantly correlated $\left(\mathrm{R}^{2}=0.48, \mathrm{p}\right.$-value $\left.=0.5 \mathrm{E}^{-14}\right)$ and had a regional average of $16.1 \pm 17.0$ for the subtropical Atlantic (Figure 4). Terrestrial organic matter is typically characterized as being depleted in nitrogen relative to carbon (Hedges et al., 1997). Glaser et al. found that pine wood char, at a combustion temperature of $300^{\circ} \mathrm{C}$, had $\mathrm{C} / \mathrm{N}$ ratios ranging from $34-50$, which suggests that this terrestrial organic matter is more nitrogen-enriched (1998). The deviation of the BC fraction from the Redfield ratio is an additional indicator of terrestrial origin.

Black nitrogen appeared to have greater concentrations in the regions directly influenced by biomass combustion, such as wildfires from the Savanna grasslands. Concentrations of black nitrogen were highest in the Southwest Atlantic at $0.4 \pm 0.6 \mu \mathrm{g}$ $\mathrm{L}^{-1}$, which agrees with the elevated black carbon concentrations likely due to inputs from the Paraná River (Table 2). The Amazon region and African plume influenced Equator and East Atlantic regions all had a black nitrogen concentration of $0.1 \mu \mathrm{g} \mathrm{L}^{-1}$. The oligotrophic Sargasso Sea and Caribbean Sea had an average regional black nitrogen concentration below the detection limit. This is expected for the Sargasso Sea since it has minimal terrestrial inputs and $\delta^{13} \mathrm{C}$ data suggests that combustion byproducts from the Caribbean Sea region are derived by fossil fuel combustion, which would have less efficient nitrogen retention (Knicker, 2010).

\section{6: Estimate of surface water $B C$ flux}

We estimated the magnitude of $\mathrm{BC}$ export from the surface mixed layer to the deep ocean in an oligotrophic marine environment. For that purpose, we combined the 
measured ratio of $\mathrm{BC}$ to the $\mathrm{POC}$ in the surface ocean with previously reported POC export fluxes $(>53 \mu \mathrm{m})$ from the Equatorial Atlantic region during the spring/summer season using ${ }^{234} \mathrm{Th}-{ }^{238} \mathrm{U}$ disequilibria, sediment traps, and model simulations (Jahnke, 1996; Buesseler, 1998; Charette and Moran, 1999; Antia et al., 2001; Anderson and Pondaven, 2003; Thomalla et al., 2006).

The following assumptions were made in order to approximate the magnitude of BC export fluxes: 1) that little variation occurs to POC export fluxes within a given region during different years, 2) that the $>53 \mu \mathrm{m}$ particulate organic carbon size fraction is representative of the $>1 \mu \mathrm{m}$ size fraction collected and analyzed in this study, and 3) that the $\mathrm{BC} / \mathrm{POC}$ ratio remained constant within the water column. An estimated $\mathrm{BC}$ export flux has not been assessed in a remote region and its magnitude could provide valuable insight to the movement of $\mathrm{BC}$ in an aquatic environment.

Black carbon export fluxes from the surface mixed layer ranged from $0.2 \mathrm{gC} \mathrm{m}^{-2} \mathrm{yr}^{-1}$ in the Sargasso Sea region up to $16.3 \mathrm{gC} \mathrm{m}^{-2} \mathrm{yr}^{-1}$ in the East Atlantic region within the African emission plume (Table 3). Estimated BC export fluxes were lowest in the Sargasso Sea and Caribbean Sea, at $0.2-4.8$ and $1.7 \mathrm{gC} \mathrm{m}^{-2} \mathrm{yr}^{-1}$, respectively. This is expected since the Sargasso Sea had significantly the lowest regional average BC concentration and very few export estimates have been measured in the Caribbean Sea. The regions with terrestrial influence all had greater BC export fluxes. The Southwest Atlantic region, near the Paraná River, had a regional BC export flux range 
from 1.5 up to13.1 $\mathrm{gC} \mathrm{m}^{-2} \mathrm{yr}^{-1}$ while the Amazon region had a large range from 0.6$13.1 \mathrm{gC} \mathrm{m}^{-2} \mathrm{yr}^{-1}$.

Charette and Moran (1999) estimated a regional POC export flux of $78.0 \mathrm{gC} \mathrm{m}^{-2} \mathrm{yr}^{-1}$ from a transect across the Equatorial Atlantic region during the spring of 1996. We applied the basin-wide BC/POC average of $17 \%$ from this study to deduce that the spring/summer average BC export flux for the subtropical Atlantic was $12.5 \mathrm{gC} \mathrm{m}^{-2} \mathrm{yr}^{-}$ ${ }^{1}$ (Table 1; Table 3). For comparison, Flores-Cervantes et al. (2009) estimated that the average $\mathrm{BC}$ export in the Gulf of Maine during the spring/summer of 2006 was 10 $\mathrm{gC} \mathrm{m}^{-2} \mathrm{yr}^{-1}$ with a range between 0.7 to $31 \mathrm{gC} \mathrm{m}^{-2} \mathrm{yr}^{-1}$.

Our estimated remote regional values fall within the same order of magnitude as the coastal Gulf of Maine. Our BC/POC ratio was derived from a surface water depth of $\sim 5 \mathrm{~m}$ and is not representative of the chlorophyll-a maximum depth. Thus the mean integrated surface mixed layer BC/POC ratio is likely smaller than our derived ratio at $5 \mathrm{~m}$ due to non-steady state POC production. Thus we can conclude that the upper limit estimate of $\mathrm{BC}$ export flux for this region is $\sim 12.5 \mathrm{gC} \mathrm{m}^{-2} \mathrm{yr}^{-1}$. This demonstrates that remote regions with elevated fluvial and atmospheric inputs can have $\mathrm{BC}$ export ratios comparable to a coastal environment. These novel flux approximations suggest that surface mixed layer BC export is an important pathway for transporting this fixed carbon to the deep ocean. 
Additionally, the estimated $\mathrm{BC}$ export fluxes were implemented to predict the $\mathrm{BC}$ residence time in the surface mixed later of the equatorial Atlantic region. Moran and Charette (1999) had determined POC residence times in this region to average $14 \pm 27$ days with the longest residence time occurring in an oligotrophic gyre (29 days) and the shortest occurring in the region of equatorial upwelling (1.7 to 4.9 days). Likewise, POC residence time in the Pacific Ocean was 14 days within the equatorial upwelling and 6-7 days elsewhere (Peña et al., 1991).

The estimated $\mathrm{BC}$ residence time within the surface mixed layer (fixed to $70 \mathrm{~m}$, the approximate depth of the surface mixed layer boundary) ranged from 4 to 15 days. The shortest residence times were estimated within the equatorial and Amazon regions at 4 and 8 days, respectively, while the longer residence times occurred within the Eastern Atlantic (9 days), Sargasso Sea (10 days), and Southwest Atlantic (15 days). These $\mathrm{BC}$ residence times suggest that the lifetime of $\mathrm{BC}$ in the surface mixed layer is on the order of days to weeks.

\section{Conclusion}

Particulate black carbon was detected in all surface water samples within the subtropical Atlantic Ocean. Sub-regional average black carbon concentrations ranged from 0.9 to $3.0 \mu \mathrm{g} \mathrm{L}^{-1}$ and composed a basin-wide average of $1.8 \%$ of the collected particulates. This concentration is an order of magnitude higher than black carbon concentrations quantified in the underlying sediments, suggesting that black carbon undergoes substantial degradation between input into the surface waters and 
deposition to marine sediments or that the surface mixed layer and deep ocean could be a temporary storage reservoir for BC. Stable carbon analysis suggests that $\mathrm{C}_{4}$ plant material was the primary source of black carbon to the region and that atmospheric deposition could account for a substantial fraction of carbon input. Black carbon composed an average of $17 \pm 6 \%$ of the particulate organic carbon. Black nitrogen, as defined by the chemothermal oxidation method, was detected on $40 \%$ of the samples, suggesting that particulate black carbon could be a source of terrestrial nitrogen to oligotrophic environments.

\section{Acknowledgements}

We thank the National Science Foundation for support (OCE-0851044) and the crew and captain of the $\mathrm{R} / \mathrm{V}$ Endeavor and $\mathrm{R} / \mathrm{V}$ Knorr for their help with collecting the samples. We acknowledge the help of Rick McKinney and Julia Sullivan (U.S. Environmental Protection Agency) in instrumental support. Erin Markham (URI) and Hilary Hamer (RPI) are also acknowledged for assisting in the sample collection. Pat Kelly (GSO-URI) and Matthew Baumann (GSO-URI) are acknowledged for providing constructive edits.

\section{References}

Agusti, S., and C. M. Duarte (1999), Phytoplankton chlorophyll a distribution and water column stability in the central Atlantic Ocean, Oceanol Acta, 22(2), 193-203.

Akin, D. E., J. R. Wilson, and W. R. Windham (1983), Site and Rate of Tissue Digestion in Leaves of C-3, C-4, and C3/C4 Intermediate Panicum Species, Crop Sci, 23(1), 147-155. 
Aller, R. C., and N. E. Blair (2006), Carbon remineralization in the Amazon-Guianas tropical mobile mudbelt: A sedimentary incinerator, Cont Shelf Res, 26(17-18), 22412259.

Anderson, T. R., and P. Pondaven (2003), Non-redfield carbon and nitrogen cycling in the Sargasso Sea: pelagic imbalances and export flux, Deep-Sea Res Pt I, 50(5), 573591.

Antia, A. N., et al. (2001), Basin-wide particulate carbon flux in the Atlantic Ocean: Regional export patterns and potential for atmospheric $\mathrm{CO} 2$ sequestration, Global Biogeochem Cy, 15(4), 845-862.

Armenteras-Pascual, D., J. Retana-Alumbreros, R. Molowny-Horas, R. M. RomanCuesta, F. Gonzalez-Alonso, and M. Morales-Rivas (2011), Characterising fire spatial pattern interactions with climate and vegetation in Colombia, Agr Forest Meteorol, 151(3), 279-289.

Atkinson, L. P., A. Valle-Levinson, D. Figueroa, R. De Pol-Holz, V. A. Gallardo, W. Schneider, J. L. Blanco, and M. Schmidt (2002), Oceanographic observations in Chilean coastal waters between Valdivia and Concepcion, J Geophys Res-Oceans, 107(C7).

Benner, R., B. Biddanda, B. Black, and M. McCarthy (1997), Abundance, size distribution, and stable carbon and nitrogen isotopic compositions of marine organic matter isolated by tangential-flow ultrafiltration, Mar Chem, 57(3-4), 243-263.

Buesseler, K. O. (1998), The decoupling of production and particulate export in the surface ocean, Global Biogeochem Cy, 12(2), 297-310.

Cahoon, D. R., B. J. Stocks, J. S. Levine, W. R. Cofer, and K. P. Oneill (1992), Seasonal Distribution of African Savanna Fires, Nature, 359(6398), 812-815.

Cerling, T. E., Y. Wang, and J. Quade (1993), Expansion of C4 Ecosystems as an Indicator of Global Ecological Change in the Late Miocene, Nature, 361(6410), 344345 .

Charette, M. A., and S. B. Moran (1999), Rates of particle scavenging and particulate organic carbon export estimated using Th-234 as a tracer in the subtropical and equatorial Atlantic Ocean, Deep-Sea Res Pt Ii, 46(5), 885-906.

Currie, L. A., et al. (2002), A critical evaluation of interlaboratory data on total, elemental, and isotopic carbon in the carbonaceous particle reference material, NIST SRM 1649a, J Res Natl Inst Stan, 107(3), 279-298. 
Depetris, P. J., \& Lenardon, A. M. (1982), Particulate and dissolved phases in the Parana River, Transport of Carbon and Minerals in Major World Rivers, Pt, 1, 385395.

Dickens, A. F., Y. Gelinas, C. A. Masiello, S. Wakeham, and J. I. Hedges (2004), Reburial of fossil organic carbon in marine sediments, Nature, 427(6972), 336-339.

Ding, Y., Y. Yamashita, W. K. Dodds, and R. Jaffe (2013), Dissolved black carbon in grassland streams: Is there an effect of recent fire history?, Chemosphere, 90(10), 2557-2562.

Duncan, B. N., R. V. Martin, A. C. Staudt, R. Yevich, and J. A. Logan (2003), Interannual and seasonal variability of biomass burning emissions constrained by satellite observations, J Geophys Res-Atmos, 108(D2).

Elmquist, M., O. Gustafsson, and P. Andersson (2004), Quantification of sedimentary black carbon using the chemothermal oxidation method: an evaluation of ex situ pretreatments and standard additions approaches, Limnol Oceanogr-Meth, 2, 417-427.

Elmquist, M., G. Cornelissen, Z. Kukulska, and O. Gustafsson (2006), Distinct oxidative stabilities of char versus soot black carbon: Implications for quantification and environmental recalcitrance, Global Biogeochem Cy, 20(2).

Elmquist, M., I. Semiletov, L. D. Guo, and O. Gustafsson (2008), Pan-Arctic patterns in black carbon sources and fluvial discharges deduced from radiocarbon and PAH source apportionment markers in estuarine surface sediments, Global Biogeochem Cy, 22(2).

Fischer, G. (1991), Stable Carbon Isotope Ratios of Plankton Carbon and Sinking Organic-Matter from the Atlantic Sector of the Southern-Ocean, Mar Chem, 35(1-4), 581-596.

Flores-Cervantes, D. X., D. L. Plata, J. K. MacFarlane, C. M. Reddy, and P. M. Gschwend (2009), Black carbon in marine particulate organic carbon: Inputs and cycling of highly recalcitrant organic carbon in the Gulf of Maine, Mar Chem, 113(34), 172-181.

Gardner, W. D., A. Mishonov, and M. J. Richardson (2006), Global POC concentrations from in-situ and satellite data, Deep-Sea Res Pt Ii, 53(5-7), 718-740.

Gelinas, Y., K. M. Prentice, J. A. Baldock, and J. I. Hedges (2001), An improved thermal oxidation method for the quantification of soot/graphitic black carbon in sediments and soils, Environ Sci Technol, 35(17), 3519-3525. 
Geyer, W. R., P. S. Hill, and G. C. Kineke (2004), The transport, transformation and dispersal of sediment by buoyant coastal flows, Cont Shelf Res, 24(7-8), 927-949.

Glaser, B., L. Haumaier, G. Guggenberger, and W. Zech (1998), Black carbon in soils: the use of benzenecarboxylic acids as specific markers, Org Geochem, 29(4), 811-819.

Gustafsson, Ö., Gschwend, P. M., Buesseler, K. O. (1997), Using 234Th disequilibria to estimate the vertical removal rates of polycyclic aromatic hydrocarbons from the surface ocean, Mar. Chem., 57, 11-23.

Gustafsson, O., and P. M. Gschwend (1998), The flux of black carbon to surface sediments on the New England continental shelf, Geochim Cosmochim Ac, 62(3), 465472.

Gustafsson, O., F. Haghseta, C. Chan, J. MacFarlane, and P. M. Gschwend (1997), Quantification of the dilute sedimentary soot phase: Implications for PAH speciation and bioavailability, Environ Sci Technol, 31(1), 203-209.

Hammes, K., et al. (2007), Comparison of quantification methods to measure firederived (black/elemental) carbon in soils and sediments using reference materials from soil, water, sediment and the atmosphere, Global Biogeochem Cy, 21(3).

Hedges, J. I., R. G. Keil, and R. Benner (1997), What happens to terrestrial organic matter in the ocean?, Org Geochem, 27(5-6), 195-212.

Holtvoeth, J., T. Wagner, and C. J. Schubert (2003), Organic matter in riverinfluenced continental margin sediments: The land-ocean and climate linkage at the Late Quaternary Congo fan (ODP Site 1075), Geochem Geophy Geosy, 4.

Jaffe, R., Y. Ding, J. Niggemann, A. V. Vahatalo, A. Stubbins, R. G. M. Spencer, J. Campbell, and T. Dittmar (2013), Global Charcoal Mobilization from Soils via Dissolution and Riverine Transport to the Oceans, Science, 340(6130), 345-347.

Jahnke, R. A. (1996), The global ocean flux of particulate organic carbon: Areal distribution and magnitude, Global Biogeochem Cy, 10(1), 71-88.

Keiluweit, M., P. S. Nico, M. G. Johnson, and M. Kleber (2010), Dynamic Molecular Structure of Plant Biomass-Derived Black Carbon (Biochar), Environ Sci Technol, 44(4), 1247-1253.

Knap, A., T. Jickells, A. Pszenny, and J. Galloway (1986), Significance of Atmospheric-Derived Fixed Nitrogen on Productivity of the Sargasso Sea, Nature, 320(6058), 158-160. 
Knicker, H. (2010), "Black nitrogen" - an important fraction in determining the recalcitrance of charcoal, Org Geochem, 41(9), 947-950.

Koch, D., T. C. Bond, D. Streets, N. Unger, and G. R. van der Werf (2007), Global impacts of aerosols from particular source regions and sectors, J Geophys Res-Atmos, 112(D2).

Lohmann, R., K. Bollinger, M. Cantwell, J. Feichter, I. Fischer-Bruns, and M. Zabel (2009), Fluxes of soot black carbon to South Atlantic sediments, Global Biogeochem Cy, 23.

Martin, M. V., R. E. Honrath, R. C. Owen, G. Pfister, P. Fialho, and F. Barata (2006), Significant enhancements of nitrogen oxides, black carbon, and ozone in the North Atlantic lower free troposphere resulting from North American boreal wildfires, $J$ Geophys Res-Atmos, 111(D23).

Masiello, C. A. (2004), New directions in black carbon organic geochemistry, Mar Chem, 92(1-4), 201-213.

Masiello, C. A., and E. R. M. Druffel (1998), Black carbon in deep-sea sediments, Science, 280(5371), 1911-1913.

Masiello, C. A., and P. Louchouarn (2013), Fire in the Ocean, Science, 340(6130), 287-288.

Mayer, L. M., L. L. Schick, M. A. Allison, K. C. Ruttenberg, and S. J. Bentley (2007), Marine vs. terrigenous organic matter in Louisiana coastal sediments: The uses of bromine : organic carbon ratios, Mar Chem, 107(2), 244-254.

McMeeking, G. R., et al. (2010), Black carbon measurements in the boundary layer over western and northern Europe, Atmos Chem Phys, 10(19), 9393-9414.

Michaels, A. F., D. A. Siegel, R. J. Johnson, A. H. Knap, and J. N. Galloway (1993), Episodic Inputs of Atmospheric Nitrogen to the Sargasso Sea - Contributions to New Production and Phytoplankton Blooms, Global Biogeochem Cy, 7(2), 339-351.

Mitra, S., T. S. Bianchi, B. A. McKee, and M. Sutula (2002), Black carbon from the Mississippi River: Quantities, sources, and potential implications for the global carbon cycle, Environ Sci Technol, 36(11), 2296-2302.

Montoya, J. P., E. J. Carpenter, and D. G. Capone (2002), Nitrogen fixation and nitrogen isotope abundances in zooplankton of the oligotrophic North Atlantic, Limnol Oceanogr, 47(6), 1617-1628. 
Moreira-Turcq, P., P. Seyler, J. L. Guyot, and H. Etcheber (2003), Exportation of organic carbon from the Amazon River and its main tributaries, Hydrol Process, 17(7), 1329-1344.

Muller-Karger, F. E. R., P. L.; Mcgillicuddy, D. (1995), On the offshore dispersal of the Amazon's Plume in the North Atlantic: Comments on the paper by A. Longhurst, "Seasonal cooling and blooming in tropical oceans", Deep Sea Research Part I: Oceanographic Research Papers, 42(11-12), 2127-2131, 2133-2137.

Nadelhoffer, K. F., and B. Fry (1988), Controls on Natural N-15 and C-13 Abundances in Forest Soil Organic-Matter, Soil Sci Soc Am J, 52(6), 1633-1640.

O'Dowd, C. D., M. C. Facchini, F. Cavalli, D. Ceburnis, M. Mircea, S. Decesari, S. Fuzzi, Y. J. Yoon, and J. P. Putaud (2004), Biogenically driven organic contribution to marine aerosol, Nature, 431(7009), 676-680.

Paolini, J. (1990), Dissolved and Particulated Organic-Carbon in Major Rivers of South-America, Interciencia, 15(6), 358-366.

Perry, K. D., T. A. Cahill, R. A. Eldred, D. D. Dutcher, and T. E. Gill (1997), Longrange transport of North African dust to the eastern United States, J Geophys ResAtmos, 102(D10), 11225-11238.

Putaud, J. P., et al. (2000), Chemical mass closure and assessment of the origin of the submicron aerosol in the marine boundary layer and the free troposphere at Tenerife during ACE-2, Tellus B, 52(2), 141-168.

Ramanathan, V., and G. Carmichael (2008), Global and regional climate changes due to black carbon, Nat Geosci, 1(4), 221-227.

Raymond, P. A., and J. E. Bauer (2001), Riverine export of aged terrestrial organic matter to the North Atlantic Ocean, Nature, 409(6819), 497-500.

Redfield, A. C. (1958), The Biologocal Control of Chemical Factors in the Environment, American Scientist, Autumn, 205-221.

Ribeiro, L. G. L., R. S. Carreira, and A. L. R. Wagener (2008), Black carbon contents and distribution in sediments from the Southeastern Brazilian coast (Guanabara Bay), J Brazil Chem Soc, 19(7), 1277-1283.

Sanchez-Garcia, L., I. Cato, and O. Gustafsson (2010), Evaluation of the influence of black carbon on the distribution of PAHs in sediments from along the entire Swedish continental shelf, Mar Chem, 119(1-4), 44-51. 
Schmidt, M. W. I., and A. G. Noack (2000), Black carbon in soils and sediments: Analysis, distribution, implications, and current challenges, Global Biogeochem Cy, 14(3), 777-793.

Schmidt, M. W. I., J. O. Skjemstad, C. I. Czimczik, B. Glaser, K. M. Prentice, Y. Gelinas, and T. A. J. Kuhlbusch (2001), Comparative analysis of black carbon in soils, Global Biogeochem Cy, 15(1), 163-167.

Schulz-Bull, D. E., G. Petrick, R. Bruhn, and J. C. Duinker (1998), Chlorobiphenyls (PCB) and PAHs in water masses of the northern North Atlantic, Mar Chem, 61(1-2), 101-114.

Schwartz, D., A. Mariotti, R. Lanfranchi, and B. Guillet (1986), C-13/C-12 Ratios of Soil Organic-Matter as Indicators of Vegetation Changes in the Congo, Geoderma, 39(2), 97-103.

Subramaniam, A., et al. (2008), Amazon River enhances diazotrophy and carbon sequestration in the tropical North Atlantic Ocean, P Natl Acad Sci USA, 105(30), 10460-10465.

Talbot, R. W., R. C. Harriss, E. V. Browell, G. L. Gregory, D. I. Sebacher, and S. M. Beck (1986), Distribution and Geochemistry of Aerosols in the Tropical NorthAtlantic Troposphere - Relationship to Saharan Dust, J Geophys Res-Atmos, 91(D4), 5173-5182.

Thomalla, S., R. Turnewitsch, M. Lucas, and A. Poulton (2006), Particulate organic carbon export from the North and South Atlantic gyres: The Th-234/U-238 disequilibrium approach, Deep-Sea Res Pt Ii, 53(14-16), 1629-1648.

Thomalla, S., R. Turnewitsch, M. Lucas, and A. Poulton (2006), Particulate organic carbon export from the North and South Atlantic gyres: The Th-234/U-238 disequilibrium approach, Deep-Sea Res Pt Ii, 53(14-16), 1629-1648.

Vanderstraeten, P. F., M.; Brasseur, O.; Offer, Z. Y. (2011), Black Carbon Instead of Particle Mass Concentration as an Indicator for the Traffic Related Particles in the Brussels Capital Region, Journal of Environmental Protection, 2(5), 525-532.

Wagner, T. D., L. M. (1999), Terrestrial organic matter in marine sediments of the Central Equatorial Atlantic. Supplement to: Wagner, Thomas; Dupont, Lydie M (1999): Terrestrial Organic Matter in Marine Sediments: Analytical Approaches and Eolian-Marine Records in the Central Equatorial Atlantic, Fischer, G\&Wefer, G (eds.), Use of Proxies in Paleoceanography - Examples from the South Atlantic, Springer, Berlin, Heidelberg, 547-574. 
Wagner, T., Dupont, L. M. (1999), Terrestrial Organic Matter in Marine Sediments: Analytical Approaches and Eolian-Marine Records in the Central Equatorial Atlantic, Use of Proxies in Paleoceanography, 547-574.

Wefer, G., Fischer, G. (1993), Seasonal patterns of vertical particle flux in equatorial and coastal upwelling areas of the eastern Atlantic, Deep Sea Research Part I: Oceanographic Research Papers, 40(8), 1613-1645.

Wright, L. D., and C. A. Nittrouer (1995), Dispersal of River Sediments in Coastal Seas - 6 Contrasting Cases, Estuaries, 18(3), 494-508. 
Tables

\begin{tabular}{c|ccc|c|ccc} 
& $\begin{array}{c}{[\mathbf{B C}]} \\
\mathbf{u g} / \mathbf{L}\end{array}$ & $\begin{array}{c}\mathbf{P O C}] \\
\mathbf{u g} / \mathbf{L}\end{array}$ & $\begin{array}{c}{[\mathbf{O C}]} \\
\mathbf{u g} / \mathbf{L}\end{array}$ & $\mathbf{B C} / \mathbf{P O C}$ & $\mathbf{C}_{\mathbf{B C}} / \mathbf{N}_{\mathbf{B C}}$ & $\mathbf{C}_{\mathbf{P O C}} / \mathbf{N}_{\mathbf{P O C}}$ & $\mathbf{C}_{\mathbf{O C}} / \mathbf{N}_{\mathbf{O C}}$ \\
\hline Caribbean & $2.0 \pm 1.3$ & $13.9 \pm 11.5$ & $11.9 \pm 11.5$ & $0.23 \pm 0.29$ & $20.7 \pm 10.8$ & $9.9 \pm 3.6$ & $7.8 \pm 4.5$ \\
$\quad$ Sea & & & & & & & \\
Amazon & $2.1 \pm 1.4$ & $21.3 \pm 11.2$ & $19.2 \pm 10.2$ & $0.10 \pm 0.05$ & $16.4 \pm 21.0$ & $7.0 \pm 2.1$ & $6.8 \pm 2.3$ \\
Equator & $1.5 \pm 1.6$ & $15.6 \pm 16.9$ & $14.1 \pm 15.2$ & $0.10 \pm 0.13$ & $20.2 \pm 15.6$ & $6.9 \pm 1.4$ & $6.3 \pm 1.1$ \\
Sargasso & $0.9 \pm 0.4$ & $4.4 \pm 2.2$ & $3.6 \pm 2.2$ & $0.16 \pm 0.11$ & $15.8 \pm 6.0$ & $10.3 \pm 3.6$ & $9.0 \pm 3.7$ \\
$\quad$ Sea & & & & & & & \\
$\quad$ SW & $3.0 \pm 3.0$ & $10.6 \pm 7.5$ & $10.6 \pm 8.1$ & $0.25 \pm 0.27$ & $15.0 \pm 23.3$ & $6.7 \pm 1.3$ & $6.4 \pm 2.5$ \\
Atlantic & $1.3 \pm 1.9$ & $12.3 \pm 20.2$ & $10.9 \pm 18.3$ & $0.15 \pm 0.12$ & $12.2 \pm 4.7$ & $7.2 \pm 2.1$ & $6.5 \pm 2.0$ \\
E. Atlantic & & & & & & &
\end{tabular}

Table 1. Concentrations of particulate black carbon (BC), bulk particulate organic carbon (POC), and the labile organic carbon (OC) fraction (POC-BC), along with the ratio of $\mathrm{BC}$ within the $\mathrm{POC}$, and the carbon to nitrogen ratio for each organic carbon pool. 


\begin{tabular}{c|ccc|cc|cc} 
Region & $\boldsymbol{\delta}^{\mathbf{1 3}} \mathbf{C}-\mathbf{P O C}$ & $\boldsymbol{\delta}^{\mathbf{1 3}} \mathbf{C}-\mathbf{B C}$ & $\boldsymbol{\delta}^{\mathbf{1 3}} \mathbf{C}-\mathbf{O C}$ & $\begin{array}{c}\boldsymbol{\delta}^{\mathbf{1 5}} \mathbf{N}- \\
\mathbf{P O C}\end{array}$ & $\begin{array}{c}\boldsymbol{\delta}^{\mathbf{1 5}} \mathbf{N}- \\
\mathbf{B C}\end{array}$ & $\begin{array}{c}\mathbf{P O N} \\
\mathbf{u g} / \mathbf{L}\end{array}$ & $\begin{array}{c}\mathbf{B N} \\
\mathbf{u g} / \mathbf{L}\end{array}$ \\
\hline $\begin{array}{c}\text { Caribbean } \\
\text { Sea }\end{array}$ & $-19.5 \pm 1.8$ & $-17.5 \pm 5.1$ & $-20.7 \pm 3.5$ & $-0.6 \pm 1.1$ & $3.7 \pm 1.2$ & $1.4 \pm 0.7$ & $0.0 \pm 0.1$ \\
Amazon & $-20.4 \pm 3.4$ & $-18.9 \pm 2.8$ & $-18.8 \pm 4.8$ & $0.5 \pm 2.1$ & $-0.4 \pm 4.7$ & $3.2 \pm 1.9$ & $0.1 \pm 0.2$ \\
Equator & $-21.8 \pm 2.1$ & $-18.9 \pm 2.4$ & $-21.9 \pm 1.4$ & $1.0 \pm 1.1$ & $2.0 \pm 1.3$ & $2.5 \pm 2.0$ & $0.1 \pm 0.1$ \\
Sargasso Sea & $-21.5 \pm 0.6$ & $-19.2 \pm 3.9$ & $-20.5 \pm 7.1$ & $0.3 \pm 1.7$ & $1.5 \pm 0.8$ & $0.5 \pm 0.4$ & $0.0 \pm 0.0$ \\
SW Atlantic & $-24.0 \pm 2.3$ & $-22.2 \pm 1.0$ & $-22.7 \pm 2.7$ & $3.4 \pm 2.3$ & $2.0 \pm 1.8$ & $2.2 \pm 1.4$ & $0.4 \pm 0.6$ \\
E. Atlantic & $-21.3 \pm 1.4$ & $-19.4 \pm 3.0$ & $-18.7 \pm 9.7$ & $0.8 \pm 1.2$ & $-0.2 \pm 4.5$ & $1.9 \pm 2.9$ & $0.1 \pm 0.1$
\end{tabular}

Table 2. Stable carbon $\left(\delta^{13} \mathrm{C}\right)$ and nitrogen $\left(\delta^{15} \mathrm{~N}\right)$ ratios for the particulate organic carbon (POC) and black carbon (BC) fractions, as well as particulate organic nitrogen (PON) and black nitrogen (BN) concentrations. 


\begin{tabular}{ccc} 
Region & $\begin{array}{c}\text { POC Flux } \\
\left(\mathbf{g C ~ m}^{-\mathbf{2}} \mathbf{y r}^{\mathbf{- 1}}\right)\end{array}$ & $\begin{array}{c}\text { BC Flux } \\
\left(\mathbf{g C ~ m}^{-\mathbf{2}} \mathbf{y r}^{-\mathbf{1}}\right)\end{array}$ \\
\hline Sargasso Sea & $1.2-29.8^{\mathrm{abc}}$ & $0.2-4.8$ \\
E. Atlantic & $1.1-109^{\mathrm{cde}}$ & $0.2-16.3$ \\
Amazon & $6.0-131^{\mathrm{cf}}$ & $0.6-13.1$ \\
SW Atlantic & $6.0-52.6^{\mathrm{cef}}$ & $1.5-13.1$ \\
Equator & $3.6-219^{\mathrm{cf}}$ & $0.4-21.9$ \\
Caribbean Sea & $7.2^{\mathrm{c}}$ & 1.7 \\
\hline Eq. Atlantic & $\mathbf{7 8 . 0}$ & $\mathbf{1 2 . 5}$ \\
Gulf of Maine & - & $\mathbf{0 . 7}-\mathbf{3 1}$
\end{tabular}

Table 3: Deduced black carbon (BC) export flux approximations using reported

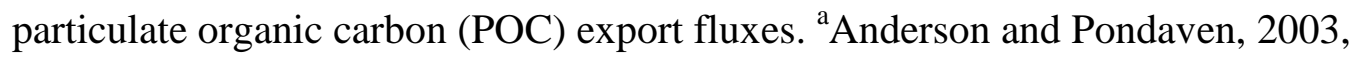
${ }^{\mathrm{b}}$ Buesseler, 1998, ${ }^{\mathrm{C}}$ Jahnke, 1996; ${ }^{\mathrm{d}}$ Thomalla et al., 2006; ${ }^{\mathrm{e}}$ Antia et al., 2001, ${ }_{\mathrm{f}}$ Charette and Moran, 1999, ${ }^{\mathrm{g}}$ Flores-Cervantes et al., 2009. 


\section{Figures}

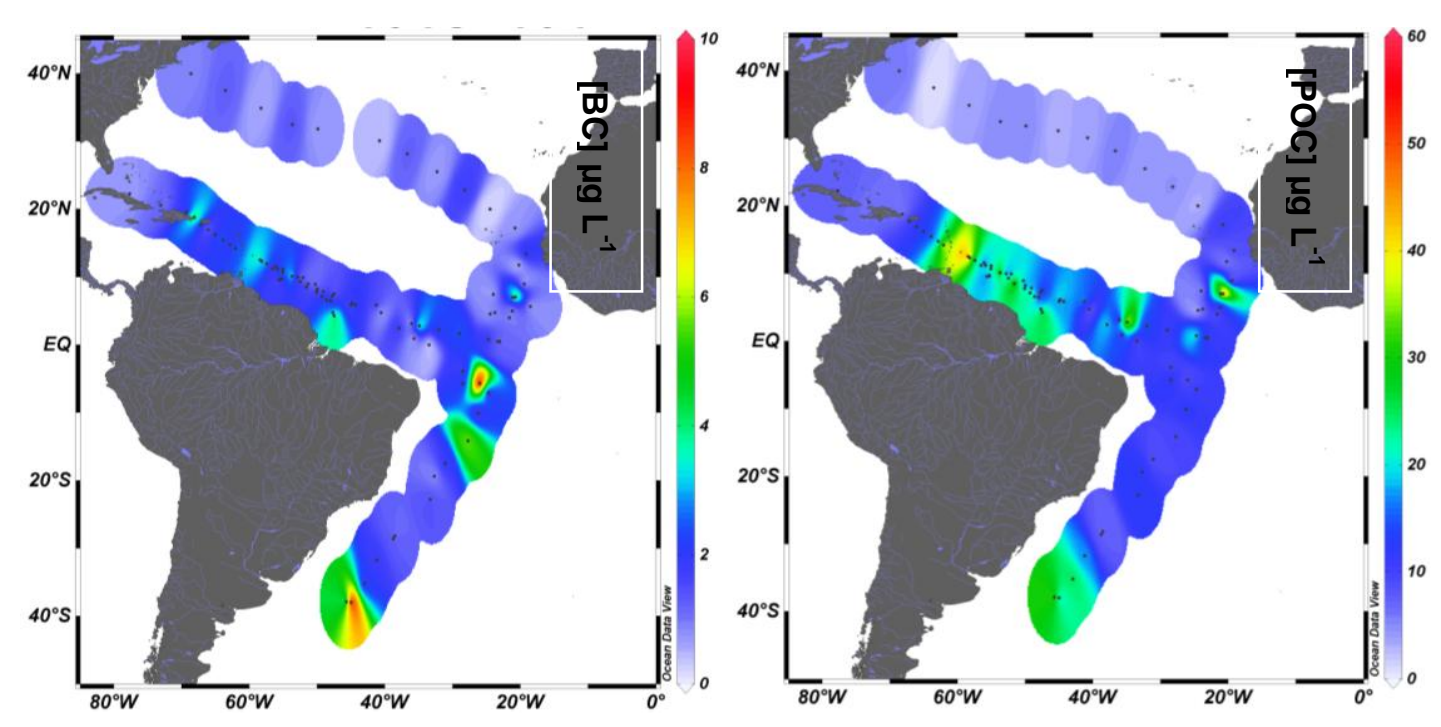

Figure 1. Concentrations of A) particulate black carbon (BC) and B) bulk particulate organic carbon (POC) for all samples within the study region. Concentrations are in $\mu \mathrm{g} \mathrm{L}^{-1}$ and gray dots represent the endpoint of water filtration. 


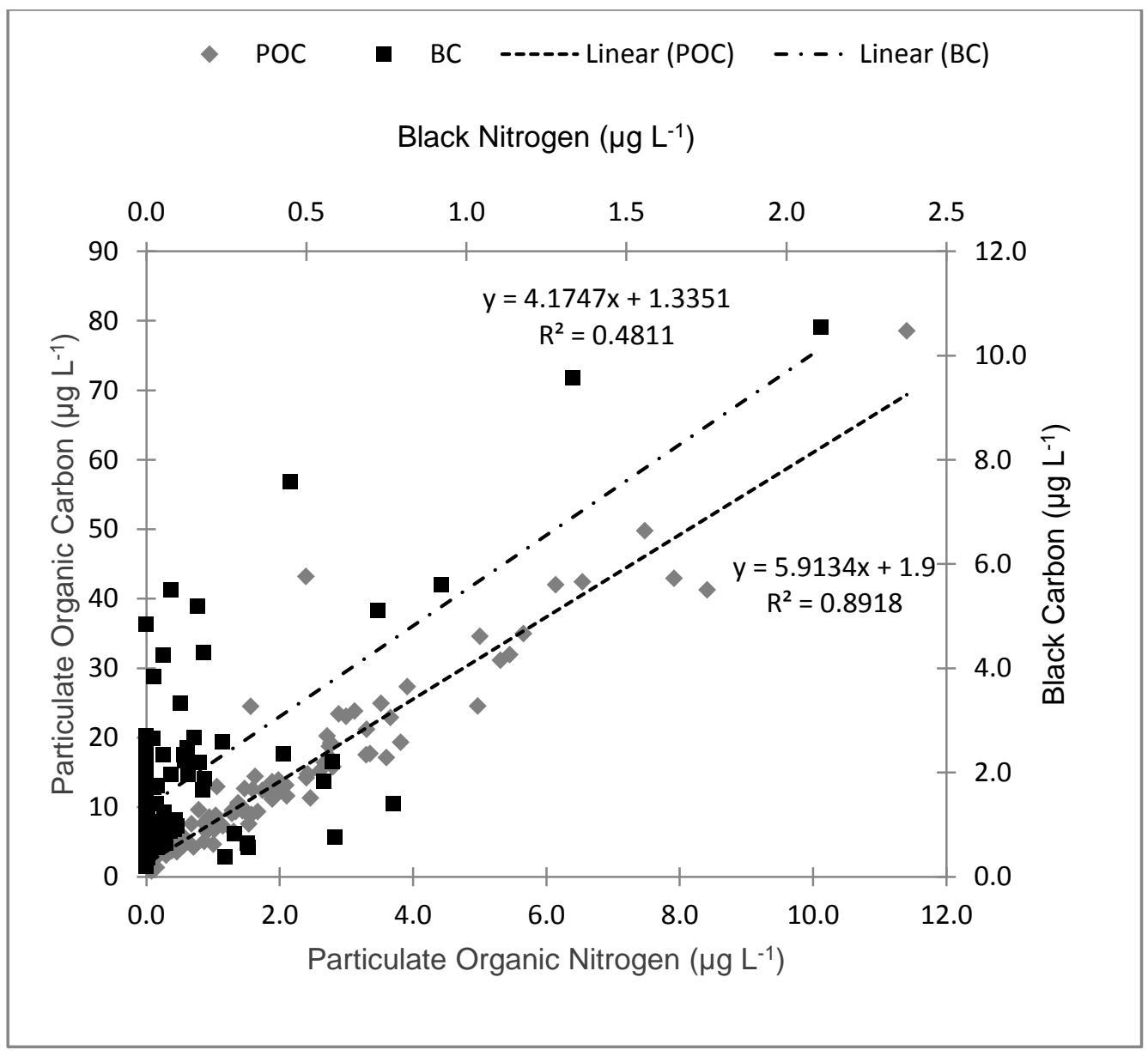

Figure 2. Scatter plot of the particulate organic carbon (POC) versus particulate organic nitrogen and black carbon (BC) versus black nitrogen. 


\section{Supporting Information}

Particulate black carbon concentrations in the surface mixed layer across the Subtropical Atlantic Ocean

Kari Pohl

Rainer Lohmann

Included in the supporting information are:

Table S1. Average black carbon (BC) concentration and number of samples (n) derived for each standard reference material (SRM) used in the analysis. The nd is a non-detect and represents carbon values below the instrumental detection limit.

Table S2. The average blank carbon and nitrogen value for the total organic carbon (POC), total organic nitrogen (PON), black carbon (BC), and black nitrogen (BN) for this study. All sample concentrations were blank correlated by these averaged values.

Figure S1. Surface water current direction and intensity for A) July 15, 2010 and B) April 15, 2013 predicted from the Ocean Surface Current Analysis- Real Time (OSCAR) model through NOAA. 


\begin{tabular}{c|c|c} 
SRM (BC) & Average (\%) & n \\
\hline $1941 \mathrm{~b}$ & $0.8 \pm 0.1$ & 17 \\
$1649 \mathrm{a}$ & $3.0 \pm 0.2$ & 4 \\
mollisol & $0.2 \pm 0.0$ & 3 \\
grass char & nd & 3 \\
melanodin & nd & 2 \\
sand & nd & 8
\end{tabular}

Table S1. Average black carbon (BC) concentration and number of samples (n) derived for each standard reference material (SRM) used in the analysis. The nd is a non-detect and represents carbon values below the instrumental detection limit.

\begin{tabular}{c|ccccc} 
Blank & POC (\%) & BC (\%) & PON (\%) & BN (\%) & $\mathbf{n}$ \\
\hline R/V Endeavor & $0.9 \pm 0.5$ & $1.1 \pm 0.6$ & $0.2 \pm 0.2$ & $0.2 \pm 0.1$ & 6 \\
R/V Knorr & $1.3 \pm 0.4$ & $1.3 \pm 0.2$ & $0.3 \pm 0.2$ & $0.3 \pm 0.5$ & 5
\end{tabular}

Table S2. The average blank carbon and nitrogen value for the total organic carbon (POC), total organic nitrogen (PON), black carbon $(\mathrm{BC})$, and black nitrogen $(\mathrm{BN})$ for this study. All sample concentrations were blank correlated by these averaged values. 

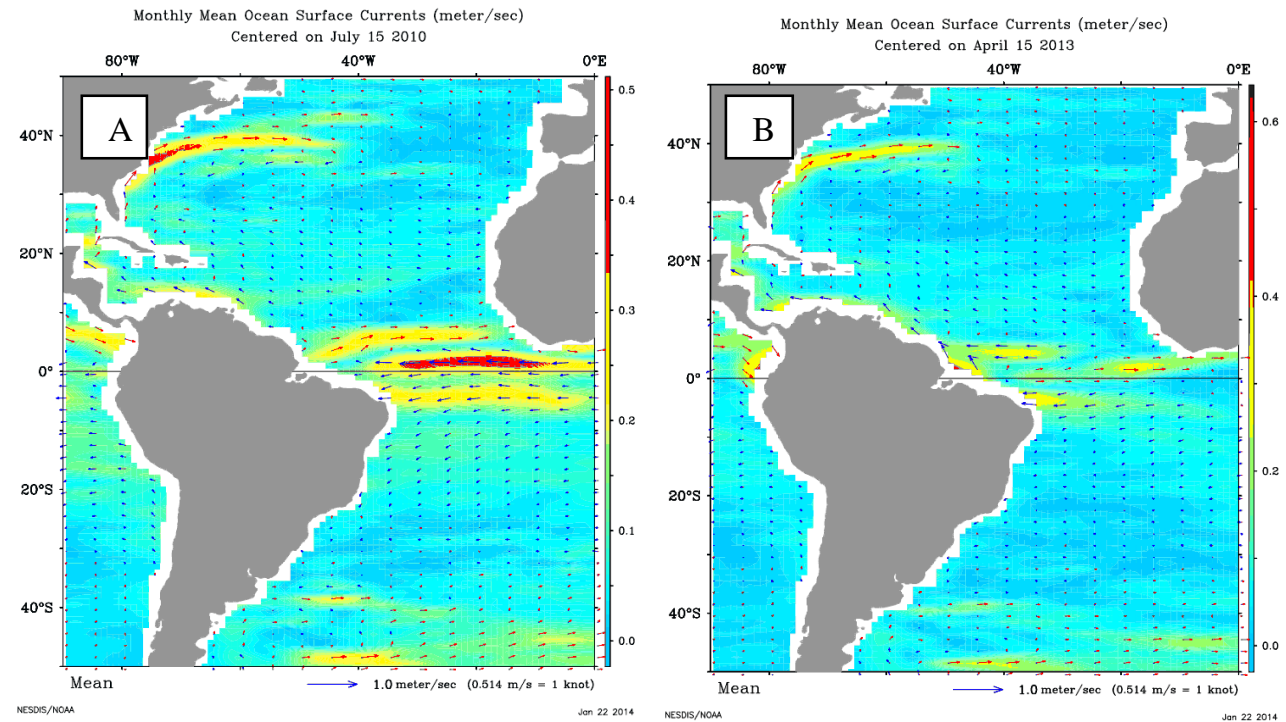

Figure S1. Surface water current direction and intensity for A) July 15, 2010 and B) April 15, 2013 predicted from the Ocean Surface Current Analysis- Real Time (OSCAR) model through NOAA. 


\section{CHAPTER 6}

\section{CONCLUSION}

Black carbon was found to be a ubiquitous form of terrestrial organic carbon in the Subtropical Atlantic Ocean as it was detected in all samples measured in this investigation regardless of location or environmental medium. The presence of black carbon in these deep sediments demonstrates the environmental stability and persistence of these structures from significant photochemical and microbial degradation. The universal detection and stability of sedimentary black carbon in aged sediments also indicates its ability to be a short-term sink for fixed atmospheric carbon. Similarly, the detection of black carbon on all samples quantified in the marine atmospheric boundary layer and marine surface mixed layer shows that the atmosphere and surface ocean are important reservoirs for black carbon before sediment deposition. Likewise, the ubiquity of black carbon on filtered water and air samples demonstrates that both atmospheric and fluvial transport are important mechanisms for moving black carbon from the terrestrial to the marine environment. The dominance of black carbon in this remote study region implies that the long-range transport of black carbon should allow for global distribution despite proximity to a point source.

The study area was specifically selected due to the enhanced terrestrial contributions from numerous major rivers, including the Amazon, Niger, Congo, Paraná, and 
Orinoco. Samples within these fluvial plumes had elevated black carbon concentrations in the surface mixed layer and underlying sediments. This demonstrates that black carbon transport and deposition is greatest in areas directly influenced by a fixed terrestrial source. Additionally, the Subtropical Atlantic Ocean receives inputs from the African emission plume, which transports wildfire, agricultural burning, and fossil fuel emissions westward across the equator. Samples quantified within this emission plume were elevated compared to regions without significant fluvial or atmospheric contributions. Black carbon concentrations on average were $5 \mathrm{X}$ (sediments), 4X (marine boundary layer), and 1.5X (surface mixed layer) greater within this emission plume compared to regions with assumed minimal terrestrial inputs, such as the Sargasso Sea.

This combination of significant fluvial and atmospheric deposition allows the Subtropical Atlantic Ocean to contain elevated concentrations of combustion byproducts such as black carbon. Similar regions with fluvial inputs or wind-driven transport could also have an enhanced potential for elevated black carbon deposition and should be investigated in the future. For example, this research would suggest that black carbon concentrations would be elevated in the fluvial plumes of the $\mathrm{Ob}$, Yenisey, and Lena Rivers in the Arctic Ocean as well as in the Bay of Bengal from the atmospheric deposition originating from India. These regions must be studied in order to enhance the understanding of the global mass balance of black carbon. 
Black carbon is part of a combustion continuum of forms ranging in stability from char-like (less stable) to soot-like (highly stable). Since there is no standard protocol, black carbon is operationally defined by the method used for quantification. This study implemented numerous measurement techniques; however, the chemothermal oxidation at $375^{\circ} \mathrm{C}$ was used on all environmental matrices (sediment, filtered atmospheric and surface water particles) to detect soot-like black carbon. Sediment soot-like black carbon concentrations ranged between $1 \pm 0 \mathrm{~g}_{\mathrm{BC}} \mathrm{kg}_{\text {sediment }}{ }^{-1}$ off the eastern coast of Argentina up to $7 \pm 2 \mathrm{~g}_{\mathrm{BC}} \mathrm{kg}_{\text {sediment }}{ }^{-1}$ in the Niger and Senegal Deltas. The overall average soot-like black carbon concentration for the Subtropical Atlantic was $5 \pm 2 \mathrm{~g}_{\mathrm{BC}} \mathrm{kg}_{\text {sediment }}{ }^{-1}$, which exceeded previous pelagic estimates. Soot-like black carbon composed significant levels of the bulk sedimentary organic carbon, ranging between $15-55 \%$. A second measurement technique called the pyrene fluorescence loss was also utilized in order to broaden the sediment black carbon measurements to include the more thermally labile fractions, such as char-like materials. The ratio of black carbon via chemothermal oxidation to the black carbon via pyrene fluorescence loss was $\sim 1$ in all regions, suggesting that soot-like carbon was the dominate form of sedimentary black carbon.

Soot-like black carbon concentrations from the atmospheric marine boundary layer were elevated above previous model outputs. Atmospheric soot-like black carbon concentrations ranged from $0.1 \pm 0.1 \mu \mathrm{g} \mathrm{m}^{-3}$ within the African emission plume up to $0.8 \pm 0.3 \mu \mathrm{g} \mathrm{m}^{-3}$ in the Caribbean Sea with an overall average of $0.5 \pm 0.7 \mu \mathrm{g} \mathrm{m}^{-3}$ for the Subtropical Atlantic. These soot concentrations were lower than initially hypothesized 
for the African emission plume but greater over the Caribbean Sea. However, black carbon concentrations were greater within the emission plume when alterative measurements were used. In the African emission plume, the thermal optical transmission method measured $0.4 \pm 0.4 \mu \mathrm{g} \mathrm{m}^{-3}$ while optical transmission attenuation measured $0.3 \pm 0.4 \mu \mathrm{g} \mathrm{m}^{-3}$. The pyrene fluorescence loss technique (soot + char components) detected a regional average of $0.7 \pm 0.9 \mu \mathrm{g} \mathrm{m}^{-3}$, suggesting a large contribution of char-like materials, presumably from grass combustion. This highlights that only using soot-like measurements could drastically under-estimate the contribution of combustion-derived aerosols in emission plumes. Future atmospheric analyses of black carbon should implement numerous techniques in order to best apportion and assess the total black carbon concentration. Correctly quantifying the atmospheric concentrations of combustion-derived aerosols will allow for better estimates of albedo alterations (in regards to climate change and cloud formation) as well as human health risks in urban environments.

One novel feature of this work was quantifying the particulate black carbon concentrations in the surface mixed layer, which previously had not been done in a remote region. Soot-like black carbon was detected on all filtered particles with concentrations ranging from $0.9 \pm 0.4 \mu \mathrm{g} \mathrm{L}^{-1}$ in the Sargasso Sea up to $3.0 \pm 3.0 \mu \mathrm{g} \mathrm{L}^{-1}$ in the Paraná River plume, with an overall basin average of $1.9 \pm 1.8 \mu \mathrm{g} \mathrm{L}^{-1}$. The soot-like black carbon composed between 10-25\% (regional average of $17 \pm 6 \%$ ) of the particulate organic carbon, suggesting that terrigenous-derived carbon had a dominant presence in the Subtropical Atlantic surface water and that up to a quarter of the 
organic carbon was not autochthonous production. Additionally, black nitrogen was detected on $40 \%$ of the chemothermally oxidized samples and contributed up to $18 \%$ of the particulate nitrogen. Thus, black carbon could be an important terrestrial source of the macronutrient nitrogen to oligotrophic regions.

Black carbon and organic carbon source was accessed on all samples using the stable carbon isotope fraction $\left(\delta^{13} \mathrm{C}\right)$. Regardless of environmental matrix, the $\delta^{13} \mathrm{C}$ of the bulk total organic carbon was significantly different than the soot-like black carbon. The $\delta^{13} \mathrm{C}$ of the sedimentary black carbon had the trend of becoming more enriched closer to the African continent, suggesting large inputs of $\mathrm{C}_{4}$-derived terrestrial material, such as grass burning. A similar trend was observed in the marine boundary layer samples, and to a smaller extent, the surface water particles. This indicates that $\mathrm{C}_{4}$ plant material had a significant contribution to the marine organic matter pool in the Subtropical Atlantic region.

Additionally, the $\delta^{13} \mathrm{C}$ of the labile organic carbon fraction (the non-black carbon portion of the bulk total organic carbon) also had an enriched $\delta^{13} \mathrm{C}$ indicative of $\mathrm{C}_{4}$ inputs (terrestrial source). This estimates that the maximum contribution of terrestrial organic material to deep Subtropical Atlantic sediments could range from 35-88\%, proposing that previous measurements of terrestrial-derived organic carbon may have under-estimated the fraction of terrigenous materials preserved in sediments. Sedimentary organic carbon should be further investigated as two separate fractions (black carbon and the thermally labile fraction) to assess if the Subtropical Atlantic 
Ocean is a unique storage basin for terrestrial organic matter, or if the presence of terrestrial organic materials in the ocean has been underestimated. The optimal location for this question would be to investigate an area with minimal $\mathrm{C}_{4}$ plant inputs, such as the Arctic Ocean.

Black carbon fluxes to deep sediments were derived in multiple locations throughout the Subtropical Atlantic Ocean. Fluxes of soot-like black carbon ranged from $0.9 \mu \mathrm{g}$ $\mathrm{cm}^{-2} \mathrm{ka}^{-1}$ in the Southeast Atlantic up to $38 \mu \mathrm{g} \mathrm{cm}^{-2} \mathrm{ka}^{-1}$ in the Senegal Delta. The fluvial-influenced regions had greater black carbon fluxes, agreeing with previous studies that fluvial transport was the primary mechanism for the black carbon deposition to the marine environment. However, atmospheric emission plumes, such as the African plume, are quantitatively important. Fluxes of soot-like black carbon were approximately $6 \mathrm{X}$ greater in the Sierra Leone Rise sediments (directly influenced by the African plume) than the Southwest Atlantic (remote) site. This emphasizes that the atmospheric deposition of black carbon is important and should be considered as a significant black carbon transport vector to remote regions.

This study allowed for black carbon fluxes to be assessed in three separate environmental matrices in order to compare the magnitude and importance of the ocean as a sink for this form of organic carbon. Sediment fluxes (as described in Chapter 2, Table 1) were determined using three approaches including previously published sedimentation rates, radiocarbon dating, and a depth-based algorithm. Surface mixed layer fluxes (as described in Chapter 5, Table 2) were approximated 
using previously measured particulate organic carbon export fluxes. Atmospheric black carbon fluxes (Table 3) were calculated using a combination of previously measured dry deposition velocities and Stoke's Law (Eq. 1) where $V_{t}$ is the terminal settling velocity of black carbon, $\rho_{\mathrm{BC}}$ is the average density of soot $\left(1 \mathrm{~g} \mathrm{~cm}^{-3}\right), \mathrm{D}_{\mathrm{BC}}$ is the diameter of a soot particle (defined as $10 \mu \mathrm{m}$ ), g is the gravitational acceleration constant of $9.807 \mathrm{~m} \mathrm{~s}^{-2}$, and $\mu$ is the dynamic viscosity of air at sea level and under standard temperature and pressure $\left(1.81 \times 10^{-5} \mathrm{~Pa} \mathrm{~s}\right)$.

$$
V_{t}=\frac{\rho_{B C} D_{B C}^{2} g}{18 \mu}
$$

Sediment and atmospheric black carbon fluxes were smaller than the black carbon export flux out of the surface mixed layer (Table 4). The sedimentary black carbon flux was the smallest of the three environmental matrices; however, it was on the same order of magnitude as the atmospheric flux. These deep sediments represent older (>400 years before present) black carbon accumulation thus there is a potential lag between the contemporary atmospheric and surface ocean black carbon fluxes and these aged sediments. In addition, temporary black carbon fluxes are well above preindustrial fluxes, suggesting that average sediment fluxes over the last few centuries should be below fluxes out of the atmosphere and surface water. This work suggests that sediment fluxes will increase with time as more anthropogenic-produced black carbon particles are included in the sedimentation. 
The atmospheric black carbon flux to the surface ocean ranged between 5.1 to $15.7 \mu \mathrm{g}$ $\mathrm{cm}^{-2} \mathrm{yr}^{-1}$ and was on the same order of magnitude as the sediment black carbon flux (Table 4). The magnitude of this depositional flux is as predicted from model estimates for the Equatorial Atlantic. The ECHAM5-HAM-OM1 atmospheric model predicts that elemental carbon depositional fluxes in this region would range between 0.1 to $25 \mu \mathrm{g} \mathrm{cm}^{-2} \mathrm{yr}^{-1}$ where the greatest fluxes are within the African emission plume and closest to the terrestrial environment. Our black carbon depositional fluxes were greatest over the Caribbean Sea $\left(15.7 \mu \mathrm{g} \mathrm{cm}^{-2} \mathrm{yr}^{-1}\right)$, Amazon Region $\left(9.2 \mu \mathrm{g} \mathrm{cm}^{-2} \mathrm{yr}^{-1}\right)$, and within the African Plume $\left(8.9 \mu \mathrm{g} \mathrm{cm}^{-2} \mathrm{yr}^{-1}\right)$, agreeing with the ECHAM5-HAMOM1 model outputs. Black carbon has a short atmospheric half-life of < 30 days. Thus, the marine boundary layer is a source of recently produced black carbon to the surface ocean and is an important transport mechanism of black carbon to remote environments, especially in regions close land or within an emission plume.

The greatest black carbon fluxes were determined to be in the surface mixed layer. These export fluxes were calculated using the low-end estimated black carbon fluxes derived from previously measured POC export. Although this flux approximation is attributed with the most uncertainty, it provides insight that the deep ocean could have a greater black carbon storage potential than previously estimated. Surface water black carbon fluxes followed a similar trend to the atmospheric fluxes such that regions with a high atmospheric input were also attributed to greater surface mixed layer fluxes (Table 4). The greatest surface water black carbon export was determined in the 
Northwest Argentina region $\left(150 \mu \mathrm{g} \mathrm{cm}^{-2} \mathrm{yr}^{-1}\right)$ followed by the Amazon region $(60 \mu \mathrm{g}$ $\left.\mathrm{cm}^{-2} \mathrm{yr}^{-1}\right)$, and Caribbean Sea $\left(40 \mu \mathrm{g} \mathrm{cm}^{-2} \mathrm{yr}^{-1}\right)$.

One important parameter that future investigation needs to better quantify is the flux of particulate black carbon from the surface mixed layer to the deep ocean. Black carbon concentrations and fluxes were greater in the surface water than the underlying sediments by an order of magnitude, suggesting that some degradation (photochemical and/or biological) could occur during the vertical flux of black carbon. Black carbon concentrations need to be measured vertically in the water column in order to assess degradation throughout the surface mixed layer and into the deep ocean. One parameter missing from this study is the understanding of how the ratio of black carbon to particulate organic carbon changes with depth. This ratio would have significantly improved our black carbon export flux calculations and should be quantified in future investigations.

The disequilibrium of ${ }^{234} \mathrm{Th} /{ }^{238} \mathrm{U}$ would be a helpful tool to validate the black carbon export fluxes made in this study. It is important to assess if the movement of black carbon from the surface to deep ocean is great enough for the deep ocean to be considered a storage reservoir for black carbon. Additionally, the spatial distribution of black carbon needs to be measured globally in the deep ocean, as this environmental matrix has not yet been measured for particulate black carbon concentrations to date. 
Overall, black carbon is an important form of organic matter and its presence in the tropical Atlantic Ocean suggests that this region has the potential to remove black carbon from the active carbon cycle for geological time scales. We need to better understand the degradation of black carbon before and after its deposition to marine sediments in order to fully understand the scale and magnitude of this sink. Additionally, we need to better quantify the black carbon fluxes from the surface mixed layer to the deep ocean in order to give insights to the possible role black carbon plays in the biological pump and transfer of carbon out of the euphotic zone. This investigation needs to be applied to other regions with known emission plumes, such as the coastal environments near the United Kingdom and China, in order to fully understand the global mass balance of black carbon and the fate of terrestrial organic carbon in the environment. 


\section{Tables}

\begin{tabular}{c|cc}
\multicolumn{1}{c}{ Region } & \multicolumn{2}{c}{$\begin{array}{c}\text { Surface Ocean } \mathrm{F}_{\mathrm{BC}}\left(\mathrm{g} \mathrm{m}^{-2} \mathrm{yr}^{-1}\right) \\
\text { Range Low-High }\end{array}$} \\
\hline Sargasso Sea & 2.3 & $0.2-4.8$ \\
African Plume & 3.6 & $0.2-16.3$ \\
Amazon Region & 6.9 & $0.6-13.1$ \\
Southwest Atlantic & 5.3 & $1.5-13.1$ \\
Equator & 11.1 & $0.4-21.9$ \\
Caribbean Sea $^{2}$ & 1.7 & \\
\hline Gulf of Maine $^{\mathrm{a}}$ & 10.0 & $0.7-31$
\end{tabular}

Table 1: Deduced black carbon export flux $\left(\mathrm{F}_{\mathrm{BC}}\right)$ from the surface mixed layer to the deep ocean. ${ }^{\mathrm{a}}$ Flores-Cervantes et al., 2009. 


\begin{tabular}{c|c|c|c} 
& \multicolumn{3}{|c}{ Sediment $\mathrm{F}_{\mathrm{BC}}\left(\mu \mathrm{g} \mathrm{cm}^{-2} \mathrm{yr}^{-1}\right)$} \\
\hline A) Region & Literature & $\boldsymbol{\Delta}^{14} \mathbf{C}$ & Depth \\
\hline Amazon Region & 2.9 & 4.1 & 18.5 \\
Sierra Leone Rise & 6.3 & 10.0 & 23.6 \\
Niger Delta & 22.5 & $\mathrm{n} / \mathrm{a}$ & 47.0 \\
Senegal Delta & 38 & $\mathrm{n} / \mathrm{a}$ & 870.4 \\
S-Atlantic & 0.9 & $\mathrm{n} / \mathrm{a}$ & 0.6
\end{tabular}

\begin{tabular}{c|c|c|c} 
& \multicolumn{3}{|c}{ Sedimentation Rate $\left(\mathrm{cm} \mathrm{ka}^{-1}\right)$} \\
B) Region & Literature & $\boldsymbol{\Delta}^{14} \mathbf{C}$ & Depth \\
\hline Amazon Region & 1.3 & 4.4 & 18.6 \\
Sierra Leone Rise & 2.7 & 3.4 & 16.0 \\
Niger Delta & 10.0 & $\mathrm{n} / \mathrm{a}$ & 48.5 \\
Senegal Delta & 6.9 & $\mathrm{n} / \mathrm{a}$ & 316.3 \\
S-Atlantic & 2.5 & $\mathrm{n} / \mathrm{a}$ & 3.0
\end{tabular}

Table 2: A) Sediment black carbon fluxes $\left(\mathrm{F}_{\mathrm{BC}}\right)$ derived by the chemothermal oxidation method using B) sedimentation rates from previously reported values from www.pangaea.de (Literature), radiocarbon $\left(\Delta^{14} \mathrm{C}\right)$, or from a depth-based algorithm (Depth) using Middelburg et al., 1997. 


\begin{tabular}{c|cc|c|cc|c|c}
$\begin{array}{c}\text { Atmospheric } \\
\mathbf{F}_{\mathrm{BC}}\left(\boldsymbol{\mu g} \mathbf{~ c m}^{-2} \mathbf{y r}^{-1}\right)\end{array}$ & \multicolumn{2}{|c|}{$\begin{array}{c}\text { Jurado et } \\
\text { al., 2004 }\end{array}$} & $\begin{array}{c}\text { Stoke's } \\
\text { Law }\end{array}$ & \multicolumn{2}{|c|}{$\begin{array}{c}\text { González-Gaya } \\
\text { et al., 2014 }\end{array}$} & $\begin{array}{c}\text { Nho-Kim } \\
\text { et al., 2004 }\end{array}$ & $\begin{array}{c}\text { Vong et } \\
\text { al., 2010 }\end{array}$ \\
\hline Caribbean Sea & 2.6 & 52.8 & 7.9 & 15.0 & 20.5 & 0.7 & 10.0 \\
Amazon Region & 0.6 & 11.3 & 1.7 & 20.6 & 28.1 & 0.1 & 2.1 \\
African Plume & 0.4 & 7.2 & 1.1 & 22.0 & 30.1 & 0.1 & 1.4 \\
Sargasso Sea & 0.2 & 4.9 & 0.7 & 12.1 & 16.6 & 0.1 & 0.9 \\
\hline $\mathrm{D}_{\mathrm{p}}(\mu \mathrm{m})$ & 1 & 10 & 10 & $0.7-2.7$ & $>2.7$ & $0.5-1.0$ & 0.78 \\
$\mathrm{~V}_{\mathrm{d}}\left(\mathrm{cm} \mathrm{s}^{-1}\right)$ & 0.1 & 2.0 & 0.3 & - & - & 0.03 & 0.4 \\
$\mathrm{~F}_{\mathrm{DD}}\left(\mathrm{g} \mathrm{m}^{-2} \mathrm{~d}^{-1}\right)$ & - & - & - & 0.4 & 0.5 & - & -
\end{tabular}

Table 3: Estimated atmospheric black carbon settling fluxes $\left(\mathrm{F}_{\mathrm{BC}}\right)$ to the Tropical Atlantic surface ocean using previously derived depositional velocities $\left(v_{D}\right)$ or dry deposition particle fluxes $\left(\mathrm{F}_{\mathrm{DD}}\right)$ for various particle diameters $\left(\mathrm{D}_{\mathrm{p}}\right)$. 


\begin{tabular}{c|ccc}
\multicolumn{4}{c}{ Flux $\left(\boldsymbol{\mu g B C ~} \mathbf{~ c m}^{-\mathbf{2}} \mathbf{y r}^{\mathbf{- 1}}\right)$} \\
\hline Region & $\begin{array}{c}\text { Marine Boundary } \\
\text { Layer }\end{array}$ & $\begin{array}{c}\text { Surface Mixed } \\
\text { Layer }\end{array}$ & $\begin{array}{c}\text { Pelagic } \\
\text { Sediments }\end{array}$ \\
\hline Amazon Region & 9.2 & 60 & 2.9 \\
African Plume & 8.9 & 20 & 6.3 \\
Sargasso Sea & 5.1 & 20 & na \\
Caribbean Sea & 15.7 & 40 & na \\
NW Argentina & na & 150 & 0.9 \\
\hline Previous Estimates & $0.1-25^{*}$ & $4.4^{* *}$ & $0.002-3.6^{* * *}$ \\
\hline
\end{tabular}

Table 4. Summary of black carbon fluxes $\left(\mu \mathrm{gBC} \mathrm{cm}^{-2} \mathrm{yr}\right)$ in all environmental matrices analyzed in this work. Black carbon fluxes in this table were derived using the chemothermal oxidation at $375^{\circ} \mathrm{C}$ method since this approach was used for all samples. Marine boundary layer predicts the terminal black carbon flux out of the atmosphere into the surface water using depositional velocities from Table 3, the surface mixed layer flux is the black carbon export from the surface to deep ocean using the low-end export fluxes in Table 2, and pelagic sediment is the black carbon flux to the sediments using the sedimentation rates in Table 1. *Lohmann et al., 2009 **pre-industrial estimate derived by Coppola et al., $2014 * * *$ Suman et al., 1997.

\section{Works Cited in Conclusion}

Coppola, A. I., L. A. Ziolkowski, C. A. Masiello, and E. R. M. Druffel (2014), Aged black carbon in marine sediments and sinking particles, Geophys Res Lett, 41(7), 2427-2433.

Flores-Cervantes, D. X., D. L. Plata, J. K. MacFarlane, C. M. Reddy, and P. M. Gschwend (2009), Black carbon in marine particulate organic carbon: Inputs and cycling of highly recalcitrant organic carbon in the Gulf of Maine, Mar Chem, 113(34), 172-181. 
González-Gaya, B. n. Z. n. i.-R., Javier; Ojeda, María-José; Jiménez, Begoña; Dachs, Jordi (2014), Field Measurements of the Atmospheric Dry Deposition Fluxes and Velocities of Polycyclic Aromatic Hydrocarbons to the Global Oceans, Environ Sci Technol, 48(5), 5583-5592.

Jurado, E., F. M. Jaward, R. Lohmann, K. C. Jones, R. Simo, and J. Dachs (2004), Atmospheric dry deposition of persistent organic pollutants to the Atlantic and inferences for the global oceans, Environ Sci Technol, 38(21), 5505-5513.

Lohmann, R., K. Bollinger, M. Cantwell, J. Feichter, I. Fischer-Bruns, and M. Zabel (2009), Fluxes of soot black carbon to South Atlantic sediments, Global Biogeochem Cy, 23.

Middelburg, J. J., K. Soetaert, and P. M. J. Herman (1997), Empirical relationships for use in global diagenetic models, Deep-Sea Res Pt I, 44(2), 327-344.

Nho-Kim, E. Y., M. Michou, and V. H. Peuch (2004), Parameterization of sizedependent particle dry deposition velocities for global modeling, Atmos Environ, 38(13), 1933-1942.

Suman, D. O., Kuhlbusch, T. A. J., Lim, B. (1997), Marine Sediments: A reservoir for black carbon and their use as spatial and temporal records of combustion, Sediment Records of Biomass Burning and Global Change, edited by J. S. Clark, H. Cachier, J. G. Goldhammer, B. J. Stocks(Springer-Verlag).

Vong, R. J., I. J. Vong, D. Vickers, and D. S. Covert (2010), Size-dependent aerosol deposition velocities during BEARPEX' 07, Atmos Chem Phys, 10(12), 5749-5758. 